\title{
Methodology and Experiments to Determine Soot and NOx Yields from a Vertical Lab-Scale Flare Burning Alkane-Mixtures and Ethylene
}

By

\section{Darcy James Corbin}

\author{
A thesis submitted to the \\ Faculty of Graduate and Postdoctoral Affairs in \\ partial fulfillment of the requirements for the degree of
}

Masters of Applied Science

In

Mechanical Engineering

\author{
Carleton University \\ Ottawa, Ontario \\ (C) 2014 \\ Darcy James Corbin
}




\section{Abstract}

Species yields and combustion efficiency of lab-scale flares, turbulent non-premixed buoyant flames, were measured. A new facility was constructed allowing gas mixtures to be burned on 38.1 to $76.2 \mathrm{~mm}$ diameter flares at flow rates up to 410 standard litres per minute. A methodology was developed to quantify species yields and combustion efficiency within calculated uncertainties. Results showed combustion efficiencies greater than $97.8 \%$ in all cases, with up to $90 \%$ of the non- $\mathrm{CO}_{2}$ carbon emitted as soot. Soot yields were heavily dependent on flare gas chemistry, ranging from an average of $7.34 \cdot 10^{-5} \mathrm{~kg}$-soot $/ \mathrm{kg}$-flare-gas for methane tests to $1.20 \cdot 10^{-2} \mathrm{~kg}$-soot $/ \mathrm{kg}$-flare-gas for ethylene tests. $\mathrm{NO}_{\mathrm{X}}$ data suggest that average mass yield per energy content of the flare gas is $3.76 \cdot 10^{-2} \mathrm{~kg}-\mathrm{NO}_{\mathrm{X}} / \mathrm{GJ}$ and is independent of exit conditions and fuel chemistry for the range of fuels considered. Results are compared with published soot and $\mathrm{NO}_{\mathrm{X}}$ emission factors and potential scaling methods are discussed. 


\section{Acknowledgements}

I would like to thank many people that have contributed to my studies, and by extension my life, in the three-plus years since I packed a car and left the west coast.

To Professor Johnson, thank you for giving me the chance to join your research group and pursue my graduate studies at Carleton. It's been a whirlwind three-plus years and you've consistently been there to support, advise, motivate, and encourage. Your enthusiasm and passion for what you do is inspiring and I've learned a great deal from you. Most importantly, I think we've had some fun along the way.

I would like to thank all members of the Energy and Emissions Research Lab. Oleg, thank you for your work in getting this project built and showing me the value of a mid-day stroll. Brian, thank you for helping me find solutions to countless problems on both flares. Pat, thanks for always being down to talk hockey. Steve, Dave, Jan, Graham, Robin, Ian, Carol, Jason, Brad, Simon, Melina, David, it's been a pleasure to work with all of you and best of luck moving forward.

To the many people I've met in Ottawa, and especially those who've also lived in Monk, you have made my time here memorable and I hope we remain friends for years wherever we end up. Thanks to $\mathrm{BC}$ friends for coming to visit and always keeping in touch.

Mom and Dad. What can I say? Thank you for your love and support in every way possible for the last 28 years. Amo, thanks for being a cool sister. 


\section{Table of Contents}

Abstract

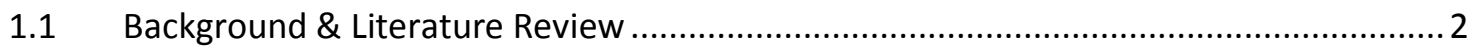

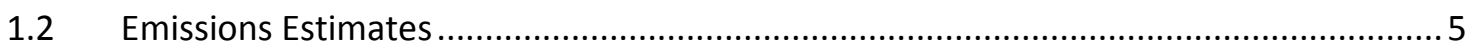

1.2.1 Current Emission Factors for Flares ................................................................. 6

1.3 Flow Regimes for Non-premixed Diffusion Flames and Flares ..................................13

1.4 Existing Literature on Emission Quantification from Turbulent Non-Premixed Diffusion

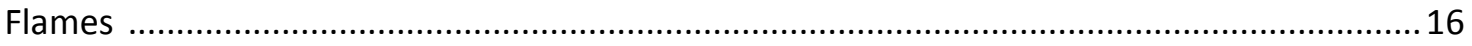

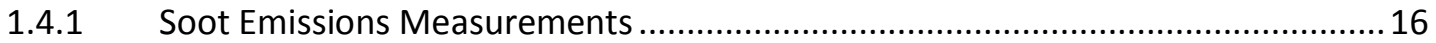

1.4.2 $\mathrm{NO}_{\mathrm{x}}$ Emissions Measurements and Suggested Scaling .........................................2 20

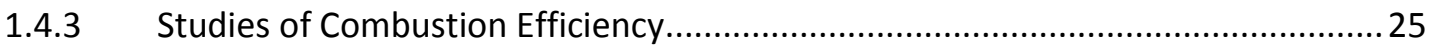

$1.5 \quad$ Field Measurements of Large-Scale Flares …............................................................. 28

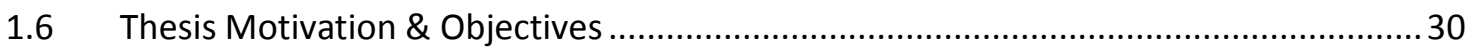

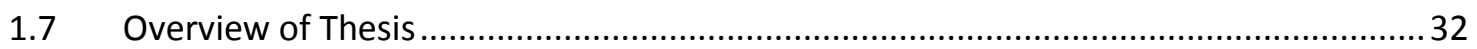

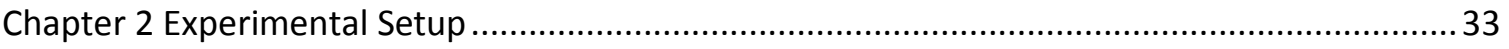

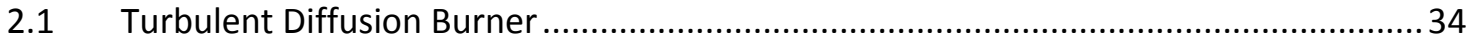

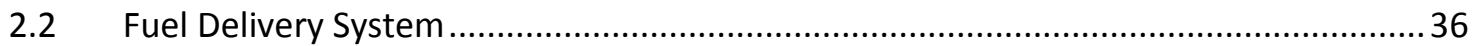

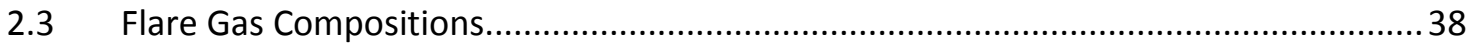

2.4 Exhaust System and Experimental Infrastructure ….................................................. 39 


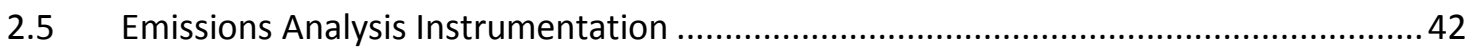

2.5.1 Gas-Phase Measurements and Gas-Phase Sample Train ..................................... 42

2.5.2 Soot Measurement with LII and Solid-Phase Sampling Train ................................45

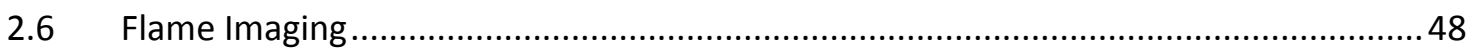

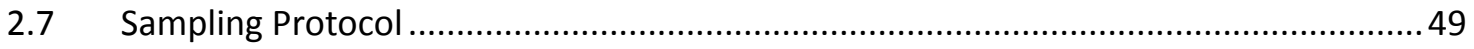

2.8 Methodology

Chapter 3 Detailed Expressions and Methodologies for Measuring Flare Combustion Efficiency,

Species Emission Rates, and Associated Uncertainties........................................................52

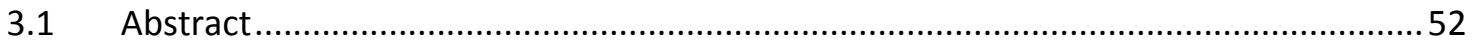

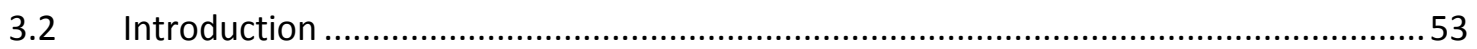

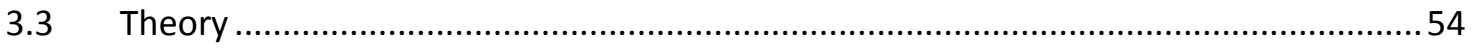

3.3.1 General Combustion Efficiency and Species Conservation Equations....................55

3.3.2 Combustion Efficiency and Species Emission Rates Assuming Gas Phase Only

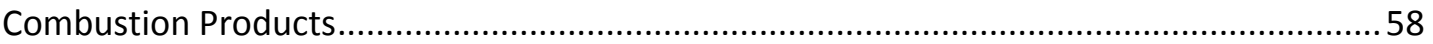

3.3.3 Comparison with Simplified Expressions for Combustion Efficiency used in Other Works

3.3.4 Combustion Efficiency and Species Emission Rates with In Situ Black Carbon Measurement.

3.3.5 Efficiency Measurements Using a Tracer Injection for Plume Flow Rate Measurement.....

3.4 Quantifying Anticipated Uncertainties for a Range of Operating Conditions ...............75

3.4.1 Anticipated Uncertainties in Measured Combustion Efficiency .............................76

3.4.2 Anticipated Uncertainties in Measured Species Emission Rates ........................... 77

3.5 Demonstration Experiments and Comparison of Methodologies and Uncertainties ... 78

3.5.1 Combustion Efficiency Measurements and Discussion .......................................... 80

3.5.2 Calculated Species Yields for Various Methods ................................................... 81

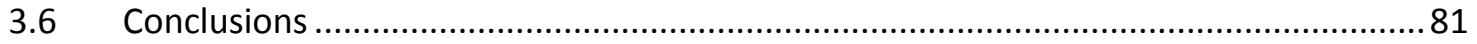

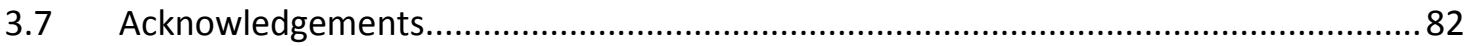

Chapter 4 Species Emissions, Combustion Efficiency and Flame Length Results......................... 83

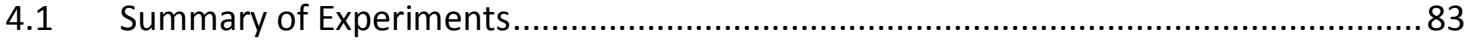

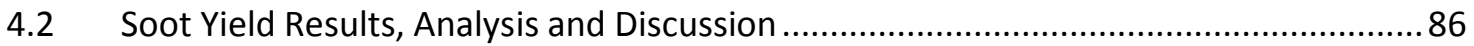

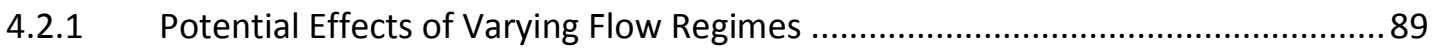

4.2.2 Scaling of Soot Emissions with Heating Value ................................................... 93 
4.2.3 Comparison of present Soot Yield data with Current Emission Factors

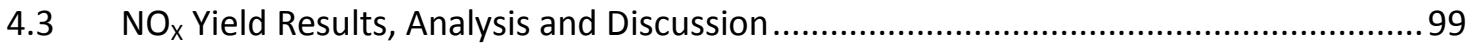

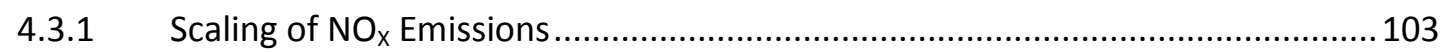

4.3.2 Recommendations for Estimating NOx Emissions from Flares............................... 107

4.4 Combustion Efficiency Results, Analysis and Discussion ......................................... 109

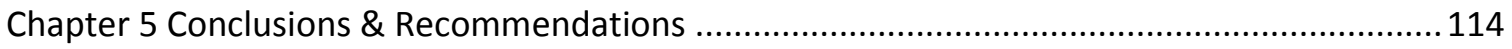

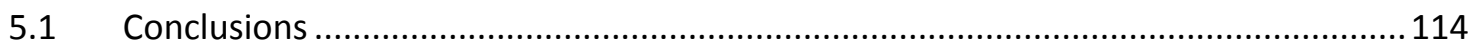

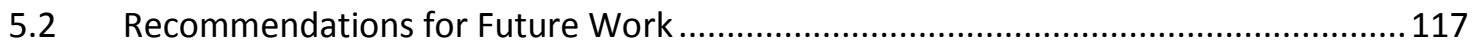

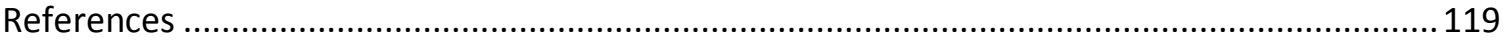

Appendix A Supplemental Information for Calculating Uncertainty on Combustion Efficiency,

Plume Flow Rate, Species Emissions Rates, and Destruction Removal Efficiency ................ 125

Appendix B $\quad$ CO and Hydrocarbon Results, Analysis and Discussion ................................... 143

Appendix C Flame Length Results, Analysis and Discussion ............................................... 147

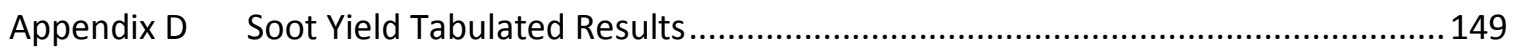

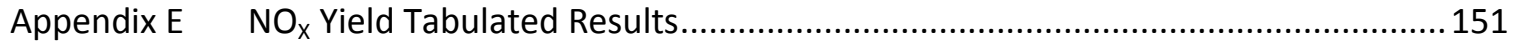

Appendix F Combustion Efficiency Tabulated Results....................................................... 153 


\section{List of Tables}

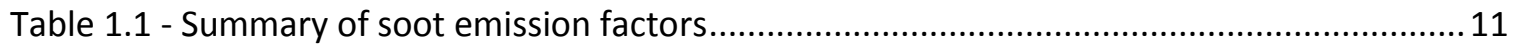

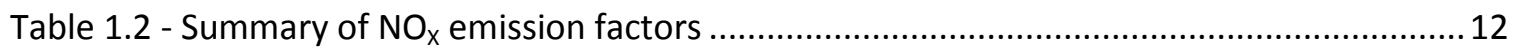

Table 1.3 - Summary of literature reporting soot emissions from turbulent non-premixed

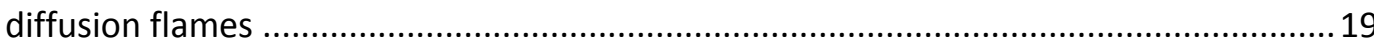

Table 1.4: Summary of literature reporting $\mathrm{NO}_{\mathrm{x}}$ emissions from turbulent non-premixed

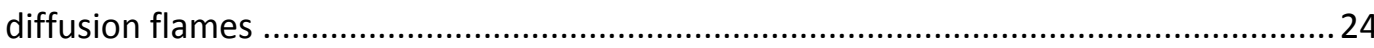

Table 1.5: Summary of literature reporting combustion efficiency from turbulent non-premixed diffusion flames

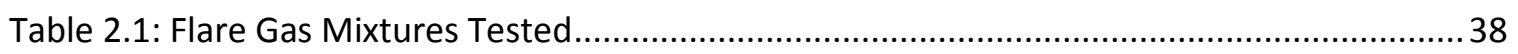

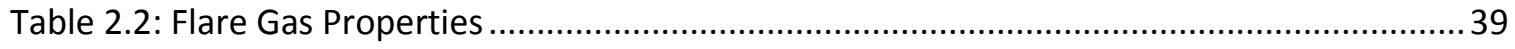

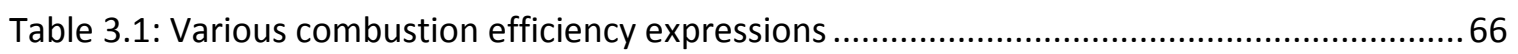

Table 3.2: Experimental Operating Conditions ........................................................................ 80

Table 4.1 - Summary of test conditions showing range of fuel mixtures tested at different exit velocity and burner diameter combinations 


\section{List of Figures}

Figure 1.1: Schematic of generic solution gas typical of the Alberta upstream oil and gas industry

Figure 1.2: Delichatsios (1993) map showing regimes for jet diffusion flame exit conditions defined by exit Reynolds number and Global Froude number as defined by Eq. (1.2)...14

Figure 1.3: Costa et al. (2004) figure showing $\mathrm{NO}_{\mathrm{x}}$ emission index scaling changes for jet diffusion flames transitioning from buoyancy-dominated to momentum-dominated regimes as characterized by the exit Froude number as defined by Eq. (1.4).

Figure 1.4: Proposed $\mathrm{NO}_{\mathrm{x}}$ scaling law including experimental data from literature (Rokke et al. 1992). Froude number is defined by Eq. (1.4).

Figure 2.1: Experiment schematic with flare pit dimensions and overview of fuel delivery system, air supply system, hood and screen details, and dilution tunnel overview. .....................34

Figure 2.2: Modular burner schematic (Canteenwalla, 2007) ................................................... 36

Figure 2.3: Diagram of probe locations in dilution tunnel. LII, FTIR, and thermocouple probe locations and dimensions shown. Pressure tap locations marked.

Figure 2.4: FTIR probe traverse $\mathrm{CO}_{2}$ concentration measurements at $50 \%$ and $100 \%$ fan settings with low and high flare gas flow rates.

Figure 2.5: Rear of LII. Pictured components of sample train include a) heated hose, b) sample cell, c) outlet thermocouple, d) particulate filter, and e) MFC.

Figure 2.6: LII probe traverse measurements at $50 \%$ and $100 \%$ fan settings with low and high flare gas flow rates

Figure 3.1: Control volume (CV, indicated by dashed blue line) for combustion process illustrating the overall mass balance defined by Eq. (3.4) (sum of terms outside CV) and the breakdown of terms relevant to the species mass balance defined by Eq. (3.5) . Red arrows indicate terms containing products of combustion .56

Figure 3.2: Potential bias errors incurred when using different efficiency expressions (McDaniel (1983), Pohl et al. (1986), Torres, Herndon, Kodesh, et al. (2012), Strosher (2000)) as a function of dilution ratio for nominal ambient concentrations of $\mathrm{CO}_{2}=400 \mathrm{ppm}$, $\mathrm{CO}=1.5 \mathrm{ppm}_{\mathrm{v}}$, and $\mathrm{CH}_{4}=1.8 \mathrm{ppm}_{\mathrm{v}}$, where the flare gas contains (a) no $\mathrm{CO}_{2} ;$ (b) $5 \% \mathrm{CO}_{2} \ldots .68$

Figure 3.3: a) Expected absolute uncertainty on measured combustion efficiency (e.g. $99 \% \pm 4 \%$ equates to a range of $95-103 \%$ at a dilution ratio of 200 using the tracer injection method) evaluated with Eq. (3.12) and corresponding supplementary material. Combustion efficiencies greater than $100 \%$ are not possible in practice and uncertainties extending beyond this threshold are mathematical artefacts from the uncertainty analysis. b) Expected relative uncertainty on measured species yield (e.g. $1.0 \mathrm{~kg} / \mathrm{kg}$ $\pm 10 \%(0.1 \mathrm{~kg} / \mathrm{kg}))$ evaluated using Eq. (3.13) with plume flow rate defined by Eq. (3.11) (carbon-balance) and Eq. (3.22) (tracer injection). 
Figure 3.4: a) Combustion efficiency and uncertainties calculated using derived carbon-balance and tracer injection methods on a 1.5 inch flare over a range of flare gas flow rates. $b$ ) $\mathrm{NO}_{\mathrm{x}}$ and soot species yields and uncertainties calculated using derived carbon-balance and tracer injection methods on a 1.5 inch flare over a range of flare gas flow rates. Combustion efficiencies greater than $100 \%$ are not possible in practice and uncertainties extending beyond this threshold are mathematical artefacts from the uncertainty analysis.

Figure 4.1: Comparison of soot yield calculated with the carbon-balance and tracer-injected methods for HVY 4-Mix, ethylene, and propane flare gases.

Figure 4.2: Comparison of bias and total (precision and bias) relative uncertainty on measured soot yield for test cases with three and four experimental repeats.

Figure 4.3: Soot yield calculated using the carbon-balance method for the 38.1, 50.8 and $76.2 \mathrm{~mm}$ burners with AVG 6-Mix, HVY 4-Mix and methane flare gas mixtures.

Figure 4.4: Soot yield on a a) per flare gas mass and $b$ ) per flare gas carbon mass basis calculated using the carbon balance method for the $50.8 \mathrm{~mm}$ burner with AVG 6-Mix, HVY 4-Mix, ethylene, methane and propane flare gas mixtures.

Figure 4.5: Flare exit conditions for 38.1, 50.8 and $76.2 \mathrm{~mm}$ burners with AVG 6-Mix, HVY 4-Mix, ethylene, methane and propane flare gas mixtures. 90

Figure 4.6: Soot yield normalized by the maximum yield for a given flare gas and burner diameter plotted against the a) Fire and b) Global Froude numbers, as well as c) Reynolds number and d) a Reynolds-Global Froude parameter for 38.1, 50.8 and $76.2 \mathrm{~mm}$ burners with AVG 6-Mix, HVY 4-Mix, ethylene, methane and propane flare gas mixtures. Possible transition lines of $(R e=4000)$ and $\left(R e \cdot F r_{g}{ }^{2}=1.46\right)$ shown in $\left.\mathrm{c}\right)$ and d) as dashed and solid vertical lines respectively.

Figure 4.7: Soot yield normalized by the maximum yield for a given flare gas and burner diameter plotted against Reynolds numbers a) less than and b) greater than 4000, as well as Reynolds-Global Froude parameter values c) less than and d) greater than 1.46 for 38.1, 50.8 and $76.2 \mathrm{~mm}$ burners with AVG 6-Mix, HVY 4-Mix, ethylene, methane and propane flare gas mixtures.

Figure 4.8: Soot yield calculated using the carbon balance method and plotted against volumetric heating value (HV) for (a) AVG 6-Mix, HVY 4-Mix, ethylene, methane and propane flare gases and 38.1, 50.8 and $76.2 \mathrm{~mm}$ burners; and (b) the maximum soot yield for a flare gas and burner diameter combination for alkane-based flare gases (AVG 6-Mix, HVY 4-Mix, methane and propane) and 38.1, 50.8 and $76.2 \mathrm{~mm}$ burners. Panel (c) is a zoomed image of panel (b) to better illustrate the correlation with the data for the methane-based flare gases only.

Figure 4.9: Soot yield calculated using the carbon balance method for the $50.8 \mathrm{~mm}$ burner with AVG 6-Mix, HVY 4-Mix, ethylene, methane and propane flare gas mixtures showing a) a shaded area encompassing the range of soot emission factors and b) with specific emission factors from the literature. .99

Figure 4.10: $\mathrm{NO}_{x}$ yields on a per flare gas a) mass, b) volume and c) energy content basis calculated using the carbon balance method plotted against flare gas mass flow rate for 
the 38.1, 50.8 and $76.2 \mathrm{~mm}$ burners with AVG 6-Mix, HVY 4-Mix, ethylene, methane and propane flare gas mixtures. Emission factors from the literature also plotted in their published form as per appropriate reference. 102

Figure 4.11: $\mathrm{NO}_{\mathrm{x}}$ Emission Index a) by volume and $\mathrm{b}$ ) by mass plotted against Froude number for 38.1, 50.8 and 76.2 mm burners with AVG 6-Mix, HVY 4-Mix, ethylene, methane and propane flare gas mixtures. Also shown: a) theoretical scaling law of $Y_{N O_{X}} \frac{\rho_{0} u_{0}}{d_{0}}=44$. $\mathrm{Fr}^{0.6}$ (Rokke et al., 1992); b) curve fit of $Y_{N O_{X}} \frac{u_{0}}{d_{0}}=26.15 \cdot \mathrm{Fr}^{0.559}$; c) data and curve fit of b) with linear axis scaling. 104

Figure 4.12: $\mathrm{NO}_{\mathrm{x}}$ yields calculated on a mass basis using the carbon balance method for the 38.1, 50.8 and $76.2 \mathrm{~mm}$ burners with AVG 6-Mix, HVY 4-Mix, ethylene, methane and propane flare gas mixtures plotted against the velocity parameter adapted from Froude number scaling. 105

Figure 4.13: a) $\mathrm{NO}_{x}$ yield and b) $\mathrm{NO}_{\mathrm{x}}$ yield multiplied by the stoichiometric mixture fraction, $f_{S}$, calculated using the carbon balance method plotted against adiabatic flame temperature for the 38.1, 50.8 and $76.2 \mathrm{~mm}$ burners with AVG 6-Mix, HVY 4-Mix, ethylene, methane and propane flare gas mixtures.

Figure 4.14: $\mathrm{NO}_{x}$ yields calculated using the carbon balance method for the 38.1, 50.8 and $76.2 \mathrm{~mm}$ burners with AVG 6-Mix, HVY 4-Mix, ethylene, methane and propane flare gas mixtures compared to emission factors from the literature. 108

Figure 4.15: Mixed-phase combustion efficiency calculated using the carbon balance method for the 38.1, 50.8 and $76.2 \mathrm{~mm}$ burners with AVG 6-Mix, HVY 4-Mix, ethylene, methane and propane flare gas mixtures.

Figure 4.16: Carbon yields of various species calculated using the carbon balance method for the 38.1, 50.8 and 76.2 mm burners with AVG 6-Mix, HVY 4-Mix, ethylene (EY), methane (ME) and propane (PR) flare gas mixtures. 112

Figure 4.17: Gas-phase only combustion efficiency calculated using the carbon balance method for the 38.1, 50.8 and $76.2 \mathrm{~mm}$ burners with AVG 6-Mix, HVY 4-Mix, ethylene, methane and propane flare gas mixtures. 


\section{Nomenclature}

Latin

Symbols

ARPEL Asociacion Regional de Empresas de

Petroleo y Gas Natural en Latino America

y el Caribe

BC Black Carbon

CAPP Canadian Association of Petroleum

Producers

$\mathrm{CV} \quad$ Control Volume

d Diameter

DIAL Differential Absorption Lidar

DRE Destruction Removal Efficiency

DSCF Dry Standard Cubic Feet

$E_{N O x}$

EEA

$\mathrm{E} \& \mathrm{P}$

$f_{s}$

$f_{v}$

$\mathrm{Fr}$

$F r_{f}$

$F r_{g}$

FTIR

$g$

GGFR

GHG

GWP

$\mathrm{HHV}$

ID

$L G R$

LII

$M$

$\dot{m}$

mean

$n$

$\dot{n}$

NAEI

NPRI

OLF
$\mathrm{NO}_{\mathrm{X}}$ Yield

European Environment Agency

Exploration and Production

Stoichiometric Mixture Fraction

Soot volume fraction

Froude Number

Fire Froude number

Global Froude number

Fourier Transform Infrared Spectrometer

Gravitational Constant

Global Gas Flaring Reduction

Greenhouse Gas

Global Warming Potential

Higher Heating Value

Inside diameter

Los Gatos Reasearch

Laser Induced Incandescence

Molar mass

Mass flow rate

Mean of data set

Number of points of data set

Mole flow rate

National Atmospheric Emissions

Inventory

National Pollutant Release Inventory

Norwegian Oil Industry Association
First Use

Units

Eq.

Po.

$\mathrm{m}$

$\%$

$\mathrm{ft}^{3} / \min$

53

$\mathrm{kg} / \mathrm{kg}$

(1.6)

6

22

8

7

14

$\mathrm{ppb}_{\mathrm{v}}$

67

(1.4) 15

(1.3) 13

(1.2) 13

$9.81 \mathrm{~m} / \mathrm{s}^{2}$

40

14

4

3

3

$\begin{array}{ll}\mathrm{MJ} / \mathrm{m}^{3} & 7\end{array}$

$\mathrm{mm}$

$\mathrm{kg} / \mathrm{kmol}$

60

$\mathrm{kg} / \mathrm{s}$

54

98

98

$\mathrm{kmol} / \mathrm{s}$

57

8 
Latin

Symbols

\begin{tabular}{ll} 
Symbols & \multicolumn{1}{c}{ Description } \\
\hline$P$ & Pressure \\
PM & Particulate Matter \\
$\dot{Q}$ & Flow rate \\
$R e$ & Reynolds number \\
$R_{u}$ & Universal gas constant \\
& \\
$R S S$ & Residual sum of squares \\
SCF & Standard Cubic Feet \\
$S L P M$ & Standard Litres per Minute \\
$S V F$ & Soot Volume Fraction \\
$T$ & Temperature \\
$\triangle T_{f}$ & Flame Characteristic Temperature Rise \\
$T C E Q$ & Texas Commision on Environmental \\
& Quality
\end{tabular}

UKOOA United Kingdom Offshore Operator

Association

US EPA United States Environmental Protection

Agency

$X \quad$ Mole fraction, concentration

$Y \quad$ Mass fraction
First Use

Eq.

$\mathrm{Pa}$

Pg.

$\mathrm{m}^{3} / \mathrm{s}$

8314

$\mathrm{J} / \mathrm{kmol}-\mathrm{K}$

4

67

13

69

103

$\mathrm{ft}^{3} / \min$

6

$\mathrm{L} / \mathrm{min}$

K

14

14

28

$\mathrm{m} / \mathrm{s}$

14

8
Other Symbols

$\rho$

$\mu$

$\eta$

$\#_{c, i}$

$\sigma$
First Use

Eq. $\quad$ Pg

$\mathrm{kg} / \mathrm{m}^{3}$

14

$\mathrm{kg} / \mathrm{m}-\mathrm{s}$

14

$\%$

52

59

98 


\begin{tabular}{|c|c|c|}
\hline \multirow[b]{2}{*}{ Subscripts } & \multirow[b]{2}{*}{ Description } & First Use \\
\hline & & Eq. $\quad$ Pg. \\
\hline 0 & Refers to conditions at the burner exit & 14 \\
\hline 2.5 & Particulate matter (PM) less than 2.5 nanometres size & 4 \\
\hline 10 & Particulate matter (PM) less than 10 nanometres size & 8 \\
\hline$\infty$ & Refers to ambient conditions & 14 \\
\hline$a d$ & Refers to adiabatic conditions & 14 \\
\hline combusted & Refers to portion of flare species combusted & 72 \\
\hline $\begin{array}{l}\text { combustion } \\
\text { air }\end{array}$ & $\begin{array}{l}\text { Refers to portion of air required for stoichiometric } \\
\text { combustion of flare gas }\end{array}$ & 54 \\
\hline dilution air & Refers to portion of air diluting the products of combustion & 54 \\
\hline$F G$ & Refers to flare gas & 54 \\
\hline$F L$ & Refers to flare liquid & 72 \\
\hline$i$ & Refers to a given species & 53 \\
\hline inert & Refers to inert species in the flare gas & 54 \\
\hline measured & $\begin{array}{l}\text { Refers to conditions measured at LII, specifically } \\
\text { temperature and SVF }\end{array}$ & 68 \\
\hline plume & Refers to diluted plume, sum of products and dilution air & 54 \\
\hline produced & Refers to production rate due to chemical reactions & 54 \\
\hline tracer & Refers to the tracer gas acetylene & 71 \\
\hline
\end{tabular}




\section{Preface}

This thesis includes an integrated article that has been published to a scholarly journal:

Corbin, DJ, MR Johnson (2014) Detailed Expressions and Methodologies for Measuring Flare Combustion Efficiency, Species Emission Rates, and Associated Uncertainties, Industrial \& Engineering Chemistry Research 53 (49), pp 19359-19369. doi: 10.1021/ie502914k

The article is included in its entirety as Chapter 3 with the corresponding supplemental material included as Appendix A. The article details the methodology used to produce the results presented in this thesis. The article is reproduced as published with modifications to formatting and the numbering of sections, figures, tables and equations. The preferred method of citing this work from the thesis is to directly reference the published article if possible. The article is copyright of the American Chemical Society and subject to their Journal Publishing Agreement which permits use of authored work by the author in a thesis.

\section{Student Statement Regarding Student Involvement}

I, Darcy Corbin, was fully involved and responsible for setting up equipment, obtaining data, analyzing results, and writing the first drafts of the material presented in the article noted above and included as Chapter 3 of the thesis.

Darcy J Corbin

\section{Supervisor Statement Regarding Student Involvement}

The student, Darcy Corbin, was fully involved and responsible for setting up equipment, obtaining data, analyzing results, and writing the first drafts of the material presented in the article noted above and included as Chapter 3 of the thesis.

Matthew R Johnson 


\section{Chapter 1}

\section{Introduction}

\subsection{Background \& Literature Review}

Flaring is the practice of waste gas disposal through the process of combustion. During oil extraction, if it is uneconomical to capture the associated gas products, they are either directly vented to the atmosphere or flared. Because raw methane $\left(\mathrm{CH}_{4}\right)$, the main component in waste gas streams in the upstream energy industry, has a 100-year timehorizon Global Warming Potential (GWP) $30^{1}-36^{2}$ times higher than carbon dioxide $\left(\mathrm{CO}_{2}\right)$ on a mass basis (Myhre et al., 2013), flaring can reduce greenhouse gas (GHG) emissions relative to venting. Factoring the differences in molecular masses between $\mathrm{CO}_{2}$ and $\mathrm{CH}_{4}$, flaring one unit of $\mathrm{CH}_{4}$ produces 10.9-13.1 times less $\mathrm{CO}_{2}$ equivalent GHG emissions than direct venting of that same gas. This highlights the importance of the combustion process in effectively converting methane and other hydrocarbon constituents to carbon dioxide $\left(\mathrm{CO}_{2}\right)$. Since in practice hydrocarbon combustion is not perfect, black carbon (BC), unburned or reformed hydrocarbons, and other toxic air pollutants are generally produced via the flaring process. These products of incomplete combustion have important effects on both public health and the environment at large (US EPA, 2012).

\footnotetext{
${ }^{1}$ Value for 'fossil methane' without climate-carbon feedbacks

${ }^{2}$ Value for 'fossil methane' with climate-carbon feedbacks
} 
Efforts funded by the World Bank Global Gas Flaring Reduction (GGFR) partnership using satellite observations to estimate gas flaring volumes indicate global gas flaring exceeded 133 billion cubic metres in 2010, and flaring volumes in Canada exceeding 2 billion cubic metres in the same year (NGDC, 2014). Studies suggest that the volume of natural gas flared globally is about $5 \%$ of world consumption (US EPA, 2012). Flaring activities can be categorized into three rough categories: emergency flaring, process flaring and production flaring (Johnson, Kostiuk, et al., 2001). Emergency flaring encompasses unexpected releases of combustible gas due to a variety of potential causes and generally entails high volumes of gas being flared over short durations of time. Process flaring is primarily found in downstream oil or gas processing facilities, where waste products of varying composition may be continuously flared at relatively low flow rates. Production flaring includes both short term flaring during commissioning of new gas wells (well test flaring) and continuous flaring of unusable solution gas over the lifetime of an oil-well. Solution gas flares are the primary focus of the current work, and comprise the majority of flaring activity in the Alberta upstream oil and gas industry (Johnson, Kostiuk, et al., 2001).

Solution gas flares, as illustrated schematically in Figure 1.1, are generally described as simple pipe-flares, in which a straight length of pipe nominally between 3 10 inches in diameter extends vertically into the air in the order of 10 meters (Johnson, Kostiuk, et al., 2001). The pipe exit may be contain a simple wind shroud (usually a larger diameter, open-ended cylinder encircling the exit and aligned with the pipe) or may be unmodified. These simple designs are in contrast with large, multi-burner engineered tips which are more common in process flaring applications. Additionally, common 
practices such as steam- or air-assisted flaring (where pressurized steam or air are injected into the combustion zone to promote mixing and suppress soot formation) are generally not implemented in the remote locations which are characteristic of upstream oil and gas flaring. Due to the simple design, combustion is carried out under nonpremixed conditions. Flare gas absent of an oxidizer is delivered to the tip of the flare where it exits at near atmospheric conditions in terms of temperature and pressure. An electronic ignitor or a pilot flame may be installed at the tip to ensure continuous ignition of the flared gas.

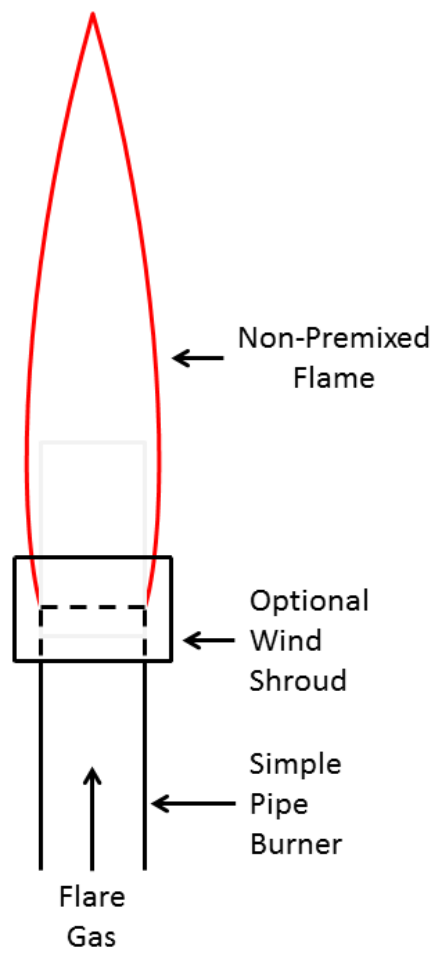

Figure 1.1: Schematic of generic solution gas typical of the Alberta upstream oil and gas industry

The importance of $\mathrm{BC}$ as an emission from flaring is a major motivation for the current work. Black carbon in the atmosphere is believed to be the $2^{\text {nd }}$ most important climate forcer after $\mathrm{CO}_{2}$ (Bond et al., 2013). While the fraction of global BC emissions 
attributable to gas flaring may be small $(<3 \%)$, the majority of flaring activity takes place in sensitive northern latitudes (Stohl et al., 2013). Flaring is the largest anthropogenic source of $\mathrm{BC}$ north of $60 \mathrm{~N}$ ( $2^{\text {nd }}$ to natural biomass combustion overall $)$ and estimated as the single largest source north of $66 \mathrm{~N}$ (i.e. north of the Arctic circle). Simulations suggest that $\mathrm{BC}$ from flaring constitutes $42 \%$ of the annual mean $\mathrm{BC}$ level in the Arctic (Stohl et al., 2013) making it the dominant source in the region.

Particulate matter (PM) with a diameter less than 2.5 micrometres $\left(\mathrm{PM}_{2.5}\right)$ has been a component of the National Ambient Air Quality Standards issued by the United States Environmental Protection Agency (US EPA) since its differentiation from larger PM in 1997. The US EPA defines black carbon as synonymous with elemental carbon, soot, and light-absorbing carbon and distinct from both organic and carbonate carbon forms (US EPA, 2004). In recent years, it has been suggested that in addition to the acknowledgement of $\mathrm{PM}_{2.5}$ as a significant health hazard, $\mathrm{BC}$ specifically should be investigated as an equal or greater hazard due to recent developments in monitoring technology. Specifically, BC can be causally linked to lung cancer and cardiovascular mortality, and possibly adverse birth and nervous system effects (Grahame et al., 2014).

\subsection{Emissions Estimates}

Estimates of flare-generated pollutant emissions are generally calculated based on simple emission factors. For example, the Canadian Association of Petroleum Producers (CAPP) recommends single-valued emission factors for various species (particulate, $\left.\mathrm{NO}_{\mathrm{X}}, \mathrm{CO}\right)$ for use in reporting flare-generated emissions to the Canadian National Pollutant Release Inventory (NPRI). As further summarized in the following section, these emission factors are in general overly simplified and of questionable validity. 
Poorly estimated emission magnitudes adversely impact the accuracy of national and international pollutant inventories, and impedes sound policy decisions. Better emissions quantification remains a critical experimental research challenge. Numerous studies emphasize the necessity of continued work in the quantification of emissions and development of emission factors for flaring activities in particular (Stohl et al., 2013; US EPA, 2012; Arctic Council, 2011).

\subsubsection{Current Emission Factors for Flares}

A review of available emission factors in the literature has shown that most are ultimately sourced from a very limited number of primary studies and published values. The most accessible emission factor data for flaring activity in North America is published by the US EPA and CAPP. Other emission factors are available for flaring activity in Latin America, Europe, and the UK. Emission factors discussed in this section are summarized in Table 1.1, which considers soot emission factors, and Table 1.2, which considers $\mathrm{NO}_{\mathrm{X}}$ emission factors. The tables report the emission factors both in the units presented in the relevant cited source document, and in a common set units as calculated by the author. Also listed is the composition of the flare gas used in the development of each factor.

The US EPA provides emission factors for flaring from a number of sources. AP 42 compiles pollutant emission factors for stationary sources and provides two subsections relevant to flaring. Landfill gas flaring is outlined in Section 2.4 (US EPA, 1998) of the AP 42 document and includes a soot emission factor of $17 \mathrm{lb} / 10^{6}$ dry standard cubic feet (DSCF) of methane and a NOx emission factor of $40 \mathrm{lb} / 10^{6}$ DSCF of methane. These numbers are attributed to testing on enclosed flares (US EPA, 1998). Section 13.5 (US EPA, 1995) of AP 42 covers industrial flares and provides four single- 
value soot emission values ranging from $0-274 \mu \mathrm{g} / \mathrm{L}$ of exhaust product for flares ranging from non-smoking to heavily-smoking operating conditions. A single $\mathrm{NO}_{\mathrm{X}}$ emission factor of $0.068 \mathrm{lb} / 10^{6} \mathrm{Btu}$ of flared gas is also provided. These soot and NOx factors are cited from flare experiments (McDaniel, 1983) in which crude propylene was used as fuel. A third set of emission factors available from the US EPA online WebFIRE database (US EPA, 2014) suggests values of $53 \mathrm{lb} / 10^{6}$ standard cubic feet (SCF) for soot and $28.3 \mathrm{lb} / 10^{6} \mathrm{SCF}$ for $\mathrm{NO}_{\mathrm{x}}$. These values are derived from a confidential US EPA report (US EPA, 1991) and reference a landfill gas flare as a data source. These data are the basis for the emission factors recommended in the CAPP NPRI.

The Asociacion Regional de Empresas de Petroleo y Gas Natural en Latino America y el Caribe (ARPEL) publishes emission factors for solution gas ${ }^{3}$ combustion from heavy crude oil primary (sweet) and thermal (sour) facilities, as well as for steam assisted flaring at gas plants (Franklin and Leahey, 1998). These values are derived from documents and presentations by CAPP, US EPA and the now defunct Canadian Ministry of Energy, Mines and Resources. Separate single-valued soot emission factors of 0.0023 and $0.0023 \mathrm{~kg} / \mathrm{m}^{3}$ are suggested for sweet and sour crude oil facilities respectively. For steam-assisted flaring at gas facilities, a factor of $43.0 \mathrm{t} / \mathrm{PJ}$ is recommended. The $\mathrm{NO}_{\mathrm{X}}$ emission factor for flaring associated with crude oil facilities is $0.0016 \mathrm{~kg} / \mathrm{m}^{3}$, while for steam-assisted flaring at gas facilities it is over fifty percent greater at $59.0 \mathrm{t} / \mathrm{PJ}$ of fired gas.

\footnotetext{
${ }^{3}$ Defined here as gas that is co-produced with oil and/or gas released from oil when it is reduced to atmospheric pressures from formation pressures.
} 
In their guidance document for reporting to the NPRI, CAPP provides singlevalued emission factors for soot and $\mathrm{NO}_{\mathrm{X}}$ (CAPP, 2007). Both emission factors are derived from US EPA emission factors; the soot emission factor is attributed to a confidential US EPA report (US EPA, 1991) investigating emissions from landfill gas flaring, and the $\mathrm{NO}_{\mathrm{X}}$ emission factor is attributed to AP 42 Section 13.5 (US EPA, 1995). The CAPP soot emission factor of $2.5632 \mathrm{~kg} / 1000 \mathrm{~m}^{3}$ (significant figures as reported) is scaled to a nominal higher heating value (HHV) of $45 \mathrm{MJ} / \mathrm{m}^{3}$ for upstream oil and gas (UOG) flaring from the US EPA factor for landfill gas which has an assumed HHV of $15 \mathrm{MJ} / \mathrm{m}^{3}$ and is presented on a per volume basis. The NOx emission factor of $1.345 \mathrm{~kg} / 1000 \mathrm{~m}^{3}$ was converted from the US EPA factor which is presented on a per energy content basis also using a nominal HHV of $45 \mathrm{MJ} / \mathrm{m}^{3}$.

The Exploration \& Production (E\&P) Forum (Shah and Pope, 1994) report provides a gas flaring emission factor for $\mathrm{NO}_{\mathrm{X}}$ only. The reported value of $0.0015 \mathrm{t} / \mathrm{t}$ flared gas is based on emission factors from three primary sources, although it is not clear how the final value was calculated. The sources for the $\mathrm{NO}_{\mathrm{X}}$ emission factor include a Norwegian Oil Industry Association (OLF) report (OLF Environmental Programme, 1991) and a United Kingdom Offshore Operator Association (UKOOA) report (UKOOA, 1993) neither of which could be found, as well as E\&P Forum internal data which shares a value with the work of McDaniel (1983).

The European Environment Agency (EEA) publishes regular updates of emission factors for a variety of industries and activities. The most recent publication (Trozzi, 2013) provides soot and NOx emission factors relevant to flaring in oil and gas extraction. The soot emission factor of $2.6 \mathrm{~kg} / \mathrm{Mg}$ throughput is taken directly from a 
publication relevant to the Mexican oil industry (Villasenor et al., 2003). The $\mathrm{NO}_{\mathrm{X}}$ emission factor of $1.4 \mathrm{~kg} / \mathrm{Mg}$-gas-burned is the result of a geometric mean of three published values from the Norwegian (Havs, 2012) and Mexican (Villasenor et al., 2003) petroleum industries, and the E\&P Forum (Shah and Pope, 1994).

The UK National Atmospheric Emissions Inventory (NAEI) publishes regular updates to a variety of emission factors with the latest published data for the year 2012 (NAEI, 2012). Emission factors are given for both upstream oil production flaring and upstream gas production activities. $\mathrm{PM}_{10}$ (particulate matter less than 10 microns in size) and $\mathrm{PM}_{2.5}$ (less than 2.5 microns in size) emission factors of 0.7 and $0.31 \times 10^{-6} \mathrm{kt} / \mathrm{t}$ are specified. $\mathrm{A} \mathrm{NO}_{\mathrm{X}}$ emission factor of $1.4 \times 10^{-6} \mathrm{kt} / \mathrm{t}$ is also provided. The emission factors for $\mathrm{PM}$ and $\mathrm{NO}_{\mathrm{X}}$ are listed for both upstream oil and upstream gas production separately with the same numbers used for each activity. The primary source of these factors is not readily apparent.

The work of Villasenor et al. (2003) is the basis for emission factors applied to the petroleum exploration and production industry in Mexico. The factors reported are broadly referenced from the USEPA AP 42 report and the ARPEL emissions inventory discussed previously. The emission factors of $2.1 \mathrm{~g} \mathrm{PM}_{10} / \mathrm{Sm}^{3}$ and $1.6 \mathrm{~g} \mathrm{NO}_{\mathrm{X}} / \mathrm{Sm}^{3}$ match exactly with the sour gas flaring emission factors provided by ARPEL, which is likely the primary source for the emission factors in this work.

As summarized in Table 1.1 and Table 1.2, soot and $\mathrm{NO}_{\mathrm{X}}$ emission factors are available from many sources with somewhat limited information as to the source of the emission factor or the applicability to upstream oil and gas flares. The emission factors 
as reported are defined using various base units, which underscores the lack of consistency or knowledge on the appropriate scaling of emission factors for different flare gases with a potentially wide range of densities and heating values. Available soot emission factors appear in almost equal number on a mass of soot per mass of flare gas basis and mass of soot per volume of flare gas basis with a single factor given on a mass of soot per energy content of flare gas basis. These emission factors when converted to common units range by more than an order of magnitude from 0.00031 to $0.0034 \mathrm{~kg}$ soot/kg-flare-gas. $\mathrm{NO}_{\mathrm{X}}$ emission factors are presented on mass of $\mathrm{NO}_{\mathrm{X}}$ per mass, volume, and energy content of flare gas basis. When converted to common units the emission factors range from 0.000533 to $0.00317 \mathrm{~kg}-\mathrm{NO}_{2} / \mathrm{kg}$-flare-gas. The order of magnitude differences among the soot and $\mathrm{NO}_{\mathrm{X}}$ emission factors taken from data on flare gases as chemically disparate as methane and crude propylene emphasises the need for caution when using current single-value emission factors and the importance flare gas composition in determining pollutant emission rates. Additionally, it is noted that many of the emission factors are directly referenced or adapted from other emission factors. Specifically, for soot emission the emission factors of ARPEL, CAPP, EEA and Villasenor all come from previously published US EPA factors, which themselves are either taken from confidential test data or the work of McDaniel on crude propylene flames with soot concentration data for an unknown dilution of products. Although current $\mathrm{NO}_{\mathrm{X}}$ emission factors are attributed to a more diverse set of sources, details of the test conditions and measurements that produced the factors are limited. 
Table 1.1 - Summary of soot emission factors

\begin{tabular}{|c|c|c|c|c|}
\hline Standard & $\begin{array}{l}\text { Reported } \\
\text { Emission } \\
\text { Factor }\end{array}$ & $\begin{array}{l}\text { EF Equivalent } \\
\text { (kg-PM/kg- } \\
\text { flare-gas) }\end{array}$ & Flare Gas & Primary Source \\
\hline $\begin{array}{l}\text { AP } 42, \text { Vol I, Sec } 2.4 \\
\text { US EPA (1998) }\end{array}$ & $\begin{array}{l}17 \mathrm{lb} / 10^{6} \\
\text { DSCF } \\
\text { Methane }\end{array}$ & $0.00032^{a}$ & Methane & - Enclosed Flares \\
\hline $\begin{array}{l}\text { AP 42, Vol I, } \\
\text { Sec } 13.5 \text { US EPA } \\
(1995)\end{array}$ & $\begin{array}{l}0,40,177,274 \\
\mu g / L \text { exhaust } \\
\text { gas }^{b}\end{array}$ & $\begin{array}{l}0,0.00050 \\
0.00219,0.00340\end{array}$ & $\begin{array}{l}\text { Crude } \\
\text { Propylene }\end{array}$ & - McDaniel (1983) \\
\hline $\begin{array}{l}\text { WebFIRE, US EPA } \\
(2014)\end{array}$ & $53 \mathrm{lb} / 10^{6} \mathrm{SCF}$ & $0.0010^{\mathrm{a}}$ & Landfill Gas & $\begin{array}{l}\text { - Confidential Report No. ERC-55, April 21, } \\
1991\end{array}$ \\
\hline $\begin{array}{l}\text { ARPEL (Franklin and } \\
\text { Leahey, 1998) }\end{array}$ & $\begin{array}{l}0.0023,0.0021 \\
\mathrm{~kg} / \mathrm{m}^{3} \text {-gas- }^{\mathrm{c}} \\
\text { burned } \\
\text { tonnes/PJ- } \\
\text { fired }\end{array}$ & $\begin{array}{l}0.0027^{\mathrm{a}}, 0.0025^{\mathrm{a}} \\
0.00228^{\mathrm{a}, \mathrm{d}}\end{array}$ & $\begin{array}{l}\text { Solution Gas } \\
\text { (Sweet, Sour), } \\
\text { Natural Gas } \\
\text { Steam } \\
\text { Assisted }\end{array}$ & $\begin{array}{l}\text { USEPA External Combustion Sources, } \\
\text { 4/93, Table 1.3-10, New Source } \\
\text { Performance Standards for Fossil Fuel } \\
\text { Fired Burners }\end{array}$ \\
\hline CAPP (2007) & $\begin{array}{l}2.5632 \mathrm{~kg} / 10^{3} \\
\mathrm{~m}^{3}\end{array}$ & $0.00302^{a}$ & Solution Gas & $\begin{array}{l}\text { - USEPA WebFIRE 6.22, April 21, } 1991 . \\
\text { Landfill gas adjusted to } 45 \mathrm{MJ} / \mathrm{m}^{3} \mathrm{HHV}\end{array}$ \\
\hline EEA (Trozzi, 2013) & $\begin{array}{l}2.6 \mathrm{~kg} / \mathrm{Mg}- \\
\text { throughput }\end{array}$ & 0.0026 & $\begin{array}{l}\text { Flaring in Oil } \\
\text { and Gas } \\
\text { Extraction }\end{array}$ & - Villasenor et al. (2003) \\
\hline NAEI (2012) & $\begin{array}{l}0.7^{\mathrm{e}}, 0.31^{\dagger} \times 10^{-} \\
{ }^{6} \mathrm{kt} / \mathrm{t}\end{array}$ & $0.0007,0.00031$ & $\begin{array}{l}\text { Upstream Gas } \\
\text { Production }\end{array}$ & - Unknown \\
\hline $\begin{array}{l}\text { Villasenor et al. } \\
(2003)\end{array}$ & $2.1 \mathrm{~g} / \mathrm{Sm}^{3}$ & $0.0025^{\mathrm{a}}$ & Sour Gas & - US EPA AP 42 (2001)/ARPEL (1998) \\
\hline \multicolumn{5}{|c|}{$\begin{array}{l}\text { a Assumed gas density of } 0.85 \mathrm{~kg} / \mathrm{m}^{3} \\
{ }^{\mathrm{b}} \text { Calculated following McEwen (2010), corrections made for crude propylene } \\
{ }^{\mathrm{c}} \text { Values given are for "Solution Gas Combustion Heavy Crude Oil Primary (Sweet)/Thermal (Sour) Facilities" respectively } \\
{ }^{\mathrm{d}} \text { Assumed HHV of } 45 \mathrm{MJ} / \mathrm{m}^{3} \\
{ }^{\mathrm{e}} \mathrm{PM}_{10} \\
{ }^{\mathrm{f}} \mathrm{PM}_{2.5}\end{array}$} \\
\hline
\end{tabular}


Table 1.2 - Summary of $\mathrm{NO}_{\mathrm{x}}$ emission factors

\begin{tabular}{|c|c|c|c|c|}
\hline Standard & $\begin{array}{l}\text { Reported } \\
\text { Emission } \\
\text { Factor }\end{array}$ & $\begin{array}{l}\text { EF Equivalent } \\
\text { (kg-NO } / \mathrm{kg}- \\
\text { flare-gas) }\end{array}$ & Flare Gas & Primary Source \\
\hline $\begin{array}{l}\text { AP } 42 \text {, Vol I, Sec } 2.4 \\
\text { US EPA (1998) }\end{array}$ & $\begin{array}{l}40 \mathrm{lb} / 10^{6} \\
\text { DSCF } \\
\text { Methane }\end{array}$ & $0.00075^{\mathrm{a}}$ & Methane & - Enclosed Flares \\
\hline $\begin{array}{l}\text { AP 42, Vol I, } \\
\text { Sec 13.5 US EPA } \\
\text { (1995) }\end{array}$ & $\begin{array}{l}0.068 \mathrm{lb} / 10^{6} \\
\text { BTU }\end{array}$ & $0.0014^{\mathrm{b}, \mathrm{c}}$ & $\begin{array}{l}\text { Crude } \\
\text { Propylene }\end{array}$ & - McDaniel (1983) \\
\hline $\begin{array}{l}\text { WebFIRE, US EPA } \\
(2014)\end{array}$ & $\begin{array}{l}28.3 \mathrm{lb} / 10^{6} \\
\text { SCF }\end{array}$ & $0.000533^{\mathrm{a}}$ & Landfill Gas & $\begin{array}{l}\text { - Confidential Report No. ERC-55, April 21, } \\
1991\end{array}$ \\
\hline $\begin{array}{l}\text { ARPEL (Franklin and } \\
\text { Leahey, 1998) }\end{array}$ & $\begin{array}{l}0.0016 \mathrm{~kg} / \mathrm{m}^{3}- \\
\text { gas }{ }^{\mathrm{d}}, 59.9 \\
\text { tonnes/PJ- } \\
\text { fired }\end{array}$ & $\begin{array}{l}0.0019^{\mathrm{a}} \\
0.00317^{\mathrm{a}, \mathrm{e}}\end{array}$ & $\begin{array}{l}\text { Solution Gas } \\
\text { (Sweet, Sour), } \\
\text { Natural Gas } \\
\text { Steam } \\
\text { Assisted }\end{array}$ & $\begin{array}{l}\text { - CAPP, Climate Change Workshop on } \\
\text { Benchmarking of Energy Use and } \\
\text { Emissions, Calgary, Alberta, July 18, } 1995 \\
\text { - CAPP Guide: Voluntary Challenge, June } \\
\text { 30, 1995, Table } 3\end{array}$ \\
\hline CAPP (2007) & $\begin{array}{l}1.345 \mathrm{~kg} / 10^{3} \\
\mathrm{~m}^{3}\end{array}$ & $0.001582^{\mathrm{a}}$ & Solution Gas & $\begin{array}{l}\text { - USEPA AP } 421995 \text {, Section } 13.5 \text { adjusted } \\
\text { to } 45 \mathrm{MJ} / \mathrm{m}^{3} \mathrm{HHV}\end{array}$ \\
\hline $\begin{array}{l}\text { E\&P Forum (Shah } \\
\text { and Pope, 1994) }\end{array}$ & $\begin{array}{l}0.0015 \\
\text { tonnes/tonne- } \\
\text { flared }\end{array}$ & 0.0015 & Solution Gas & - OLF (1991), UKOA (1993), Internal Data \\
\hline EEA (Trozzi, 2013) & $\begin{array}{l}1.4 \mathrm{~kg} / \mathrm{Mg} \text {-gas- } \\
\text { burned }\end{array}$ & 0.0014 & $\begin{array}{l}\text { Flaring in Oil } \\
\text { and Gas } \\
\text { Extraction }\end{array}$ & $\begin{array}{l}\text { - OLF (2012), Villasenor et al. (2003), E\&P } \\
\text { Forum (1994) }\end{array}$ \\
\hline NAEI (2012) & $1.4 \times 10^{-6} \mathrm{kt} / \mathrm{t}$ & 0.0014 & $\begin{array}{l}\text { Upstream Gas } \\
\text { Production }\end{array}$ & - Unknown \\
\hline $\begin{array}{l}\text { Villasenor et al. } \\
(2003)\end{array}$ & $1.6 \mathrm{~g} / \mathrm{Sm}^{3}$ & $0.0019^{b}$ & Sour Gas & - US EPA AP 42 (2001)/ARPEL (1998) \\
\hline \multicolumn{5}{|c|}{$\begin{array}{l}{ }^{\mathrm{a}} \text { Assumed gas density of } 0.85 \mathrm{~kg} / \mathrm{m}^{3} \\
\mathrm{~b} \text { Assumed gas density of } 1.90 \mathrm{~kg} / \mathrm{m}^{3} \\
{ }^{\mathrm{c}} \text { Assumed HHV of } 93 \mathrm{MJ} / \mathrm{m}^{3} \\
\mathrm{~d} \text { Value given is for Solution Gas Combustion Heavy Crude Oil Primary (Sweet)/Thermal (Sour) Facilities } \\
{ }^{\mathrm{e}} \text { Assumed HHV of } 45 \mathrm{MJ} / \mathrm{m}^{3}\end{array}$} \\
\hline
\end{tabular}




\subsection{Flow Regimes for Non-premixed Diffusion Flames and Flares}

Efforts have been made (Delichatsios, 1993) to distinguish flames into a number of regimes through various dimensionless expressions which speak to the overall fluid dynamic characteristics of the flame itself. These efforts deconstruct the flame into two regions: a transition region close to the nozzle and the remainder of the flame downstream of this region. Flames can exist in which both regions are laminar, both regions are turbulent, or the transition region is laminar while the rest of the flame is turbulent. As proposed by Delichatsios (1993), in cases where the Reynolds number exceeds 4000 , turbulence is induced by inertia (momentum) in the region near the exit of the nozzle. Alternatively at Reynolds numbers lower than 4000, transition from a laminar flame at the nozzle exit and laminar conditions in the nozzle exit to turbulent conditions in the downstream region can occur through buoyancy mechanisms caused by combustion related density gradients. Delichatsios (1993) suggests that a dimensionless Froude number, which compares gravitational and inertial properties, can be useful to describe which regime describes a given flame as illustrated in Figure 1.2. Several modifications to the basic Froude number are suggested which take into account stoichiometric and other fuel chemistry effects. Reynolds number $(R e)$ and the modified Froude number known as the Global Froude number $\left(F r_{g}\right)$ are defined by Eq. (1.1) and Eq. (1.2) below. An additional parameter, the Fire Froude number $\left(F r_{f}\right)$, which will be discussed later in Chapter 4 is defined by Eq. (1.3).

$$
\begin{gathered}
R e=\frac{\rho_{0} u_{0} d_{0}}{\mu_{0}} \\
F r_{g}=\frac{u_{0} f_{s}^{3 / 2}}{\left(g d_{0}\right)^{1 / 2}}\left(\frac{\rho_{\infty}}{\rho_{0}}\right)^{1 / 4}
\end{gathered}
$$




$$
F r_{f}=\frac{u_{0} f_{s}^{3 / 2}}{\left(g d_{0}\right)^{1 / 2}}\left(\frac{\rho_{\infty}}{\rho_{0}}\right)^{1 / 4}\left(\frac{T_{\infty}}{\Delta T_{f}}\right)^{1 / 2}
$$

In Eq. (1.1) above, $\rho$ is the density, $u$ is the velocity, $d$ is the diameter, and $\mu$ is the viscosity, where subscript 0 represents conditions at the exit of the flare. In addition, for Eq. (1.2) and Eq. (1.3), $f_{s}$ is the stoichiometric mixture fraction, $g$ is the gravitational constant, and $T$ is the temperature, where subscript $\infty$ represents ambient conditions and $\Delta T_{f}$ is calculated as $T_{\infty}$ subtracted from the adiabatic flame temperature, $T_{a d}$.

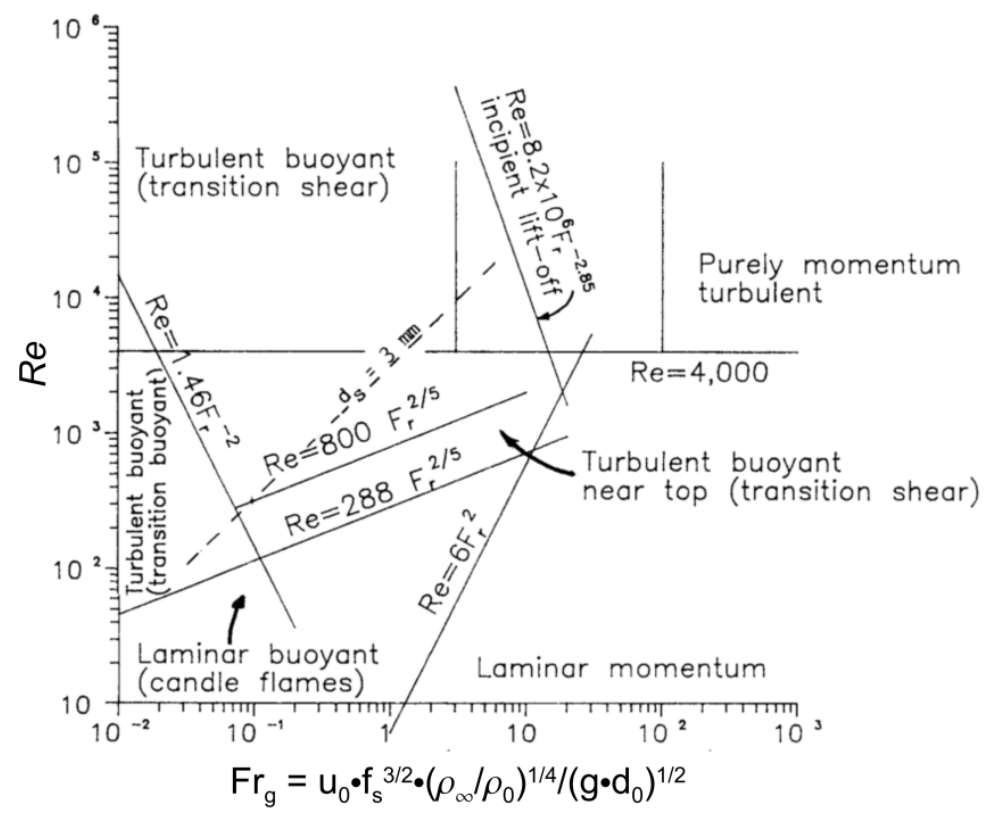

Figure 1.2: Delichatsios (1993) map showing regimes for jet diffusion flame exit conditions defined by exit Reynolds number and Global Froude number as defined by Eq. (1.2).

Recent work (Costa et al., 2004) suggests the transition from buoyancy to momentum dominated flames may also be important when investigating $\mathrm{NO}_{\mathrm{X}}$ emissions as shown in Figure 1.3. Experiments expanding earlier work (Rokke et al., 1992), which investigated primarily buoyancy controlled flames, to include flames in the momentum controlled regime suggest there may be a decrease in the defined $\mathrm{NO}_{\mathrm{X}}$ emission index at 
increased Froude numbers $(F r)$ as defined by Eq. (1.4). The same experiments show a decline in radiant fraction of the flame in the buoyant region before a possible leveling off of radiant fraction in the momentum dominated flames. However no correlation was found between the measured radiant fraction and a $\mathrm{NO}_{\mathrm{X}}$ emission index. This suggests any dependence of $\mathrm{NO}_{\mathrm{X}}$ emission index on radiant fraction is secondary to the effects accounted for in the Froude number correlation $\left(\mathrm{Fr}^{3 / 5}\right)$.

$$
F r=\frac{u_{0}^{2}}{g d_{0}}
$$

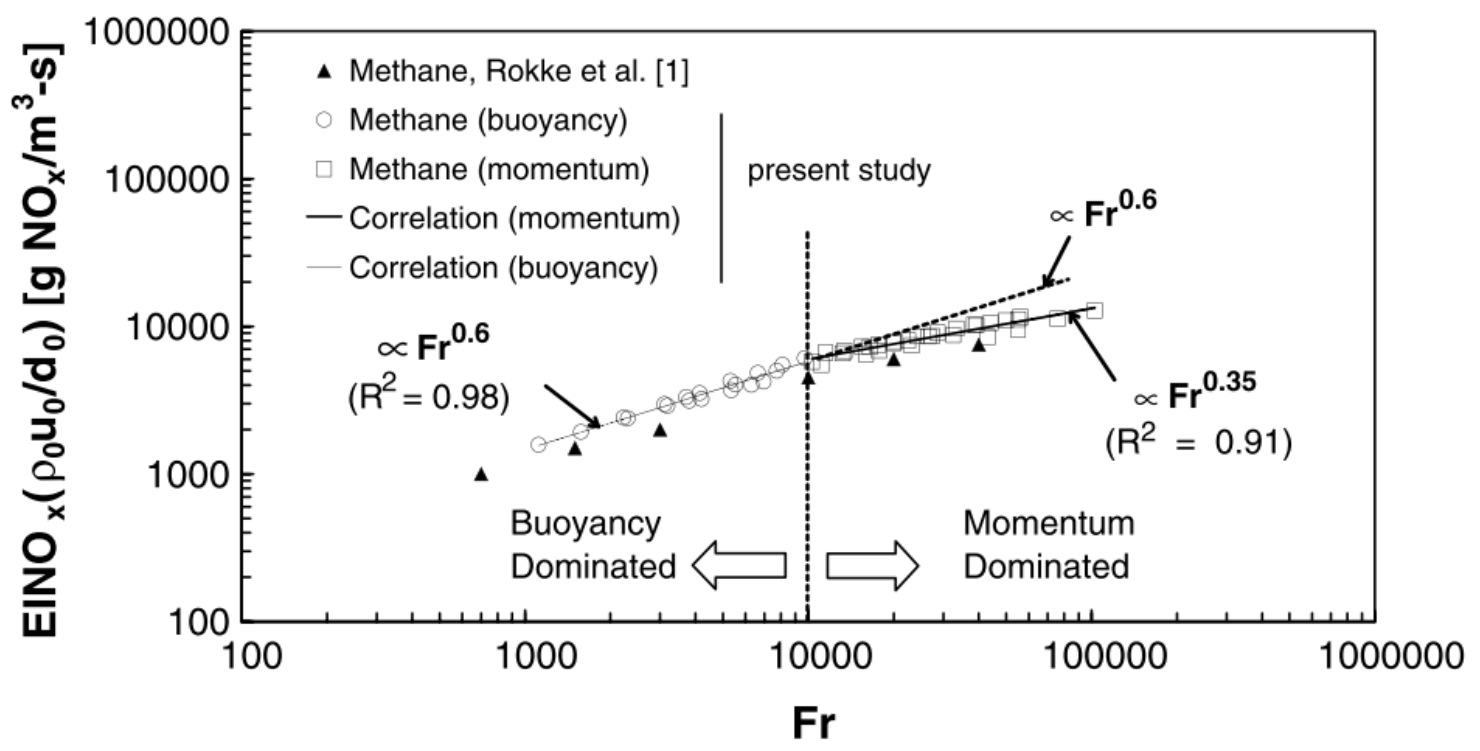

Figure 1.3: Costa et al. (2004) figure showing $\mathrm{NO}_{\mathrm{X}}$ emission index scaling changes for jet diffusion flames transitioning from buoyancy-dominated to momentumdominated regimes as characterized by the exit Froude number as defined by Eq. (1.4).

The preceding definitions of flame regimes and their suspected impact on emissions over a wide range of operating conditions is developed considering only the nozzle outlet conditions for vertical diffusion flames. In real world gas flaring 
applications, flames are subject to varying speeds of crosswind which will also have an effect on the combustion process. Primarily, transitions between laminar and turbulent flow at the outlet of the nozzle are complicated by the increased mixing via the presence of these crosswinds. Work on this subject has shown the importance of both the relative jet and crossflow velocities using a "mixing index" (product of air and fuel velocities) (Ellzey et al., 1990) and momentum ratio (ratio of fuel and crossflow velocities squared) (Bandaru and Turns, 2000; Johnson and Kostiuk, 2000). The quantifiable impact of crosswind on soot emissions, $\mathrm{NO}_{\mathrm{X}}$ emissions, and combustion efficiency is discussed further in Sections 1.4.1, 1.4.2, and 1.4.3 respectively.

\subsection{Existing Literature on Emission Quantification from Turbulent Non-Premixed Diffusion Flames}

\subsubsection{Soot Emissions Measurements}

Becker and Liang (1982) examined free turbulent diffusion flames for a range of alkane and alkene fuels measuring soot emissions and radiant cooling (ratio of radiant heat loss and energy of combustion). Both were found to plateau at a Richardson number, $R i$, (defined in Eq. (1.5)), with $L_{f}$ denoting the flame length) greater than 2000. Soot emissions expressed as a "soot yield factor" (ratio of soot output to carbon input) were observed to plateau at 0.0015-0.0045 for fuels other than acetylene, which had $\sim 100$ times greater soot yields. The soot yield factor stabilized at $\sim 0.0003$ for Richardson numbers less than 200 , where buoyancy was found to be unimportant. The experimental results and the form of the Richardson number, with its inverse proportionality to exit velocity, indicate that soot emissions are up to an order of magnitude greater at low velocities compared to high velocities for a given flare gas. 


$$
R i=\frac{g L_{f}^{3}}{\left(u_{0} d_{0}\right)^{2}}\left(\frac{\rho_{\infty}}{\rho_{0}}\right)
$$

Sivathanu and Faeth (1990) measured the overfire soot volume fractions on 5, 50 and $234 \mathrm{~mm}$ burners for acetylene, propylene, ethylene, and propane buoyant jet-flames. Soot generation (percent of fuel carbon converted to soot) was found to vary with residence time before plateauing for residence times much larger than the smoke point residence time.

McEwen (2010) measured soot yields from lab-scale flares burning methane and methane-based flare gases from 12.7 to $76.2 \mathrm{~mm}$. Based on the results it was suggested that soot yield may plateau for burners over $38.1 \mathrm{~mm}$ in diameter operating at conditions where the Fire Froude number is greater than 0.003. Comparisons to emission factors were made and the potential soot yield scaling with the gas heating value was made for heating values in the range of 38 to $47 \mathrm{MJ} / \mathrm{m}^{3}$. The suggestion of soot yield plateauing at increased Froude numbers contradicted the relation Becker and Liang (1982) found between soot yield and the Richardson number.

There are significantly less data available on the effect of crosswind on soot or BC emission rates. Ellzey et al. (1990) studied the soot yield from small diameter (1.19 to $2.41 \mathrm{~mm}$ ) propane diffusion flames in cross-flow and co-flow configurations. They showed that soot yields decreased with the scaled product of jet and air velocities for the cross-flow configuration. The reduction in soot yield with increases of air velocity was attributed to higher mixing. The effect of crosswind on $\mathrm{BC}$ emissions is an obvious area 
for future work, however the goals of the present work are to examine the zero-crosswind condition in which soot yield is may be at a maximum. 
Table 1.3 - Summary of literature reporting soot emissions from turbulent non-premixed diffusion flames

\begin{tabular}{|c|c|c|c|c|c|}
\hline Reference & $\begin{array}{l}\text { Diameter(s) } \\
(\mathrm{mm})\end{array}$ & $\begin{array}{l}\text { Velocities } \\
(\mathrm{m} / \mathrm{s})\end{array}$ & Fuel & Flame Type & Goals and Conclusions and Notes \\
\hline (Becker and Liang, 1982) & $0.7-10.9$ & $8-170$ & $\begin{array}{l}\mathrm{CH}_{4}, \mathrm{C}_{2} \mathrm{H}_{6}, \mathrm{C}_{3} \mathrm{H}_{8} \\
\mathrm{C}_{2} \mathrm{H}_{4}, \mathrm{C}_{2} \mathrm{H}_{2}\end{array}$ & $\begin{array}{l}\text { Turbulent buoyant } \\
\text { flames ranging from } \\
\text { forced to fully natural } \\
\text { convection }\end{array}$ & - $\mathrm{C}_{2} \mathrm{H}_{4}>\mathrm{C}_{3} \mathrm{H}_{8}>\mathrm{CH}_{4}, \mathrm{C}_{2} \mathrm{H}_{6}$ soot emission \\
\hline (Sivathanu and Faeth, 1990) & $5-234$ & $<30$ & $\begin{array}{l}\mathrm{C}_{2} \mathrm{H}_{2}, \mathrm{C}_{2} \mathrm{H}_{4} \\
\mathrm{C}_{3} \mathrm{H}_{6}, \mathrm{C}_{3} \mathrm{H}_{8}\end{array}$ & $\begin{array}{l}\text { Diffusion flames in still } \\
\text { air }\end{array}$ & $\begin{array}{l}\text { - Soot generation on per fuel basis increased with flame residence time } \\
\text { before approaching asymptotes } \\
\text { - SVF directly related to mixing and analogous to laminar flamelet concept } \\
\text { for nonpremixed flames }\end{array}$ \\
\hline (McEwen and Johnson, 2012) & $12.7-76.2$ & $0.1-2.2$ & $\begin{array}{l}\mathrm{CH}_{4}, \mathrm{C}_{2} \mathrm{H}_{6}, \mathrm{C}_{3} \mathrm{H}_{8} \\
\mathrm{C}_{4} \mathrm{H}_{10}\end{array}$ & $\begin{array}{l}\text { Diffusion flame with } \mathrm{N}_{2} \\
\text { and } \mathrm{CO}_{2} \text { diluent }\end{array}$ & $\begin{array}{l}\text { - Soot yields possibly plateau at Fire Froude numbers greater than } 0.003 \\
\text { - Potential for scaling with flare gas heating value proposed }\end{array}$ \\
\hline (Ellzey et al., 1990) & $1.19-2.41$ & $0.351-1.981$ & $\mathrm{C}_{3} \mathrm{H}_{8}$ & $\begin{array}{l}\text { Diffusion flame in cross- } \\
\text { flow and co-flow }\end{array}$ & $\begin{array}{l}\text { - Soot yield decreases with scaled product of jet and air velocity in cross- } \\
\text { flow } \\
\text { - Diameter not an important parameter }\end{array}$ \\
\hline (McDaniel, 1983) & $101.6 / 219.075$ & $0.03-8.7$ & $\begin{array}{l}\text { Crude } \\
\text { Propylene }\end{array}$ & $\begin{array}{l}\text { Air- and steam-assisted } \\
\text { industrial flares }\end{array}$ & $\begin{array}{l}\text { - Four undiluted soot concentrations measured for heavy-, average-, light- } \\
\text { and non-smoking operating conditions with varying steam-assist }\end{array}$ \\
\hline (Allen and Torres, 2011) & 609.6 / 914.4 & $0.083-0.24$ & $\begin{array}{l}\mathrm{C}_{3} \mathrm{H}_{6}, \mathrm{C}_{3} \mathrm{H}_{8} \\
\text { natural gas }\end{array}$ & $\begin{array}{l}\text { Air- and steam-assisted } \\
\text { industrial flares }\end{array}$ & - Soot emissions less than $0.5 \%$ of the fuel carbon on a molar basis \\
\hline
\end{tabular}




\subsection{2 $\mathrm{NO}_{\mathrm{X}}$ Emissions Measurements and Suggested Scaling}

Several investigations have been made throughout the literature examining the emissions of $\mathrm{NO}_{\mathrm{X}}$ from turbulent non-premixed diffusion flames and the potential for emissions scaling of $\mathrm{NO}_{\mathrm{X}}$. Experiments on propane flames (exit velocities, $u_{0}$, of $2.2-240 \mathrm{~m} / \mathrm{s}$ and stack diameters, $d_{0}$, of $\left.4-50 \mathrm{~mm}\right)$ and methane flames $\left(u_{0}=9.5-81 \mathrm{~m} / \mathrm{s}, d_{0}=10-28\right.$ $\mathrm{mm}$ ) were performed (Rokke et al., 1992) and compared with previous literature and a theoretical scaling expression (proposed by Rokke) as part of an investigation into the emissions of $\mathrm{NO}_{\mathrm{X}}$ over a range of Froude numbers in the buoyancy-controlled flame regime. Using a simple tube burner with no pilot, measurements of the relevant gases were measured in axial- and radial-profiles using a moveable single point probe. The measured ratio of $\mathrm{NO}_{\mathrm{X}}$ to $\mathrm{CO}_{2}$ was used to calculate a $\mathrm{NO}_{\mathrm{X}}$ emission rate or yield. In a comparison with literature available at the time of Rokke et al. (1992), the proposed scaling relation (Eq. (1.6)) appears to fit the data well for the various hydrocarbons and non-hydrocarbon fuels as shown in Figure 1.4. The theoretical scaling law in which flame volume is the most important parameter was derived from chemical kinetics and jet flame behaviour and examines three mechanisms for $\mathrm{NO}_{\mathrm{X}}$ production: the thermal, prompt, and nitrous-oxide mechanisms (Rokke et al., 1992).

$$
E_{N O_{X}}\left[\frac{\rho_{0} u_{0}}{d_{0}}\right]\left(\frac{g}{m^{3} s}\right) \approx 44 F r^{0.6}
$$




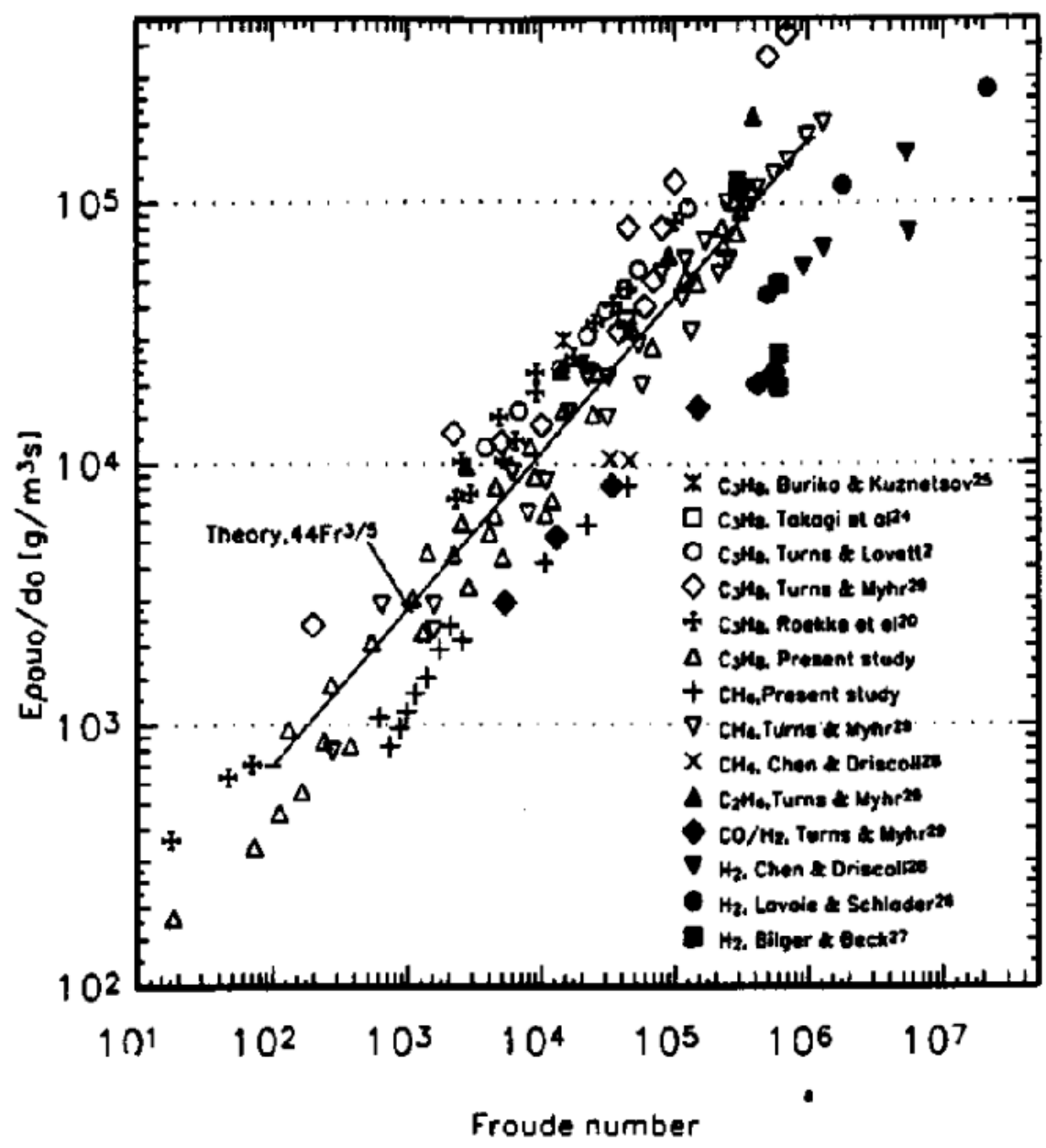

Figure 1.4: Proposed $\mathrm{NO}_{\mathrm{X}}$ scaling law including experimental data from literature (Rokke et al. 1992). Froude number is defined by Eq. (1.4).

More recent work (Costa et al., 2004) looked to re-examine $\mathrm{NO}_{\mathrm{X}}$ emissions and scaling in the buoyancy dominated regime and extend understanding into the momentum dominated regime. Methane flames were tested on 5,6 and $8 \mathrm{~mm}$ burners with exit velocities ranging from $9.4-89.9 \mathrm{~m} / \mathrm{s}$. The measurements suggest transition from buoyancy- to momentum-controlled flames occurs at a Froude number of approximately 10,000 , with scaling in the buoyancy-controlled region agreeing well with the proposed scaling law of Eq. (1.6). In the momentum-controlled region, the data suggest the $\mathrm{NO}_{\mathrm{X}}$ 
emission index dependency decreases to $\mathrm{Fr}^{0.35}$. $\mathrm{NO}_{\mathrm{X}}$ emissions were examined in the context of measurements on flame geometry and radiant fractions.

Propane and ethylene flames (Santos and Costa, 2005) were subsequently tested as an extension of the previously discussed methane experiments. Using the same three burners $(5,6$ and $8 \mathrm{~mm})$, exit velocities of $5-137.4 \mathrm{~m} / \mathrm{s}$ were tested to span the buoyancy- and momentum-controlled regime transition. It was found that the transition point varies depending on the hydrocarbon fuel tested with the data suggesting that it is the sooting propensity and related flame radiation losses and not the flame regime that may control the $\mathrm{NO}_{\mathrm{X}}$ scaling. Additionally, data from sooty (ethylene) flames suggest a unique scaling parameter compared to earlier data.

The first comprehensive $\mathrm{NO}_{\mathrm{x}}$ emissions study of flames in cross-flow (Bandaru and Turns, 2000) utilized a $4.12 \mathrm{~mm}$ horizontal tube with jet velocities of $15-100 \mathrm{~m} / \mathrm{s}$ burning in a vertical air jet. Pure methane, propane and ethylene were burned over a wide range of jet velocities in one or two different cross-flow conditions. Pilot flames were used in some instances to maintain a minimum allowed flame attachment with the burner tube. The results show that $\mathrm{NO}_{\mathrm{X}}$ yield on a mass per mass of gas flared basis remains relatively flat regardless of fuel jet velocity. The propane and ethylene flames exhibited higher $\mathrm{NO}_{\mathrm{X}}$ emissions at higher cross-flow velocities while the methane was tested only at a single cross-flow velocity. It is suggested that a decrease in radiant fraction and therefore soot production caused by the strong cross-flow creates a hotter flame and increased $\mathrm{NO}_{\mathrm{X}}$ production in the ethylene flame. 
The author is not aware of any comprehensive examination of the effect of horizontal crosswind on NOx production from a vertical diffusion flame (as relevant to a gas flare) with the possible exception of one recent paper using a pilot-scale flame with an open fan system (Talebi et al., 2014). A burning methane/propane/butane mixture was subjected to cross-flow from the open-fan system and single-point sampling was used to estimate emission indices. The results suggest $\mathrm{NO}_{\mathrm{X}}$ may decrease slightly (approximately $30 \%$ for range of cross-flow tested) with crosswind. Similar to the examination of soot yield in the current work, it is expected that the results for $\mathrm{NO}_{\mathrm{X}}$ yield under quiescent conditions will represent a maximum. 
Table 1.4: Summary of literature reporting $\mathrm{NO}_{\mathrm{X}}$ emissions from turbulent non-premixed diffusion flames

\begin{tabular}{|c|c|c|c|c|c|}
\hline Reference & $\begin{array}{l}\text { Diameter(s) } \\
(\mathrm{mm})\end{array}$ & $\begin{array}{l}\text { Velocities } \\
\text { (m/s) }\end{array}$ & Fuel(s) & Flame Type & Goals and Conclusions and Notes \\
\hline (Rokke et al., 1992) & $4-50$ & $2.2-240$ & $\mathrm{CH}_{4}, \mathrm{C}_{3} \mathrm{H}_{8}$ & $\begin{array}{l}\text { Unconfined, vertical, } \\
\text { turbulent jet diffusion } \\
\text { flame }\end{array}$ & - Good agreement between experimental results and scaling theory \\
\hline (Costa et al., 2004) & $5-8$ & $9.4-89.9$ & $\mathrm{CH}_{4}$ & $\begin{array}{l}\text { Unconfined, vertical, } \\
\text { turbulent jet diffusion } \\
\text { flame }\end{array}$ & $\begin{array}{l}\text { - Transition from buoyancy to momentum driven occurs at } \mathrm{Fr}=10^{4} \\
\text { - For buoyancy dominated flames volume is the primary scaling factor }\end{array}$ \\
\hline (Bandaru and Turns, 2000) & 4.12 & $15-100$ & $\mathrm{CH}_{4}, \mathrm{C}_{3} \mathrm{H}_{8}, \mathrm{C}_{2} \mathrm{H}_{4}$ & $\begin{array}{l}\text { Horizontal diffusion } \\
\text { flame in cross-flow }\end{array}$ & $\begin{array}{l}\text { - } \quad \text { Higher } \mathrm{NO}_{x} \text { yield in ethylene than other flames }(\mathrm{g} / \mathrm{kg}) \\
\text { - } \quad \mathrm{NO}_{x} \text { yield coupled to soot by radiant fraction }\end{array}$ \\
\hline (Talebi et al., 2014) & unknown & unknown & $\mathrm{CH}_{4}, \mathrm{C}_{3} \mathrm{H}_{8}, \mathrm{C}_{4} \mathrm{H}_{10}$ & $\begin{array}{l}\text { Diffusion flame in cross- } \\
\text { flow }\end{array}$ & - $\mathrm{NO}_{\mathrm{x}}$ yield decreases with increasing crosswind \\
\hline (McDaniel, 1983) & $101.6 / 219.075$ & $0.03-8.7$ & $\begin{array}{l}\text { Crude } \\
\text { Propylene }\end{array}$ & $\begin{array}{l}\text { Air- and steam-assisted } \\
\text { industrial flares }\end{array}$ & - 0.018 to $0.208 \mathrm{lb} / 10^{6}$ Btu with an average of $0.068 \mathrm{lb} / 10^{6}$ \\
\hline
\end{tabular}




\subsubsection{Studies of Combustion Efficiency}

Measurement of combustion efficiency (generally the percent of fuel carbon oxidized to form $\mathrm{CO}_{2}$ ) of lab-scale flames in the literature is quite limited. Strosher (2000) conducted measurements on lab-, pilot- and field-scale flares to measure combustion efficiencies and hydrocarbon emissions. Lab-scale tests included flows of pure flare gases, hydrocarbon liquids and entrained mixtures on flares with tip orifice diameters of 0.1-3.0 mm and a maximum exit velocity of Mach 0.2. Pilot-scale experiments extended the range of diameters tested to $2-6 \mathrm{~mm}$. Results of lab and pilot scale tests showed flares burning methane to have combustion rates greater than $99 \%$, while flares burning propane produced elevated soot compared to the methane flames and had combustion efficiencies around $98 \%$. Field tests in which samples were extracted from a single point probes suspended downstream of the flame tip were conducted on sweet gas flares at an oil battery and sour gas flares at a different battery. Local efficiencies at the probe as low as $\sim 62 \%$ were reported. Addition of liquid fuels to the flare gas stream, the presence of crosswind and impurities in the flare gases at the field sites were suggested as reasons for the low efficiency values.

The effect of cross-flow on combustion efficiency (Kostiuk et al., 2000) has been studied in some detail, where wind tunnel experiments suggest that efficiencies remain relatively high (greater than 96.5\%) unless the flame is subjected to a strong crosswind (greater than $6 \mathrm{~m} / \mathrm{s}$ ) (Johnson and Kostiuk, 2000) or low flare gas heating value (equal to

or less than $20 \mathrm{MJ} / \mathrm{m}^{3}$ ) (Johnson and Kostiuk, 2002). It is suggested that the decrease in combustion efficiency at cross winds is a results of unburned fuel ejected near the exit of the stack (Poudenx, 2000; Johnson, Wilson, et al., 2001). Efficiency measurements at 
zero-crosswind as in the present experiments therefore represent a best case scenario for the conversion of hydrocarbon to carbon dioxide at high combustion efficiency. A discussion of additional combustion efficiency measurements conducted on large-scale flares is continued in Section 1.5. 
Table 1.5: Summary of literature reporting combustion efficiency from turbulent non-premixed diffusion flames

\begin{tabular}{|c|c|c|c|c|c|}
\hline Reference & $\begin{array}{l}\text { Diameter(s) } \\
(\mathrm{mm})\end{array}$ & $\begin{array}{l}\text { Velocities } \\
(\mathrm{m} / \mathrm{s})\end{array}$ & Fuel & Flame Type & Goals and Conclusions and Notes \\
\hline Strosher (2000) & $0.1-200$ & $<$ Mach 0.2 & $\begin{array}{l}\mathrm{CH}_{4}, \mathrm{C}_{3} \mathrm{H}_{8} \text {, liquid } \\
\text { fuels, natural } \\
\text { gas, solution } \\
\text { gas }\end{array}$ & $\begin{array}{l}\text { Non-premixed diffusion } \\
\text { flame }\end{array}$ & $\begin{array}{l}\text { - Efficiencies }>99 \% \text { for } \mathrm{CH}_{4} \text { flames for laminar, transitional and turbulent } \\
\text { flows } \\
\text { - Efficiencies 98\% for } \mathrm{C}_{3} \mathrm{H}_{8} \text { flames with increased soot } \\
\text { - Pilot- and field-scale flares showed decreased efficiencies partially due to } \\
\text { flare gas contents and crosswinds }\end{array}$ \\
\hline Kostiuk et al. (2000) & $10.8-33.3$ & $0.5-2.0$ & $\begin{array}{l}\text { Natural gas, } \\
\text { propane }\end{array}$ & $\begin{array}{l}\text { Non-premixed diffusion } \\
\text { flame in crosswind }\end{array}$ & $\begin{array}{l}\text { - High efficiencies (> 99.5\%) for flames in near-quiescent conditions } \\
\text { - Decrease in efficiency down to } ~ \\
88 \% \text { with increasing crosswind }\end{array}$ \\
\hline Johnson and Kostiuk (2000) & 24.6 & $1.0-4.0$ & $\begin{array}{l}\text { Natural gas, } \\
\text { propane }\end{array}$ & $\begin{array}{l}\text { Non-premixed diffusion } \\
\text { flame in crosswind }\end{array}$ & $\begin{array}{l}\text { - Increased cross wind speed lowers combustion efficiency } \\
\text { - Increased jet velocity lessens the effects of crosswind }\end{array}$ \\
\hline McDaniel (1983) & $101.6 / 219.1$ & $0.03-8.7$ & $\begin{array}{l}\text { Crude } \\
\text { Propylene }\end{array}$ & $\begin{array}{l}\text { Air- and steam-assisted } \\
\text { industrial flares }\end{array}$ & $\begin{array}{l}\text { - Efficiency calculated from single point samples collected above a vertical } \\
\text { flare with high efficiencies found except when detached }\end{array}$ \\
\hline Pohl et al. (1986) & $76.2-304.8$ & $<300$ & $\mathrm{C}_{3} \mathrm{H}_{8}$ & $\begin{array}{l}\text { Steam-assisted flare } \\
\text { with } \mathrm{N}_{2} \text { diluent }\end{array}$ & - Efficiencies high (> 98\%) when flame is stable \\
\hline Allen and Torres (2011) & $609.6 / 914.4$ & $0.083-0.24$ & $\begin{array}{l}\mathrm{C}_{3} \mathrm{H}_{6}, \mathrm{C}_{3} \mathrm{H}_{8} \\
\text { natural gas }\end{array}$ & $\begin{array}{l}\text { Air- and steam-assisted } \\
\text { industrial flares }\end{array}$ & - High efficiencies until steam-quenched \\
\hline
\end{tabular}




\subsection{Field Measurements of Large-Scale Flares}

The measurement of gas and solid phase emissions from in-situ flares remains a difficult task. To date a limited amount of work exists in which experimental measurements of flares have progressed beyond lab-scale. The work of McDaniel (1983) is one of the first instances of this scale of work being accomplished, although measurements of $\mathrm{BC}$ were presented in terms of plume concentrations only. Performed on both air- and steamassisted flares burning crude propylene ( $80 \%$ propylene and $20 \%$ propane by volume), and primarily investigating combustion efficiency, this work provided the basis for many US EPA emission factors as detailed previously. Steam-assisted flare tests were performed on a $219.1 \mathrm{~mm}$ diameter industrial flare with an outlet area of $27.0 \mathrm{in}^{2}$ and crude propylene flow rates of $24.4-473$ SCFM and varying steam-assist rates. Airassisted flaring was performed on a $101.6 \mathrm{~mm}$ diameter industrial flare with one of two "spider" burners having outlet areas of 5.30 or $11.24 \mathrm{in}^{2}$ and crude propylene flow rates of $22.7-481.6$ SCFM and varying air-assist rates. Additional tests were performed on both flares in which the crude propylene was diluted with nitrogen to produce a lower energy content flare gas. Flow rates with nitrogen dilution were expanded to 0.35 703 SCF per minute and $0.54-639$ SCF per minute for steam- and air-assisted flaring respectively. Results from the testing campaign suggest that combustion efficiency was generally high (>98\%) with a small decrease for highly diluted relief gas and large decreases when excessive steam- or air-assist was employed. Soot emissions were recorded for three individual tests in which no steam- or air assist was employed and the relief gas was not diluted. Soot emissions were measured as a concentration and resulted in 40, 177 and $274 \mu \mathrm{g} / \mathrm{L}$ with the non-smoking tests assumed zero. $\mathrm{NO}_{\mathrm{X}}$ emissions varied 
widely over conditions including steam- and air-assist and varying levels of relief gas dilution (from 0.018 to $0.208 \mathrm{lb} / 10^{6} \mathrm{Btu}$ ) with an average of $0.0672 \mathrm{lb} / 10^{6} \mathrm{Btu}$ and standard deviation of $0.0393 \mathrm{lb} / 10^{6} \mathrm{Btu}$.

Combustion efficiency and soot emission measurements were later made on flares ranging from $3-12$ inches burning propane (Pohl et al., 1986). While soot emissions were not measured directly as either a rate or yield, they are stated to account for less than $0.5 \%$ of the unburned hydrocarbons emitted. The study showed that combustion efficiency remains high (>98\%) up to the point of stability (dependent on either exit velocity or a decreased heating value).

Recent work by the University of Texas through the Texas Commission on Environmental Quality (TCEQ) reported measurements on a pair of industrial flares associated with air- and steam-assisted flaring (Allen and Torres, 2011). The primary scope of the study was to investigate combustion efficiency and hydrocarbon destruction removal efficiency. The gases flared consisted of pure propylene as well as propylene/natural gas and propane/natural gas mixtures. Dilution of the hydrocarbon mixture with nitrogen allowed for varied energy content gas to be flared. Additionally, $\mathrm{NO}_{\mathrm{X}}$ emissions were reported for a limited number of test cases burning propane/natural gas mixtures (Torres, Herndon, Wood, et al., 2012) and ranged from 0.009$0.033 \mathrm{lb} \mathrm{NO}_{\mathrm{X}} / 10^{6}$ Btu for steam-assisted flaring and 0.037-0.083 $\mathrm{lb} \mathrm{NO}_{\mathrm{X}} / 10^{6}$ Btu for airassisted flaring. Carbon particulate emissions were mentioned only in passing and were suggested to constitute less than $0.5 \%$ of the fuel carbon on a molar basis (Torres, Herndon, Kodesh, et al., 2012) or approach $0.2 \%$ of the total carbon by mole at the highest soot emitting conditions (Herndon et al., 2012). 
Measurements of $\mathrm{NO}_{\mathrm{X}}$ emissions from large onshore flares in Norway were conducted (Bakken et al., 2008) at four separate installations using Differential Absorption Lidar (DIAL). The data released with industry cooperation are averages of both $\mathrm{NO}_{\mathrm{X}}$ and flare gas flow rates over the measurement period. Flaring was generally performed at low and constant rates on $0.55-1.22$ metre diameter burners with flare gas composition including both methane and hydrogen with possible steam-assist. Heating values of the flared gas also varied with the inclusion of diluents in the gas stream.

More recently, a technique for quantifying in situ $\mathrm{BC}$ mass emission rates from flares known as sky-LOSA has been deployed in field measurements (Johnson et al., 2013; Johnson et al., 2011; Johnson et al., 2010). In these limited field trials, flares have been found to emit $\mathrm{BC}$ at rates varying from $0.067 \mathrm{~g} / \mathrm{s}$ to $2.0 \mathrm{~g} / \mathrm{s}$, although to date these measurements have not been referenced to known flare gas flow rates or flare gas composition.

\subsection{Thesis Motivation \& Objectives}

The motivations for the current work stem from the questionable applicability of current single value emission factors for soot and $\mathrm{NO}_{\mathrm{X}}$ as well as the critical lack of data at the operating conditions of upstream oil and gas flares as characterized by low Froude numbers $(<\sim 100$ as defined by Eq. (1.4), $<\sim 0.1$ as defined by Eq. (1.2)). The lack of quantitative data with defined uncertainties in the range of operating conditions examined in the current work is important for qualifying the effects of operating regimes on the emissions of turbulent non-premixed diffusion flames. The critical lack of data available in literature to allow for accurate quantification of soot emissions from buoyancy- 
dominated flames is a compelling reason for the continuation of research on the subject (Crosland et al., 2014).

As such, the objectives for the current work were as follows:

- Construct and commission the Carleton Lab-Scale Flare facility and develop a quantitative methodology for evaluating flare performance in terms of overall combustion efficiency and various species emission rates with associated uncertainties;

- Develop a methodology for evaluating combustion efficiency and species emissions from a non-premixed diffusion flame which does not require explicit measurement of the plume flow rate;

- Develop an ancillary method for injecting a tracer gas into the plume upstream of the combustion zone such that direct measurement of the plume flow rate can be made (where the two distinct measurement methods will present distinct uncertainties and have inherent advantages to application in different scenarios);

- Generate new data to confirm the expected high combustion efficiencies as well as quantify $\mathrm{BC}, \mathrm{NO}_{\mathrm{X}}$ and other emission rates for turbulent, non-premixed diffusion flames operating in the buoyancy-dominated regimes typical of upstream oil and gas flaring;

- Investigate the trends discernable in combustion efficiency and various species emission rates as burner diameter, exit velocity, and flare gas composition are varied; and 
- Investigate the potential for correlating results to facilitate the development of improved $\mathrm{BC}$ and $\mathrm{NO}_{\mathrm{x}}$ emission factors for flares relevant to the upstream oil and gas industry.

\subsection{Overview of Thesis}

Chapter 2 details the experimental setup used in the current work. Chapter 3 reports the development of a new quantitative methodology and expressions for experimental uncertainty recently published in Industrial \& Engineering Chemistry Research. Experimental results and discussion are presented in Chapter 4, followed by conclusions and recommendations for further work in Chapter 5. 


\section{Chapter 2}

\section{Experimental Setup}

The Carleton lab-scale flare facility was designed and built to increase the experimental scale of the work accomplished by Canteenwalla (2007) and McEwen (2010) using a smaller-scale experiment housed at the National Research Council of Canada. Specifically, it was desired to create a facility that could accommodate flames up to approximately 3 metres in length at flare gas flow rates of up to 600 standard litres per minute (SLPM). The description of the facility will be discussed in terms of several distinct components, which were either borrowed from previous experiments or designed and built as part of the new facility. These components include: the modular turbulent diffusion burner, the fuel delivery system, the various flare gas compositions tested, the controllable exhaust system, the experimental analysis instrumentation, and the flame imaging equipment. The turbulent diffusion burner was previously used in the work of Canteenwalla (2007) and McEwen (2010) and will be discussed within that context in Section 2.1. Section 2.2 discusses the fuel delivery system and provides details of all components upstream of the burner including the mass flow controllers, gas storage and handling, and other related components. As detailed in Section 2.3, the flare gas compositions examined in the current work were either a selection of pure fuels or a set of mixtures representative of flared gases from the Alberta upstream oil and gas industry. The description of the exhaust system in Section 2.4 includes details of the exhaust 
system design, as well as the physical dimensions of the exhaust collection system and the immediate surroundings of the burner. Section 2.5 discusses the gaseous species and soot sampling equipment as well as details of the temperature and pressure sensors. Section 2.6 describes the flame imaging equipment and includes details of the camera and associated hardware as well as a discussion of the imaging procedure.

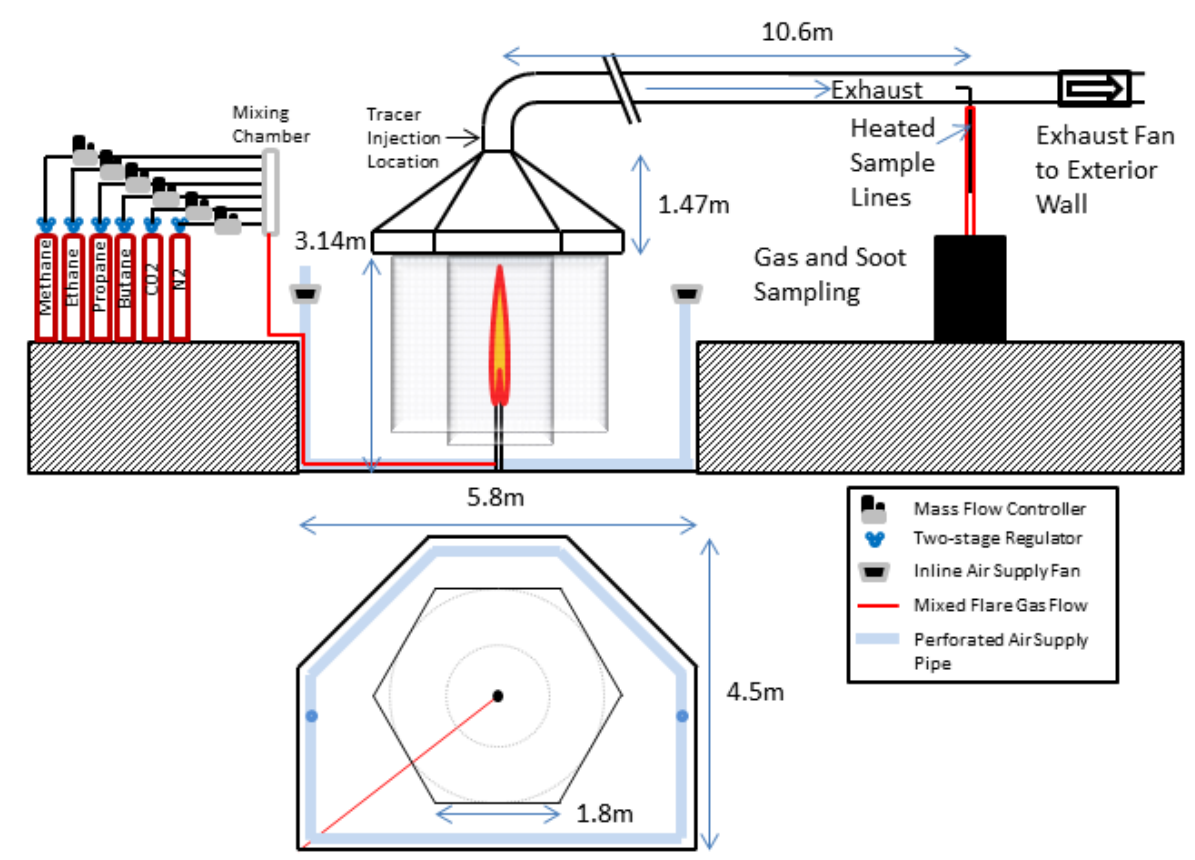

Figure 2.1: Experiment schematic with flare pit dimensions and overview of fuel delivery system, air supply system, hood and screen details, and dilution tunnel overview.

\subsection{Turbulent Diffusion Burner}

Designed by Canteenwalla (2007), the modular burner includes five different tip sizes, of which three were used in the current work (38.1, 50.8 and $76.2 \mathrm{~mm}$ internal diameter (ID)). Briefly, the flare gas is delivered to the burner by tubing that is further discussed in Section 2.2. The upstream tubing runs along the floor of the flare pit and connects to the burner with a $90^{\circ}$ elbow which enters the burner vertically from 
underneath as shown at the bottom of Figure 2.2. The flare gas passes through a diffusion chamber filled with $5 \mathrm{~mm}$ diameter glass beads that diffuse the incoming fuel jet before it enters a vertical constant diameter settling chamber containing three evenly spaced mesh screens. The diffuser and settling chamber are shared between all burner diameters. The topmost three components as shown in Figure 2.2 (converging nozzle, turbulence generating grid and burner exit) are interchangeable as a set, with each burner exit section having a dedicated turbulent generating grid and converging nozzle tailored to the dimensions of the given exit tube.

The burner exit tubes were designed and manufactured with an inner to outer diameter ratio of 0.89 , which is representative of simple pipe flares. Exit length and turbulence generating grids were designed to produce fully developed turbulent pipe flow at the exit plane characteristic of real flares. Details on the velocity profile, and turbulence intensity $(\sim 3-6 \%$ at the core) at the exit plane for the $38.1 \mathrm{~mm}$ burner as well as overall burner dimensions can be found in the work of Canteenwalla (2007). 


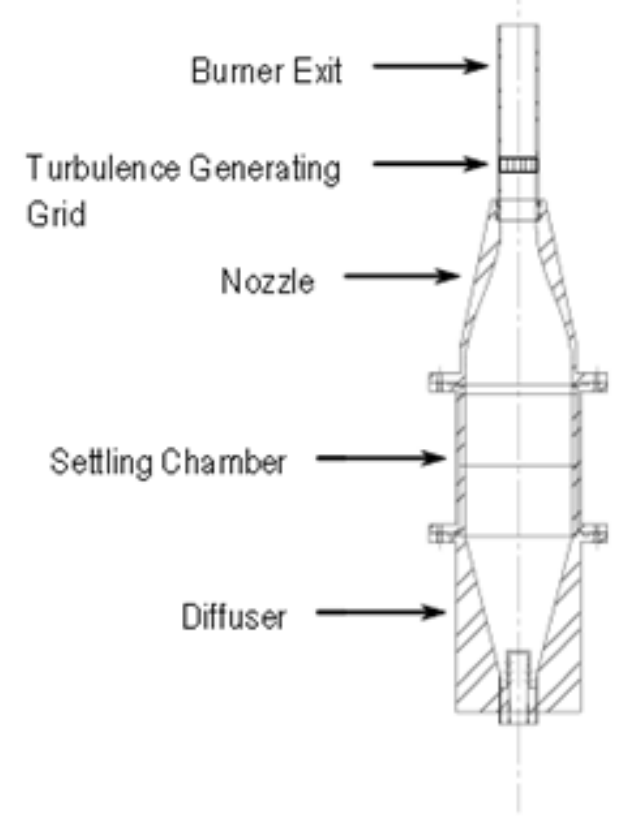

Figure 2.2: Modular burner schematic (Canteenwalla, 2007).

The temperature of the flare gas in the burner exit was measured using a $1 / 16$ " diameter K-type thermocouple probe (CASS-116G-12) which passed approximately $5 \mathrm{~mm}$ over the top edge of the burner and was bent $90^{\circ}$ extending upstream into the burner exit $45 \mathrm{~mm}$.

\subsection{Fuel Delivery System}

The fuel delivery system is comprised of six independently-controlled Brooks mass flow controllers (MFC), which control the flow of various pure gases contained in pressurized cylinders. The controllers were operated using either analog (a) or digital (d) communications and included Smart Series controllers 5853S(d) for methane $(0-600$ SLPM), SLA5851S(a) for ethane (0 - 50 SLPM), SLA5851S(d) for propane (0 - 25 SLPM), SLA5851S(a) for butane (0 - 10 SLPM), SLA5851S(a) for carbon dioxide (0 - 
20 SLPM), and 5850S(d) for nitrogen (0 - 16 SLPM). Standard conditions are defined as a pressure of 1 atmosphere $(101.325 \mathrm{kPa})$ and a temperature of $273.15 \mathrm{~K}$.

For the specified gases, calibration of the flow controllers was accomplished using either a SENSIDYNE Gilibrator $2(0-30$ litres per minute) or a Siemens Sitrans F C Mass 2100 Coriolis flowmeter. Additionally, for cases where either pure ethylene or propane was flared, the $5853 \mathrm{~S}(\mathrm{~d})$ methane controller was used to allow flow rates of up to 182.41 and 109.45 SLPM respectively. In these instances the Coriolis meter was installed upstream of the Brooks MFC to directly measure the mass flow of the flare gas during the test.

During the development of the final test protocol it was determined that cooling of the gases due to expansion in the pressurized cylinders and across regulators over the length of the test could be significant enough to affect the ability of the Brooks MFC to provide a steady flow rate. As such, a heated water bath was installed upstream of the mass flow controllers and each gas was passed through 25 feet of 1/2" or 1/4" diameter coiled copper tubing immersed in the bath. Tests were operated with the bath at a constant temperature of $25^{\circ} \mathrm{C}$ with heating and temperature control provided by a Thermo Scientific SC 150 Immersion Circulator. T-type grounded-thermocouples (Omega TC-TNPT-G-72) were installed downstream of the bath and upstream of the MFCs to ensure a steady gas temperature was held for the duration of each flare test. Downstream of the MFCs, the pure gases were combined and mixed in a $60 \mathrm{~cm}$ long, $50.8 \mathrm{~mm}$ diameter mixing chamber, after which approximately 12 metres of $3 / 4$ " steel tubing lead to the modular burner stand. 


\subsection{Flare Gas Compositions}

Five flare gas compositions were chosen for the current work based on their relevance to upstream oil and gas flaring. The two methane-based flare gases are representative of compositions relevant to the Alberta upstream oil and gas industry as detailed in the work of McEwen (2010) and based on industry correspondence. Three pure flare gases including methane, ethylene, and propane were tested based on their varying propensity to soot and respective relevance to industrial flaring applications. The flare gas compositions and details on gas purity can be found in Table 2.1 below.

Table 2.1: Flare Gas Mixtures Tested

\begin{tabular}{ccccccc}
\hline & & \multicolumn{5}{c}{ Flare Gas Mixture Compositions (by volume) } \\
\cline { 2 - 7 } $\begin{array}{c}\text { Component } \\
\text { Species }\end{array}$ & $\begin{array}{c}\text { Component } \\
\text { Purity (\%) }\end{array}$ & $\begin{array}{c}\text { Average } \\
\text { 6-Mix (\%) }\end{array}$ & $\begin{array}{c}\text { Heavy } \\
\text { 4-Mix (\%) }\end{array}$ & $\begin{array}{c}\text { Pure } \\
\mathbf{C H}_{\mathbf{4}} \mathbf{( \% )}\end{array}$ & $\begin{array}{c}\text { Pure } \\
\mathbf{C}_{\mathbf{2}} \mathbf{H}_{\mathbf{4}} \mathbf{( \% )}\end{array}$ & $\begin{array}{c}\text { Pure } \\
\mathbf{C}_{3} \mathbf{H}_{\mathbf{8}} \text { (\%) }\end{array}$ \\
\hline Methane & 99.0 & 85.24 & 74.54 & 100 & 0 & 0 \\
\hline Ethane & 99.0 & 7.06 & 15.47 & 0 & 0 & 0 \\
\hline Propane & 99.0 & 3.11 & 6.83 & 0 & 0 & 100 \\
n-Butane & 99.0 & 1.44 & 3.16 & 0 & 0 & 0 \\
$\mathrm{CO}_{2}$ & 99.9 & 1.91 & 0 & 0 & 0 & 0 \\
$\mathrm{~N}_{2}$ & 99.999 & 1.24 & 0 & 0 & 0 & 0 \\
\hline Ethylene & 99.5 & 0 & 0 & 0 & 100 & 0 \\
\hline
\end{tabular}

Additional information on relevant properties of the mixed and pure flare gases can be found in Table 2.2. All properties are evaluated at standard temperature and pressure $(273.15 \mathrm{~K}$ and $1 \mathrm{~atm})$. Higher heating values and adiabatic temperatures for the flare gases were obtained from NASA Chemical Equilibrium with Applications (CEA) computer program and evaluated for stoichiometric combustion. 
Table 2.2: Flare Gas Properties

\begin{tabular}{|c|c|c|c|c|c|}
\hline Property & $\begin{array}{c}\text { Average } \\
6-\text { Mix (\%) }\end{array}$ & $\begin{array}{c}\text { Heavy } \\
\text { 4-Mix (\%) }\end{array}$ & $\begin{array}{c}\text { Methane } \\
(\%)\end{array}$ & $\begin{array}{c}\text { Ethylene } \\
(\%)\end{array}$ & $\begin{array}{c}\text { Propane } \\
(\%)\end{array}$ \\
\hline $\begin{array}{c}\text { Molecular } \\
\text { Weight }(\mathrm{kg} / \mathrm{kmol})\end{array}$ & 19.19 & 21.46 & 16.04 & 28.05 & 44.10 \\
\hline Density $\left(\mathrm{kg} / \mathrm{m}^{3}\right)$ & 0.86 & 0.96 & 0.72 & 1.25 & 1.97 \\
\hline $\begin{array}{l}\text { Higher Heating } \\
\text { Value }(\mathrm{kJ} / \mathrm{kg})\end{array}$ & 51061 & 53506 & 55528 & 50313 & 50368 \\
\hline $\begin{array}{l}\text { Volumetric } \\
\text { Heating Value } \\
\left(\mathrm{kJ} / \mathrm{m}^{3}\right)\end{array}$ & 43729 & 51228 & 39747 & 62977 & 99099 \\
\hline $\begin{array}{l}\text { Adiabatic Flame } \\
\text { Temperature }(\mathrm{K})\end{array}$ & 2228.3 & 2240.3 & 2224.2 & 2264.8 & 2368.2 \\
\hline $\begin{array}{l}\text { Stoichiometric } \\
\text { Air-Fuel Ratio }\end{array}$ & 16.33 & 16.57 & 17.19 & 14.75 & 15.64 \\
\hline $\begin{array}{l}\text { Stoichiometric } \\
\text { Mixture Fraction }\end{array}$ & 0.059 & 0.057 & 0.055 & 0.064 & 0.060 \\
\hline $\begin{array}{l}\text { Carbon Density } \\
\text { (kg-carbon/kg- } \\
\text { flare-gas) }\end{array}$ & 0.739 & 0.776 & 0.749 & 0.856 & 0.817 \\
\hline
\end{tabular}

\subsection{Exhaust System and Experimental Infrastructure}

The exhaust system and experimental infrastructure for the current work was designed and built to accommodate heat release rates and flame lengths corresponding to the flaring of up to 600 SLPM of methane. A limiting factor in the design process was to maintain an acceptable upper temperature limit in the duct at the highest flow rates of flared gas. Construction of the facility required the installation of a concrete flare pit in a shared laboratory space at Carleton University as seen in Figure 2.1. The pit, measuring 1.88 metres deep, is an irregularly shaped hexagon in which the modular burner is centred. An air supply system was installed at the base of the pit walls to overcome issues related to expected recirculation zones that were encountered during the commissioning process. Perforated plastic pipe was installed around the pit circumference with air supplied by a pair of inline fans installed on opposing pit walls. Supply air was drawn from the end of the laboratory opposite the flare pit through steel ducting. Centered above the modular burner is a custom, steel-constructed hexagonal- 
exhaust hood which measures approximately 1.8 metres per side with an included diameter of 3.1 metres. The bottom plane of the hood hangs 3.14 metres above the floor of the pit. The exhaust hood contracts to a $40.6 \mathrm{~cm}$ diameter opening which connects to the dilution tunnel. At the far downstream end of the dilution tunnel, an IAP Vane Axial VAX 180 exhaust fan controlled by a 5 HP Danfoss VLT-HVAC variable speed drive provides up to 100,000 SLPM of ventilation. The maximum exhaust flow rate and dimensions of the exhaust hood correspond to a maximum face velocity of $0.22 \mathrm{~m} / \mathrm{s}$ at the entrance plane of the hood.

The dilution tunnel is constructed from round steel ducting and is wrapped in insulation to limit heat loss from the sample volume and maintain temperature from the hood exit to the sample points. The duct extends vertically from the top of the hood and bends $90^{\circ}$ to the horizontal. It follows a diagonal path before bending $45^{\circ}$ and running perpendicular to the exit wall. A total horizontal length of 10.6 metres extends from the $90^{\circ}$ bend to the sampling location.

The hood suspends two concentric wire mesh shrouds (1.5 and 3.1 metres in diameter) centered on the burner axis and hanging 0.42 and 0.60 metres above the pit floor respectively. The screens are intended to reduce turbulent air flow that may be created by the irregular shape of the pit or its location in the laboratory.

The pressure and temperature of the dilution tunnel were measured at the sample location shown in Figure 2.3. The temperature was measured using a 1/8" diameter Ttype thermocouple probe (Omega CPSS-18-G-12) inserted such that the tip was positioned in the centre of the dilution tunnel. The barometric pressure in the lab was 
measured with an Omega pressure transducer (part number MMB26V10H2C0T3A8P) capable of measuring $880-1100 \mathrm{mBar}$. The sample pressure in the dilution tunnel was measured by an Ashcroft CXLdp differential pressure transducer with a range of 2 inches water column. The negative terminal of the differential pressure transducer was connected to a network of flexible nylon tubes which connected to four static pressure taps spaced evenly on the circumference of the dilution tunnel at the sample location. The static taps were constructed of $1 / 2$ " male NPT fittings threaded into flat steel plate. The steel were mounted flush to the outside dilution tunnel.

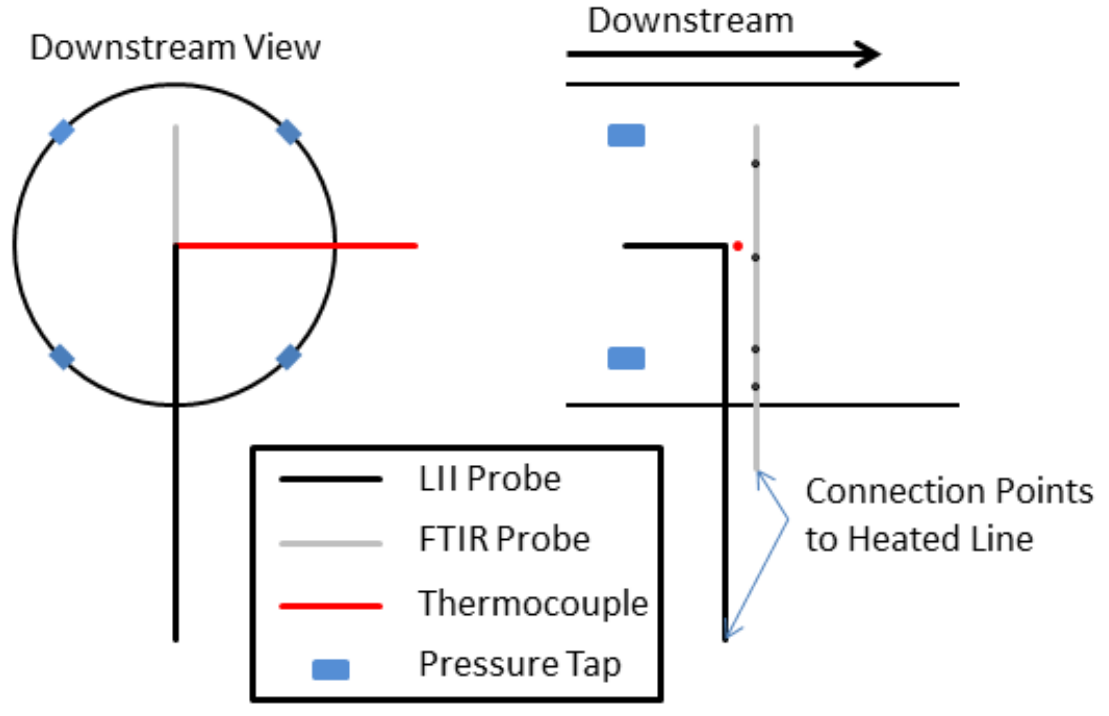

Figure 2.3: Diagram of probe locations in dilution tunnel. LII, FTIR, and thermocouple probe locations and dimensions shown. Pressure tap locations marked.

To accommodate measurement of the dilution tunnel flow rate using an injected tracer gas, an injection point downstream of the combustion zone just inside the dilution tunnel entrance was selected. Labeled as the tracer injection location in Figure 2.1, the tracer gas is delivered to the injection point from a pressurized gas cylinder by a 
dedicated Brooks SLAMf50 digitally-controlled mass flow controller with a range of 05 SLPM of $\mathrm{C}_{2} \mathrm{H}_{2}$. At the injection point, a standard $1 / 4$ " stainless steel tube is inserted through the wall of the dilution tunnel. Connected to the internal end of the tube is a 10 " diameter ring constructed of $1 / 4$ " stainless steel tube with $1 / 32$ " diameter holes regularly spaced around the ring. The holes face in the downstream direction, which in the installed configuration is vertically upward. Prior to the selection of acetylene as the injected tracer gas, the potential for decomposition of acetylene at the potentially high temperatures in the dilution tunnel was investigated in well-stirred reactor simulations using Cantera software. Results suggested that the $\mathrm{C}_{2} \mathrm{H}_{2}$ should not react at the range of temperatures encountered experimentally. Subsequent experimental tests demonstrated that the injection of acetylene had no measureable effect on the combustion efficiency or species yields within the achievable measurement uncertainties when compared to data where no acetylene was injected.

\subsection{Emissions Analysis Instrumentation}

\subsubsection{Gas-Phase Measurements and Gas-Phase Sample Train}

Two instruments were used to measure gas concentrations in the current work. A MKS MultiGas 2030 Fourier Transform Infrared Spectrometer (FTIR) Continuous Gas Analyzer was the primary gas analysis instrument and a Los Gatos Research (LGR) Ultra-Portable Gas Analyzer was the secondary instrument for measuring concentrations of the tracer gas when it was present.

The FTIR instrument uses spectral absorption properties to measure up to 20 gas species simultaneously. The bias errors associated with measured concentrations of the gas species relevant to the current work are the larger of $2 \%$ of the measured value or the 
minimum detection limit. The minimum detection limit for measured species are $0.15 \mathrm{ppm}_{\mathrm{v}}$ for $\mathrm{CO}, 0.10 \mathrm{ppm}_{\mathrm{v}}$ for $\mathrm{CH}_{4}, 0.15 \mathrm{ppm}_{\mathrm{v}}$ for $\mathrm{C}_{2} \mathrm{H}_{6}, 0.30 \mathrm{ppm}_{\mathrm{v}}$ for $\mathrm{C}_{3} \mathrm{H}_{8}$ and $\mathrm{C}_{2} \mathrm{H}_{4}, 0.50 \mathrm{ppm}_{\mathrm{v}}$ for $\mathrm{NO}$ and $0.05 \mathrm{ppm}_{\mathrm{v}}$ for $\mathrm{NO}_{2}$. The lower detection limit for $\mathrm{CO}_{2}$ was never encountered since measured concentrations were never below the threshold at which the $2 \%$ value was the controlling uncertainty. The LGR analyzer for measuring the acetylene tracer concentration has a bias error on the measured concentration of $2 \mathrm{ppb}_{\mathrm{v}}$.

The sample train for the FTIR and the LGR analyzer are partially shared and will be discussed jointly as a gas-only sample train which is distinct from the soot sample train discussed in Section 2.5.2. The sample probe for this gas-only stream is a standard $1 / 4$ " diameter stainless steel tube. The open-ended tube is inserted vertically through the bottom surface of the duct to a depth of $353 \mathrm{~mm}$ ( $\sim 86.9 \%$ of the total duct diameter) and has $1 / 8$ " holes drilled at $22,71,188$ and $305 \mathrm{~mm}(\sim 5.4,17.5,46.3$ and $75.0 \%$ of total duct diameter) measured from the bottom surface of the duct (See Figure 2.3). The probe exits the duct vertically where the sample is split (using a tee-fitting) into two streams, one directed to the FTIR and the other to the LGR analyzer. The stream directed towards the FTIR connects from the tee-fitting to a 1/4" OD, 10-foot long Technical Heaters Inc. Series 500 flexible hose which is electrically heated to $191^{\circ} \mathrm{C}$. The heated hose connects to a MKS-supplied, heated sample pump (also operated at $191^{\circ} \mathrm{C}$ ) that contains a pair of filters to remove particulate so that the sample cell in the FTIR will not be contaminated. The pump exit connects to another 1/4" OD, 10-foot long Technical Heaters Inc. Series 702 flexible hose (also heated to $191{ }^{\circ} \mathrm{C}$ ) that connects to the measurement device. The LGR analyzer directed stream connects from the tee-fitting to $1 / 4$ " flexible nylon 
tubing and is drawn by a dedicated internal pump installed in the analyzer. The stream directed to the LGR analyzer is also passed through a pair of filters for removal of particulate. An exposed length of the gas-probe extending approximately $5 \mathrm{~cm}$ from the bottom of the duct to the tee-fitting as well as the tee-fitting was also electrically heated to $191^{\circ} \mathrm{C}$.

To satisfy the assumption of fully mixed conditions in the duct and ensure that the sampled concentrations were representative of the average concentrations, several traverses of a gas-sample probe were made across the duct diameter at different fan speeds and flare gas flow rates. As illustrated in Figure 2.4, gas-sample probe traverses were completed at a fan speed of 50\% with flare gas flow rates of 27.36 and 136.81 SLPM and a fan speed of 100\% with flare gas flow rates of 27.36 and 246.26 SLPM. At each probe position, the measured $\mathrm{CO}_{2}$ concentration for five consecutive 1 minute FTIR scans are plotted. While there is some visible scatter in the measured concentrations at the higher flow rates, the average at a given probe position is well within the uncertainty on the average of all measurements for that fan speed and flare gas flow rate combination. These results demonstrate that the species in the exhaust system are well-mixed. 


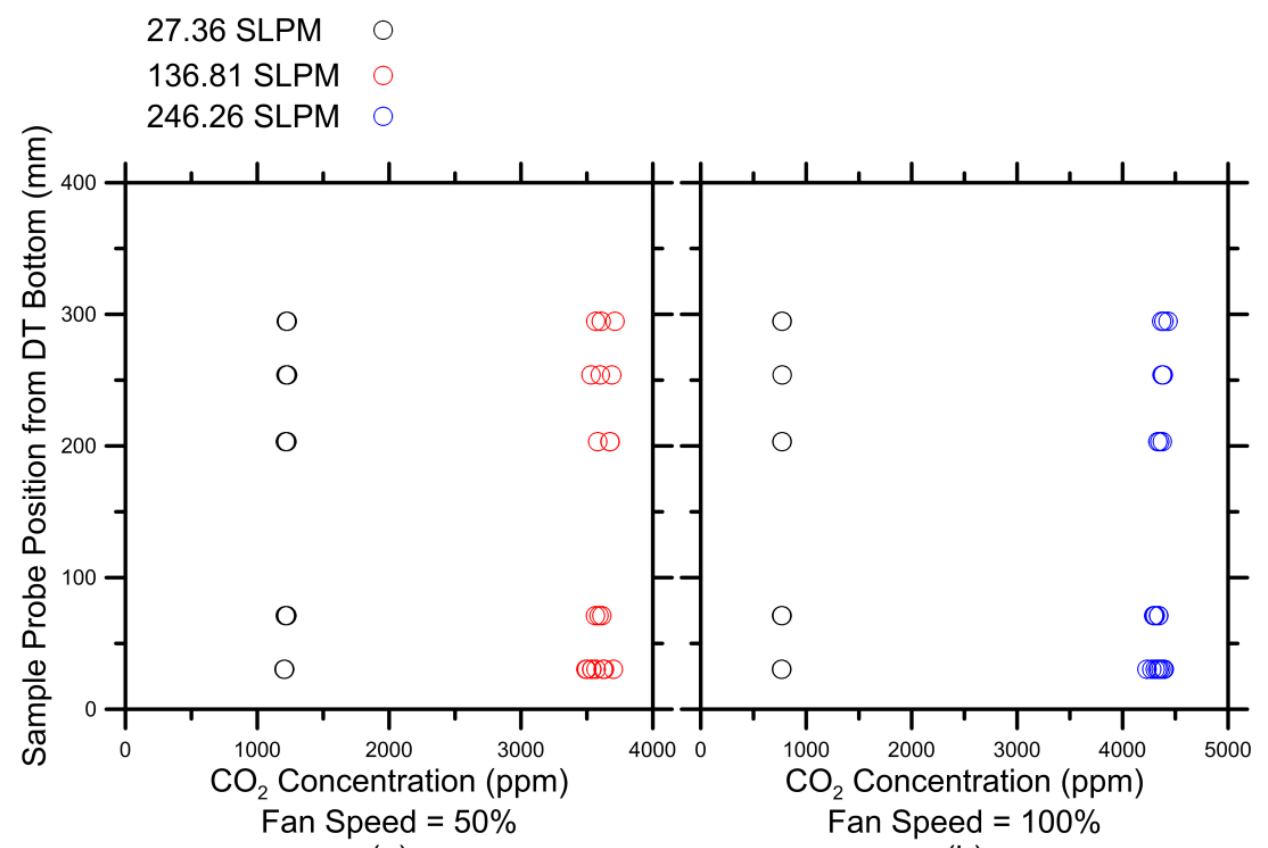

(a)

(b)

Figure 2.4: FTIR probe traverse $\mathrm{CO}_{2}$ concentration measurements at $50 \%$ and $100 \%$ fan settings with low and high flare gas flow rates.

\subsubsection{Soot Measurement with LII and Solid-Phase Sampling Train}

An Artium 200 commercial Laser Induced Incandescence (LII) instrument was used to perform soot measurement in the current work. The LII device measures the soot volume fraction (SVF) present in a sampled volume. Only black carbon is measured as volatile particulate is sublimated by the laser energy.

The sample train connecting and controlling the flow of sample to the LII is partially depicted in Figure 2.5. The soot sampling probe installed in the duct as depicted in Figure 2.3 exits the bottom of the duct vertically and connects to a 5/16" ID, 10 foot Technical Heaters Inc. Series 212 fluoropolymer-lined flexible hose which is electrically heated to $65^{\circ} \mathrm{C}$ to limit thermophoretic losses of particulate to the wall. The probe itself is constructed of standard $3 / 8^{\prime \prime}$ diameter stainless steel tubing and with the tip bent $90^{\circ}$ from the vertical. The bent portion was directed upstream during the tests and extends 
$125 \mathrm{~mm}$ in length from the centre of the vertical portion. The length of probe extending from the duct and connecting to the heated hose was also electrically heated to $65^{\circ} \mathrm{C}$. The downstream end of the heated hose connected directly to the intake sample port of the LII. From the outlet sample port of the LII, the sample gas passed through an insulated tee fitting containing an exposed T-type thermocouple probe (Omega TC-TNPT-E-72) that measured the temperature of the sample gas and allowed for the measured soot volume fraction to be corrected to the measured duct sample temperature as outlined by Eq. (3.18) in Section 3.3.4. Additional equipment on the downstream side of the LII sample train includes a filter for removing the soot and protecting downstream instruments, a Brooks 5851S digitally controlled MFC which maintained a controlled flow of sample through the LII, and a vacuum pump to draw a sample flow from the duct. 


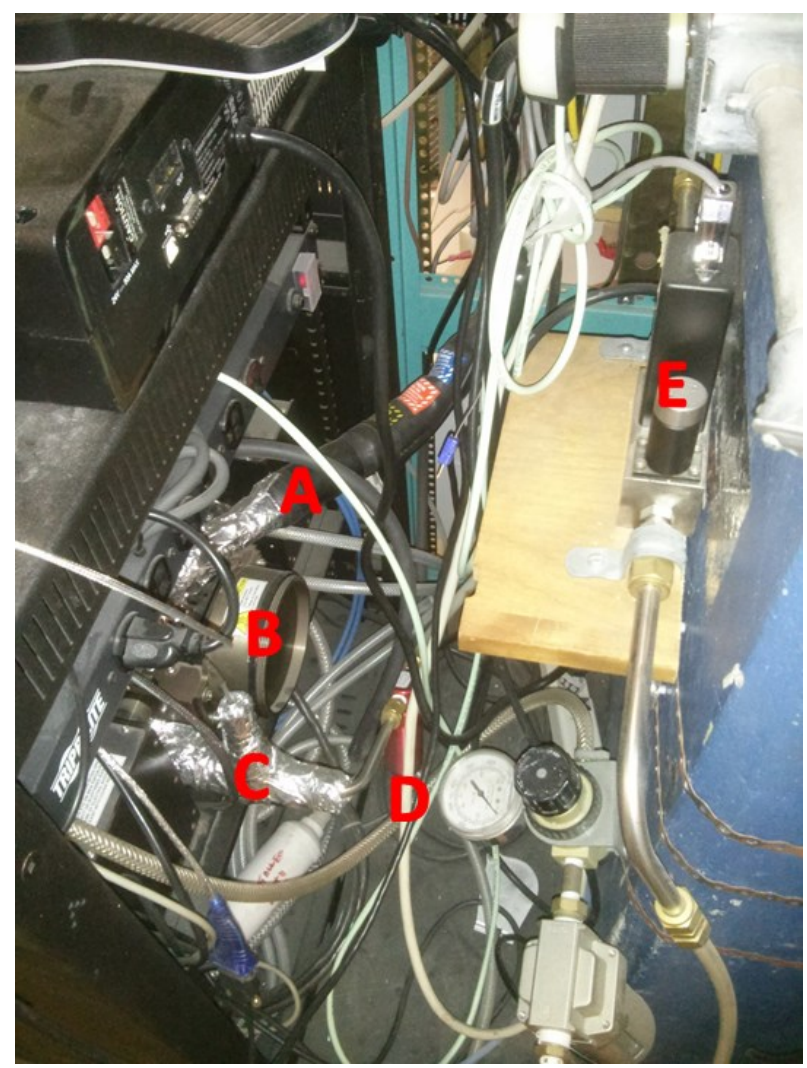

Figure 2.5: Rear of LII. Pictured components of sample train include a) heated hose, b) sample cell, c) outlet thermocouple, d) particulate filter, and e) MFC.

To satisfy the assumption of fully mixed conditions in the duct and to ensure the sampled SVF was consistent throughout the duct, several traverses across the duct diameter were made with the LII-sample probe at different fan speeds and flare gas flow rates. As illustrated in Figure 2.6, the LII-sample probe traverses were completed at a fan speed of $50 \%$ with a flare gas flow rate of 27.36 SLPM and a fan speed of $100 \%$ with flare gas flow rates of 27.36 and 267.54 SLPM. Measurements were conducted with the LII-sample probe facing both upstream and downstream to determine whether isokinetic sampling was necessary. Five consecutive 1 minute SVF measurements were made at each probe position and the results are plotted with the standard deviation of the 1 minute interval represented with the error bars. It is apparent that the SVF measured at each 
location was consistent within expected error and that the orientation of the probe did not affect the measured SVF. These results demonstrate that the soot particles are wellmixed within the sample duct such that representative measurements can be obtained with single point samples.

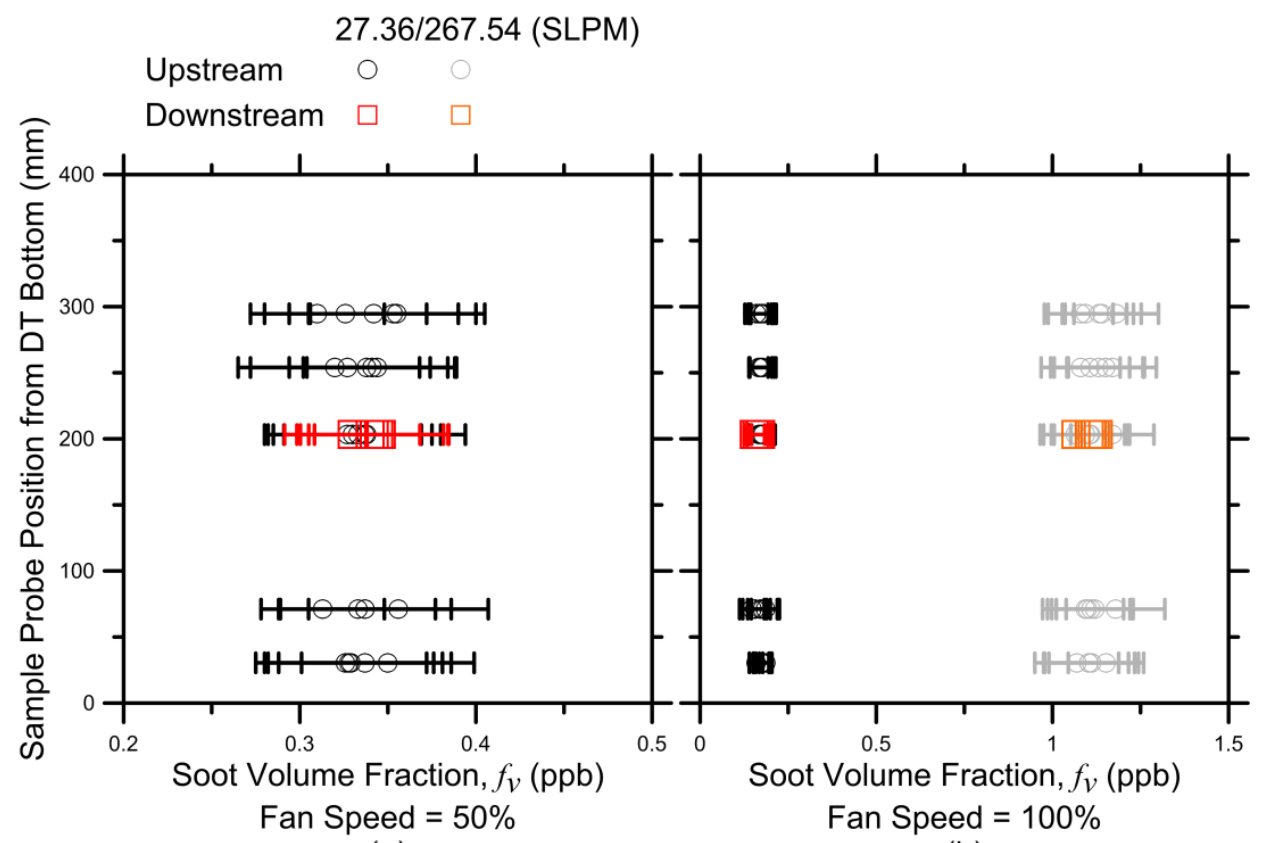

(a)

(b)

\section{Figure 2.6: LII probe traverse measurements at $50 \%$ and $100 \%$ fan settings with low and high flare gas flow rates.}

\subsection{Flame Imaging}

Flame length was determined through analysis of static images (2048 x 1088 pixels) taken with a Basler acA2000-340km CMOS camera and acquired through a NI PCIe1433 acquisition card. The camera was mounted to a sliding carriage on a vertical rail that allowed the camera to be repositioned appropriately for a given test condition. After installation, a checkered calibration sheet made up of alternating black and white 1" squares was suspended vertically in the plane of the burner. Images of the calibration sheet were taken from each of the preselected camera positions and an image correction 
was applied using the common commercial software $\mathrm{DaVis}(\mathrm{LaVision} \mathrm{GmbH})$ to account for image distortion away from the centreline of the image. Markers placed intermittently in the checker pattern of the calibration sheet allowed the height of a given pixel above the burner exit to be determined during the correction processing. Individual images of a test flame were binarized over a range of thresholds prior to the averaging of a set of images for each binarization threshold. Approximately 1500 images were used to determine flame length which was a large enough sample that the flame length for a given test converged to a consistent mean value. With the mean flame image, the length of a flame was arbitrarily defined as the measured distance between the burner exit and the highest pixel in which the flame was present for $10 \%$ of the images collected.

\subsection{Sampling Protocol}

A standard for performing measurements on the lab-scale flare was developed based on a review of previous sampling protocols and experience gained during the commissioning of the facility. The most important aspects of the sampling protocol were to measure ambient concentrations of relevant species before and after the test to ensure effective plume capture, to allow adequate warm-up time such that conditions reached a steadystate, and to monitor flare gas temperatures at the outlet of the thermal heating bath to ensure a consistent flow of the individual flare gas components. An additional consideration for experiments was a large outside door in the laboratory space in which the lab-scale flare was constructed. It was important that the door remained in either an open or closed state for the time leading up to and during a single test. This was deemed important as somewhat significant $(50-100$ ppm $)$ changes in ambient $\mathrm{CO}_{2}$ concentrations could occur if the door changed state (open to closed, closed to open) 
during a test which impacted combustion efficiency and also plume flow rate calculations.

Measurement of relevant ambient concentrations $\left(\mathrm{CO}_{2}, \mathrm{CO}, \mathrm{NO}, \mathrm{NO}_{2}, \mathrm{CH}_{4}, \mathrm{C}_{2} \mathrm{H}_{6}\right.$, $\mathrm{C}_{3} \mathrm{H}_{8}, \mathrm{C}_{2} \mathrm{H}_{4}$ ) in the laboratory were accomplished using the MKS FTIR gas-analyzer and taken for a period of at least 10 minutes both before and after each test. Ambient concentrations measured before each test were used in the calculations of combustion efficiency and species yields. Measurements of ambient concentrations take after each test, primarily $\mathrm{CO}_{2}$, were used to verify that plume capture had been effective. This was determined based on the $\mathrm{CO}_{2}$ concentration returning to the pre-test ambient value shortly after the flame was extinguished and flare gas flow stopped. It was observed that often hydrocarbon concentrations were high after the tests which are attributed to residual flare gas from the delivery line slowly purging.

The warm-up period to steady state criteria was evaluated based on a number of measured temperatures and concentrations. The criteria included measured temperatures for the duct sample probe, burner exit, LII sample, the methane flare gas at the exit of the thermal heating bath, and a position on the outside of the duct wall. The steady-state criteria for the various temperature measurements were a rate of increase less than $0.5^{\circ} \mathrm{C}$ per minute. The measured duct concentration of $\mathrm{CO}_{2}$ was also considered and was deemed to have reached steady-state when the rate of change was less than $2 \%$ over the previous two FTIR scans. The $2 \%$ value corresponds to the expected uncertainty on a $\mathrm{CO}_{2}$ measurement at the concentrations encountered. In cases where the LGR gasanalyzer was used in conjunction with an injected tracer gas, the tracer gas concentration reaching a steady-state value was an additional consideration. Both concentration 
measurements implied a steady-state molar flow rate in the duct, and along with steady temperatures, implied a steady-state mass flow rate in the duct.

\subsection{Methodology}

The methodologies for evaluating the measurements in the current work are outlined in Chapter 3. The methods for evaluating combustion efficiency considering gas-phase species only and with the inclusion of a soot measurement are outlined in Sections 3.3.2 and 3.3.4 respectively. Similarly, all species yields calculated in the current work, which are calculated with the inclusion of a soot measurement in all instances, are outlined in Section 3.3.4. 


\section{Chapter 3}

\section{Detailed Expressions and Methodologies for Measuring Flare Combustion Efficiency, Species Emission Rates, and Associated Uncertainties}

This chapter has been peer-reviewed and was published in Industrial \& Engineering Chemistry Research on November 5, 2014. It should be cited as:

Corbin, DJ, MR Johnson (2014) Detailed Expressions and Methodologies for Measuring Flare Combustion Efficiency, Species Emission Rates, and Associated Uncertainties, Industrial \& Engineering Chemistry Research 53 (49), pp 19359-19369. doi: 10.1021/ie502914k

This paper was co-authored by the thesis author, Darcy Corbin, and his M.A.Sc. supervisor Prof. Matthew Johnson. Mr. Corbin performed the initial derivations of all expressions, produced the synthetic data, and calculated the associated uncertainties. He also led construction on the Carleton Lab-Scale Flare facility and performed experimental measurements to produce the data considered in the analysis. Development of the concept of complementary methods for evaluating the performance of the combustion process, as well as writing and editing of the manuscript were performed jointly.

\subsection{Abstract}

Two complementary analytical methods for quantifying carbon conversion efficiency and species emission rates of gas flares in the form of turbulent non-premixed flames are derived and tested experimentally. Full mathematical expressions for partial derivative terms necessary to facilitate quantitative uncertainty analysis are also derived and presented as supplementary material. Key assumptions are individually tested and the 
resulting generalized expressions are quantitatively compared with several other simplified expressions for calculating flare efficiency found in the literature. The first approach uses a carbon-balance approach to link measured concentrations of diluted combustion products to known flare gas outlet conditions while considering both the dilution of the combustion products and ambient levels of relevant species in the dilution and combustion air. This method is further extended to allow explicit consideration of solid-phase black carbon (soot) that may be present in the products. A second distinct method utilizes a tracer gas injected into the diluted plume to enable quantification of species emission rates from the combustion process directly. Experiments reveal how the two approaches each have advantages in different situations allowing experiments to be better optimized to reduced uncertainties. In addition, the tracer injection method is extensible for use in quantifying efficiencies and liquid-fallout on flares burning a mixedphase fuel stream.

\subsection{Introduction}

Flaring is the practice of burning unusable or unwanted flammable gas which might otherwise be vented directly to the atmosphere. Ideally, the combustion process would convert $100 \%$ of fuel-bound carbon to carbon dioxide. However, under certain conditions (e.g. strong crosswind, low heating value, excess steam- or air-assist) the carbon conversion efficiency can be reduced (Johnson, Wilson, et al., 2001; Johnson and Kostiuk, 2000; Johnson and Kostiuk, 2002; Torres, Herndon, Kodesh, et al., 2012; Torres, Herndon, and Allen, 2012; Pohl et al., 1986) and the portion of unburned or partially reacted species leaving the flare can increase. Of particular interest are the potential release of unburned methane (Johnson, Wilson, et al., 2001) and black carbon 
(McEwen and Johnson, 2012; Johnson et al., 2011; Johnson et al., 2013), both of which are potent short-lived climate forcing agents (IPCC, 2013).

This paper develops and critiques analytical methods for calculating carbon conversion efficiencies and species emission rates from unconfined, non-premixed jet flames using gas and particulate samples collected from the plume. The methods each use a system of species conservation equations considering various plume constituents to determine the overall rate of conversion of fuel-bound carbon to carbon dioxide. The robustness of the methods was analyzed using prescribed synthetic test data to mimic the combustion process over a range of anticipated potential conditions, and subsequently tested in lab-scale experiments. A quantitative uncertainty analysis was also performed for the various test conditions and the appropriateness of each method for use in further lab and field experiments is discussed.

\subsection{Theory}

Combustion efficiency, $\eta$, can be defined in different ways, however, for the current analysis it will be defined as carbon conversion efficiency which compares the mass of fully oxidized carbon (i.e. mass of carbon within carbon dioxide) produced by combustion to the mass of carbon in the form of hydrocarbons in the fuel stream (Bourguignon et al., 1999):

$$
\eta[\%]=\frac{\text { mass of carbon in produced } \mathrm{CO}_{2}}{\text { mass of carbon in hydrocarbon fuel stream }} \times 100
$$

It is noted that for cases where $\eta<100 \%$, this definition does not impose any restrictions on the composition or phase of incomplete combustion products. In general 
these products may include gas phase species such as carbon monoxide and unburned or reformed hydrocarbons, as well as particulate phase soot. In some situations, it may also be useful to define a destruction removal efficiency of any combustible species $i$ in the fuel stream $\left(D R E_{i}\right)$ as:

$$
D R E_{i}[\%]=\left(1-\frac{\text { production rate of species } i}{\text { flow rate of species } i \text { in the fuel stream }}\right) \times 100
$$

\subsubsection{General Combustion Efficiency and Species Conservation Equations}

Incomplete combustion of a general hydrocarbon fuel or fuel blend $\left(C_{x} H_{y}\right)$ can be summarized with the following global combustion equation:

$$
C_{x} H_{y}+O_{2}=b \mathrm{CO}_{2}+d H_{2} \mathrm{O}+e C O+f C H_{4}+\sum_{m, n} g_{m, n} C_{m} H_{n}+h C_{(s)}
$$

The potential products of incomplete combustion may take the form of carbon monoxide $(\mathrm{CO})$, unburned methane $\left(\mathrm{CH}_{4}\right)$, unburned and/or reformed gas-phase non- $\mathrm{CH}_{4}$ hydrocarbons $\left(C_{m} H_{n}\right)$, and carbon in the form of soot $\left(C_{(s)}\right)$. It is noted that the form of any unburned hydrocarbon species is not restricted to the same form as the hydrocarbons entering in the fuel stream $\left(C_{x} H_{y}\right)$ or entrained in the ambient air. The summation term, $\sum_{m, n} g_{m, n} C_{m} H_{n}$, is thus used to represent all produced non- $\mathrm{CH}_{4}$ hydrocarbons. The utility of separating $\mathrm{CH}_{4}$ and $C_{(\mathrm{s})}$ from $\mathrm{C}_{m} H_{n}$ in Eq. (3.3) will become apparent further in the development where $C_{(\mathrm{s})}$ may be neglected for the purpose of considering gasphase-only species, and where the influence of ambient concentrations of $\mathrm{CH}_{4}$ may be directly considered while ambient concentrations of other species are deemed negligible. 
Figure 3.1 shows a schematic of an arbitrary control volume $(\mathrm{CV}$, represented by the dashed blue line) enclosing the flame, within which all chemical reactions and product dilution occur. The figure introduces various mass flow rates $(\dot{m})$ that are important to consider for use throughout the manuscript. Flare gas $\left(\dot{m}_{F G}\right)$, and an unknown flow rate of ambient air $\left(\dot{m}_{\infty}\right)$, enter the CV. Inside the CV, the flare gas is split into hydrocarbons $\left(\dot{m}_{C_{x} H_{y}, F G}\right)$ and diluents $\left(\left\{\dot{m}_{F G}\right\}_{\text {inert }}\right)$ that may be present. The ambient air is split into air involved directly in the combustion process ( $\left.\dot{m}_{\text {combustion air }}\right)$ and air entrained during subsequent dilution of the combustion products ( $\left.\dot{m}_{\text {dilution air }}\right)$. The two constituents of the flare gas stream combine with the combustion air and react to release a variety of combustion products $\left(\dot{m}_{\text {produced }}\right)$ as well as any inert species originating in the flare gas. The products are then diluted by the remainder of the ambient air entering the control volume before exiting as the overall plume flow rate $\left(\dot{m}_{\text {plume }}\right)$.

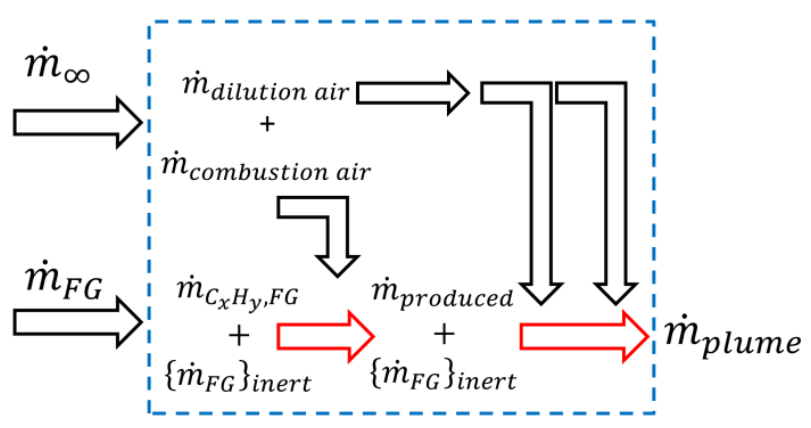

Figure 3.1: Control volume (CV, indicated by dashed blue line) for combustion process illustrating the overall mass balance defined by Eq. (3.4) (sum of terms outside $\mathrm{CV}$ ) and the breakdown of terms relevant to the species mass balance defined by Eq. (3.5) . Red arrows indicate terms containing products of combustion.

By considering the $\mathrm{CV}$ shown in Figure 3.1, an expression for the overall mass balance can be derived as follows: 


$$
\dot{m}_{\text {plume }}=\dot{m}_{F G}+\dot{m}_{\infty}
$$

Although the present equations are derived with the intent of evaluating combustion from non-premixed turbulent diffusion flames such as gas flares, the application of the CV illustrated in Figure 3.1 and the overall mass balance defined by Eq. (3.4) are not necessarily restricted to non-premixed combustion. Since the choice of $\mathrm{CV}$ does not specify whether the mixing of fuel and oxidizer occur across a flame front, as in a non-premixed configuration, or upstream of the flame, as in a premixed flame, the developed equations may thus be extended to any general hydrocarbon / oxygen combustion system.

Similarly, a species mass balance can be developed for individual species relevant to the combustion process. The mass emission rate of a species $i$ as a component of the diluted combustion products can be written as $Y_{i, p l u m e} \dot{m}_{\text {plume }}$, where $Y$ is mass fraction and $Y_{i, p l u m e}$ represents the mass fraction of species $i$ in the diluted plume. The specific species emission rate will depend on the chemical production rate (positive or negative) of species $i, \dot{m}_{i, \text { produced }}$; the potential emissions of species $i$ as an inert component of the fuel (i.e. as would occur in a fuel stream containing $\mathrm{CO}_{2}$ diluent), $\left\{Y_{i, F G} \dot{m}_{F G}\right\}_{\text {inert }}$; and the rate at which species $i$ is entrained into the plume as an ambient constituent of the entrained air, $Y_{i, \infty} \dot{m}_{\infty}$.

$$
Y_{i, p l u m e} \dot{m}_{\text {plume }}=\dot{m}_{i, \text { produced }}+\left\{Y_{i, F G} \dot{m}_{F G}\right\}_{\text {inert }}+Y_{i, \infty} \dot{m}_{\infty}
$$


Eq. (3.5) implicitly assumes that any trace species (e.g. hydrocarbons or $\mathrm{CO}_{2}$ ) present in the combustion air as a constituent of $\dot{m}_{\infty}$ do not react. Any potential contribution to the species mass balance due to reactions of these trace species in the combustion air would be negligible relative to the mass of these same species present in air entrained into the plume (Poudenx, 2000). Eq. (3.5) further assumes that the constituents of the plume are well mixed such that the composition may be described using a single mass fraction for each species. This well-mixed state is readily achieved in the present experiments where the entire plume is captured and mixed in a duct prior to sampling, and the implications for other sampling systems are further discussed in Section 3.3.2 below.

\subsubsection{Combustion Efficiency and Species Emission Rates Assuming Gas Phase Only Combustion Products}

The initial base case for analysis considers gas-phase products of combustion only, and inherently assumes that any non-gaseous species have negligible contribution to the overall carbon mass balance. This scenario is relevant to flares burning primarily 'light' methane-based solution gas, which is a typical flare gas composition in the upstream oil and gas industry (Johnson and Coderre, 2012). Available experimental data for turbulent non-premixed flames burning light hydrocarbon fuels confirm that the proportion of carbon mass emitted in the form of soot is likely negligible. Furthermore, experiments by Pohl et al. (1986) on propane- and propane/nitrogen-fueled vertical diffusion flames established on 3-12" diameter flare burners suggest that soot accounts for less than $0.5 \%$ of the fuel carbon mass for these flames. More recent experiments (McEwen and Johnson, 2012) on lab-scale flares (1-2" diameter) burning primarily methane mixtures consistent with compositions entering solution gas flares in the Alberta upstream 
petroleum industry (Johnson and Coderre, 2012), suggest that soot will account for no more than $0.1 \%$ of the combusted carbon by mass.

By considering only gas phase products of combustion, Eq. (3.3) simplifies to:

$$
C_{x} H_{y}+O_{2}=b C O_{2}+d H_{2} O+e C O+f C H_{4}+\sum_{m, n} g_{m, n} C_{m} H_{n}
$$

Using the relationship between mole and mass fractions, Eq. (3.5) can be more conveniently written in molar form since typical gas analyzers measure volume or mole fraction:

$$
X_{i, p l u m e} \dot{n}_{\text {plume }}=\dot{n}_{i, \text { produced }}+\left\{X_{i, F G} \dot{n}_{F G}\right\}_{\text {inert }}+X_{i, \infty} \dot{n}_{\infty}
$$

where $X_{i}$ denotes the mole fraction of species $i$, and $\dot{n}$ denotes molar flow rate. The definition of combustion efficiency, Eq. (3.1), can similarly be rewritten in molar form where $X_{C_{x} H_{y}, F G}$ is the mole fraction of hydrocarbon $C_{x} H_{y}$ in the fuel stream and $x$ is the relevant carbon coefficient:

$$
\eta[\%]=\frac{\dot{n}_{\mathrm{CO}_{2}, \text { produced }}}{x\left(X_{C_{x} \mathrm{H}_{y}, \mathrm{FG}}\right) \dot{n}_{F G}} \times 100
$$

Destruction efficiency can also be expressed in molar form where $X_{i, F G}$ is the mole fraction of species $i$ in the fuel stream:

$$
\operatorname{DRE}[\%]=\left(1-\frac{\dot{n}_{i, \text { produced }}}{X_{i, F G} \dot{n}_{F G}}\right) \times 100
$$


In the current lab-scale experiment, the flare is centred under a large collection hood connected to a variable speed exhaust extraction system. The flow rate of the exhaust plume can be directly controlled to provide the lowest possible dilution for a given fuel flow rate, while still capturing the entire product plume. The sampling point is more than 10 metres downstream of the duct entrance and, during commissioning of the facility, sample probes were traversed across the duct to verify that gas species mole fractions and soot volume fractions were consistent across the diameter over the range of test conditions.

More generally, in other laboratory setups or especially in field measurement scenarios, it is likely impossible to capture the entire plume. If only a portion of the plume is captured for sampling (e.g. as would occur if single point samples were drawn from a region of the plume), then Eq. (3.5) can still be applied so long as the measured species mole fractions in the captured portion of the plume are assumed to be equal to the mean species mole fractions of the entire plume. Alternatively, the developed equations remain valid for determining local combustion or destruction removal efficiencies at a point in the plume, although it should be noted that the relationship between local and overall efficiencies is not necessarily straightforward if spatial variations in velocity and species concentrations in the plume are significant. While experiments in low-turbulence wind tunnels (Poudenx, 2000) have shown that the plume of a lab-scale flare may be quite inhomogeneous in the near field of the flame (sampling from 1.17 to 1.38 flame lengths downstream of burner exit), these same data suggest that samples drawn from a central region of the plume are representative of the plume as a whole. This latter approach was used in recent field measurements (Allen and Torres, 2011) where a 
$50.8 \mathrm{~cm}$ sample intake was used to capture $15-20 \%$ of the product volume at several metres ( $>2$ flame lengths) from the burner exit. The sampling system was designed with the intent of sampling a large volume of plume and forcing mixing before the sample was measured. Although possible inhomogeneity of the plume as a function of sampling location was not investigated (Herndon et al., 2012), additional review of the results from this study suggest that the relative levels of carbon-based species (ratio of $\mathrm{CO}$ to $\mathrm{CO}_{2}$ for example) in the measured plume were well-correlated and independent of time and dilution.

The gas-phase species mole fractions of relevant species in the diluted plume: $X_{\mathrm{CO}_{2}}, X_{C O}, X_{\mathrm{CH}_{4}}, X_{C_{m} H_{n}}$ are all directly measureable using gas analyzers. The flow rate and composition of flare gas are also directly measureable, meaning $x, X_{C_{x} H_{y}, F G}$, $\left\{X_{i, F G}\right\}_{\text {inert }}, M_{F G}$, and $\dot{n}_{F G}$ are also known. By rearranging Eq. (3.7) in terms of the species production rate and combining with Eq. (3.4) to eliminate the entrained air term, a carbon balance can be derived in which the only unknown term is the plume flow rate.

$$
x\left(X_{C_{x} H_{y}, F G}\right) \dot{n}_{F G}=\sum_{i} \#_{C, i}\left(X_{i, p l u m e}-X_{i, \infty} \frac{M_{\text {plume }}}{M_{\infty}}\right) \dot{n}_{\text {plume }}+\sum_{i} \#_{C, i}\left(X_{i, \infty} \frac{M_{F G}}{M_{\infty}} \dot{n}_{F G}\right)-\left\{X_{C 0_{2}, F G} \dot{n}_{F G}\right\}_{\text {inert }}
$$

where $\#_{C, i}$ indicates the number of carbons per molecule of each species in the plume (ie. $\#_{C, i}=1$ for $\mathrm{CO}_{2}$ and $\#_{C, i}=m$ for $\mathrm{C}_{\mathrm{m}} \mathrm{H}_{\mathrm{n}}$ ) and $\mathrm{CO}_{2}$ is assumed to be the only potential carbon-based inert species in the flare gas. 
Eq. (3.10) explicitly considers species mole fractions measured in the plume, the exact dilution of the products of combustion, and the contribution by ambient species in the entrained air to the determination of combustion efficiency.

However the overall mass balance brings in the molecular mass of the plume, $M_{\text {plume }}$, which is unknown and depends on the dilution ratio (where dilution ratio is defined as the volume of air diluting the combustion products over the volume of combustion products) and specific chemical composition of the products. If gas analyzers are capable of measuring water vapour in the plume, $M_{\text {plume }}$ can be directly calculated based on the measured volume fraction of $\mathrm{CO}_{2}, \mathrm{CO}, \mathrm{CH}_{4}, \mathrm{C}_{\mathrm{m}} \mathrm{H}_{\mathrm{n}}$, and $\mathrm{H}_{2} \mathrm{O}$ with the assumption that the ratio of $\mathrm{N}_{2}$ to $\mathrm{O}_{2}$ in the atmosphere is fixed. Alternatively, it is simpler and ultimately accurate to assume that the molecular mass of the plume is equivalent to that of the ambient air. Even at a low dilution ratio of 10 (which would be difficult to achieve in a practical experiment), the deviation in calculated molar mass of the plume versus that of air is less than $0.5 \%$ for flare efficiencies above $80 \%$. The influence of this assumption is further damped in the calculation of efficiency, such that the resultant absolute bias error in the calculated efficiency is less than $5 \times 10^{-3}$ at an efficiency of $80 \%$ and dilution ratio of 10 . The effect of assuming $M_{\text {plume }}=M_{\infty}$ is even less pronounced at higher efficiencies and/or higher dilution ratios. With the assumptions that $M_{\text {plume }}=M_{\infty}$ the plume flow rate can be explicitly solved for as shown below.

$$
\begin{gathered}
\dot{n}_{\text {plume }, \text { gas }}=\frac{x\left(X_{C_{x} H_{y}, F G}\right) \dot{n}_{F G}+X_{C O_{2}, F G} \dot{n}_{F G}-\left(X_{C O_{2}, \infty}+X_{C O, \infty}+X_{C H_{4}, \infty}+\sum_{m, n} \#_{C, C_{m} H_{n}} X_{C_{m} H_{n}, \infty}\right) \frac{M_{F G}}{M_{\infty}} \dot{n}_{F G}}{X_{C O_{2}, \text { plume }}-X_{C O_{2}, \infty}+A} \\
\text { where } \quad A=\left(X_{C o, p l u m e}-X_{C O, \infty}+X_{C H_{4}, p l u m e}-X_{C H_{4}, \infty}+\sum_{m, n} \#_{C, C_{m} H_{n}}\left(X_{C_{m} H_{n}, p l u m e}-X_{C_{m} H_{n}, \infty}\right)\right)
\end{gathered}
$$


By substituting the plume flow rate into the species balance equation for $\mathrm{CO}_{2}$, the efficiency defined in Eq. (3.8) can be expressed explicitly as:

$$
\begin{aligned}
\eta[\%] & =\frac{x\left(X_{C_{x} H_{y}, F G}\right) B-X_{C O_{2}, F G} A+\left(X_{C O_{2}, \infty} D-X_{C O_{2}, p l u m e}\left(X_{C O, \infty}+X_{C H_{4}, \infty}+\sum_{i} \#_{C, C_{m} H_{n}} X_{C_{m} H_{n}, \infty}\right)\right) \frac{M_{F G}}{M_{\infty}}}{x\left(X_{C_{x} H_{y}, F G}\right)\left(X_{C O_{2}, p l u m e}-X_{C O_{2}, \infty}+A\right)} \times 100 \\
\text { where } \quad A & =\left(X_{C O, p l u m e}-X_{C O, \infty}+X_{C H_{4}, p l u m e}-X_{C H_{4}, \infty}+\sum_{m, n} \#_{C, C_{m} H_{n}}\left(X_{C_{m} H_{n}, p l u m e}-X_{C_{m} H_{n}, \infty}\right)\right) \\
B & =\left(X_{C O_{2}, p l u m e}-X_{C O_{2}, \infty}\right) \text {, and } \\
D & =\left(X_{C O, p l u m e}+X_{C H_{4}, p l u m e}+\sum_{i} \#_{C, C_{m} H_{n}} X_{C_{m} H_{n}, p l u m e}\right)
\end{aligned}
$$

In Eq. (3.12), it can be noted that all rate terms (fuel hydrocarbon flow rate and gross fuel flow rate) have been removed from the equation and only rate independent mole fractions remain. The conversion efficiency is thus a function of the carbon-based species mole fractions in the plume and ambient air as well as the flare gas composition.

With the plume flow rate defined per Eq. (3.11), the emission rate of any species, whether carbon-based or not (e.g. nitric oxide), can be determined by rearranging Eq. (3.7) as follows.

$$
\dot{m}_{i, p r o d u c e d}=M_{i}\left(\left(X_{i, p l u m e}-X_{i, \infty}\right) \dot{n}_{\text {plume,gas }}-\left\{X_{i, F G} \frac{\dot{m}_{F G}}{M_{F G}}\right\}_{\text {inert }}+X_{i, \infty} \frac{\dot{m}_{F G}}{M_{\infty}}\right)
$$

Using Eq. (3.13) and the plume flow rate defined by Eq. (3.11), the destruction removal efficiency $\left(D R E_{i}\right)$ of any combustible species $i$ present in the flare gas can be defined as: 


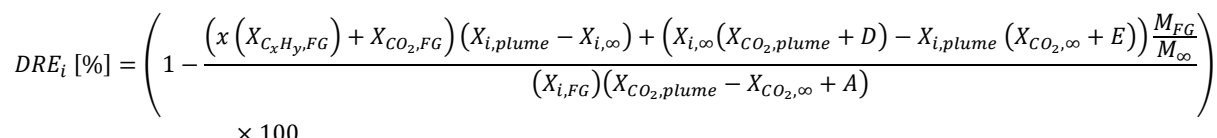

$$
\begin{aligned}
& \text { where } A=\left(X_{\text {Co,plume }}-X_{C 0, \infty}+X_{C H_{4}, p l u m e}-X_{C_{4}, \infty}+\sum_{m, n} \#_{C, C_{m} H_{n}}\left(X_{C_{m} H_{n}, p l u m e}-X_{C_{m} H_{n}, \infty}\right)\right) \text {, } \\
& D=\left(X_{C O, p l u m e}+X_{C H_{4}, p l u m e}+\sum_{i} \#_{C, C_{m} H_{n}} X_{C_{m} H_{n}, p l u m e}\right) \text {, and } \\
& E=\left(X_{C O, \infty}+X_{C H_{4}, \infty}+\sum_{m, n} \#_{C, C_{m} H_{n}} X_{C_{m} H_{n}, \infty}\right) \text {. }
\end{aligned}
$$

In cases where the combustion efficiency is suitably high, it may be sufficiently accurate and simpler to assume $100 \%$ combustion efficiency when calculating the plume flow rate. In this case the carbon balance for combustion considers only $\mathrm{CO}_{2}$ as a product, and Eq. (3.11) simplifies to:

$$
\dot{n}_{\text {plume }, 100 \%}=\frac{x\left(X_{C_{x} H_{y}, F G}\right) \dot{n}_{F G}+X_{C O_{2}, F G} \dot{n}_{F G}-X_{C_{2}, \infty} \frac{M_{F G}}{M_{\infty}} \dot{n}_{F G}}{\left(X_{C O_{2}, p l u m e}-X_{C O_{2}, \infty}\right)}
$$

The assumption of $100 \%$ combustion efficiency can then be relaxed, and Eq. (3.15) used instead of Eq. (3.11) in combination with Eq. (3.13) to derive production rates of other species from their change in measured mole fractions in the plume relative to ambient.

Quantification of the uncertainty in the measured plume flow rate defined by Eq. (3.11), combustion efficiency defined by Eq. (3.12), gaseous species mass emission rate defined by Eq. (3.13), and flare gas species destruction removal efficiency Eq. (3.14) can be accomplished using expressions developed in the supplementary material. The uncertainty on combustion efficiency can be calculated following the instructions in Section A1 with systematic error defined by Eq. (A.5). For plume flow rate, the uncertainty can be evaluated following the instructions in Section A2 with 
systematic error defined by Eq. (A.7). The uncertainty of gas-phase species emission rates can be calculated following the instructions in Section A4.1 for non-carbon-based species, or Section A4.2 for carbon-based species with systematic error defined by Eq. (A.10) or Eq. (A.13) respectively. Similarly, the systematic error for the DRE of a non-carbon-based flare gas species is defined by Eq. (A.12) and of a carbon-based flare gas species by Eq. (A.15).

\subsubsection{Comparison with Simplified Expressions for Combustion Efficiency used in Other Works}

A number of different expressions for efficiency have been employed by previous researchers, each of which relies on various simplifications to the method outlined above. The simplifications range from neglecting only the ambient species present in the combustion air to neglecting all ambient concentrations completely, and none of these methods is directly applicable to fuel streams which contain $\mathrm{CO}_{2}$. To the authors' knowledge, no previous studies have attempted a comprehensive uncertainty analysis of the methods employed, with the possible exception of Bourguignon et al. (1999) who considered the uniquely specific problem of flare efficiency measurements in a closedloop windtunnel. This is not necessarily surprising given the inherent difficulty in fully accounting for entrained ambient species in situations where sampling rates, entrainment rates, and combustion efficiency are all unknown. One of the most robust analysis of combustion efficiency found in the literature (Poudenx, 2000) neglects the presence of ambient species in the combustion air itself and the possibility of $\mathrm{CO}_{2}$ as a fuel diluent. An oxygen balance is used to estimate a product dilution factor and corrects the contribution of ambient species to plume levels using this factor. Similarly, the method employed by Pohl et al. (1986) corrects for the influence of ambient species 
concentrations on measured plume dilution by using the theoretical production/consumption of carbon dioxide or oxygen assuming complete combustion to determine a dilution factor. In the mid-1980s EPA flare study (McDaniel, 1983), ambient concentrations of all major species were considered by directly subtracting background levels from measured plume values, although the mass balance includes a minor assumption that the volume of combustion air and the ambient species entrained with it are negligible compared to amounts entrained for dilution. In the efficiency calculations shown in the published overview of the recent TCEQ flare study (Allen and Torres, 2011), only ambient $\mathrm{CO}_{2}$ was considered (Torres, Herndon, Kodesh, et al., 2012) while other ambient species were neglected. The equation for combustion efficiency for labscale and field measurements reported by Strosher (2000) includes no explicit correction for ambient concentrations of carbon-containing species. The combustion efficiency expressions used in the respective studies are summarized in Table 3.1.

Table 3.1: Various combustion efficiency expressions

\begin{tabular}{|c|c|}
\hline $\begin{array}{l}\text { McDaniel } \\
(1983)\end{array}$ & $\frac{X_{C O_{2}, \text { plume }}-X_{C_{2}, \infty}}{X_{C O_{2}, \text { plume }}-X_{C O_{2}, \infty}+X_{C O, p l u m e}-X_{C O, \infty}+\sum_{m, n} \#_{C, C_{m} H_{n}} X_{C_{m} H_{n}, p l u m e}-\sum_{m, n} \#_{C, C_{m} H_{n}} X_{C_{m} H_{n}, \infty}+\text { Soot }}$ \\
\hline $\begin{array}{l}\text { Pohl et al. } \\
\text { (1986) }\end{array}$ & $\begin{array}{c}\frac{(D F+1) X_{C O_{2}, \text { plume }}-(D F) X_{C O_{2}, \infty}}{(D F+1)\left(X_{C O_{2}, \text { plume }}+X_{C O, p l u m e}+\sum_{m, n} \#_{C, C_{m} H_{n}} X_{C_{m} H_{n}, \text { plume }}+\text { Soot }\right)-(D F)\left(X_{C O_{2}, \infty}+X_{C O, \infty}+\sum_{m, n} \#_{C, C_{m} H_{n}} X_{C_{m} H_{n}, \infty}\right)} \\
\text { where } \quad D F=\frac{X_{i, p l u m e}-X_{i, S R=1, \text { theoretical }}}{X_{i, \infty}-X_{i, p l u m e}}\end{array}$ \\
\hline $\begin{array}{l}\text { Poudenx } \\
(2000)\end{array}$ & $\begin{array}{c}\frac{X_{C O_{2}, p l u m e}-(1-\alpha) X_{C O_{2}, \infty}}{X_{C O_{2}, \text { plume }}+X_{C O, p l u m e}+\sum_{m, n} \#_{C, C_{m} H_{n}} X_{C_{m} H_{n}, p l u m e}-(1-\alpha)\left(X_{C O_{2}, \infty}+X_{C O, \infty}+\sum_{m, n} \#_{C, C_{m} H_{n}} X_{C_{m} H_{n}, \infty}\right)} \\
\text { where } \quad \alpha=1-\frac{X_{O_{2}, p l u m e}}{X_{O_{2}, \infty}}\end{array}$ \\
\hline $\begin{array}{l}\text { Strosher } \\
(2000)\end{array}$ & $\frac{X_{C O_{2}, \text { plume }}}{X_{C O_{2}, \text { plume }}+X_{\text {Co,plume }}+\sum_{m, n} \#_{C, C_{m} H_{n}} X_{C_{m} H_{n}, \text { plume }}+\text { Soot }}$ \\
\hline $\begin{array}{c}\text { Torres, } \\
\text { Herndon, } \\
\text { Kodesh, et al. } \\
\text { (2012) }\end{array}$ & $\frac{X_{\mathrm{CO}_{2}, \text { plume }}-X_{\mathrm{CO}_{2}, \infty}}{X_{\mathrm{CO}_{2}, \text { plume }}-X_{\mathrm{CO}_{2}, \infty}+X_{C O, \text { plume }}+\sum_{m, n} \#_{C, C_{m} H_{n}} X_{C_{m} H_{n}, \text { plume }}}$ \\
\hline
\end{tabular}


The effect of neglecting or partially neglecting ambient concentrations on the calculated efficiency will vary with both the level of ambient species and the dilution of the products with entrained air. Each species in the efficiency equations of Table 3.1 is implicitly or explicitly multiplied by its respective carbon number, $\#_{C, i} . \mathrm{CO}_{2}, \mathrm{CO}$, and $\mathrm{CH}_{4}$ each has a carbon number of one (one carbon atom per molecule), while $\#_{C, i}>1$ for higher hydrocarbons. Thus, the effect of neglecting one ambient $\mathrm{CO}$ molecule is equivalent to neglecting one $\mathrm{CH}_{4}$ molecule, with each having half the effect of an ethane $\left(\mathrm{C}_{2} \mathrm{H}_{6}\right)$ molecule $\left(\#_{C, i}=2\right)$. Figure 3.2a shows the discrepancy between efficiencies calculated using the equations above and the actual efficiency as a function of dilution ratio assuming nominal ambient concentrations of $\mathrm{CO}_{2}=400 \mathrm{ppm}_{\mathrm{v}}, \mathrm{CO}=1.5 \mathrm{ppm}_{\mathrm{v}}$ (US EPA, 2013a), and $\mathrm{CH}_{4}=1.8 \mathrm{ppm}_{\mathrm{v}}$ (US EPA, 2013b). Figure 3.2b shows the different bias errors incurred if $\mathrm{CO}_{2}$ is present in the flare gas at $5 \%$ by volume. The efficiency expressions defined by McDaniel (1983) and Pohl et al. (1986) have distinct bias errors, however the differences are negligible over the conditions shown in Figure 3.2. Although the maximum dilution ratio in the present experiments is 216 , recent airborne field measurements using highly sensitive cavity ringdown gas analyzers (Caulton et al., 2014) suggests that dilution ratios of 1000 or more may be relevant in other settings. 

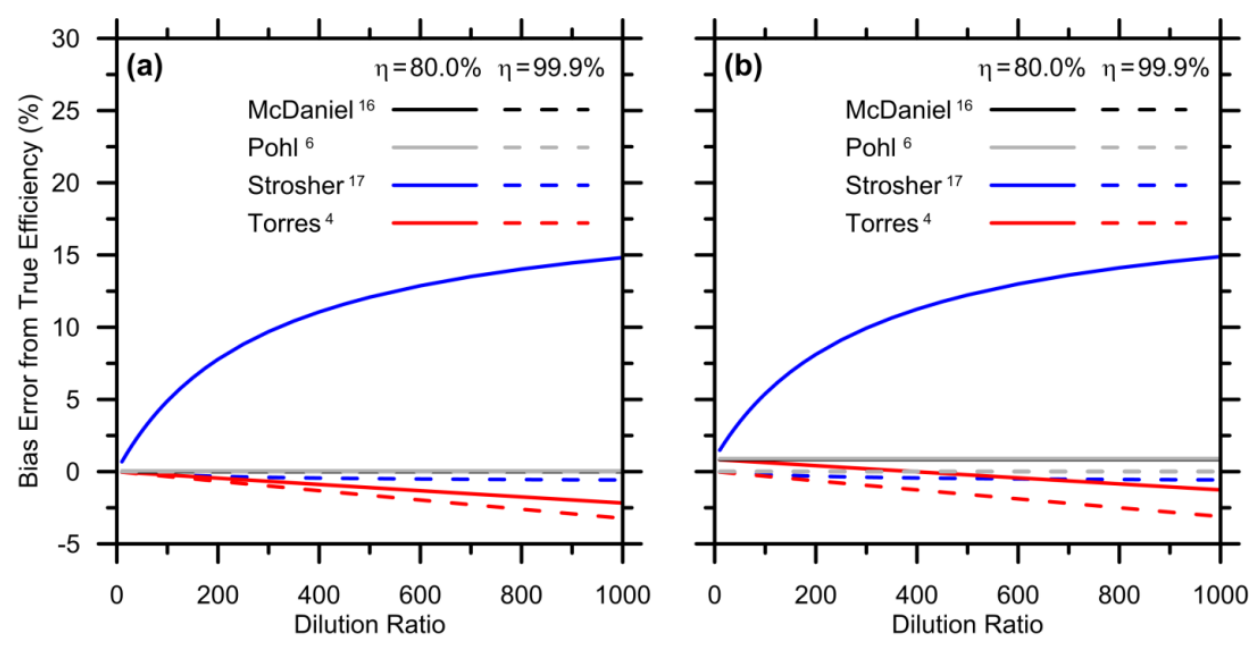

Figure 3.2: Potential bias errors incurred when using different efficiency expressions (McDaniel (1983), Pohl et al. (1986), Torres, Herndon, Kodesh, et al.

(2012), Strosher (2000)) as a function of dilution ratio for nominal ambient concentrations of $\mathrm{CO}_{2}=400 \mathrm{ppm}_{\mathrm{v}}, \mathrm{CO}=1.5 \mathrm{ppm}_{\mathrm{v}}$, and $\mathrm{CH}_{4}=1.8 \mathrm{ppm}_{\mathrm{v}}$, where the flare gas contains (a) no $\mathrm{CO}_{2}$; (b) $5 \% \mathrm{CO}_{2}$.

For all of the methods, increased ambient levels of any species that are present as products of incomplete combustion and not corrected for in the equations will result in additional underestimation of the combustion efficiency. Similarly, increased levels of carbon dioxide in the ambient air will result in overestimation of combustion efficiency for methods that do not explicitly include correction for ambient $\mathrm{CO}_{2}$ levels. If carbon dioxide were present as a fuel diluent this would induce further bias as it is unaccounted for in the final forms of the equations shown above. Across all dilution ratios and levels of carbon dioxide diluent, the generalized method derived in this paper is able to determine gaseous combustion efficiency within a maximum bias error of less than $5 \cdot 10^{-3}$ $\%$ (e.g. efficiency [\%] of $95 \pm 0.005$ ).

\subsubsection{Combustion Efficiency and Species Emission Rates with In Situ Black Carbon Measurement}

The calculation approach derived in Section 3.3.2 can be further extended to include direct measurements of emitted carbon mass in the form of soot. Revised species 
balances as well as a general mass balance are used to produce a carbon balance, which allows for closed forms of plume flow rate, combustion efficiency, and species production rates to be developed. This method includes the same assumptions as the gaseous-phase-only equations derived in Section 3.3.2, namely non-reacting ambient species, the molar mass of the plume being equivalent to the ambient value, along with the additional assumption that ambient levels of soot in the entrained air can be neglected. The global combustion expression given by Eq. (3.3) is utilized, which includes all gas species as well as soot, resulting in mixed-phase products. In the present analysis soot is considered as solid phase molecular carbon, which is consistent with measurements made with laser induced incandescence (LII).

The species balance equation for soot is:

$$
\rho_{C_{(s)}} f_{v, p l u m e} \dot{Q}_{\text {plume }}=M_{C_{(s)}} \dot{n}_{C_{(s)}, \text { produced }}
$$

where $f_{v \text {,plume }}$, is the soot volume fraction in the plume which may be measured using LII or other techniques and $\rho_{C_{(s)}}$ is the density of soot which has an assumed (Johnson et al., 2013) value of $1860 \mathrm{~kg} / \mathrm{m}^{3}$ with an approximate normally distributed standard deviation of $120 \mathrm{~kg} / \mathrm{m}^{3}$.

Using the carbon balance technique outlined in a previous section, the plume flow rate can be modified for the inclusion of produced soot:

$$
\begin{aligned}
& \dot{n}_{\text {plume }, \text { gas }}=\frac{x\left(X_{C_{x} H_{y}, F G}\right) \dot{n}_{F G}+X_{C O_{2}, F G} \dot{n}_{F G}-\left(X_{C O_{2}, \infty}+X_{C O, \infty}+X_{C H_{4}, \infty}+\sum_{i} \#_{C, C_{m} H_{n}} X_{C_{m} H_{n}, \infty}\right) \frac{M_{F G}}{M_{\infty}} \dot{n}_{F G}}{X_{C O_{2}, \text { plume }}-X_{C O_{2}, \infty}+\frac{\rho_{C_{(s)}} f_{v, p l u m e} R_{u} T_{\text {plume }}}{M_{C_{(s)}} P_{\text {plume }}}+A} \\
& \text { where } \mathrm{A}=\left(X_{C O, \text { plume }}-X_{C O, \infty}+X_{C H_{4}, \text { plume }}-X_{C H_{4}, \infty}+\sum_{m, n} \#_{C, C_{m} H_{n}}\left(X_{C_{m} H_{n}, \text { plume }}-X_{C_{m} H_{n}, \infty}\right)\right) .
\end{aligned}
$$


In Eq. (3.17), it is implicitly assumed that the sampled volume of soot particles is negligible relative to the sampled gas volume, such that gaseous species mole fractions obtained using typical gas analyzers which require filtered samples free from particulate, are equal to the mole fractions in an unfiltered sample. This is quite reasonable given that measured volume fractions of soot in the plume are typically of the order of parts per million or less. It is further noted that the use of Eq. (3.17) requires measurement of the plume temperature, $T_{\text {plume }}$, and static pressure, $P_{\text {plume }}$, which are necessary to convert the measured soot volume fraction to moles of carbon. Additionally, a correction to the soot volume fraction measured by the LII (or other instrument) must be made to account for differences in temperature between the measurement cell and the plume (McEwen, 2010) as defined below.

$$
f_{v, \text { plume }}=f_{v, \text { measured }} \frac{T_{\text {measured }}}{T_{\text {plume }}}
$$

From Eq. (3.17) and Eq. (3.18), the new closed form equation below can be developed to evaluate combustion efficiency with the inclusion of direct soot measurement.

$$
\begin{aligned}
& \eta[\%]=\frac{x\left(X_{C_{x} H_{y}, F G}\right) B-X_{C O_{2}, F G} F+\left(X_{C O_{2}, \infty} G-X_{C O_{2}, p l u m e}\left(X_{C O, \infty}+X_{C H_{4}, \infty}+\sum_{i} \#_{C, C_{m} H_{n}} X_{C_{m} H_{n}, \infty}\right)\right) \frac{M_{F G}}{M_{\infty}}}{x\left(X_{C_{x} H_{y}, F G}\right)\left(X_{C O_{2}, p l u m e}-X_{C O_{2}, \infty}+F\right)} \times 100 \\
& \text { where } \quad B=\left(X_{C 0_{2}, \text { plume }}-X_{C O_{2}, \infty}\right) \text {, } \\
& F=\left(X_{C o, p l u m e}-X_{C O, \infty}+X_{C H_{4}, p l u m e}-X_{C H_{4}, \infty}+\sum_{m, n} \#_{C, C_{m} H_{n}}\left(X_{C_{m} H_{n}, p l u m e}-X_{C_{m} H_{n}, \infty}\right)+H\right), \\
& G=\left(X_{\text {Co,plume }}+X_{C H_{4}, \text { plume }}+\sum_{i} \#_{C, C_{m} H_{n}} X_{C_{m} H_{n}, p l u m e}+H\right) \text {, and } \\
& H=\frac{\rho_{C_{(s)}} f_{v, \text { measured }} R_{u} T_{\text {sample }}}{M_{C_{(s)}} P_{\text {plume }}} .
\end{aligned}
$$


Similar to the scenario in which only gas-phase species are considered, using Eq. (3.13) and the plume flow rate defined by Eq. (3.17), the destruction removal efficiency $\left(D R E_{i}\right)$ of any combustible species $i$ present in the flare gas can be defined as:

$$
\begin{aligned}
& D R E_{i}[\%]=\left(\begin{array}{c}
\left.1-\frac{\left(x\left(X_{C_{x} H_{y}, F G}\right)+X_{C 0_{2}, F G}\right)\left(X_{i, p l u m e}-X_{i, \infty}\right)+\left(X_{i, \infty}\left(X_{C 0_{2}, p l u m e}+G\right)-X_{i, p l u m e}\left(X_{C O_{2}, \infty}+E\right)\right) \frac{M_{F G}}{M_{\infty}}}{X_{i, F G}\left(X_{C 0_{2}, p l u m e}-X_{C 0_{2}, \infty}+F\right)}\right) \\
\times 100
\end{array}\right. \\
& \text { where } E=\left(X_{C O, \infty}+X_{C H_{4}, \infty}+\sum_{m, n} \#_{C, C_{m} H_{n}} X_{C_{m} H_{n}, \infty}\right) \text {, } \\
& F=\left(X_{C O, \text { plume }}-X_{C O, \infty}+X_{C H_{4}, p l u m e}-X_{C H_{4}, \infty}+\sum_{m, n} \#_{C, C_{m} H_{n}}\left(X_{C_{m} H_{n}, p l u m e}-X_{C_{m} H_{n}, \infty}\right)+H\right), \\
& G=\left(X_{\text {CO,plume }}+X_{C H_{4}, \text { plume }}+\sum_{i} \#_{C, C_{m} H_{n}} X_{C_{m} H_{n}, p l u m e}+H\right) \text {, and } \\
& H=\frac{\rho C_{(s)} f_{v, \text { measured }} R_{u} T_{\text {sample }}}{M_{C_{(s)} P^{p l u m e}}} .
\end{aligned}
$$

Production rates for a general gas species can be calculated using Eq. (3.13) using the plume flow rate term defined by Eq. (3.17). Finally, the production rate of soot can be directly calculated as:

$$
\dot{m}_{C_{(s)}, \text { produced }}=\rho_{C_{(s)}} f_{v, \text { measured }} \frac{R_{u} T_{\text {sample }}}{P_{\text {plume }}} \dot{n}_{\text {plume,gas }}
$$

Quantification of the uncertainty in the measured plume flow rate defined by Eq. (3.17), combustion efficiency defined by Eq. (3.19), DRE defined by Eq. (3.20), and black-carbon emission rate defined by Eq. (3.21) can be accomplished using expressions developed in the supplementary material. The uncertainty on combustion efficiency can be calculated following the instructions in Section S.1 with systematic error defined by Eq. (A.5). The uncertainty on the plume flow rate can be calculated following the instructions in Section A2 with systematic error defined by Eq. (A.7). For 
black carbon emission rate, the uncertainty can be evaluated following the instructions in Section A4.2 with the systematic error defined by Eq. (A.14).

\subsubsection{Efficiency Measurements Using a Tracer Injection for Plume Flow Rate Measurement}

Although the generalized carbon balance methods outlined in Sections 3.3.2 and 3.3.3 are suitable for a wide variety of applications, there are cases where an alternate method is desirable, which does not rely on an explicit carbon balance as in Eq. (3.10). This would include a situation in which the fuel stream contains a significant liquid fraction that may pass through the flame without burning, and subsequently fall to the ground rather than being entrained with the product plume. Closing the carbon balance via direct measurement of all emitted carbon containing species would not be practically feasible in this situation. However, a substitute equation to use with the system of mass balance equations can be derived following an injection of a non-reacting, measurable gas tracer species into the sampling system that is otherwise not present at appreciable concentrations in ambient air or the products of combustion. Depending on the available measurement technology, it may also be possible to achieve lower overall uncertainties via a tracer-based approach as demonstrated in Section 3.5.

By injecting the gaseous tracer directly into the sampling duct, a simple species mass balance for determining the gas flow rate of the sampled plume can be derived, Eq. (3.22), and used to directly quantify the molar flux of captured plume (and hence the molar flux of captured fuel-based carbon).

$$
\dot{n}_{\text {plume,gas }}=\frac{\frac{\dot{m}_{\text {tracer }}}{M_{\text {tracer }}}\left(1-X_{\text {tracer }}^{*}\right)}{\left(X_{\text {tracer }}-X_{\text {tracer }}^{*}\right)}
$$


In Eq. (3.22), $X_{\text {tracer }}$ is the measured mole fraction of tracer in the sampling duct while the tracer is being injected, and $X_{\text {tracer }}^{*}$ is the mole fraction of tracer in the plume prior to tracer injection (i.e. when $\dot{m}_{\text {tracer }}=0$ ). Depending on the choice of tracer species, this background term may be negligible. The uncertainty in the measured plume flow rate, defined by Eq. (3.22), can be quantified following the instructions in Section S.3 of the supplemental material with systematic error defined by Eq. (A.8). Corresponding uncertainties in gas-phase species or black-carbon emission rates (defined by Eq. (3.13) and Eq. (3.21) ), where the plume flow rate is calculated using the tracerinjection method, can be quantified following the instructions in Section A4.1 with systematic error defined by Eq. (A.10) or Eq. (A.11) for gas-phase species and black carbon respectively. The uncertainties in flare gas species DRE can quantified following the instructions in Section A4.1 with systematic error defined by Eq. (A.12).

In an experiment where $100 \%$ of the plume-borne carbon is captured (gas and particulate phase), the plume molar flow rate defined in Eq. (3.22) can be used in conjunction with Eq. (3.13) to calculate species emission rates, which can then be used to determine combustion efficiency via Eq. (3.8) . Similarly, the destruction removal efficiency for a given flare gas species (Eq. (3.2) ) may be calculated using Eq. (3.13) in conjunction with Eq. (3.22) to calculate the production rate, and dividing by the flow rate of that species in the flare gas. As shown in the results, this method may lead to reduced uncertainties in calculated species production rates depending on the dilution ratio of the sample and the relative concentrations of species in the plume being measured. Furthermore, as noted above, this tracer-based measurement technique could be utilized with a sampling system capable of capturing $100 \%$ of the plume-borne carbon (i.e. 
gaseous species and soot) to quantify hydrocarbon fallout if liquid constituents were present in the flare stream. In this scenario, the fuel to product mass balance could be closed by directly measuring the plume flow rate via Eq. (3.22) and assuming any carbon not captured was in the form of liquid fallout.

The global combustion equation for a mixed phase (gas and liquid) fuelled flare which may emit unburned liquid fuel is:

$$
C_{p} H_{q_{(\text {liquid) }}}+C_{x} H_{y_{(\text {gas }}}+O_{2}=b C O_{2}+d H_{2} O+e C O+f C H_{4}+\sum_{m, n} g_{m, n} C_{m} H_{n(\text { gas })}+h C_{(s)}+j C_{p} H_{q_{(\text {(liquid) }}}
$$

Production rates of all gas species excluding the unburned liquid fuel, $C_{p} H_{q}$, can then be defined by Eq. (3.24), which is a modified version of Eq. (3.13), where subscripts $F L$ and $F G$ indicate liquid and gas phases in the flare stream respectively. The production rate of soot can be defined by Eq. (3.21) .

$$
\begin{gathered}
\dot{n}_{i, p r o d u c e d}=\left(\left(X_{i, p l u m e}-X_{i, \infty}\right) \dot{n}_{\text {plume,gas }}-\left\{X_{i, F G} \dot{n}_{F G}\right\}_{\text {inert }}\right. \\
\left.+X_{i, \infty \infty} \frac{1}{M_{\infty}}\left(M_{F G} \dot{n}_{F G}+M_{C_{p} H_{q}, F L}\left\{\dot{n}_{C_{p} H_{q}, F L}\right\}_{\text {combusted }}+M_{\text {tracer }} \dot{n}_{\text {tracer }}\right)\right)
\end{gathered}
$$

In Eq. (3.24), $\left\{\dot{n}_{C_{p} H_{q}, F L}\right\}_{\text {combusted }}$ is the portion of the liquid fuel that successfully combusts to produce gas phase products and it is assumed that the mean carbon number and molecular weight of the unburned liquid fuel is the same as that of the liquid fuel in the flare stream. From this derivation of species production rates, the liquid fallout can be quantified using the tracer measured plume flow rate Eq. (3.22) and a carbon balance of the reaction based on Eq. (3.23) . 


$$
\begin{aligned}
& \left\{\dot{n}_{C_{p} H_{q}, F L}\right\}_{\text {liquid fallout }}=\frac{x\left(X_{C_{x} H_{y}, F G}\right) \dot{n}_{F G}+p \dot{n}_{C_{p} H_{q}, F L}+\left\{X_{C 0_{2}, F G} \dot{n}_{F G}\right\}_{\text {inert }}-\sum_{i} \#_{C, i} K-\frac{\rho_{C_{(s)}} f_{v, \text { measured }} R_{u} T_{\text {sample }}}{M_{C_{(s)}} P_{p l u m e}} \dot{n}_{\text {plume,gas }}}{\left(p-\sum_{i} \#_{C, i} X_{i, \infty} \frac{M_{C_{p} H_{q}, F L}}{M_{\infty}}\right)} \\
& \text { where } K=\left[\left(X_{i, p l u m e}-X_{i, \infty}\right) \dot{n}_{\text {plume,gas }}+X_{i, \infty}\left(\frac{M_{F G}}{M_{\infty}} \dot{n}_{F G}+\frac{M_{C_{p} H_{q}, F L}}{M_{\infty}} \dot{n}_{C_{p} H_{q}, F L}+\frac{M_{\text {tracer }}}{M_{\infty}} \dot{n}_{\text {tracer }}\right)\right] .
\end{aligned}
$$

\subsection{Quantifying Anticipated Uncertainties for a Range of Operating Conditions}

The effects of key assumptions were evaluated using synthetic data for which a flare gas composition by volume of $88.01 \%$ methane, $7.28 \%$ ethane, $3.21 \%$ propane and $1.50 \%$ butane was assumed. To estimate the achievable uncertainties associated with each method, a range of flare efficiency and dilution scenarios were simulated using typical bias errors for each input variable. To reduce the number of parameters needed to define the product composition of the synthetic data, the form of the emitted product species was fixed as follows: fuel-bound carbon not fully oxidized to $\mathrm{CO}_{2}$ was emitted as soot (fixed at $0.1 \%$ of the fuel-bound carbon), $\mathrm{CO}\left(10 \%\right.$ of the non- $\mathrm{CO}_{2}$ gas-phase carbon), and unburned hydrocarbons $\left(90 \%\right.$ of non- $\mathrm{CO}_{2}$ gas-phase carbon, in the same relative volume fractions as the raw fuel). $\mathrm{NO}_{\mathrm{X}}$ emissions were fixed at the US EPA (1995) suggested emission factor of $0.068 \mathrm{lb} \mathrm{NO}_{\mathrm{X}} / 10^{6} \mathrm{BTU}$.

For the purpose of calculating uncertainties, the assumed measurement bias uncertainty on gas species concentrations was the larger of $2 \%$ of the measured value or a prescribed detection limit for low concentrations $\left(1.0,0.5\right.$ or $0.1 \mathrm{ppm}_{\mathrm{V}}$ depending on scenario), which is typical of many commercial gas analyzers. The concentration of tracer gas in the plume was held at $50 \mathrm{ppm}_{\mathrm{v}}$ independent of combustion efficiency and dilution ratio. The assumed bias uncertainty on measuring the tracer gas was $2 \mathrm{ppb}_{\mathrm{v}}$, which is attainable with commercially available modern gas analyzers specifically 
tailored for the chosen tracer species. Soot volume fraction was assumed to be measurable with relative bias uncertainty of $20 \%$, and soot density was assumed to be known to a relative bias of $4 \%$ or $75.6 \mathrm{~kg} / \mathrm{m}^{3}$ as prescribed by McEwen (2010). The bias used for the flare gas flow rates in the synthetic cases was $1.25 \%$ of the individual species flow rate, where the total fuel mass flow bias was the root sum of squares of the bias of the individual fuel species. Bias on the plume temperature and pressure was $2.2 \mathrm{~K}$ and $15 \mathrm{~Pa}$ respectively.

\subsubsection{Anticipated Uncertainties in Measured Combustion Efficiency}

The expected uncertainty on measured combustion efficiency was evaluated considering the products of combustion as defined above. Efficiency was calculated based on each of the three methods derived in Sections 3.3.2, 3.3.4, and 3.3.5, and uncertainty was determined using the detailed expressions shown in supplemental material, which were derived in accordance with ANSI/ASME (1985) procedures for estimating uncertainties. The shaded bands in Figure 3.3a represent the range of possible uncertainty for a given detection limit and dilution ratio over the range of uncertainties tested. The uncertainty in measured efficiency increases as the sample becomes more diluted and the concentrations of various species in the plume approach their respective detection limits. The uncertainties calculated for the gas-phase and mixed-phase expressions were negligibly different for the soot production rate tested $(0.1 \%$ of fuel-bound carbon), as such only the mixed-phase uncertainties are shown below. Additionally, detection limit changes made a negligible difference on the uncertainty of the tracer injection method as $\mathrm{CO}_{2}$ concentrations were always high enough so that the uncertainty was dictated by assumed $2 \%$ bias on the measured value. 

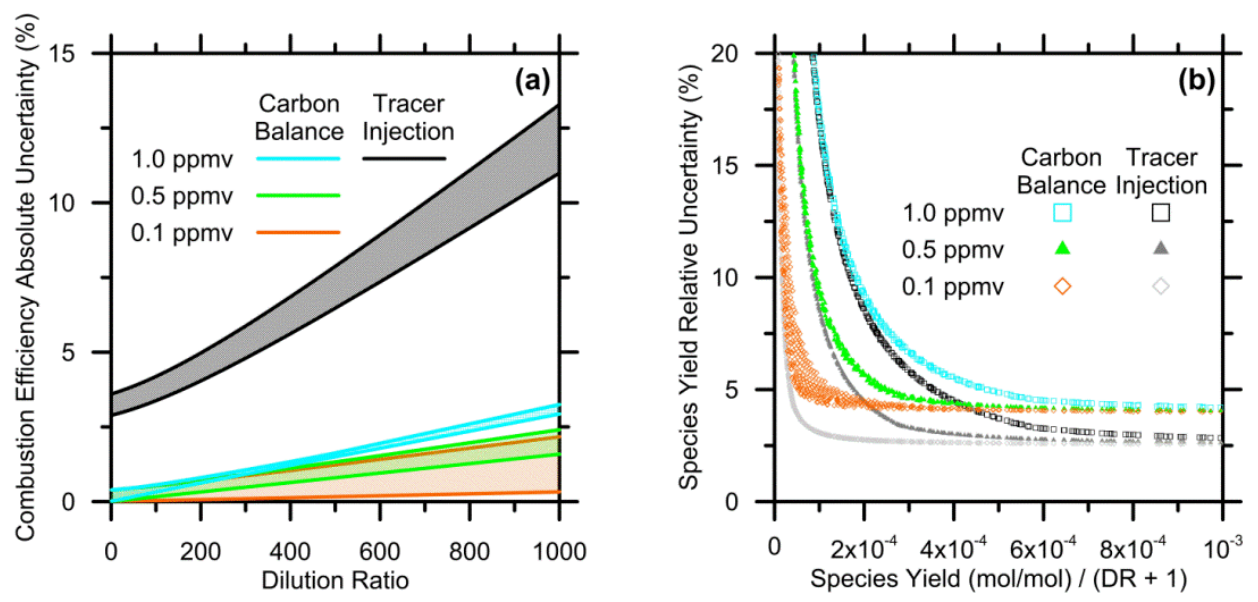

Figure 3.3: a) Expected absolute uncertainty on measured combustion efficiency (e.g. $99 \% \pm 4 \%$ equates to a range of $95-103 \%$ at a dilution ratio of 200 using the tracer injection method) evaluated with Eq. (3.12) and corresponding supplementary material. Combustion efficiencies greater than $100 \%$ are not possible in practice and uncertainties extending beyond this threshold are mathematical artefacts from the uncertainty analysis. b) Expected relative uncertainty on measured species yield (e.g. $1.0 \mathrm{~kg} / \mathrm{kg} \pm 10 \%(0.1 \mathrm{~kg} / \mathrm{kg}))$ evaluated using Eq. (3.13) with plume flow rate defined by Eq. (3.11) (carbon-balance) and Eq. (3.22) (tracer injection).

\subsubsection{Anticipated Uncertainties in Measured Species Emission Rates}

The calculation of a species emission rate or species yield (mass production rate normalized by fuel mass flow rate) is dependent on the intermediate calculation of the plume flow rate. Two methods are presented for evaluating the plume flow rate based on either an indirect method utilizing a carbon balance as developed in Section 3.3.2, or using a gaseous tracer injection for direct measurement as developed in Section 3.3.5. The inherent advantage of direct plume measurement is that an instrument with high accuracy specifically targeted to measure the chosen tracer gas will result in a uniform uncertainty across all dilution ratios (for a constant tracer concentration), whereas the uncertainty of the indirect method will increase with dilution ratio. Figure $3.3 \mathrm{~b}$ plots the relative uncertainties on a general species yield for the two methods at various dilution ratios and species yields. At low yields, the uncertainty grows exponentially as the 
concentration measured in the plume approaches the detection limit. Product dilution, as mentioned previously, has an important effect on the uncertainty of the indirect method across the range of species yields. For the direct method, product dilution has little effect at high yields until eventually the uncertainties rise as the measured concentrations of the emitted species being quantified approach the detection limit. Thus, at high species yields and/or low dilution ratios, the achievable relative uncertainty for the tracer injection method is approximately $1.35 \%$ lower than the carbon-balance method; at low species yields and/or high dilution ratios, the tracer injection method for quantifying species emissions can maintain this improved uncertainty until species detection limits are reached. In the case of $0.1 \mathrm{ppm}_{\mathrm{v}}$ bias error on the species of interest, the difference between the relative uncertainties of the two methods will increase (for a given yield/dilution ratio) making the tracer injection method preferable for quantifying species yields over this range.

\subsection{Demonstration Experiments and Comparison of Methodologies and Uncertainties}

Measurements utilizing the methods outlined above were taken in April 2014 at the Carleton University lab-scale flare facility. The facility features a modular burner centered under a large hexagonal exhaust hood (3.4 m included diameter), for which the entrance plane is $3.14 \mathrm{~m}$ above the floor beneath the burner. The exhaust hood connects to a $40.6 \mathrm{~cm}$ round steel duct which provides exhaust extraction using a variable speed fan capable of drawing $\sim 100,000$ SLPM. Sampling is conducted $10.6 \mathrm{~m}$ downstream through ports installed in the duct. Samples are drawn through heated sample lines to measurement instruments via vacuum pumps. The flare is operated such that all products 
of combustion are collected and diluted, which results in a minimum fixed operational exhaust fan setting for a given fuel mass flow rate. As such the dilution of the products is not directly controlled. Gas-phase analysis is accomplished using a MKS 2030 FTIR instrument which measures up to 20 species of interest simultaneously. Reported bias uncertainties for species of interest measured using the FTIR instrument are $0.15 \mathrm{ppm}_{\mathrm{v}}$, $0.10 \mathrm{ppm}_{\mathrm{v}}, 0.15 \mathrm{ppm}_{\mathrm{v}}, 0.30 \mathrm{ppm}_{\mathrm{v}}, 0.50 \mathrm{ppm}_{\mathrm{v}}$ and $0.05 \mathrm{ppm}_{\mathrm{v}}$ for $\mathrm{CO}, \mathrm{CH}_{4}, \mathrm{C}_{2} \mathrm{H}_{6}, \mathrm{C}_{3} \mathrm{H}_{8}, \mathrm{NO}$ and $\mathrm{NO}_{2}$ respectively. The tracer gas used in the tests presented was acetylene and measurement of the tracer gas was conducted with the same gas analyzer previously mentioned. As such, bias uncertainties on the measured tracer concentration was the greater of $2 \%$ or $0.3 \mathrm{ppm}_{\mathrm{v}}$. Soot volume fraction was continuously measured using an Artium LII 200 instrument, with an estimated bias uncertainty of $20 \%$. Four flare gas mass flow rates ranging from 0.488 to $2.15 \mathrm{~g} / \mathrm{s}$ were tested on a $38.1 \mathrm{~mm}$-diameter flare tip. The fuel was set to consist of $85.24 \%$ methane, $7.06 \%$ ethane, $3.11 \%$ propane, $1.44 \%$ butane, $1.91 \%$ carbon dioxide and $1.24 \%$ nitrogen, which is consistent with gas flared at battery sites in the upstream energy industry (Johnson and Coderre, 2012). Mass flow controllers were individually calibrated to have bias uncertainties averaging $\sim 1.33 \%$ of the set point. The relevant data to be examined in this paper are the uncertainties in measured combustion efficiency, soot yield, and various gas species emission rates. Each flare gas flow rate was tested at the maximum fan speed and exhaust flow rate to produce the highest possible dilution for the tested flaring rates. The numbered designations for each test, as well as the flare gas flow rate and dilution ratio are outlined in Table 3.2. 
Table 3.2: Experimental Operating Conditions

\begin{tabular}{|c|c|c|}
\hline $\begin{array}{c}\text { Test } \\
\text { Number }\end{array}$ & $\begin{array}{c}\text { Flare Gas Flow Rate } \\
\text { (grams/second) }\end{array}$ & Dilution Ratio \\
\hline 1 & 0.488 & 216 \\
\hline 2 & 0.878 & 110 \\
\hline 3 & 1.464 & 65 \\
\hline 4 & 2.147 & 40 \\
\hline
\end{tabular}

\subsubsection{Combustion Efficiency Measurements and Discussion}

Combustion efficiency has been evaluated using the mixed-phase carbon-balance method (Section 3.3.4) and the tracer injection method (Section 3.3.5). The uncertainties on the experimental results as seen in Figure 3.4a reflect the magnitudes suggested by the synthetic data in Figure 3.3a. The high precision of the carbon-balance method results from only trace emissions of non- $\mathrm{CO}_{2}$ carbon-based species relative to the produced $\mathrm{CO}_{2}$.

The much greater uncertainties of the tracer injection method result from the uncertainty on the measured concentrations of carbon dioxide and tracer gas in the diluted plume.
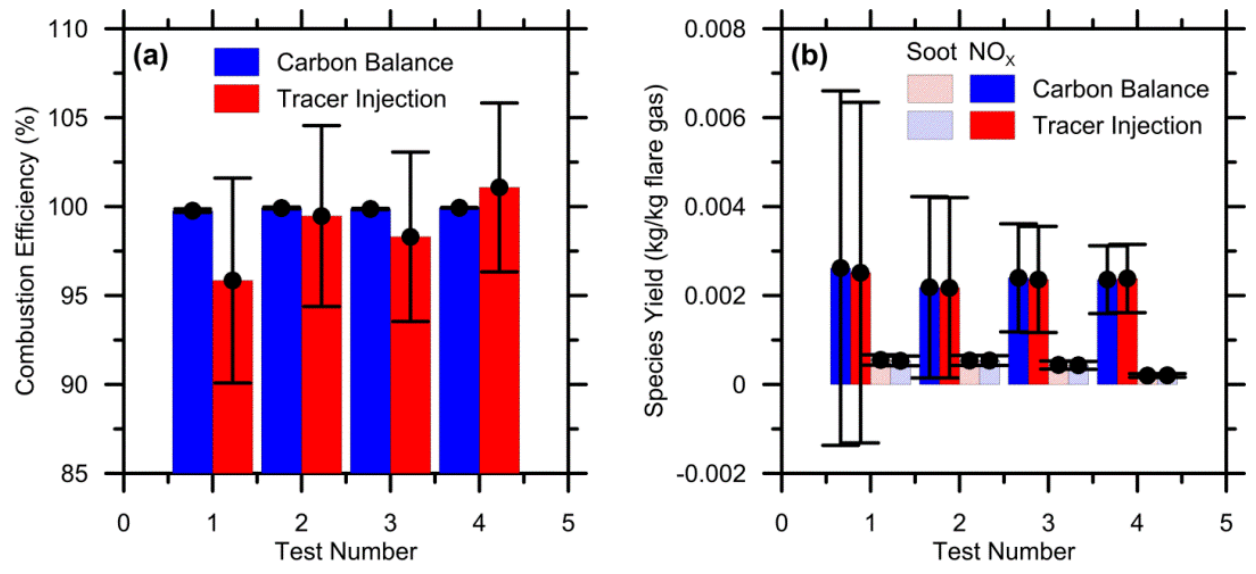

Figure 3.4: a) Combustion efficiency and uncertainties calculated using derived carbon-balance and tracer injection methods on a 1.5 inch flare over a range of flare gas flow rates. b) $\mathrm{NO}_{\mathrm{X}}$ and soot species yields and uncertainties calculated using derived carbon-balance and tracer injection methods on a 1.5 inch flare over a range of flare gas flow rates. Combustion efficiencies greater than $100 \%$ are not possible in practice and uncertainties extending beyond this threshold are mathematical artefacts from the uncertainty analysis. 


\subsubsection{Calculated Species Yields for Various Methods}

Species yields and the associated uncertainties have been evaluated for soot and $\mathrm{NO}_{\mathrm{X}}$ as plotted in Figure 3.4b. The species yields calculated with the carbon-balance and tracer injection methods agree to within $\sim 5 \%$ for a given test case and species. This discrepancy is insignificant compared to the uncertainties on the calculated yields. The relative uncertainty for a given test and species is slightly smaller for the tracer injection method when compared to the carbon-balance method, although the difference is limited by the ability to accurately measure the tracer gas with current instrumentation. The uncertainty in soot yield with either method is dominated by the $20 \%$ assumed bias on the measured soot volume fraction. For $\mathrm{NO}_{\mathrm{X}}$, the uncertainty is dominated by low plume concentrations relative to the species detection limit. The decreasing relative uncertainties from Test 1 to Test 4 are a result of decreasing dilution and therefore higher plume concentrations of relevant species. Combustion product dilution ranged from $\sim 216$ for Test 1 to $\sim 40$ for Test 4 . In the current experiment, all gas species including the tracer gas were measured using the same instrument (MKS 2030 FTIR Gas Analyzer). Future experiments may allow for the use of a device tailored specifically for measurement of the chosen tracer gas (e.g. cavity ring-down gas analyzers are readily available for the tracer (acetylene) used in the current experiment), which will result in reduced uncertainties for the tracer injection method.

\subsection{Conclusions}

Two complementary analytical approaches were developed for quantifying the combustion efficiency and species emission rates from gas flares represented as turbulent non-premixed flames. The first approach used a carbon-balance to link known flare gas 
variables to measureable gas-, or gas- and particulate-phase (soot) carbon emissions. The second method utilized a tracer gas injected into the diluted combustion plume to enable direct relation of measured species concentrations and emission rates. Detailed expressions were derived to enable quantitative evaluation of measurement uncertainties, and the accuracies of the methods were compared alongside other calculations in the literature over a wide range of potential scenarios. Experiments were also performed to further test and validate the derived methods. Analysis of results revealed that the carbon-balance approach generally provides much lower uncertainties when calculating combustion efficiency. However, for species yields, the experimental data suggest that both methods produce similar uncertainties using the current experimental instruments, and significantly improved uncertainties could be expected when using the tracer injection method with a high-precision analyzer specifically suited for measuring the chosen tracer gas.

\subsection{Acknowledgements}

The authors are grateful for the support of the Canadian Association of Petroleum Producers (CAPP), the Petroleum Technology Alliance of Canada (PTAC), Natural Resources Canada (NRCan) CanmetENERGY Devon, AB, the Texas Commission on

Environmental Quality (TCEQ) via Lamar UniFversity, and the Natural Sciences and Engineering Research Council of Canada (NSERC). 


\section{Chapter 4}

\section{Species Emissions, Combustion Efficiency and Flame Length Results}

\subsection{Summary of Experiments}

Measurement of combustion efficiency along with gas- and solid-phase species emission yields were completed for the test conditions presented in Table 4.1. Results for specific species including soot, $\mathrm{NO}_{\mathrm{X}}$, carbon monoxide and hydrocarbons are presented in Sections 4.2, 4.3, and Appendix B. All species emissions presented in these sections have been calculated using the carbon-balance method as outlined in Section 3.3.4 and are expressed as yields per unit flare gas. Combustion efficiencies calculated using gasphase species only, and with the inclusion of soot are presented in Section 4.4. The measured flame lengths for a limited number of conditions are presented in Appendix C. Combustion efficiencies and species yields have been measured for three pure flare gases (methane, ethylene and propane) as well as two methane-based flare gas mixtures (AVG 6-Mix and HVY 4-Mix) as defined in Section 2.3 previously. Ethylene and propane tests were performed on a single burner diameter (50.8 mm ID). Methane and AVG 6-Mix tests were performed on two burner diameters (50.8 and 76.2 mm ID) and HVY 4-Mix tests were performed on three burner diameters (38.1, 50.8 and $76.2 \mathrm{~mm} \mathrm{ID).} \mathrm{Exit}$ velocities of the tests ranged from 0.1 to $3.2 \mathrm{~m} / \mathrm{s}$ calculated at standard exit conditions (273.15 Kelvin and $1 \mathrm{~atm}$ ). Prior to presentation and discussion of specific results, a 
comparison of the carbon-balance and tracer-injection methods for measuring the soot yield is presented in Figure 4.1.

Table 4.1 - Summary of test conditions showing range of fuel mixtures tested at different exit velocity and burner diameter combinations

\begin{tabular}{|c|c|c|c|c|c|c|c|c|c|}
\hline \multirow{2}{*}{$\begin{array}{c}\text { Burner } \\
\text { Diameter } \\
(\mathrm{mm})\end{array}$} & \multicolumn{9}{|c|}{ Target Exit Velocity $(\mathrm{m} / \mathrm{s})$} \\
\hline & 0.1 & 0.25 & 0.5 & 0.8 & 0.9 & 1.5 & 1.85 & 2.2 & 3.2 \\
\hline 38.1 & & & $\mathrm{HVY} 4^{\mathrm{a}}$ & & HVY 4 & HVY 4 & & HVY 4 & HVY 4 \\
\hline 50.8 & $\mathrm{C}_{3} \mathrm{H}_{8}$ & $\begin{array}{l}\text { AVG } 6^{\mathrm{b}} \\
\mathrm{HVY} 4 \\
\mathrm{C}_{2} \mathrm{H}_{4} \\
\mathrm{C}_{3} \mathrm{H}_{8}\end{array}$ & $\begin{array}{l}\text { AVG } 6 \\
\mathrm{HVY} 4 \\
\mathrm{CH}_{4} \\
\mathrm{C}_{2} \mathrm{H}_{4} \\
\mathrm{C}_{3} \mathrm{H}_{8}\end{array}$ & & $\begin{array}{l}\text { AVG } 6 \\
\mathrm{HVY} 4 \\
\mathrm{CH}_{4} \\
\mathrm{C}_{2} \mathrm{H}_{4} \\
\mathrm{C}_{3} \mathrm{H}_{8}\end{array}$ & $\begin{array}{l}\text { AVG } 6 \\
\mathrm{HVY} 4 \\
\mathrm{CH}_{4} \\
\mathrm{C}_{2} \mathrm{H}_{4}\end{array}$ & HVY 4 & AVG 6 & \\
\hline 76.2 & $\begin{array}{l}\text { AVG } 6 \\
\text { HVY } 4\end{array}$ & $\begin{array}{l}\text { AVG } 6 \\
\text { HVY } 4 \\
\mathrm{CH}_{4}\end{array}$ & $\begin{array}{l}\text { AVG } 6 \\
\mathrm{HVY} 4 \\
\mathrm{CH}_{4}\end{array}$ & HVY 4 & $\begin{array}{l}\text { AVG } 6 \\
\text { HVY } 4 \\
\mathrm{CH}_{4}\end{array}$ & AVG 6 & & & \\
\hline
\end{tabular}

${ }^{\mathrm{a}}$ Heavy 4-Mix flare gas

${ }^{\mathrm{b}}$ Average 6-Mix flare gas

For a limited number of test cases, measurements were made utilizing acetylene as an injected tracer gas to allow concurrent measurement of the duct flow rate and species emission rates using the tracer-injection method as described in Section 3.3.5. Figure 4.1 presents the soot yields for the Heavy 4-Mix, ethylene, and propane tests calculated using both the tracer-injection and carbon-balance methods. The agreement between the methods was within $11.49 \%$ (well within the experimental error bars shown on the figure) for tests with fan settings between $50 \%$ and $100 \%$ corresponding to duct flow rates between 41,000 and 97,000 ALPM. 


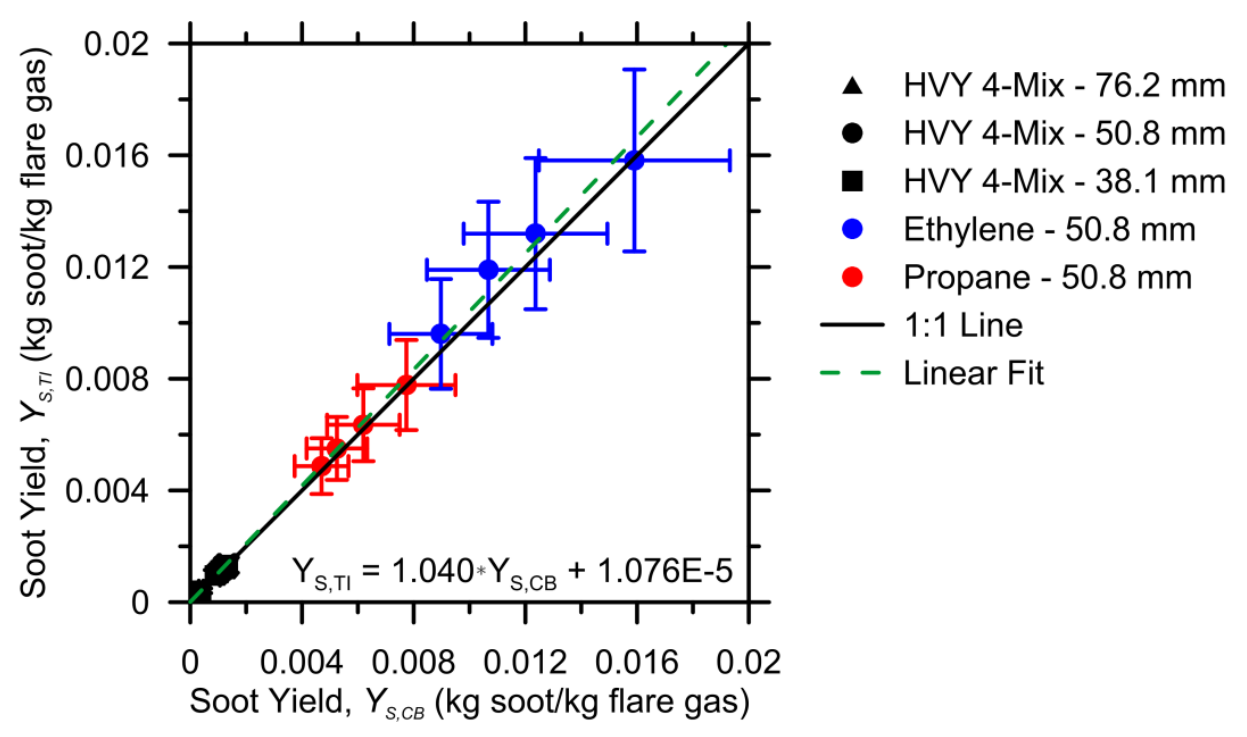

Figure 4.1: Comparison of soot yield calculated with the carbon-balance and tracer-
injected methods for HVY 4-Mix, ethylene, and propane flare gases.

Experiments at the test conditions outlined in Table 4.1 were performed between one and four times. While ideally all experiments would have been repeated multiple times, this was not possible in practice due to the time and fuel costs to run experiments, especially at the larger flow rate conditions. Thus, precision error cannot be calculated on the subset of experiments performed only once. Additionally, experiments performed only twice would require a large t-value (12.71) for the calculation of precision error. As such, all uncertainties represented in the following sections will represent bias only. To justify this presentation, Figure 4.2 shows the relative uncertainty in terms of bias only and total (precision and bias) uncertainties on measured soot yield for cases where measurements were made either three or four times. Index numbers 1-4 correspond to the test conditions of $0.9 \mathrm{~m} / \mathrm{s}$ on the $38.1 \mathrm{~mm}$ burner, 0.25 and $0.5 \mathrm{~m} / \mathrm{s}$ on the $50.8 \mathrm{~mm}$ burner and $0.25 \mathrm{~m} / \mathrm{s}$ on the $76.2 \mathrm{~mm}$ burner for the HVY 4-Mix flare gas which were each repeated four times each. Index numbers 5-9 correspond to the test conditions of 0.9 and $1.5 \mathrm{~m} / \mathrm{s}$ on the $50.8 \mathrm{~mm}$ burner, 0.1 and $0.5 \mathrm{~m} / \mathrm{s}$ on the $76.2 \mathrm{~mm}$ burner all for the 
HVY 6-Mix flare gas, and $0.1 \mathrm{~m} / \mathrm{s}$ on the $76.2 \mathrm{~mm}$ burner for the AVG 6-Mix flare gas, which were each repeated three times each. The relative bias uncertainties on soot yield for these cases ranged from $20.76-21.10 \%$ whereas the total relative uncertainties (i.e. including both bias and precision uncertainties) ranged from $23.46-34.02 \%$.

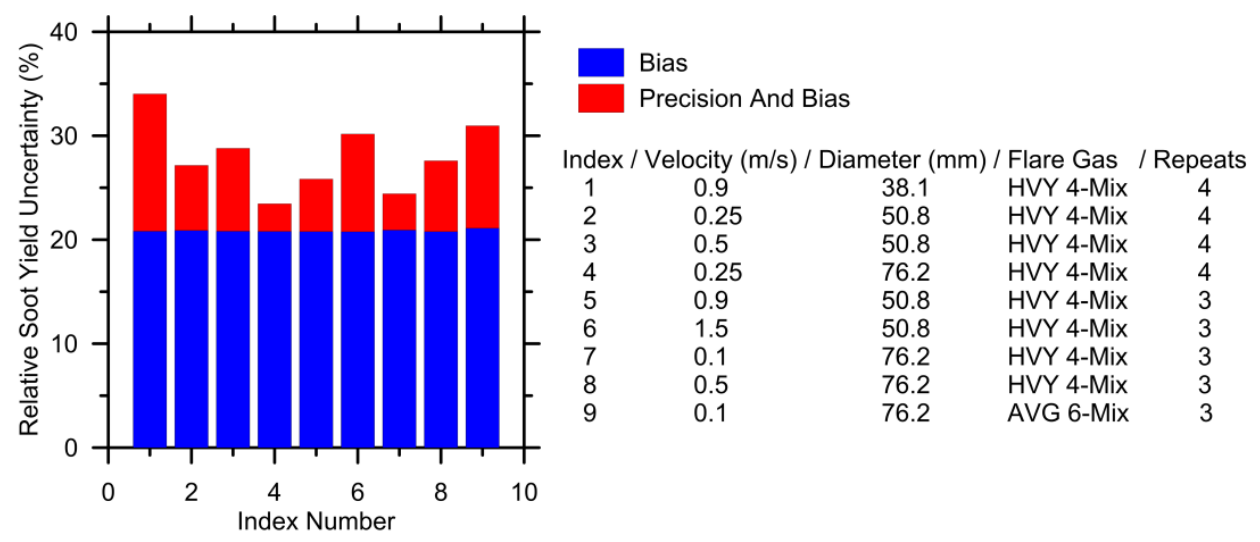

Figure 4.2: Comparison of bias and total (precision and bias) relative uncertainty on measured soot yield for test cases with three and four experimental repeats.

\subsection{Soot Yield Results, Analysis and Discussion}

Figure 4.3 presents the soot yields calculated using the carbon-balance method for pure methane and the two methane-based flare gas-mixtures. It is apparent from the data that the addition of heavier hydrocarbons (ethane, propane and butane) to a primarily methane-based flare gas dramatically affects the measured soot yield. The average soot yield for all of the AVG 6-Mix flare gas tests is 6.0 times higher than the average soot yield for all of the pure methane test cases. The average soot yield for all HVY 4-Mix tests is an additional 2.4 times higher than the average for all AVG 6-Mix flare gas tests. It is noted at this time that while soot yield does vary with flow rate and burner diameter as evident in Figure 4.3, the effect of either parameter appears less dramatic than changes 
in flare gas composition. This is further evidenced in Figure 4.4. The effects of flow rate and burner diameter are separately discussed in Section 4.2.1.

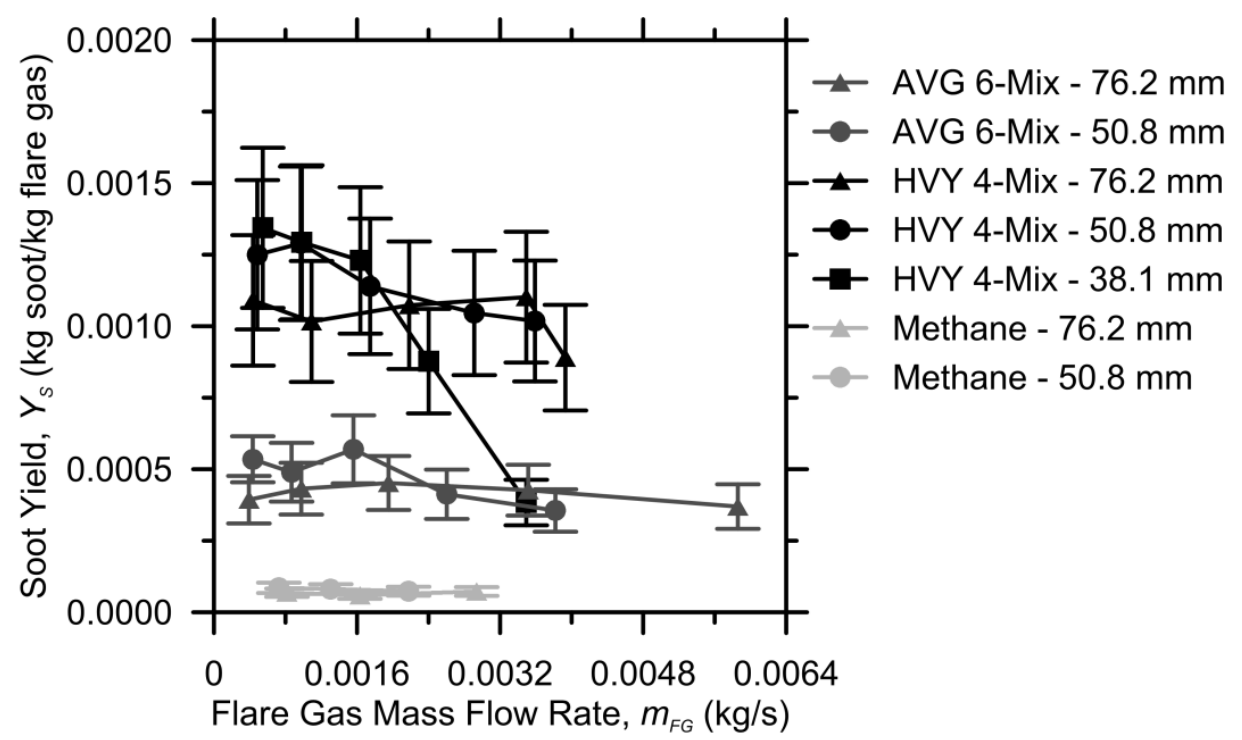

\section{Figure 4.3: Soot yield calculated using the carbon-balance method for the 38.1, 50.8 and 76.2 mm burners with AVG 6-Mix, HVY 4-Mix and methane flare gas mixtures.}

Figure 4.4 plots the $50.8 \mathrm{~mm}$ burner data for the AVG 6-Mix, HVY 4-Mix and methane flare gases along with the results for ethylene and propane tests also on the $50.8 \mathrm{~mm}$ burner. Both ethylene and propane display clear decreasing trends in soot yield as the flare gas mass flow rate is increased. More importantly, both ethylene and propane yield far greater amounts of soot than the methane-based or pure methane flare gases. The average soot yield of all propane tests is 5.6 and 81.4 times higher than the average soot yield of all HVY 4-Mix and all pure methane flare gases respectively, while average soot yields of all ethylene tests are 11.2 and 163.2 times higher respectively. Figure 4.4b displays the soot yields for all flare gases on the $50.8 \mathrm{~mm}$ burner on a per flare gas carbon mass basis instead of a per flare gas mass basis in an attempt to collapse the data and account for differences in flare gas chemistry. The flare gases increase in carbon density 
from approximately 74 to $86 \%$ in the same order as increasing soot yield with the exception of the AVG 6-Mix, which has a lower carbon density than methane due to the presence of diluents. It is clear that the differences in carbon density are not large enough to collapse the differences in soot yields among the different flare gases, which in some cases can range by orders of magnitude.
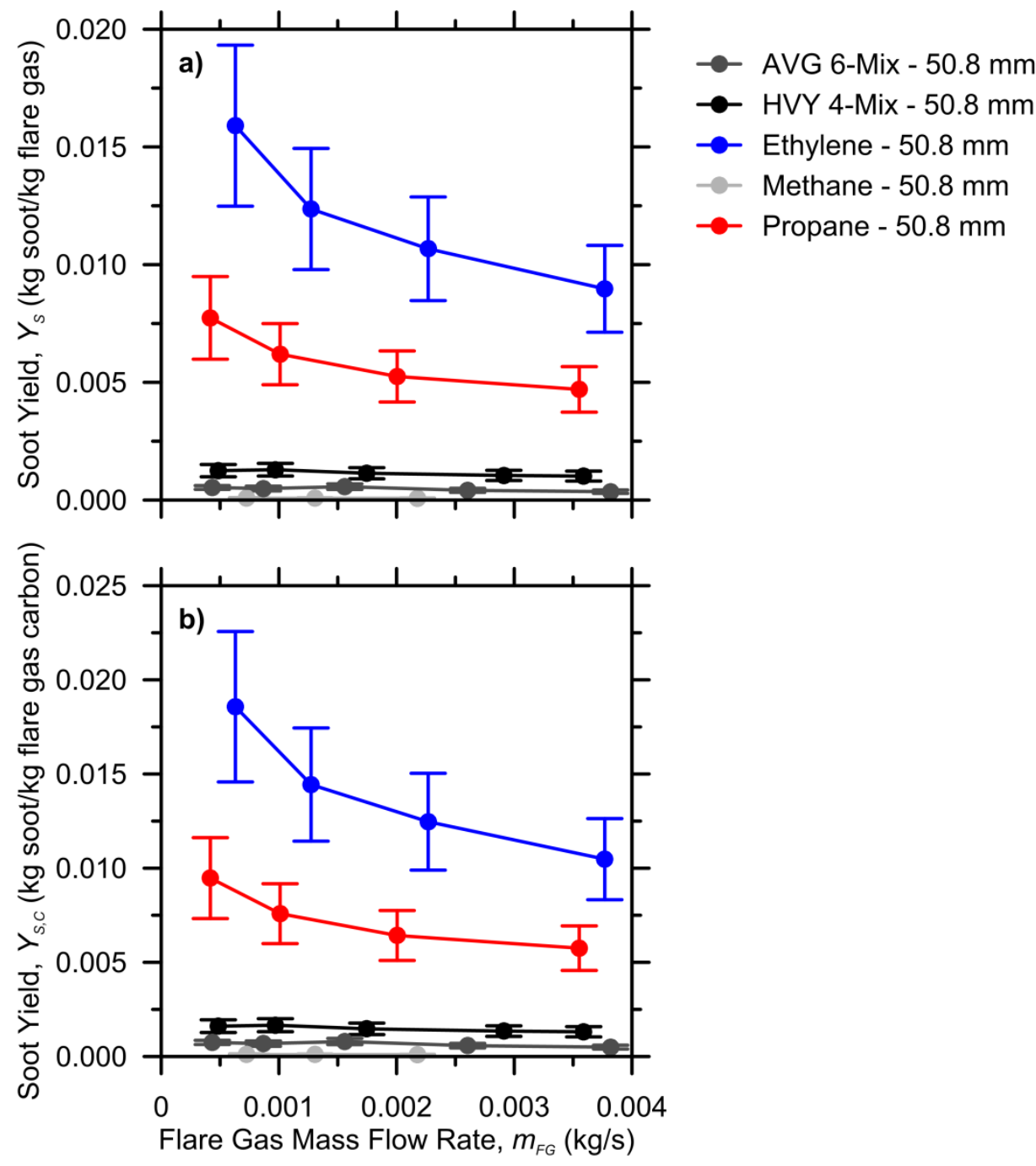

Figure 4.4: Soot yield on a a) per flare gas mass and b) per flare gas carbon mass basis calculated using the carbon balance method for the $50.8 \mathrm{~mm}$ burner with AVG 6-Mix, HVY 4-Mix, ethylene, methane and propane flare gas mixtures. 


\subsubsection{Potential Effects of Varying Flow Regimes}

While no observable trends are apparent in the pure methane data, there is a clear decrease in soot yield with increasing flow rate for the HVY 4-Mix tests on the $38.1 \mathrm{~mm}$ burner, as seen in Figure 4.3. As noted previously, similar declines in soot yield with increasing flow rate were observed for the ethylene and propane flare gases, as shown in Figure 4.4. Less definite decreases in soot yield are also discernable as the flare gas mass flow rate increases for AVG 6-Mix and HVY 4-Mix tests on the $50.8 \mathrm{~mm}$ burner. However, the data for both the AVG 6-Mix and HVY 4-Mix flare gases on the $76.2 \mathrm{~mm}$ burner present no clear trend.

As discussed in Section 1.3, Delichatsios (1993) proposed a regime map for nonpremixed diffusion flames scaled by Reynolds number $(R e)$ and a Global Fire Froude number $\left(F r_{g}\right)$ as defined by Eq. (1.1) and Eq. (1.2). Figure 4.5 shows the operating conditions for the current data plotted on the non-dimensional map. The current soot yield data span the "transition buoyant" and "transition shear" regimes defined by the solid diagonal line, as well as the transition from laminar to turbulent pipe flow as defined by the horizontal dashed line (Reynolds number of 4000). 


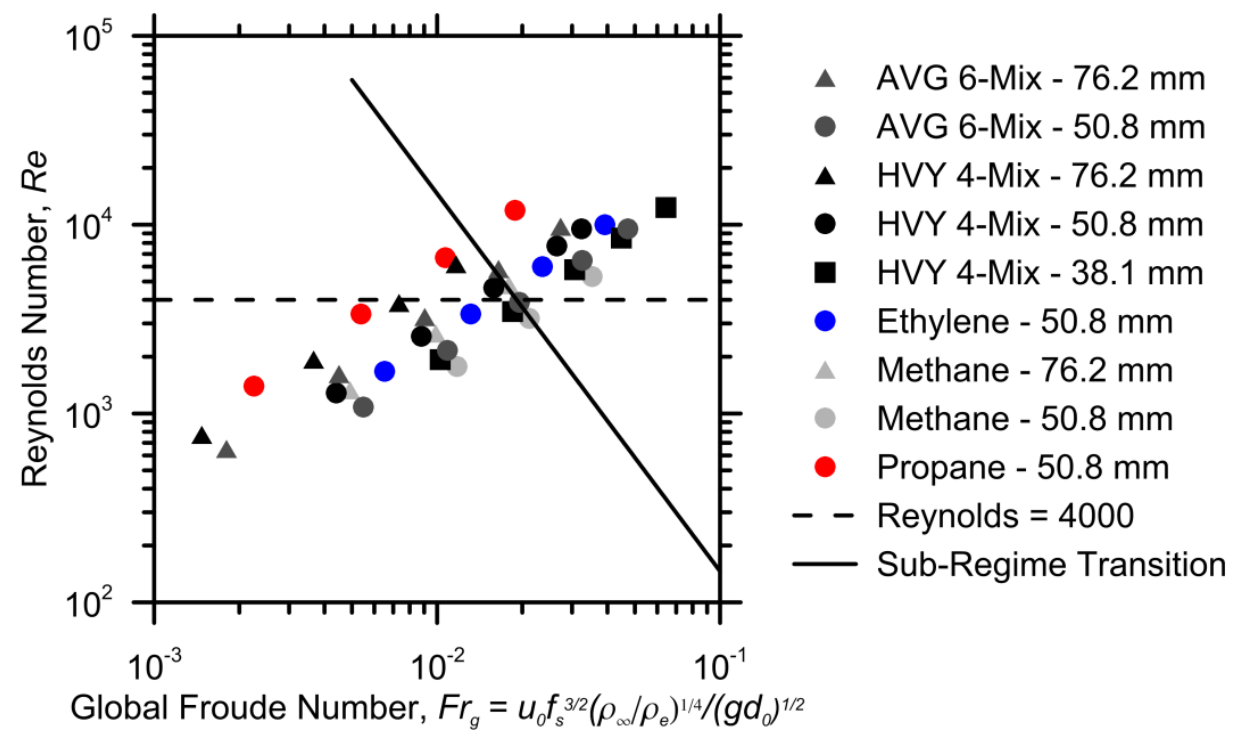

\section{Figure 4.5: Flare exit conditions for 38.1, 50.8 and 76.2 $\mathrm{mm}$ burners with AVG 6- Mix, HVY 4-Mix, ethylene, methane and propane flare gas mixtures.}

The potential implications of the "transition buoyant" and "transition shear" regime transition as defined by Delichatsios (1993) on measured soot yield are considered in Figure 4.6. To allow comparison on a single plot, the soot yield for each test has been normalized by the maximum soot yield for that respective flare gas and burner diameter combination. Figure 4.6a and Figure 4.6b plot this normalized soot yield against the Fire Froude $\left(F r_{f}\right)$ and Global Froude $\left(F r_{g}\right)$ numbers as defined by Eq. (1.3) and Eq. (1.2). Figure 4.6c and Figure 4.6d plot the normalized soot yield against Reynolds number and a parameter $\left(R e \cdot F r_{g}{ }^{2}\right)$ resulting from the definition of the solid diagonal transition line defined in Figure 4.5. The dashed vertical line in Figure 4.6c represents the transition from laminar to turbulent pipe flow $(R e=4000)$ and the solid vertical line in Figure 4.6d represents the transition-buoyant to transition-shear regime transition (Delichatsios, 1993) in terms of $R e \cdot F r_{g}{ }^{2}$. Plotted against any of the parameters represented in Figure 4.6, it is clear that the normalized soot yield for many flare gas and burner diameter combinations generally decreases as Fire Froude number, Global Froude 
number, Reynolds number, and the $R e \cdot F r_{g}{ }^{2}$ parameter are increased for a given flare gas and burner diameter combination.
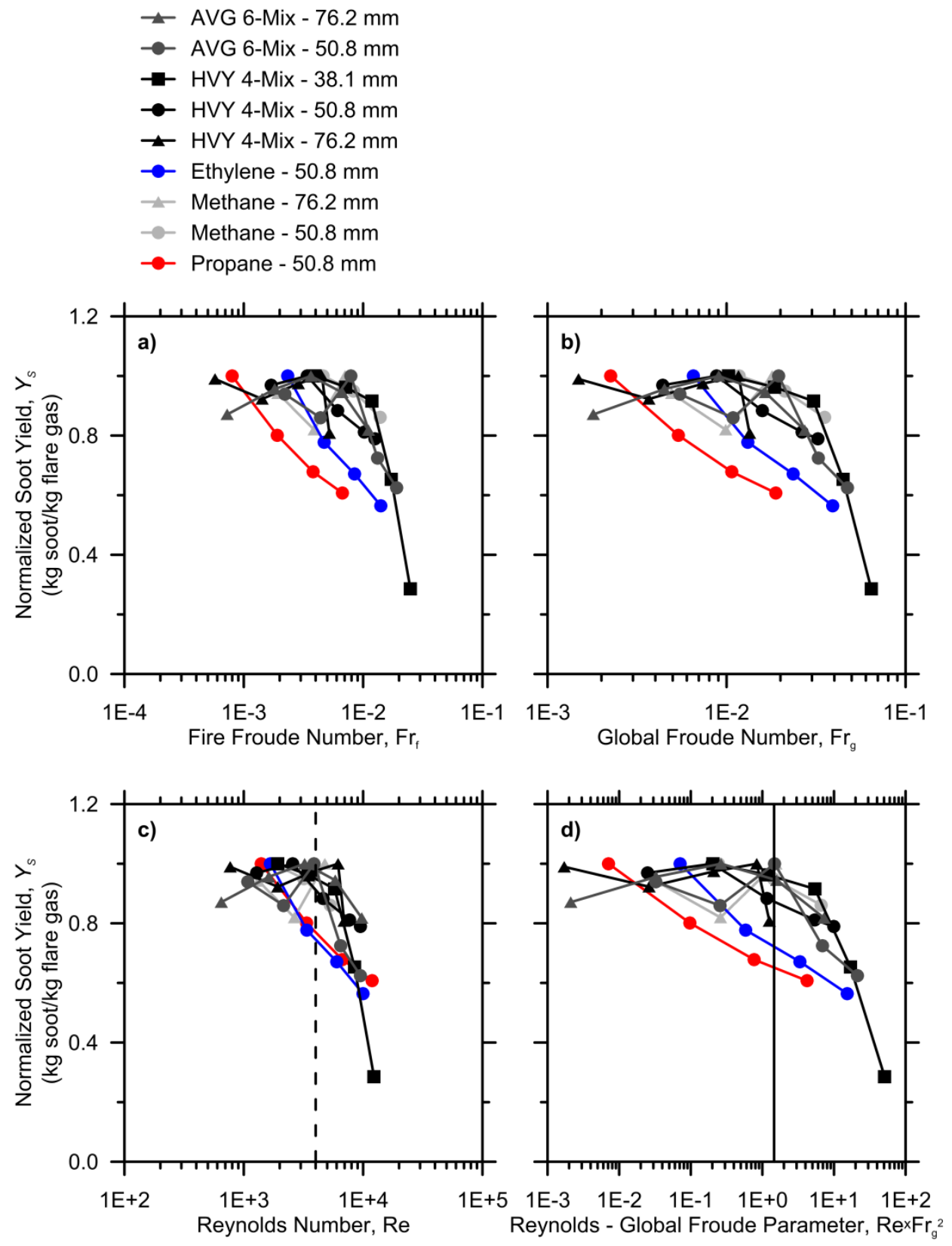

Figure 4.6: Soot yield normalized by the maximum yield for a given flare gas and burner diameter plotted against the a) Fire and b) Global Froude numbers, as well as c) Reynolds number and d) a Reynolds-Global Froude parameter for 38.1, 50.8 and 76.2 mm burners with AVG 6-Mix, HVY 4-Mix, ethylene, methane and propane

flare gas mixtures. Possible transition lines of $(\operatorname{Re}=4000)$ and $\left(\operatorname{Re} \cdot \mathrm{Fr}_{\mathrm{g}}{ }^{2}=1.46\right)$ shown in c) and d) as dashed and solid vertical lines respectively. 
Figure 4.7 examines more closely the transition points for Reynolds number and the $R e \cdot \mathrm{Fr}_{g}{ }^{2}$ parameter shown in Figure 4.6c and Figure 4.6d respectively. Figure 4.7a and Figure $4.7 \mathrm{~b}$ separate the normalized soot yields at a Reynolds number value of 4000 . Whereas the data in Figure 4.7a display no clear trend, in Figure 4.7b there are decreases in the soot yield for all flare gas species and burner diameters as Reynolds number increases. Figure $4.7 \mathrm{~b}$ does not include pure methane flare gas cases as only a single test condition for each burner diameter exceeded a Reynolds number of 4000. Similarly, Figure $4.7 \mathrm{c}$ and Figure $4.7 \mathrm{~d}$ separate the data at the transition point of $\operatorname{Re} \cdot \mathrm{Fr}_{g}{ }^{2}=1.46$. Again there is a mix of increases, decreases and general flatness in the normalized soot yields for values less than 1.46 as shown in Figure 4.7c, whereas all test conditions for $R e \cdot F r_{g}{ }^{2}$ values greater than 1.46 display decreases in soot yield as the $R e \cdot F r_{g}{ }^{2}$ parameter increases. Only single test conditions for the HVY 4-Mix flare gas on the $76.2 \mathrm{~mm}$ burner, pure methane on the 76.2 and $50.8 \mathrm{~mm}$ burners and propane on the $50.8 \mathrm{~mm}$ burner exceeded a $R e \cdot F r_{g}{ }^{2}$ value of 1.46 , thus these data do not appear in Figure 4.7d. 

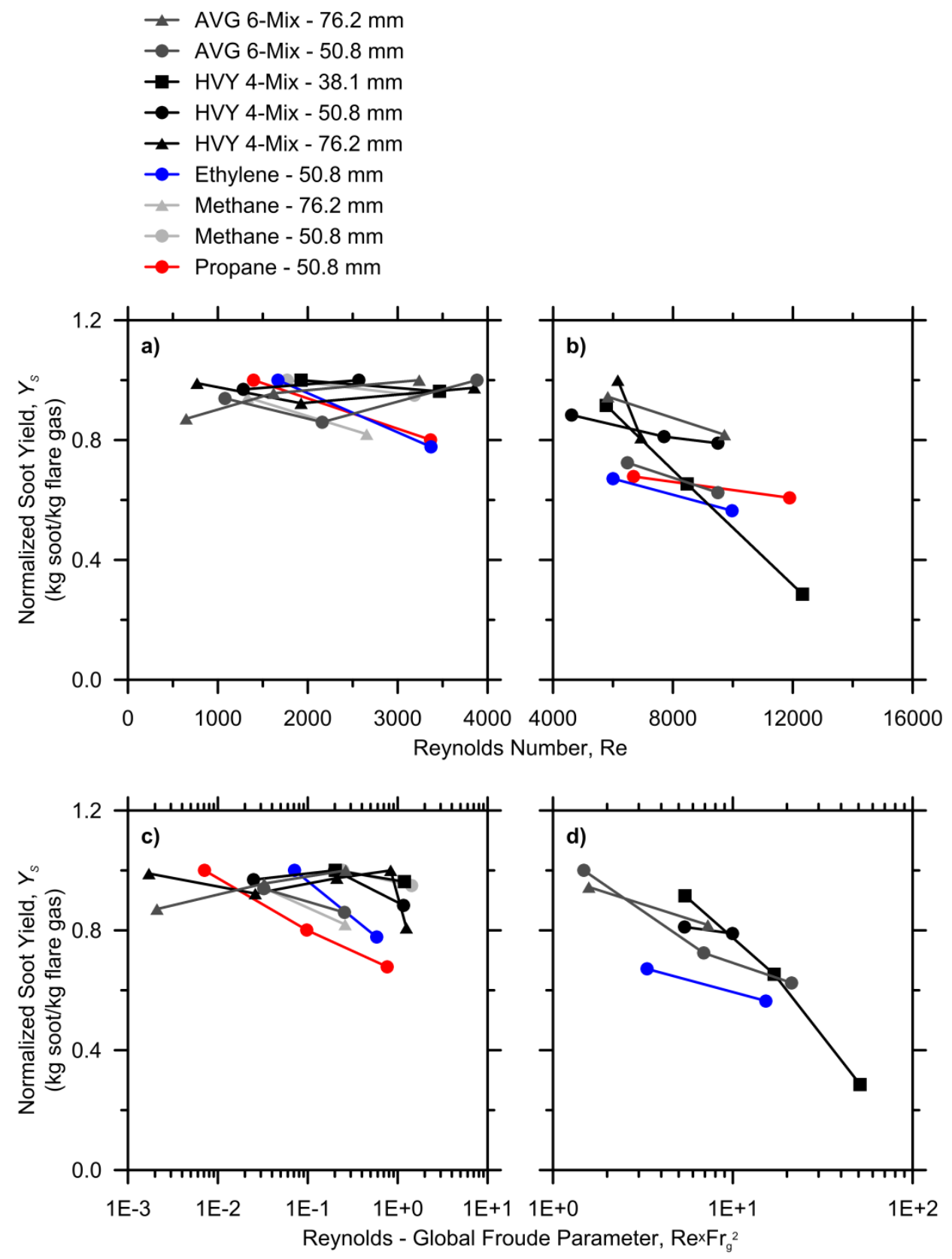

Figure 4.7: Soot yield normalized by the maximum yield for a given flare gas and burner diameter plotted against Reynolds numbers a) less than and b) greater than 4000, as well as Reynolds-Global Froude parameter values c) less than and d) greater than 1.46 for 38.1, 50.8 and $76.2 \mathrm{~mm}$ burners with AVG 6-Mix, HVY 4-Mix, ethylene, methane and propane flare gas mixtures.

\subsubsection{Scaling of Soot Emissions with Heating Value}

Certain particulate matter emission factors in the literature (e.g. the CAPP recommended emission factor for NPRI reporting outlined in Section 1.2.1, Table 1.1) attempt to 
account for varying flare gas compositions by scaling single-valued factors according to the heating value of the flare gas. As explained by McEwen and Johnson (McEwen and Johnson, 2012),

"The CAPP guide instead gives a value of $2.5632 \mathrm{~kg}$ soot per $10^{3} \mathrm{~m}^{3}$ of fuel and notes that the US EPA value has been "corrected" for a gas with a heating value of $45 \mathrm{MJ} / \mathrm{m}^{3}$. The CAPP guide does not specify how this apparent factor of 3 correction was derived, although it likely resulted from an assumed linear scaling of soot emission with heating value, since landfill gas could be expected to have a heating value on the order of $15 \mathrm{MJ} / \mathrm{m}^{3}$, and a heating value of $45 \mathrm{MJ} / \mathrm{m}^{3}$ should be typical of flare gas in the UOG industry."

Figure 4.8a investigates the appropriateness of scaling soot yield data with heating value based on the present measured data for varying flare gas compositions. The data suggest that scaling soot yield by volumetric heating value may be valid for the pure alkane (methane and propane) and alkane-based flare gas mixtures (AVG 6-Mix and HVY 4-Mix) tested, however it is not at all valid when flare gases with other chemical structures, such as the alkene ethylene, are considered.

McEwen (2010) suggested that for measured soot yield data of alkane flare gas mixtures on flares $38.1 \mathrm{~mm}$ or greater in diameter, and with Fire Froude numbers greater than 0.003 , the soot yield may scale simply with heating value. These criteria were suggested based on available data implying a soot yield plateauing beyond this threshold, although the limitations of the experimental facility used by McEwen (2010) precluded testing in this range. The current experimental facility permitted higher flare gas flow rates on the 50.8 and $76.2 \mathrm{~mm}$ diameter flares than the experiments of McEwen (2010). In contrast to the supposition of McEwen (2010), the current soot yield data as plotted against Fire Froude number in Figure 4.6a suggest that soot yield generally decreases 
with increasing Fire Froude number beyond a value of 0.003 after having previously reached a maximum.

Figure $4.8 \mathrm{~b}$ displays the maximum soot yield for each burner diameter tested on alkane flare gases from the current work along with a linear fit to these data. Selecting the maximum soot yield for a given burner and flare gas combination presents an upper bound on the soot yield which can then be applied across a range of volumetric heating values. This suggested upper bound for soot yield scaled with the flare gas volumetric heating value is compared to the fit suggested by McEwen (McEwen, 2010). The linear scaling from that work was fit for data on 38.1, 50.8 and $76.2 \mathrm{~mm}$ diameter burners with Fire Froude numbers greater than 0.003 and with volumetric heating values of 38$47 \mathrm{MJ} / \mathrm{m}^{3}$. The current data not only extends the range of volumetric heating values over which there is soot yield data for alkane flare gases available but also suggests that the increase of soot yield with respect to volumetric heating value may be steeper than previously shown. 

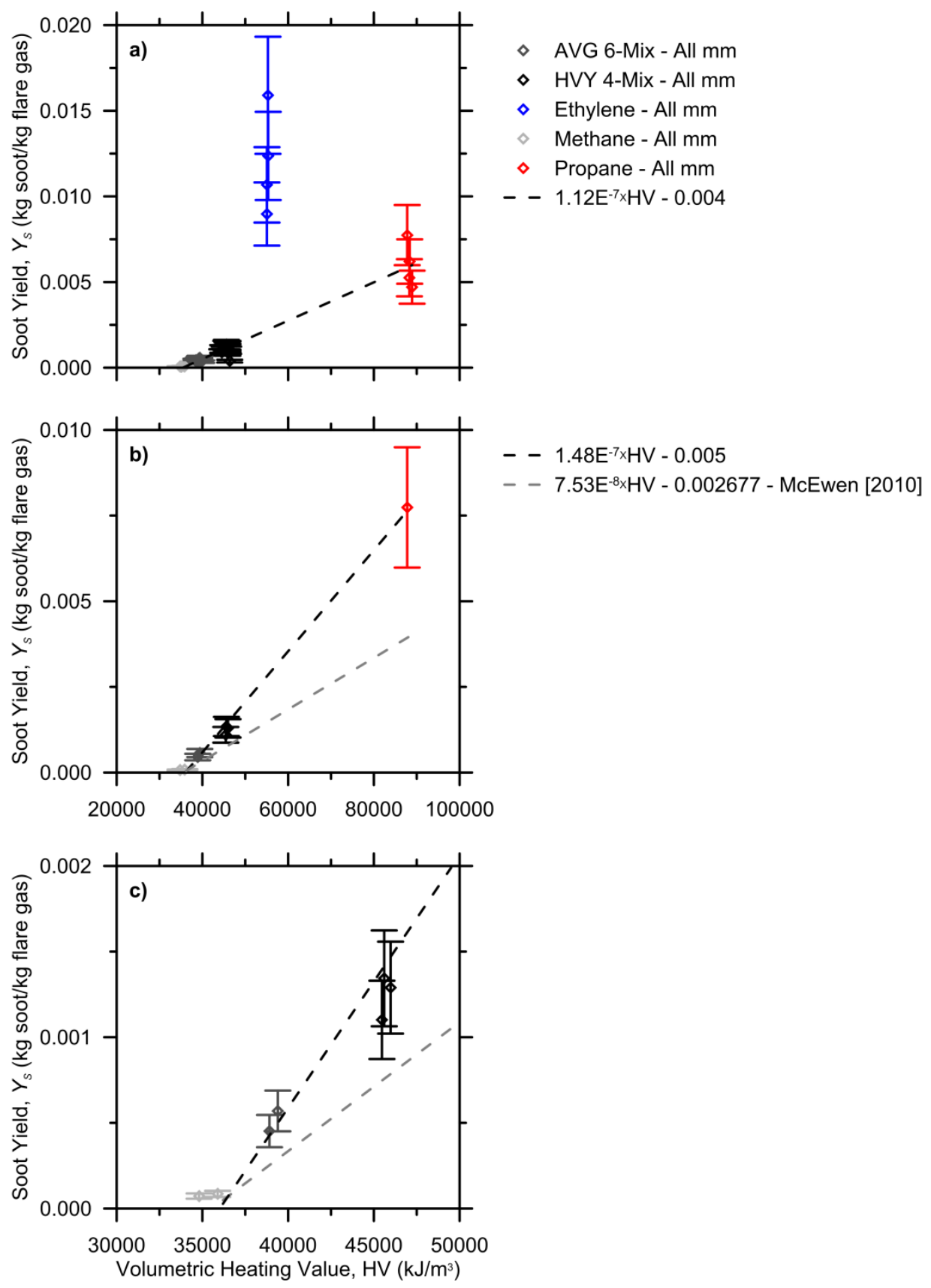

Figure 4.8: Soot yield calculated using the carbon balance method and plotted against volumetric heating value (HV) for (a) AVG 6-Mix, HVY 4-Mix, ethylene, methane and propane flare gases and 38.1, 50.8 and $76.2 \mathrm{~mm}$ burners; and (b) the maximum soot yield for a flare gas and burner diameter combination for alkanebased flare gases (AVG 6-Mix, HVY 4-Mix, methane and propane) and 38.1, 50.8 and $76.2 \mathrm{~mm}$ burners. Panel (c) is a zoomed image of panel (b) to better illustrate the correlation with the data for the methane-based flare gases only. 


\subsubsection{Comparison of present Soot Yield data with Current Emission Factors}

Figure 4.9 superimposes various particulate matter emission factors from the literature (see Section 1.2.1) on the soot yield data from the $50.8 \mathrm{~mm}$ diameter burner for all flare gases tested. In Figure 4.9a, the range of current soot emission factors is presented as the shaded grey region, where the upper limit of the range corresponds to the AP 42 Section 13.5 value of $0.0034 \mathrm{~kg} / \mathrm{kg}$-flare-gas for the "heavily smoking" case, and the lower limit of $0 \mathrm{~kg} / \mathrm{kg}$-flare-gas corresponds to the AP 42 Section 13.5 "non-smoking" case. It is clear that the range of soot emission factors after being converted to soot yield on a mass basis extends only as high as the minimum soot yield measured for the propane flare gas, while falling well below the soot yields measured for the ethylene flare gas. The conversion of emission factors to common yield units expressed per mass of flare gas was accomplished assuming a standard flare gas density of $0.85 \mathrm{~kg} / \mathrm{m}^{3}$ except in the case of the AP 42 Section 13.5 data (which is presented in terms of measured plume concentrations). The emission factors reported in AP 42 Section 13.5 were converted following the procedure outlined in McEwen (2010) with corrections for a flare gas composition of crude propylene ( $80 \%$ propylene and $20 \%$ propane) in lieu of $100 \%$ propylene. The various smoke levels attributed to this source have been converted from per volume to per mass basis based on the density of crude propylene at standard conditions. As suggested by McEwen (2010), these factors represent a minimum soot yield for the smoking conditions as dilution of the sample was unknown and an undiluted sample was assumed.

Figure $4.9 \mathrm{~b}$ shows the various emission factors along with data for the pure methane, pure propane, and methane-based flare gas mixtures. It is interesting that many 
currently available emission factors (i.e. AP 42 Section 13.5 "heavily smoking" and “average smoking”, CAPP, ARPEL Sweet/Sour/Steam-Assisted, EEA, Villasenor) lie in the region between the methane-based and pure-propane flare gases. This may suggest that these emission factors were based on flare gas compositions containing more heavy hydrocarbons than the methane-based flare gases of the current work. However, the difference in the case of the AP 42 emission factors, the values also reflect necessary assumptions to convert concentration-based emission factors into yield units. The lower cluster of emission factors (WebFIRE, NAEI, AP 42 Section 13.5 "light smoking", AP 42 Section 2.4) which are presented for methane, upstream gas production related flaring, light smoking crude propylene, and landfill waste gas respectively present values that are in line with the measured soot yields for the AVG 6-Mix and HVY 4-Mix flare gases which range from $\sim 74 \%$ to $\sim 85 \%$ methane by volume.

Of particular interest is the CAPP emission factor, which is suggested for use in the Alberta upstream oil and gas industry for flare gases with a nominal heating value of $45 \mathrm{MJ} / \mathrm{m}^{3}$. When converted to a per mass basis as specified in Table 1.1 and shown in Figure $4.9 \mathrm{~b}$, the CAPP factor predicts a soot yield value much higher than those measured in the current work for methane-based flare gases with heating values in the range of $39-51 \mathrm{MJ} / \mathrm{m}^{3}$. This suggests that the derivation of the CAPP factor from the confidential US EPA (1991) report and the application of this factor to flares in the upstream energy industry with nominal heating value of $45 \mathrm{MJ} / \mathrm{m}^{3}$ is questionable. 


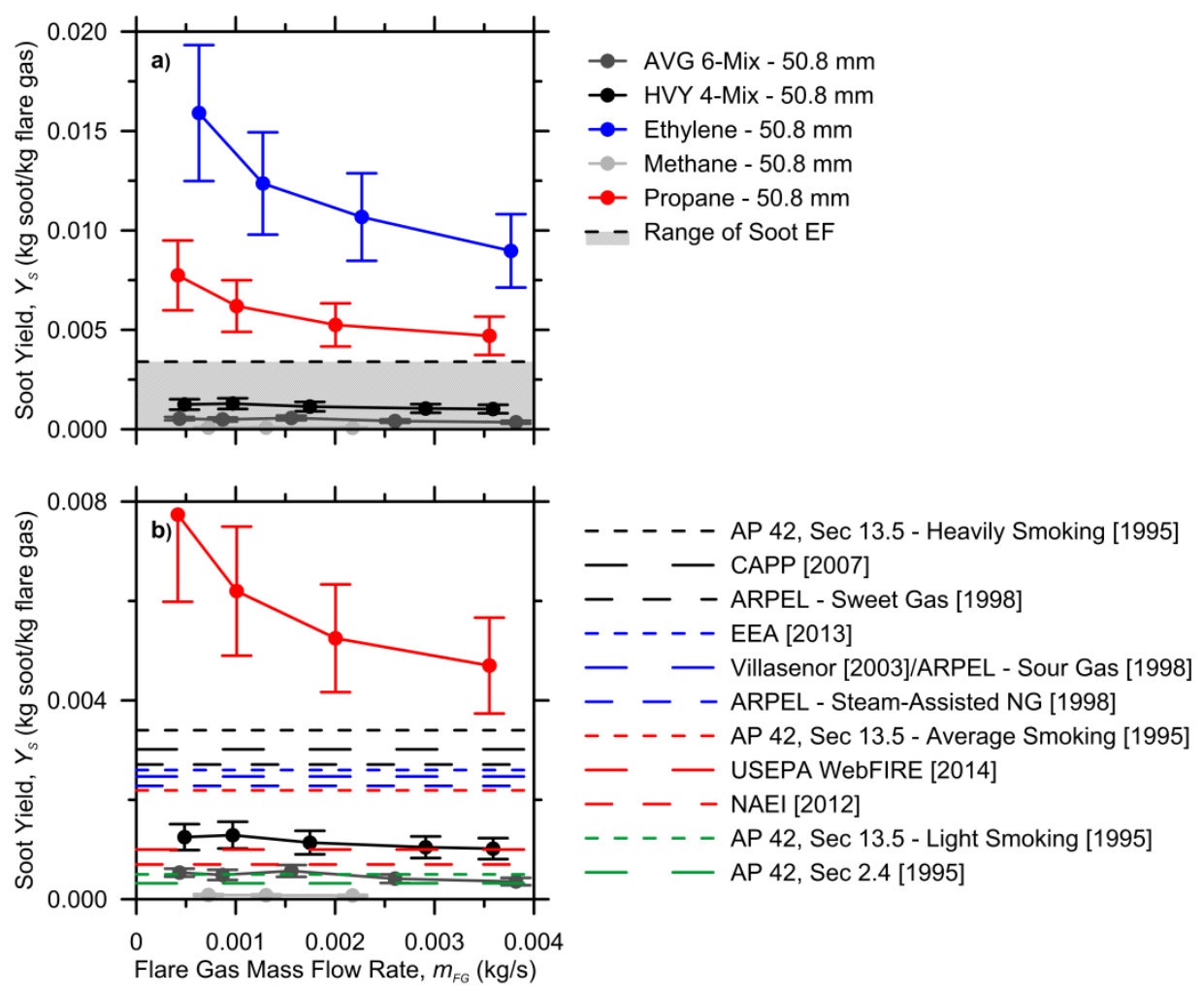

Figure 4.9: Soot yield calculated using the carbon balance method for the $50.8 \mathrm{~mm}$ burner with AVG 6-Mix, HVY 4-Mix, ethylene, methane and propane flare gas mixtures showing a) a shaded area encompassing the range of soot emission factors and b) with specific emission factors from the literature.

\subsection{NOx Yield Results, Analysis and Discussion}

The measured $\mathrm{NO}_{\mathrm{X}}$ yields for all flare gases and burner diameters are presented in Figure 4.10a,b,c on a per flare gas mass, volume, and energy content basis. The data suggest that $\mathrm{NO}_{\mathrm{X}}$ has a relatively constant yield for a given flare gas irrespective of burner diameter or the flare gas mass flow rate, which follows the idea that formation of $\mathrm{NO}_{\mathrm{X}}$ is primarily driven by the flame temperature. The $\mathrm{NO}_{\mathrm{X}}$ yield evaluated per unit mass of flare gas as shown in Figure 4.10a, or per unit energy content of flare gas adjusted by the higher heating value as shown in Figure 4.10c, collapse the data for different flare gases into a narrow range of yield values (1.36-2.34 g-NO $/ \mathrm{kg}$-flare-gas and 26.7-45.9 $\mathrm{g}$ $\mathrm{NO}_{\mathrm{X}} / 10^{9} \mathrm{~J}$-flare gas). Evaluating the $\mathrm{NO}_{\mathrm{X}}$ yield on a per volume basis adjusted for the 
density of the flare gas as in Figure $4.10 \mathrm{~b}$ expands the range of yield values (1.05$3.15 \mathrm{~kg} / 10^{3} \mathrm{~m}^{3}$-flare-gas) and suggests that yields evaluated on this basis will vary depending on the chemistry of the flare gas. Thus, emission factors presented on a per flare gas volume basis such as the CAPP factor will be valid only for a limited range of specific flare gases.

Linear curve fits were applied to the data in Figure 4.10, which all show a very slight positive correlation between the different forms of $\mathrm{NO}_{\mathrm{X}}$ yield represented and increasing flare gas mass flow rate $\left(\mathrm{r}^{2}=0.053,0.002,0.093\right.$ for the fits in Figure $4.10 \mathrm{a}, \mathrm{b}$ and $\mathrm{c}$ respectively). Assuming that there is actually no correlation between $\mathrm{NO}_{\mathrm{X}}$ yield and flare gas mass flow rate, the variance $\left(\sigma^{2}\right)$ of the data multiplied by the number of data points $(n)$ and normalized by the mean (mean) squared would indicate which form of the $\mathrm{NO}_{\mathrm{X}}$ yield has the least scatter in the data. The values for $n \sigma^{2} /$ mean $^{2}$ for the data in Figure 4.10 are $0.410,3.400$ and 0.314 for $\mathrm{NO}_{\mathrm{X}}$ yield calculated on a per mass, per volume and per energy content basis respectively. This indicates that the largest scatter occurs when NOx yields are plotted on a per volume basis (Figure 4.10b, $n \sigma^{2}$ $/$ mean $^{2}=3.4$ ) and that a single valued emission factor would be best expressed as a $\mathrm{NO}_{\mathrm{X}}$ yield on a per energy content basis best (Figure $4.10 \mathrm{c}, n \sigma^{2} /$ mean $^{2}=0.314$ ).

Figure 4.10 also includes the relevant NOx emission factors available from the literature as previously detailed in Table 1.2. The emission factors have been adjusted to SI units where necessary, but are otherwise presented in their original form in the relevant panel (a-c) of Figure 4.10 on either a per mass, per volume, or per energy content basis (e.g. AP 42 Section $13.5 \mathrm{EF}$ of $0.068 \mathrm{lb} / 10^{6} \mathrm{BTU}$ flare gas is presented on a per energy content basis in Figure $4.10 \mathrm{c}$ converted to SI units of $\mathrm{kg} / 10^{9} \mathrm{~J}$ ). This avoids 
the necessity of assuming a specific flare gas density or heating value when converting a given emission factor to a single common yield form (e.g. kg-NOX/kg-flare-gas). Figure 4.10a includes emission factors calculated for gas flaring in crude oil and gas treatment (Shah and Pope, 1994), for flaring specifically related to oil and gas extraction (Trozzi, 2013), and for upstream oil or gas production related flaring (NAEI, 2012). These emission factors from the literature and presented on a per unit mass of flare gas basis fall below the average $\mathrm{NO}_{\mathrm{X}}$ yield of $0.00198 \mathrm{~kg} / \mathrm{kg}$ calculated from the current data. Figure 4.10b presents emission factors for sour gas flares (Villasenor et al., 2003), solution gas combustion at heavy crude primary and thermal facilities (Franklin and Leahey, 1998), for flared gas in the upstream oil and gas industry (CAPP, 2007), and for landfill gas flares (US EPA, 1998; US EPA, 2014). The first three emission factors are similar to the measured yields for the methane-based flare gases and significantly lower than the ethylene and propane yields. The final two are for low energy content gases and produce values much lower than experimentally measured yields for all flare gases. Figure 4.10c shows emission factors for steam-assisted flaring (Franklin and Leahey, 1998) and for industrial flares (US EPA, 1995), which are significantly higher and slightly lower respectively than the average $\mathrm{NO}_{\mathrm{X}}$ yield of $0.0376 \mathrm{~kg} / 10^{9} \mathrm{~J}$ calculated from the current data. 


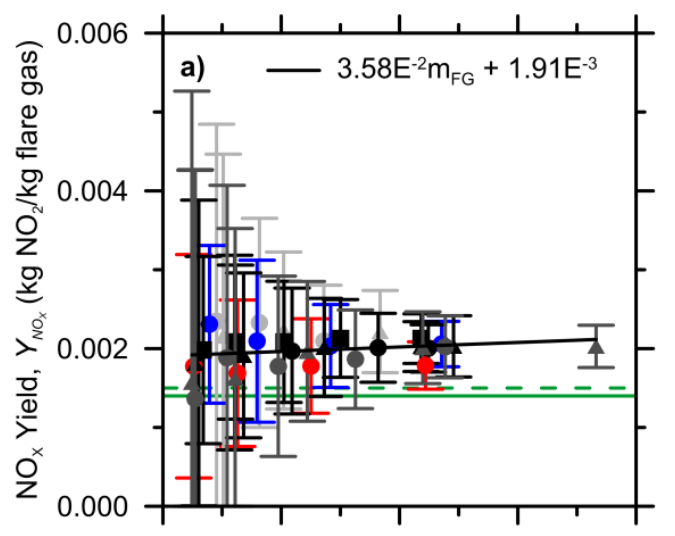

AVG 6-Mix - $76.2 \mathrm{~mm}$

- AVG 6-Mix - $50.8 \mathrm{~mm}$

( HVY 4-Mix - $76.2 \mathrm{~mm}$

- HVY 4-Mix - $50.8 \mathrm{~mm}$

- HVY 4-Mix - $38.1 \mathrm{~mm}$

- Ethylene $-50.8 \mathrm{~mm}$

$\triangle \quad$ Methane $-76.2 \mathrm{~mm}$

- Methane $-50.8 \mathrm{~mm}$

- Propane $-50.8 \mathrm{~mm}$

- - E\&P Forum [1994]

— EEA [2013] / NAEI [2012]
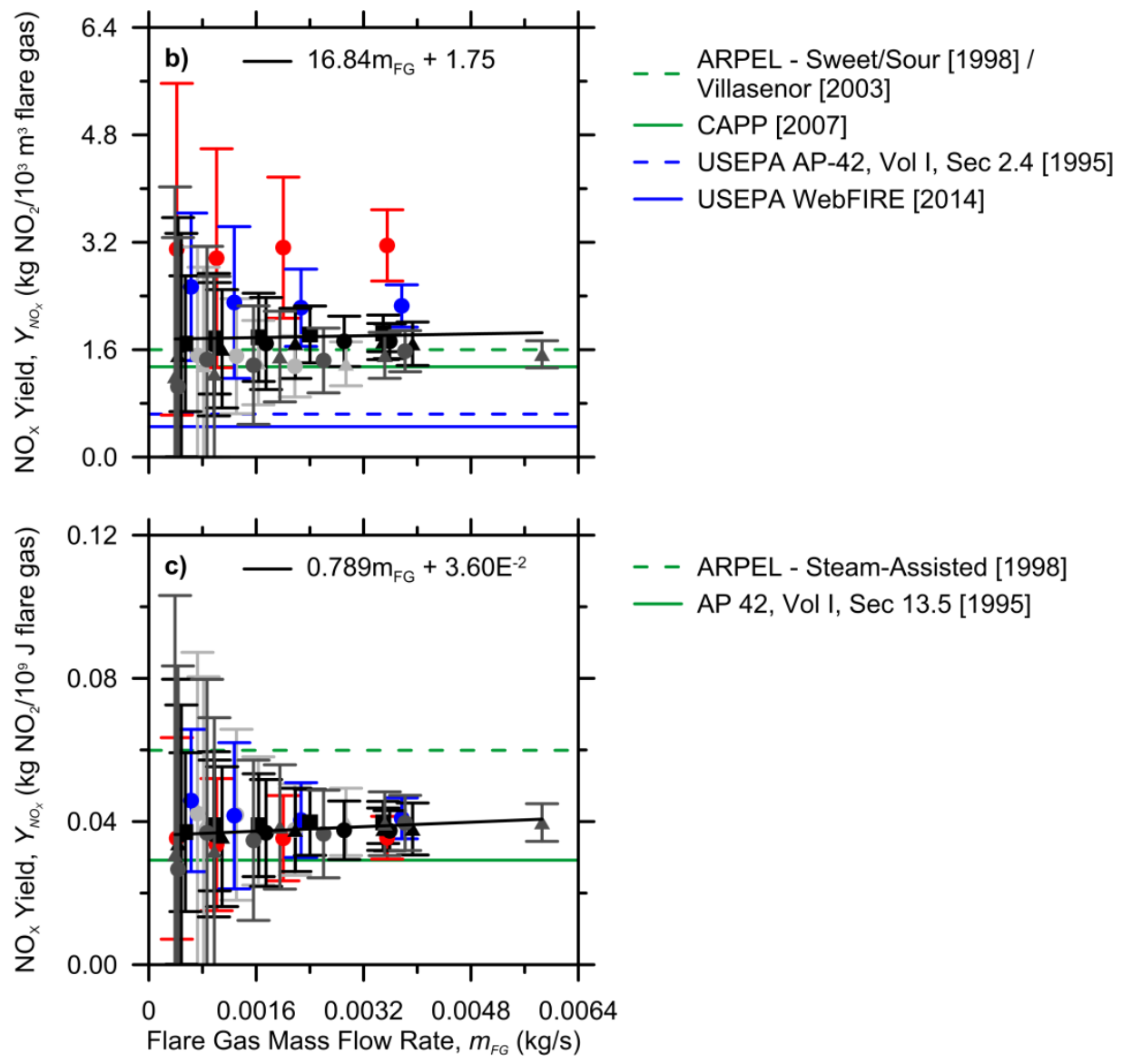

Figure 4.10: $\mathrm{NO}_{\mathrm{x}}$ yields on a per flare gas a) mass, b) volume and c) energy content basis calculated using the carbon balance method plotted against flare gas mass flow rate for the 38.1, 50.8 and $76.2 \mathrm{~mm}$ burners with AVG 6-Mix, HVY 4-Mix, ethylene, methane and propane flare gas mixtures. Emission factors from the literature also plotted in their published form as per appropriate reference. 


\subsubsection{Scaling of $\mathrm{NO}_{\mathrm{x}}$ Emissions}

As described in Section 1.3, Rokke et al. (1992) proposed a simple scaling relation for NOx yield from hydrocarbon flare gases, which relates a parameterized $\mathrm{NO}_{\mathrm{X}}$ emissions index to the Froude number (Eq. (1.4)) of the flare gas. Figure 4.11a shows the current data plotted in terms of these variables with a superimposed line representing the specific fit values of the scaling law proposed by Rokke et al. (1992) (44 as the coefficient, 0.6 as the exponent). Both axes on the plot are functions of exit velocity $\left(u_{0}\right)$ and burner diameter $\left(d_{0}\right)$ and consequently, if the exponent value on the Froude number were 0.5, then the NOx yield would be independent of Froude number (and therefore exit velocity and flare gas flow rate). As shown in Figure 4.11a, the current data generally confirm the trend of the theoretical scaling relation from the literature, but the near constant yields observed in Figure 4.10 imply an exponent on the Froude number closer to 0.5 . If the $\mathrm{NO}_{\mathrm{X}}$ emissions index is expressed on a per mass basis as in Figure $4.11 \mathrm{~b}$, the data collapses due to differences in flare gas densities and a curve fit on the current data confirms that the $\mathrm{NO}_{\mathrm{X}}$ scaling has a weaker dependence on Froude number (and therefore exit velocity) than the dependence suggested by the Rokke et al. (1992) scaling law. Figure $4.11 \mathrm{c}$ replicates the form of Figure $4.11 \mathrm{~b}$, but with linear axis to better illustrate the curve fit through the data. 


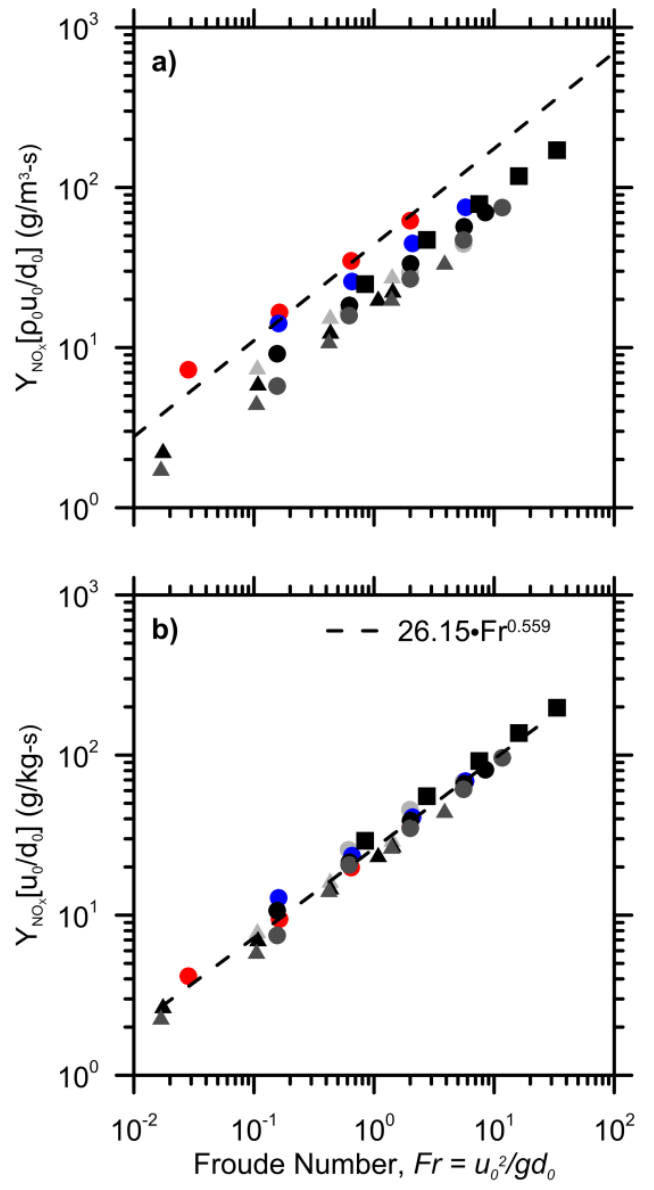

A AVG 6-Mix - $76.2 \mathrm{~mm}$

- AVG 6-Mix - $50.8 \mathrm{~mm}$

A HVY 4-Mix - $76.2 \mathrm{~mm}$

- HVY 4-Mix - $50.8 \mathrm{~mm}$

- HVY 4-Mix - $38.1 \mathrm{~mm}$

- Ethylene $-50.8 \mathrm{~mm}$

Methane $-76.2 \mathrm{~mm}$

- Methane $-50.8 \mathrm{~mm}$

- Propane $-50.8 \mathrm{~mm}$

- $44 \cdot \mathrm{Fr}^{0.6}$ Rokke et al. (1992)

Figure 4.11: $\mathrm{NO}_{\mathrm{X}}$ Emission Index a) by volume and b) by mass plotted against Froude number for 38.1, 50.8 and $76.2 \mathrm{~mm}$ burners with AVG 6-Mix, HVY 4-Mix, ethylene, methane and propane flare gas mixtures. Also shown: a) theoretical scaling law of $Y_{N O_{X}}\left[\frac{\rho_{0} u_{0}}{d_{0}}\right]=44 \cdot F^{0.6}$ (Rokke et al., 1992); b) curve fit of $Y_{N O_{X}}\left[\frac{u_{0}}{d_{0}}\right]=26.15 \cdot F r^{0.559}$; c) data and curve fit of b) with linear axis scaling.

Although the equation for the curve fit shown in both Figure $4.11 \mathrm{~b}$ and $\mathrm{c}$ shows good correlation between the $\mathrm{NO}_{\mathrm{X}}$ emission index expressed on a mass basis and the Froude number $\left(\mathrm{r}^{2}=0.984\right)$, the effectiveness of this correlation is misleading given the presence of a $u_{o} / d_{o}$ term in both axes. Figure 4.12 instead shows the $\mathrm{NO}_{\mathrm{X}}$ yield on a per mass basis as a function of $F r^{0.559}$ multiplied by $d_{o} / u_{o}$ (i.e. rewriting the yield as a function of velocity and diameter using the equation from the curve in Figure 4.11c). 
Both the gravity term in the denominator of the Froude number and the coefficient on the curve fit can be ignored as they will scale all data points equally and not affect the relative scatter. By plotting the data in accordance with the curve fit in Figure 4.11, a linear fit can be applied between $\mathrm{NO}_{\mathrm{X}}$ yield and the velocity parameter $\left(\mathrm{u}_{0}^{0.117} \mathrm{~d}_{0}^{0.441}\right)$ as shown in Figure 4.12. The plotted results illustrate that the resultant curve fit has a very weak correlation with a $\mathrm{r}^{2}$ value of 0.087 . The scatter of the data about the fit (calculated as the residual sum of squares (RSS) divided by the average of the y-axis values (mean) squared) is higher $\left(\mathrm{RSS} /\right.$ mean $\left.^{2}=0.375\right)$ than the scatter achieved when the $\mathrm{NO}_{\mathrm{x}}$ yield per energy content of the flare gas is treated as a constant (which has a comparable $n \sigma^{2} /$ mean $^{2}$ value of 0.314 ). This shows that the apparent good correlation in Figure 4.11 is primarily an artefact of having $u_{o} / d_{o}$ terms on both axes, and ultimately reflects the trivial truth that emission rate (as opposed to emission yield) scales with flow rate.

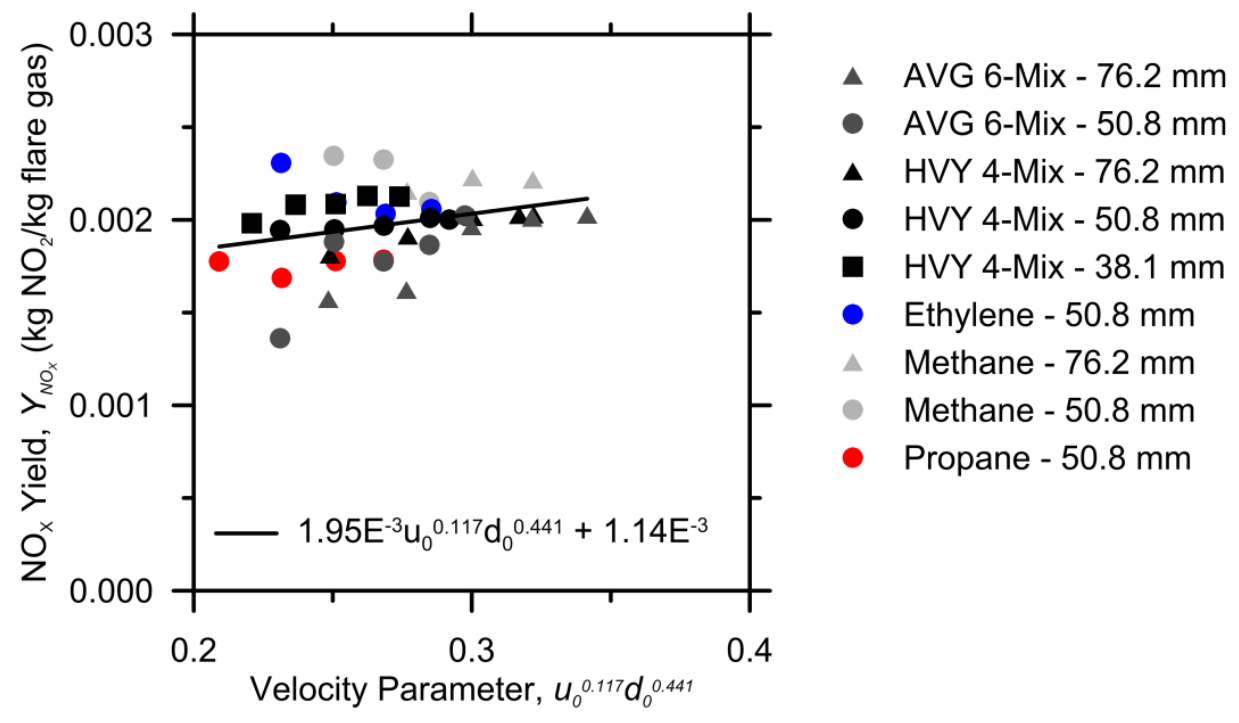

Figure 4.12: $\mathrm{NO}_{\mathrm{X}}$ yields calculated on a mass basis using the carbon balance method for the 38.1, 50.8 and 76.2 mm burners with AVG 6-Mix, HVY 4-Mix, ethylene, methane and propane flare gas mixtures plotted against the velocity parameter adapted from Froude number scaling. 
Given the importance of the thermal mechanism in production of $\mathrm{NO}_{\mathrm{X}}$ at high temperatures associated with combustion (Turns, 1995), the stoichiometric, adiabatic flame temperature $\left(T_{a d}\right)$ for the individual flare gases was investigated as a potential scaling parameter, as shown in Figure 4.13. Figure 4.13a plots NOx yield as a function of $T_{a d}$ and Figure 4.13b plots the NOx yield multiplied by the stoichiometric mixture fraction $\left(f_{s}\right)$ as a function $T_{a d}$. Multiplying the NOx yield by $f_{s}$ results in a parameter which considers the mass of $\mathrm{NO}_{\mathrm{X}}$ produced per mass of hot products rather than per mass of flare gas. In Figure 4.13a, the yields for methane are on average the highest followed by ethylene and the HVY 4-Mix which suggests weak positive correlation $\left(r^{2}=0.023\right)$ with increasing adiabatic flame temperature. In Figure 4.13b, ethylene now presents the highest average parameterized yield while propane has also increased relative to the methane-based flare gases. The $\mathrm{NO}_{\mathrm{X}}$ yields parameterized with stoichiometric mixture fraction result in adiabatic flame temperature scaling with a stronger (but still weak) positive correlation $\left(\mathrm{r}^{2}=0.274\right)$ compared to the adiabatic flame temperature alone. An explanation for the absence of $\mathrm{NO}_{\mathrm{X}}$ yield scaling with respect to the adiabatic flame temperature alone is that the heat losses due to radiation from to the production of soot in the flame lower the flame temperature relative to $T_{a d}$. For the flare gases tested, the soot yield increases is in the same order as adiabatic flame temperature and stoichiometric mixture fraction. 

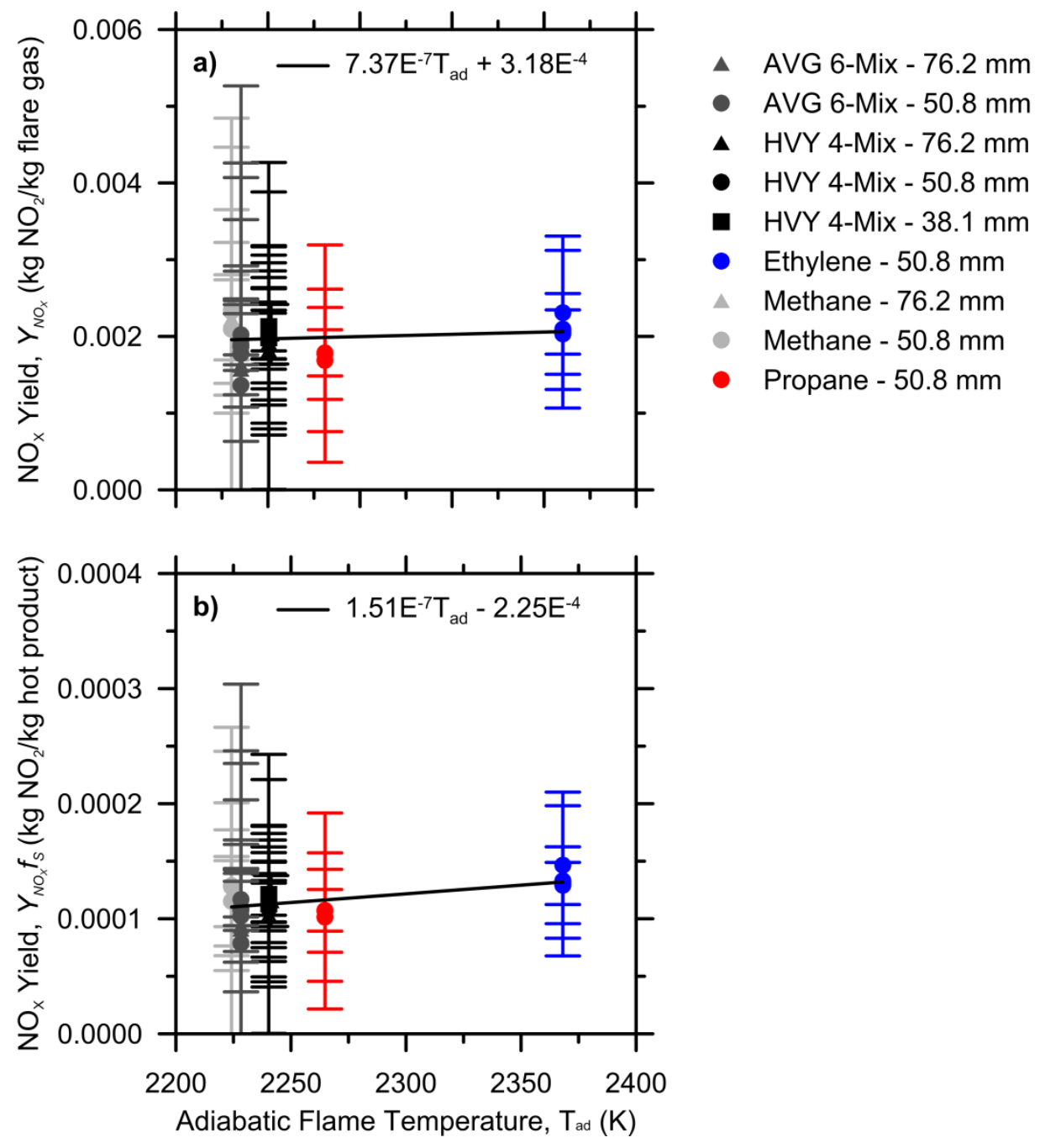

Figure 4.13: a) $\mathrm{NO}_{\mathrm{X}}$ yield and b) $\mathrm{NO}_{\mathrm{X}}$ yield multiplied by the stoichiometric mixture fraction, $f_{S}$, calculated using the carbon balance method plotted against adiabatic flame temperature for the 38.1, 50.8 and $76.2 \mathrm{~mm}$ burners with AVG 6-Mix, HVY 4Mix, ethylene, methane and propane flare gas mixtures.

\subsubsection{Recommendations for Estimating NOx Emissions from Flares}

Given that $\mathrm{NO}_{\mathrm{X}}$ yield expressed on a per energy basis gives the least scatter in the measured data, a final comparison with all emission factors from Table 1.2 is shown in Figure 4.14 on a per unit flare gas energy content basis. As discussed previously, a curve fit on the data results in a very weak upward trend $\left(\mathrm{r}^{2}=0.093\right)$ relating $\mathrm{NO}_{\mathrm{X}}$ yield and increasing flare gas flow rate. 


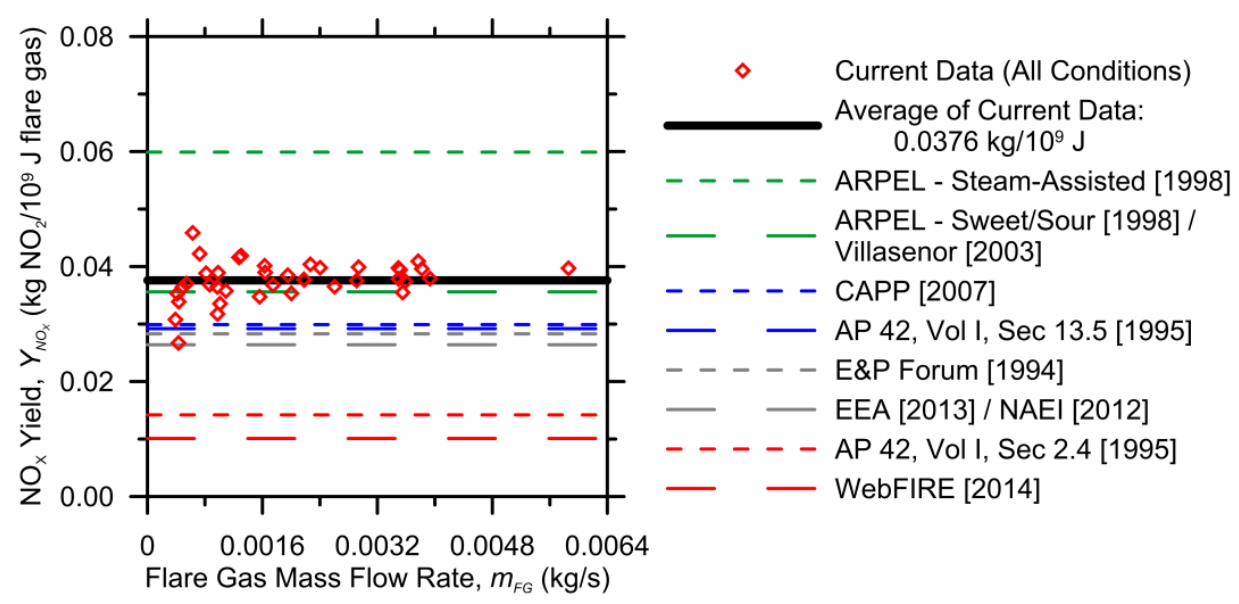

Figure 4.14: $\mathrm{NO}_{\mathrm{X}}$ yields calculated using the carbon balance method for the 38.1, 50.8 and 76.2 mm burners with AVG 6-Mix, HVY 4-Mix, ethylene, methane and propane flare gas mixtures compared to emission factors from the literature.

Several conclusions can be drawn from the investigation into $\mathrm{NO}_{\mathrm{X}}$ yields and their potential scaling. The available data suggest that a single-value $\mathrm{NO}_{\mathrm{X}}$ emission factor is best presented on a per energy content basis (adjusted for flare heating value) as this provides the least scatter independent of flare gas chemistry. Based on the present experiments as plotted in Figure 4.14, the average $\mathrm{NO}_{\mathrm{X}}$ yield calculated on a per flare gas energy content basis is $0.0376 \mathrm{~kg}-\mathrm{NO}_{\mathrm{X}} / 10^{9} \mathrm{~J}$-flare-gas. Although the fit to these data increases very slightly with flare gas flow rate, if the data for the lower flow rates with high uncertainties are neglected the slope of the curve fit approaches zero making a single-value emission factor a good approximation for $\mathrm{NO}_{\mathrm{X}}$ yield.

The average value presented for the data in Figure 4.14 compares well to the cluster of emission factors (ARPEL solution gas, Villasenor, CAPP, AP 42 Section 13.5, E\&P Forum, EEA and NAEI) that fall in the range of 0.0264 to $0.0356 \mathrm{~kg}-\mathrm{NO}_{\mathrm{X}} / 10^{9} \mathrm{~J}-$ flare-gas after being converted to common units. Plotting the emission factors in Figure 4.14 required various assumptions that should be reemphasized. Of the factors 
mentioned, only AP 42 Section 13.5 is published in the form of mass yield per unit energy content. The emission factors from ARPEL specifically for solution gas (Franklin and Leahey, 1998), Villasenor et al. (2003) (for sour gas), and CAPP (2007) (for upstream oil and gas flares) are published in the form of mass yield per unit volume and have been converted to the relevant units assuming a volumetric heating value of $45 \mathrm{MJ} / \mathrm{m}^{3}$, which is in the middle of the range of methane flare gases tested (39-

$51 \mathrm{MJ} / \mathrm{m}^{3}$ ). The emission factors from E\&P Forum (Shah and Pope, 1994), EEA (Trozzi, 2013) and NAEI (2012) (all for solution gas) are published in the form of mass yield per unit mass and have been converted to the relevant units assuming a higher heating value of $45 \mathrm{MJ} / \mathrm{m}^{3}$ and density of $0.85 \mathrm{~kg} / \mathrm{m}^{3}$.

The three outlier emission factors relative to the cluster of emission factors within the range of the current data are the ARPEL factor for steam-assisted flaring (Franklin and Leahey, 1998), the AP 42 factor (US EPA, 1998) for enclosed flares burning presumably methane, and the WebFIRE factor (US EPA, 2014) for landfill gas flaring. The validity of these factors applied to upstream oil and gas flaring is questionable because steam-assisted flaring is a fundamentally different combustion process as are enclosed flares, and landfill gas generally has high diluent content and low heating values $\left(\sim 15 \mathrm{MJ} / \mathrm{m}^{3}\right)$ which may lead to lower flame temperatures and reduced $\mathrm{NO}_{\mathrm{X}}$ yield.

\subsection{Combustion Efficiency Results, Analysis and Discussion}

The combustion efficiencies of turbulent diffusion flames were measured for the test conditions outlined in Table 1.1. It was expected based on a review of the literature that, for the range of conditions tested (i.e. higher heating value flare gases and an absence of crosswind), the results would exhibit high combustion efficiencies. As shown in Figure 
4.15, the mixed-phase combustion efficiencies measured were consistently high (> 298\%) for all but one test condition. The lone test case with measured combustion efficiency less than $98 \%$ was the lowest flow rate for ethylene which also resulted in the highest soot yield of all tests. For flares burning the methane-based mixtures (AVG 6Mix, HVY 4-Mix, and pure methane), the combustion efficiencies were greater than 99.5\% for all cases except the lowest flow rate test condition for AVG 6-Mix with the $76.2 \mathrm{~mm}$ burner. The relatively low measured combustion efficiency of $98.7 \%$ for this case was an artifact of abnormally high concentrations of ethane measured in the duct. It is believed this test case should regarded as an experimental outlier and is likely not indicative of reduced combustion efficiency in general at this flow rate for this flare gas. There was no discernable impact on combustion efficiency with changes in the burner diameter for any of the three methane-based flare gases. The heavier flare gases (ethylene, propane), which resulted in increased soot yields relative to the methane-based flare gases, showed a corresponding decrease in combustion efficiency. The general increase in combustion efficiency with increasing mass flow rate apparent in all flare gas mixtures can for the most part be attributed to decreasing soot yield with increasing mass flow rates. This trend of increasing combustion efficiency is particularly apparent in ethylene and propane while still observable in the methane-based flare gases. 


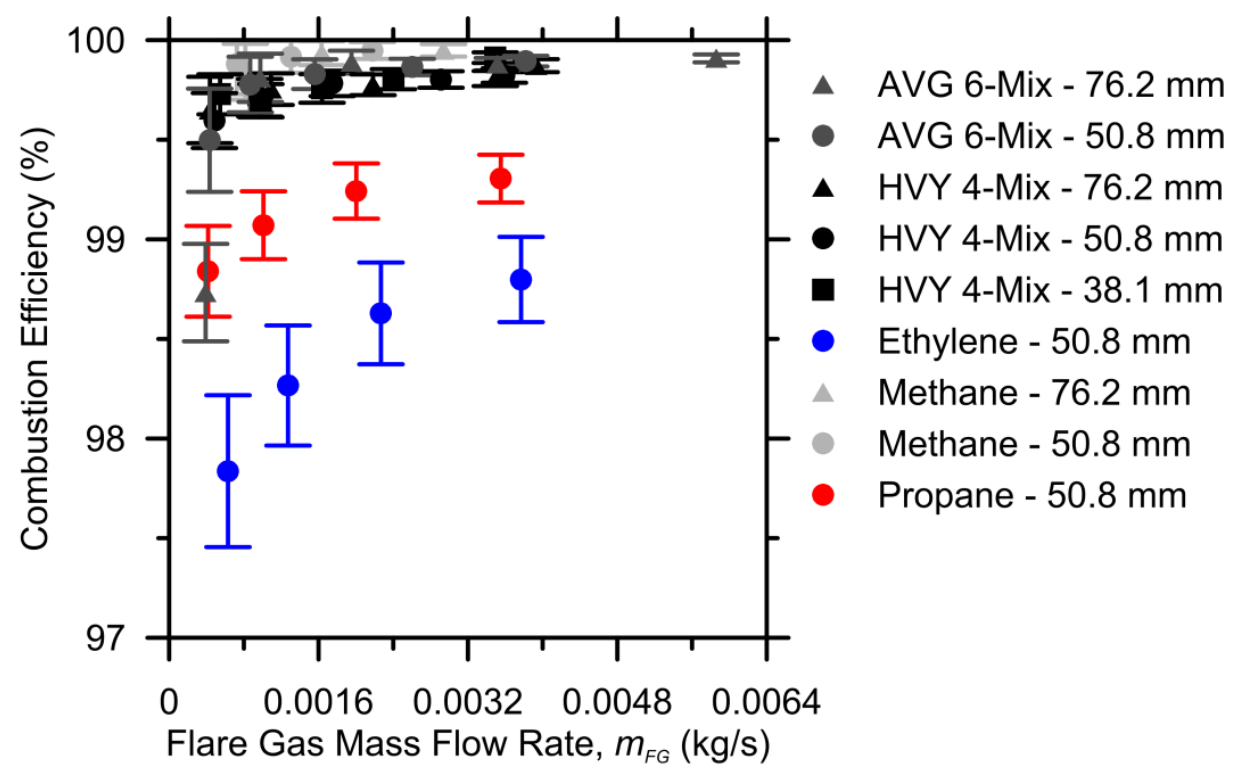

Figure 4.15: Mixed-phase combustion efficiency calculated using the carbon balance method for the 38.1, 50.8 and 76.2 mm burners with AVG 6-Mix, HVY 4-Mix, ethylene, methane and propane flare gas mixtures.

To illustrate the importance of soot as a product of incomplete combustion, individual carbon-based species yields are shown in Figure 4.16 for the various flare gases and burner diameters. The individual bars for a given burner diameter and flare gas composition set correspond to increases in flare gas mass flow rate from left to right. This figure illustrates two important points. For ethylene and propane flare gases, the carbon monoxide yield is of roughly the same magnitude as the total carbon yield for the AVG 6-Mix, HVY 4-Mix, and pure methane flare gases. However, the soot yield dominates the total carbon yield of both ethylene and propane. The previously mentioned outlier case of a high ethane measurement for the AVG 6-Mix with the $76.2 \mathrm{~mm}$ burner that resulted in decreased combustion efficiency can be seen in the right-most bar grouping. The carbon monoxide and hydrocarbon yields for methane, ethane, propane and ethylene can be found in Appendix B. 


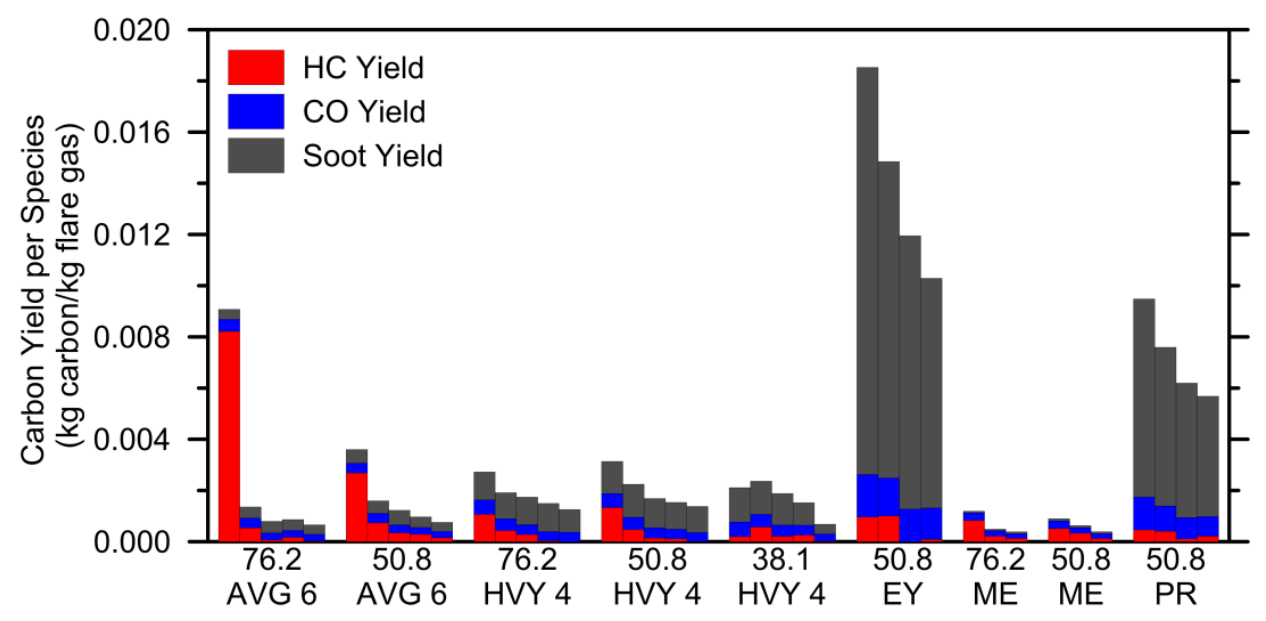

Figure 4.16: Carbon yields of various species calculated using the carbon balance method for the 38.1, 50.8 and 76.2 mm burners with AVG 6-Mix, HVY 4-Mix, ethylene (EY), methane (ME) and propane (PR) flare gas mixtures.

Figure 4.17 compares the gas-phase-only combustion efficiencies neglecting the impact of soot as a product of incomplete combustion. The gas-phase only combustion efficiency considers carbon monoxide and gaseous hydrocarbons (methane, ethane, propane, ethylene) as products of incomplete combustion. The results as shown illustrate the small change in combustion efficiency for the methane-based flare gases due to their relatively low soot yield and already high mixed-phase combustion efficiencies. The gasphase combustion efficiencies of the ethylene and propane flare gases are higher than their corresponding mixed-phase combustion efficiencies and are close to the gas phase efficiencies of the methane-based gases. This suggests that independent of the specific flare gas, gas-phase combustion efficiencies are universally high for turbulent nonpremixed diffusion flames operating with high heating values and in the absence of crosswinds. 


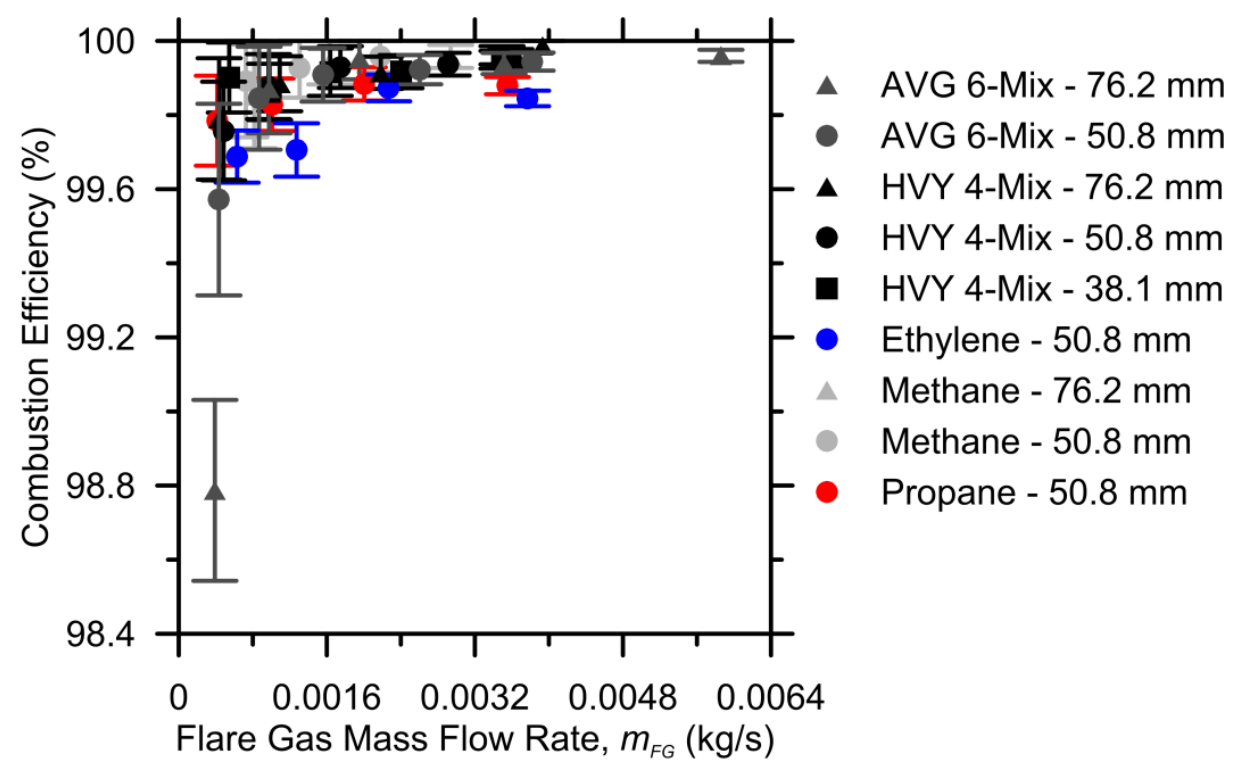

Figure 4.17: Gas-phase only combustion efficiency calculated using the carbon balance method for the 38.1, 50.8 and 76.2 mm burners with AVG 6-Mix, HVY 4Mix, ethylene, methane and propane flare gas mixtures. 


\section{Chapter 5}

\section{Conclusions \& Recommendations}

\subsection{Conclusions}

Mass emission yields of soot, $\mathrm{NO}_{\mathrm{X}}$ and several carbon-based species were measured along with combustion efficiency for several pure flare gases and two methane-based flare gas mixtures representative of compositions flared in the Alberta upstream oil and gas industry. To facilitate these measurements, a large lab-scale flare was constructed and commissioned, significantly expanding the range of experiments possible in previous work of McEwen (2010) and Canteenwalla (2007) which used a smaller facility. A new sampling protocol and calculation methodology were developed to leverage capabilities of modern high-sensitivity gas analysis equipment and enable measurements on larger flames at higher flow rates and dilution ratios. The resulting calculation methodology and uncertainty analysis procedures were published in a paper co-authored by the author of this thesis, which detailed two complementary approaches for measuring flare combustion efficiency and gas species emission rates with quantified uncertainties.

Experiments were subsequently performed on a range of flare diameters, flow rates, and flare gas compositions. Results of soot yield measurements affirmed that yield rates are most strongly influenced by flare gas chemistry, and flare gas flow rates and diameters are of secondary importance. Soot yields measured with methane-based flare gases peaked at $0.00134 \mathrm{~kg}$-soot $/ \mathrm{kg}$-flare-gas with the HVY 4-Mix flare gas 
(74.54\% $\mathrm{CH}_{4}, \quad 15.47 \% \mathrm{C}_{2} \mathrm{H}_{6}, 6.83 \% \mathrm{C}_{3} \mathrm{H}_{8}$ and $3.16 \% \mathrm{C}_{4} \mathrm{H}_{10}$ by volume). However among the three methane-based flare gases, there was more than an order of magnitude difference in soot yield between flares burning the average HVY 4-Mix soot yield and pure methane. Both propane and ethylene produced significantly more soot than the methane-based flare gases, averaging 0.00597 and $0.0120 \mathrm{~kg}$-soot $/ \mathrm{kg}$-flare-gas respectively.

The secondary effects of varying flare gas flow rate and burner diameter were investigated through scaling by non-dimensional parameters including the Fire Froude number, Global Froude number, and Reynolds number. In this context, it appears that the transitional regimes for turbulent buoyant non-premixed flames suggested by Delichatsios (1993) may correspond with decreasing soot yields in the transition-shear regime. Changes in the burner diameter for a given flare gas appear to influence soot yield less strongly than the flare gas flow rate.

The measured soot yields were compared to a number of published emission factors for various forms of gas flaring. Several of the emission factor values lie in the range of measured soot yield for the methane-based flare gases, and the remainder lie in the range between measured soot yields for methane-based and propane flare gases. An investigation into the validity of heating value scaling (which is inherently assumed in several emission factors) was undertaken. The CAPP (2007) emission factor is derived from an emission factor cited in US EPA (2014) using linear scaling with assumed heating values. The measured soot yields suggest this method may be applicable for the narrow range alkane based flare gases tested; however it is certainly not valid for the 
ethylene flare gas. It seems likely that the presence of alkenes or other non-alkane species in the flare gas would invalidate this scaling approach.

Measured $\mathrm{NO}_{\mathrm{X}}$ yields were generally constant over the range of flare gas flow rates tested for a given flare gas chemistry. Efforts were made to examine on which basis yield should be expressed to reduce the scatter among different flare gases. The proposed theoretical scaling of Rokke et al. (1992) for parameterized $\mathrm{NO}_{\mathrm{X}}$ yield as a function of Froude number was compared to the measured data and results confirmed that $\mathrm{NO}_{\mathrm{X}}$ yield can likely be expressed as a constant independent of flare gas flow rate. Analysis revealed that the scaling relation proposed by (Rokke et al., 1992) based on this parameterized $\mathrm{NO}_{\mathrm{X}}$ yield is partly an artefact of having $u_{o} / d_{o}$ terms on both axes, and the correlation simplifies to a weak scaling of mass yield with $u_{o}^{0.2}$. The scatter among this revised correlation was actually worse than the scatter observed when yield was expressed on a per flare gas energy content basis. The potential of scaling with the adiabatic flame temperature was also investigated for $\mathrm{NO}_{\mathrm{X}}$ yield on a mass basis parameterized by the stoichiometric mixture fraction, although the weak correlation could be attributed to the strong correlation between stoichiometric mixture fraction and adiabatic flame temperature.

Results of the present investigation into $\mathrm{NO}_{\mathrm{X}}$ scaling suggest $\mathrm{NO}_{\mathrm{X}}$ yield expressed on a per energy content basis $\left(\mathrm{kg} / 10^{9} \mathrm{~J}\right)$ is approximately constant over the range of conditions tested, with an average $\mathrm{NO}_{\mathrm{x}}$ yield of $0.0376 \mathrm{~kg} / 10^{9} \mathrm{~J}$. Measured NOx data expressed on a per energy content basis were compared with several published emission factors. Most of the available emission factors aligned with the present range of measured $\mathrm{NO}_{\mathrm{X}}$ yields when a representative heating value and density were used for the 
conversion to common units. Outlying published emission factors were either significantly higher (ARPEL factor for steam-assisted flaring), or significantly lower (US EPA factors for enclosed flares and landfill gas flaring).

Combustion efficiencies were also measured with and without the inclusion of soot in the calculations. The mixed-phase (with soot) combustion efficiencies decreased among the flare gases in accordance with increasing soot yield to a minimum of $97.8 \%$ for the ethylene flare gas. Gas-phase (without soot) combustion efficiencies were consistently high (>99.5\%), highlighting the fact that soot was the most significant carbon-based product of incomplete combustion accounting for up to $90 \%$ of non- $\mathrm{CO}_{2}$ carbon species.

\subsection{Recommendations for Future Work}

Several recommendations are suggested for future experiments to expand the current work. In general, the understanding of soot and $\mathrm{NO}_{\mathrm{X}}$ yields could be better understood with an expanded testing campaign specifically including propane and ethylene flare gas tests conducted on the 38.1 and $76.2 \mathrm{~mm}$ burners to confirm the expectation that burner diameter is not a leading order scaling parameter. Expansion of the range of flare gases tested to include other alkene species (possibly propylene) and alkane-alkene blends may be useful to further investigate emissions scaling among alkenes. Measurement of parameters such as the radiant fraction or a thorough examination of the literature on the soot propensity of the various flare gases may present opportunities for inter-species collapse of the soot yield data. Additionally, Laser Doppler Velocimetry (LDV) measurements of turbulence in the exit plane and along the length of the flame to investigate mixing may help better explain the influence of flare gas flow rate on soot 
yield. Further testing on different flare gases and at higher flare gas mass flow rates (and by association higher Froude numbers) would aid in confirming or refuting the suggestion that $\mathrm{NO}_{\mathrm{X}}$ yield presented on a per energy content basis is independent of flare gas chemistry and flow rate. This would allow for a more robust recommendation to be made as to an emission factor valid for a wide range of flare gas compositions and flow rates. Measurement of the flame temperature, while difficult to accomplish in sooting turbulent flames, would present a better opportunity for scaling given the importance of temperature in $\mathrm{NO}_{\mathrm{X}}$ production. Radiant heat transfer from soot particles tends to reduce the temperature from the adiabatic temperature considered in the current analysis.

Improved gas-analysis equipment with lower minimum detection limits would be beneficial in reducing the uncertainties of measured gas-species yields. For carbon-based species, this would reduce the uncertainties associated with combustion efficiency (although uncertainties would still be heavily dependent on the ability to measure $\mathrm{CO}_{2}$ better than a relative bias of $+/-2 \%$ ). For $\mathrm{NO}_{\mathrm{X}}$ yield, this would allow for a more precise examination of potential differences among gas species as well as provide more definitive evidence whether yield is truly independent of flow rate. Finally, the current work considered quiescent conditions, which are expected to represent an upper bound on both soot and $\mathrm{NO}_{\mathrm{X}}$ production. Future experiments to measure the yields of these species for flames subjected to turbulent crosswind (i.e. in a large-scale windtunnel) would provide important insight for conditions experienced by flares in the field. 


\section{References}

Allen, D.T. and Torres, V.M., (2011). TCEQ 2010 Flare Study Final Report. PGA No. 582-8-862-45-FY09-04, Austin, TX, Texas Commission on Environmental Quality (TCEQ). Available at:

http://www.tceq.texas.gov/assets/public/implementation/air/rules/Flare/2010flarestu dy/2010-flare-study-final-report.pdf

ANSI/ASME, (1985). ANSI/ASME PTC 19.1 - Part 1 - Measurement Uncertainty, Instruments and Apparatus. New York, NY, United States.

Arctic Council, (2011). Arctic Council Task Force on Short-Lived Climate Forcers Progress Report and Recommendations for Ministers, Nuuk Greenland. Arctic Council Task Force on Short-Lived Climate Forcers. Available at: http://arcticcouncil.npolar.no/accms/export/sites/default/en/meetings/2011-nuukministerial/docs/3-0a_TF_SPM_recommendations_2May11_final.pdf

Bakken, J., Langørgen, Ø., Husdal, G., and Henriksen, T.S., (2008). Improving Accuracy in Calculating NOx Emissions from Gas Flaring. In SPE Internation Conference on Health, Safety and Environment in Oil and Gas Exploration and Production, April 15-17. Nice, France, Society of Petroleum Engineers, p.SPE 111561.

Bandaru, R. V and Turns, S.R., (2000). Turbulent Jet Flames in a Crossflow: Effects of Some Jet, Crossflow, and Pilot-Flame Parameters on Emissions. Combust. Flame. 121:137-151.

Becker, H.A. and Liang, D., (1982). Total emission of soot and thermal radiation by free turbulent diffusion flames. Combust. Flame. 44:305-318.

Bond, T.C., Doherty, S.J., Fahey, D.W., Forster, P.M., Berntsen, T., DeAngelo, B.J., Flanner, M.G., Ghan, S., Kärcher, B., Koch, D., et al., (2013). Bounding the role of black carbon in the climate system: A scientific assessment. J. Geophys. Res. Atmos. 118:5380-5552.

Bourguignon, E., Johnson, M.R., and Kostiuk, L.W., (1999). The use of a closed-loop wind tunnel for measuring the combustion efficiency of flames in a cross flow. Combust. Flame. 119:319-334.

Canteenwalla, P.M., (2007). Soot emissions from turbulent diffusion flames burning simple alkane fuels. Carleton University, Ottawa, ON, Canada. 
CAPP, (2007). A Recommended Approach to Completing the National Pollutant Release Inventory (NPRI) for the Upstream Oil and Gas Industry. 2007-0009, Available at: http://www.capp.ca/library/publications/policyRegulatory/pages/pubInfo.aspx?DocI $\mathrm{d}=119572 \# \mathrm{a} 3 \mathrm{C} 7 \mathrm{EUiuvHbf}$

Caulton, D.R., Shepson, P.B., Cambaliza, M.O.L., McCabe, D., Baum, E., and Stirm, B.H., (2014). Methane destruction efficiency of natural gas flares associated with shale formation wells. Environ. Sci. Technol.. 48:9548-54.

Costa, M., Parente, C., and Santos, A., (2004). Nitrogen oxides emissions from buoyancy and momentum controlled turbulent methane jet diffusion flames. Exp. Therm. Fluid Sci.. 28:729-734.

Crosland, B.M., Thomson, K.A., and Johnson, M.R., (2014). Simultaneous Instantaneous Measurements of Soot Volume Fraction, Primary Particle Diameter, and Aggregate Size in Turbulent Buoyant Diffusion Flames. In 35th International Symposium on Combustion.

Delichatsios, M.A., (1993). Transition from momentum to buoyancy-controlled turbulent jet diffusion flames and flame height relationships. Combust. Flame. 92:349-364.

Ellzey, J.L., Berbe, J.G., Tay, E.Z.F., and Foster, D.E., (1990). Total Soot Yield from a Propane Diffusion Flame in Cross-Flow. Combust. Sci. Technol.. 71:41-52.

Franklin, N. and Leahey, D.M., (1998). Atmospheric Emissions Inventories Methodologies in the Petroleum Industry.

Grahame, T.J., Klemm, R., and Schlesinger, R.B., (2014). Public health and components of particulate matter: The changing assessment of black carbon. J. Air Waste Manage. Assoc. . 64:620-660.

Havs, P.T.I.L., (2012). Veiledning til den Årlige Utslippsrapporteringen. . 1-99.

Herndon, S.C., Nelson, D.D., Wood, E.C., Knighton, W.B., Kolb, C.E., Kodesh, Z., Torres, V.M., and Allen, D.T., (2012). Application of the Carbon Balance Method to Flare Emissions Characteristics. Ind. Eng. Chem. Res.. 51:12577-12585.

IPCC, (2013). Working Group I Contribution to the IPCC 5th Assessment Report "Climate Change 2013: The Physical Science Basis" - Final Draft Underlying Scientific-Technical Assessment. Geneva, Switzerland, Intergovernmental Panel on Climate Change (IPCC). Available at: www.ipcc.ch

Johnson, M.R. and Coderre, A.R., (2012). Compositions and greenhouse gas emission factors of flared and vented gas in the western Canadian sedimentary basin. J. Air Waste Manage. Assoc. 62:992-1002. 
Johnson, M.R., Devillers, R.W., and Thomson, K.A., (2011). Quantitative Field Measurement of Soot Emission from a Large Gas Flare Using Sky-LOSA. Environ. Sci. Technol.. 45:345-350.

Johnson, M.R., Devillers, R.W., and Thomson, K.A., (2013). A Generalized Sky-LOSA Method to Quantify Soot/Black Carbon Emission Rates in Atmospheric Plumes of Gas Flares. Aerosol Sci. Technol.. 47:1017-1029.

Johnson, M.R., Devillers, R.W., Yang, C., and Thomson, K.A., (2010). Sky-Scattered Solar Radiation Based Plume Transmissivity Measurement to Quantify Soot Emissions from Flares. Environ. Sci. Technol.. 44:8196-8202.

Johnson, M.R. and Kostiuk, L.W., (2000). Efficiencies of low-momentum jet diffusion flames in crosswinds. Combust. Flame. 123:189-200.

Johnson, M.R. and Kostiuk, L.W., (2002). A parametric model for the efficiency of a flare in crosswind. Proc. Combust. Inst.. 29:1943-1950.

Johnson, M.R., Kostiuk, L.W., and Spangelo, J.L., (2001). A characterization of solution gas flaring in Alberta. J. Air Waste Manage. Assoc.. 51:1167-1177.

Johnson, M.R., Wilson, D.J., and Kostiuk, L.W., (2001). A fuel stripping mechanism for wake-stabilized jet diffusion flames in crossflow. Combust. Sci. Technol. . 169:155174.

Kostiuk, L.W., Majeski, A.J., Poudenx, P., Johnson, M.R., and Wilson, D.J., (2000). Scaling of wake-stabilized jet diffusion flames in a transverse air stream. Proc. Combust. Inst. . 28:553-559.

McDaniel, M., (1983). Flare efficiency study. EPA-600/2-83-052, Research Triangle Park, NC, United Stated Environmental Protection Agency. Available at: http://nepis.epa.gov/Exe/ZyPURL.cgi?Dockey=P1003QGZ.txt

McEwen, J.D.N., (2010). Soot Emission Factors from Lab-Scale Flares Burning Solution Gas Mixtures. (M.A.Sc. Thesis). Carleton University, Ottawa, ON, Canada.

McEwen, J.D.N. and Johnson, M.R., (2012). Black Carbon Particulate Matter Emission Factors for Buoyancy Driven Associated Gas Flares. J. Air Waste Manage. Assoc. . 62:307-321.

Myhre, G., Shindell, D., Bréon, F.-M., Collins, W., Fuglestvedt, J., Huang, J., Koch, D., Lamarque, J.-F., Lee, D., Mendoza, B., et al., (2013). Anthropogenic and Natural Radiative Forcing. In T. F. Stocker, D. Qin, G.-K. Plattner, M. Tignor, S. K. Allen, J. Boschung, A. Nauels, Y. Xia, V. Bex, \& P. M. Midgley, eds. Climate Change 2013: The Physical Science Basis. Contribution of Working Group I to the Fifth Assessment Report of the Intergovernmental Panel on Climate Change. Cambridge, 
United Kingdom and New York, NY, USA, Cambridge University Press, pp.659740.

NAEI, (2012). Emission factors detailed by source and fuel. http://naei.defra.gov.uk/data/data-selector

NGDC, (2014). Global/Country Results 1994 - 2010. http://www.ngdc.noaa.gov/eog/interest/gas_flares.html

OLF Environmental Programme, (1991). Report Phase I, Part A, Emissions to Air.

Pohl, J.H., Lee, J., Payne, R., and Tichenor, B.A., (1986). Combustion efficiency of flares. Combust. Sci. Technol.. 50:217-231.

Poudenx, P., (2000). Plume sampling of a flare in crosswind: structure and combustion efficiency. (M.Sc. Thesis). Edmonton, University of Alberta, Edmonton, AB, Canada.

Rokke, N.A., Hustad, J.E., Sonju, O.K., and Williams, F.A., (1992). Scaling of Nitric Oxide Emissions from Buoyancy-Dominated Hydrocarbon Turbulent-Jet Diffusion Flames. Proc. Combust. Inst. 24:385-393.

Santos, A. and Costa, M., (2005). Reexamination of the scaling laws for NOx emissions from hydrocarbon turbulent jet diffusion flames. Combust. Flame. 142:160-169.

Shah, A. and Pope, P., (1994). Methods for Estimating Atmospheric Emissions from E\&P Operations. 2.59/197, London, UK, The Oil Industry International Exploration \& Production Forum. Available at: http://www.epforum.org

Sivathanu, Y.R. and Faeth, G.M., (1990). Soot volume fractions in the overfire region of turbulent diffusion flames. Combust. Flame. 81:133-149.

Stohl, A., Klimont, Z., Eckhardt, S., Kupiainen, K., Shevchenko, V.P., Kopeikin, V.M., and Novigatsky, A.N., (2013). Black carbon in the Arctic: the underestimated role of gas flaring and residential combustion emissions. Atmos. Chem. Phys.. 13:88338855.

Strosher, M.T., (2000). Characterization of emissions from diffusion flare systems. Journal of the Air \& Waste Management Association, 50(10) pp.1723-33

Talebi, A., Fatehifar, E., Alizadeh, R., and Kahforoushan, D., (2014). The Estimation and Evaluation of New CO, CO2 , and NOx Emission Factors for Gas Flares Using Pilot Scale Flare. Energy Sources, Part A Recover. Util. Environ. Eff.. 36:719-726. 
Torres, V.M., Herndon, S., and Allen, D.T., (2012). Industrial Flare Performance at Low Flow Conditions. 2. Steam- and Air-Assisted Flares. Ind. Eng. Chem. Res.. 51:12569-12576.

Torres, V.M., Herndon, S., Kodesh, Z., and Allen, D.T., (2012). Industrial Flare Performance at Low Flow Conditions. 1. Study Overview. Ind. Eng. Chem. Res.. 51:12559-12568.

Torres, V.M., Herndon, S., Wood, E., Al-Fadhli, F.M., and Allen, D.T., (2012). Emissions of Nitrogen Oxides from Flares Operating at Low Flow Conditions. Ind. Eng. Chem. Res.. 51:12600-12605.

Trozzi, C., (2013). 1.B.2.c Venting and flaring. . 1-15.

Turns, S., (1995). Understanding NOx formation in nonpremixed flames: Experiments and modeling. Prog. Energy Combust. Sci.. 21:361-385.

UKOOA, (1993). Methods for Estimating Atmospheric Emissions from UK Oil and Gas Exploration and Production Facilities in the UK Continental Shelf Area.

US EPA, (1991). Data from landfill gas flare, Confidential Report No. ERC-55.

US EPA, (1995). AP 42 - Compilation of Air Pollutant Emission Factors, Volume I, 5th ed. - Section 13.5 Industrial Flares. AP-42, Research Triangle Park, NC, U.S.

Environmental Protection Agency (US EPA). Available at: http://www.epa.gov/ttn/chief/ap42/ch13/index.html

US EPA, (1998). AP 42 - Compilation of Air Pollutant Emission Factors, Volume I, 5th ed. - Section 2.4 Municipal Solid Waste Landfills. AP-42, Research Triangle Park, NC, U.S. Environmental Protection Agency (US EPA). Available at: http://www.epa.gov/ttn/chief/ap42/ch02/index.html

US EPA, (2004). Air Quality Criteria for Particulate Matter Volume I. Research Triangle Park, NC.

US EPA, (2012). Report to Congress on Black Carbon. EPA-450/R-12-001, Research Triangle Park, NC, United States Environmental Protection Agency.

US EPA, (2013a). Carbon Monoxide - National Trends in CO Levels. http://www.epa.gov/airtrends/carbon.html\#conat

US EPA, (2013b). Atmospheric Concentrations of Greenhouse Gases. http://www.epa.gov/climatechange/pdfs/print_ghg-concentrations-2013.pdf

US EPA, (2014). WebFIRE. http://cfpub.epa.gov/webfire/ 
Villasenor, R., Magdaleno, M., Quintanar, A., Gallardo, J., Lopez, M., Jurado, R., Miranda, A., Aguilar, M., Melgarejo, L., Palmerin, E., et al., (2003). An air quality emission inventory of offshore operations for the exploration and production of petroleum by the Mexican oil industry. Atmos. Environ. . 37:3713-3729. 


\title{
Appendix A Supplemental Information for Calculating Uncertainty on Combustion Efficiency, Plume Flow Rate, Species Emissions Rates, and Destruction Removal Efficiency
}

\author{
Detailed Expressions and Methodologies for Measuring Flare \\ Combustion Efficiency, Species Emission Rates, and Associated \\ Uncertainties
}

Darcy J. Corbin and Matthew R. Johnson*

Energy \& Emissions Research Lab, Mechanical and Aerospace Engineering, Carleton University 1125 Colonel By Drive, Ottawa, ON, K1S 5B6, Canada

Calculating Uncertainty on Combustion Efficiency, Plume Flow Rate, Species Emission Rates, and Destruction Removal Efficiency

An uncertainty analysis based on the ANSI/ASME (1985) standard is outlined for the combustion efficiency, plume flow rate, species emission rate, and destruction removal efficiency (DRE) expressions developed in the manuscript. Uncertainty on a measurement is defined as the root sum of squares of the systematic and precision errors. By determining the sources of possible systematic error in a measured quantity, a set of expressions can be developed to evaluate the sensitivity of that quantity to its input variables. The systematic error of each input variable is assumed to be normally distributed. This error is generally determined by the equipment used to measure the 
input variable and does not vary among measurements in a given experimental setup. The systematic error of a function, $B_{f}$, is defined in Eq. (A.1) as the square root of the summed squared product of the sensitivity indices, $\theta_{f, i}$, and the systematic errors, $B_{x_{i}}$, of each contributing measured variable, $x_{i}$ :

$$
B_{f}=\left(\sum_{i=1}^{n}\left[\theta_{f, i} B_{x_{i}}\right]^{2}\right)^{1 / 2}
$$

Precision error, $P$, is determined from repeated measurements at the same conditions using the same experimental set up, and is defined generally by Eq. (A.2) using the $95 \%$ confidence interval student $t$-value:

$$
P=t_{v, 95 \%} \frac{\sigma}{\sqrt{N}}
$$

where $\sigma$ is the sample standard deviation and $N$ is the sample size. The degrees of freedom, $v$, for determining the student $t$-value is calculated as $N-1$. Systematic and precision error defined by Eq. (A.1) and Eq. (A.2) above are combined in quadrature to determine the total uncertainty on a set of measurements via Eq. (A.3).

$$
U=\sqrt{B_{f}^{2}+P^{2}}
$$

The sensitivity index, $\theta_{f, i}$, for a measured variable $x_{i}$ is the partial derivative of the output function with respect to that variable:

$$
\theta_{f, i}=\frac{\partial f}{\partial x_{i}}
$$

The various expressions for combustion efficiency, plume flow rate, species emission rate, and DRE presented in the manuscript have explicit partial derivatives for each measured variable. Table A1 presents a list of these measured variables alongside 
typical values of their component errors for the Carleton lab-scale flare experimental set

up. These values would be subject to adjustment depending on instrumentation used.

\section{Table A1: Variables appearing in sensitivity indices of combustion efficiency, plume gas flow rate, and species emission rate functions}

\begin{tabular}{|c|c|c|c|}
\hline$i$ & Variable, $x_{i}$ & Definition & $\begin{array}{l}\text { Typical Systematic } \\
\text { Error Value, } \boldsymbol{B}_{x_{i}}\end{array}$ \\
\hline 1 & $x$ & carbon coefficient of fuel hydrocarbons & $\sim 0.3 \%$ of carbon coefficient \\
\hline 2 & $X_{C_{x} H_{y}, F G}$ & hydrocarbon volume fraction in fuel & $\begin{array}{l}\sim 2.5 \% \text { of flare gas } \mathrm{C}_{\mathrm{X}} \mathrm{H}_{\mathrm{Y}} \\
\text { fraction }\end{array}$ \\
\hline 3 & $X_{\mathrm{CO}_{2}, \mathrm{FG}}$ & carbon dioxide diluent volume fraction in fuel & $\sim 2.5 \%$ of flare gas $\mathrm{CO}_{2}$ fraction \\
\hline 4 & $X_{\mathrm{CO}_{2}, \text { plume }}$ & plume carbon dioxide volume fraction & $2 \%$ of measured concentration \\
\hline 5 & $X_{\mathrm{CO}_{2}, \infty}$ & ambient carbon dioxide volume fraction & $2 \%$ of measured concentration \\
\hline 6 & $X_{C O, p l u m e}$ & plume carbon monoxide volume fraction & $0.15 \mathrm{ppm}_{\mathrm{v}}$ detection limit \\
\hline 7 & $X_{C O, \infty}$ & ambient carbon monoxide volume fraction & $0.15 \mathrm{ppm}_{\mathrm{v}}$ detection limit \\
\hline 8 & $X_{\mathrm{CH}_{4}, \text { plume }}$ & plume methane volume fraction & $0.10 \mathrm{ppm}_{\mathrm{v}}$ detection limit \\
\hline 9 & $X_{C_{4}, \infty}$ & ambient methane volume fraction & $0.10 \mathrm{ppm}_{\mathrm{v}}$ detection limit \\
\hline 10 & $X_{C_{m} H_{n}, \text { plume }}$ & $\begin{array}{l}\text { plume non-methane hydrocarbon volume } \\
\text { fraction }\end{array}$ & $0.30 \mathrm{ppm}_{\mathrm{v}}$ detection limit \\
\hline 11 & $X_{C_{m} H_{n}, \infty}$ & $\begin{array}{l}\text { ambient non-methane hydrocarbon volume } \\
\text { fraction }\end{array}$ & $0.30 \mathrm{ppm}_{\mathrm{v}}$ detection limit \\
\hline 12 & $f_{v, \text { measured }}$ & plume soot volume fraction & $\begin{array}{l}20 \% \text { of measured soot volume } \\
\text { fraction }\end{array}$ \\
\hline 13 & $T_{\text {sample }}$ & $\begin{array}{l}\text { soot volume fraction sample measurement } \\
\text { temperature }\end{array}$ & 2.2 Kelvin \\
\hline 14 & $P_{\text {plume }}$ & absolute pressure of plume & 15 Pascals \\
\hline 15 & $M_{F G}$ & molar mass of flare gas & $\sim 1.7 \%$ of flare gas molar mass \\
\hline 16 & $\dot{m}_{F G}$ & mass flow rate of flare gas & $\begin{array}{l}\sim 1.2 \% \text { of flare gas mass flow } \\
\text { rate }\end{array}$ \\
\hline 17 & $\dot{m}_{\text {tracer }}$ & mass flow rate of tracer gas & $\begin{array}{l}\sim 1.27 \% \text { of tracer gas mass flow } \\
\text { rate }\end{array}$ \\
\hline 18 & $X_{\text {tracer }}$ & plume tracer volume fraction with injection & $2 \%$ of measured concentration \\
\hline 19 & $X_{\text {tracer }}^{*}$ & plume tracer volume fraction prior to injection & $0.30 \mathrm{ppm}_{\mathrm{v}}$ detection limit \\
\hline 20 & $\dot{n}_{\text {plume,gas }}$ & molar flow rate of diluted combustion plume & \\
\hline 21 & $X_{i, p l u m e}$ & plume volume fraction of species $i$ & species dependant \\
\hline 22 & $X_{i, \infty}$ & ambient volume fraction of species $i$ & species dependant \\
\hline 23 & $X_{i, F G}$ & diluent volume fraction in fuel of species $i$ & species dependant \\
\hline
\end{tabular}

Multiple explicit expressions were developed for combustion efficiency and plume flow rate as outlined in the manuscript. Eq. (3.19) and Eq. (3.12) define combustion efficiency using the carbon-balance method with and without the inclusion of black carbon measurement respectively. Plume flow rate is also defined for the carbon- 
balance method with and without measurement of black carbon, Eq. (3.17) and Eq. (3.11), as well as for the tracer-injection method, Eq. (3.22). The sensitivity indices presented in the following sections are derived for the more general case including black carbon measurement. For cases where only gas phase measurements are considered, i.e. Eq. (3.12) and Eq. (3.13), terms including the measured soot volume fraction, $f_{v, \text { measured }}$, should be set to zero along with $\theta_{f, 12}$ through $\theta_{f, 14}$ in Table A2 and Table A3.

\section{A1 Sensitivity Indices for Combustion Efficiency Calculated Via the Carbon-Balance Method}

The combustion efficiency calculated using the carbon-balance method, including a black carbon measurement, is defined per Eq. (3.19) in the manuscript as:

$$
\eta[\%]=\frac{x\left(X_{C_{x} H_{y}, F G}\right) B-X_{C O_{2}, F G} F+\left(X_{C O_{2}, \infty} G-X_{C O_{2}, p l u m e}\left(X_{C O, \infty}+X_{C H_{4}, \infty}+\sum_{i} \#_{C, C_{m} H_{n}} X_{C_{m} H_{n}, \infty}\right)\right) \frac{M_{F G}}{M_{\infty}}}{x\left(X_{C_{x} H_{y}, F G}\right)\left(X_{C O_{2}, p l u m e}-X_{C O_{2}, \infty}+F\right)} \times 100
$$

where $B=\left(X_{C O_{2}, p l u m e}-X_{C O_{2}, \infty}\right)$,

$$
\begin{aligned}
& F=\left(\left(X_{C O, p l u m e}-X_{C O, \infty}+X_{C H_{4}, p l u m e}-X_{C H_{4}, \infty}+\sum_{m, n} \#_{C, C_{m} H_{n}}\left(X_{C_{m} H_{n}, p l u m e}-X_{C_{m} H_{n}, \infty}\right)\right)+H\right), \\
& G=\left(X_{C O, \text { plume }}+X_{C H_{4}, \text { plume }}+\sum_{i} \#_{C, C_{m} H_{n}} X_{C_{m} H_{n}, p l u m e}+H\right), \text { and } \\
& H=\frac{\rho C_{(s)} f_{v, \text { measured } R_{u} T_{\text {sample }}}}{M_{\left.C_{(S)}\right)^{\text {plume }}}} .
\end{aligned}
$$

The sensitivity indices for evaluating systematic error on combustion efficiency are given in Table A2 below. The numbered sensitivity indices in Table A2 correspond to the variable numbers defined in Table A1, and indicate the variable of differentiation used to develop the expression. As noted previously, if black carbon is neglected the measured soot volume fraction (contained in the coefficient $D$ ) and indices $\theta_{\eta, 12}$ through $\theta_{\eta, 14}$ should be set equal to zero. 
Table A2: Sensitivity indices for combustion efficiency, $\eta$

\begin{tabular}{|c|}
\hline$\theta_{\eta, 1}=\frac{X_{C O_{2}, F G} F-\left(X_{C O_{2}, \infty} G-X_{C O_{2}, p l u m e}\left(X_{C O, \infty}+X_{C H_{4}, \infty}+\sum_{i} \# \#_{C, C_{m} H_{n}} X_{C_{m} H_{n}, \infty}\right)\right) \frac{M_{F G}}{M_{\infty}}}{x^{2}\left(X_{C_{x} H_{y}, F G}\right)\left(X_{C O_{2}, p l u m e}-X_{C O_{2}, \infty}+F\right)} \times 100$ \\
\hline$\theta_{\eta, 2}=\frac{X_{C O_{2}, F G} F-\left(X_{C O_{2}, \infty} G-X_{C O_{2}, p l u m e}\left(X_{C O, \infty}+X_{C H_{4}, \infty}+\sum_{i} \#_{C, C_{m} H_{n}} X_{C_{m} H_{n} \infty}\right)\right) \frac{M_{F G}}{M_{\infty}}}{x\left(X_{C_{X} H_{y}, F G}\right)^{2}\left(X_{C O_{2}, p l u m e}-X_{C O_{2}, \infty}+F\right)} \times 100$ \\
\hline$\theta_{\eta, 3}=-\frac{\left(X_{C O, p l u m e}-X_{C O, \infty}+X_{C H_{4}, p l u m e}-X_{C H_{4}, \infty}+\sum_{m, n} \#_{C, C_{m} H_{n}}\left(X_{C_{m} H_{n}, p l u m e}-X_{C_{m} H_{n}, \infty}\right)+H\right)}{x\left(X_{C_{X} H_{y}, F G}\right)\left(X_{C O_{2}, p l u m e}-X_{C O_{2}, \infty}+F\right)} \times 100$ \\
\hline$\theta_{\eta, 4}=\frac{\left(x\left(X_{C_{x} H_{y}, F G}\right)+X_{C O_{2}, F G}-\left(X_{C O_{2}, \infty}+X_{C O, \infty}+X_{C H_{4}, \infty}+\sum_{i} \#_{C, C_{m} H_{n}} X_{C_{m} H_{n}, \infty}\right) \frac{M_{F G}}{M_{\infty}}\right) F}{x\left(X_{C_{x} H_{y}, F G}\right)\left(X_{C O_{2}, p l u m e}-X_{C O_{2}, \infty}+F\right)^{2}} \times 100$ \\
\hline$\theta_{\eta, 5}=-\frac{\left(x\left(X_{C_{x} H_{y}, F G}\right)+X_{C O_{2}, F G}-\left(X_{C O_{2}, p l u m e}+X_{C O, p l u m e}+X_{C H_{4}, p l u m e}+\sum_{i}{ }_{C} C_{C} C_{m} H_{n} X_{C_{m} H_{n}, p l u m e}+H\right) \frac{M_{F G}}{M_{\infty}}\right) F}{x\left(X_{C_{x} H_{y}, F G}\right)\left(X_{C O_{2}, p l u m e}-X_{C O_{2}, \infty}+F\right)^{2}} \times 100$ \\
\hline$\theta_{\eta, 6}=\theta_{\eta, 8}=\frac{\theta_{\eta, 10}}{\# C, C_{m} H_{n}}=-\frac{\left(x\left(x_{C_{x} H_{y}, F G}\right)+X_{C O_{2}, F G}-\left(X_{C O_{2}, \infty}+X_{C O, \infty}+X_{C H_{4}, \infty}+\sum_{i} \# C, C_{m} H_{n} X_{C_{m} H_{n}, \infty}\right) \frac{M_{F G}}{M_{\infty}}\right) B}{x\left(x_{C_{x} H_{y}, F G}\right)\left(x_{C O_{2}, p l u m e}-X_{C O_{2}, \infty}+F\right)^{2}} \times 100$ \\
\hline$\theta_{\eta, 7}=\theta_{\eta, 9}=\frac{\theta_{\eta, 11}}{\#_{C, C_{m} H_{n}}}=\frac{\left(x\left(x_{C_{x} H_{y}, F G}\right)+X_{C O_{2}, F G}-\left(X_{C O_{2}, p l u m e}+X_{C O, p l u m e}+X_{C H_{4}, p l u m e}+\sum_{i} \#_{C, C_{m} H_{n}} X_{C_{m} H_{n}, p l u m e}+H\right) \frac{M_{F G}}{M_{\infty}}\right) B}{x\left(X_{C_{x} H_{y}, F G}\right)\left(X_{C O_{2}, p l u m e}-X_{C O_{2}, \infty}+F\right)^{2}} \times 100$ \\
\hline$\theta_{\eta, 12}=-\frac{H}{f_{v, \text { measured }}}\left(\frac{\left(x\left(X_{C_{x} H_{y}, F G}\right)+X_{C O_{2}, F G}-\left(X_{C O_{2}, \infty}+X_{C O, \infty}+X_{C H_{4}, \infty}+\sum_{i} \# C_{C, C_{m} H_{n}} X_{C_{m} H_{n}, \infty}\right) \frac{M_{F G}}{M_{\infty}}\right) B}{x\left(X_{C_{x} H_{y, F G}}\right)\left(X_{C O_{2}, p l u m e}-X_{C O_{2}, \infty}+F\right)^{2}}\right) \times 100$ \\
\hline$\theta_{\eta, 13}=-\frac{H}{T_{\text {sample }}}\left(\frac{\left(x\left(X_{C_{x} H_{y}, F G}\right)+X_{C O_{2}, F G}-\left(X_{C O_{2}, \infty}+X_{C O, \infty}+X_{C H_{4}, \infty}+\sum_{i} \# C, C_{m} H_{n} X_{C_{m} H_{n}, \infty}\right)_{M_{\infty}}\right) B}{x\left(X_{C_{x} H_{y}, F G}\right)\left(X_{C O_{2}, p l u m e}-X_{C O_{2}, \infty}+F\right)^{2}}\right) \times 100$ \\
\hline$\theta_{\eta, 14}=\frac{H}{P_{\text {plume }}}\left(\frac{\left(x\left(X_{C_{x} H y, F G}\right)+X_{C O_{2}, F G}-\left(X_{C O_{2}, \infty}+X_{C O, \infty}+X_{C H_{4}, \infty}+\sum_{i} \#_{C, C_{m} H_{n}} X_{C_{m} H_{n}, \infty}\right) \frac{M_{F G}}{M_{\infty}}\right) B}{x\left(X_{C_{X} H_{y}, F G}\right)\left(X_{C O_{2}, p l u m e}-X_{C O_{2}, \infty}+F\right)^{2}}\right) \times 100$ \\
\hline$\theta_{\eta, 15}=\frac{\left(X_{C O_{2}, \infty} G-X_{C O_{2}, p l u m e}\left(X_{C O, \infty}+X_{C H_{4}, \infty}+\sum_{i} \# C_{C, C_{m} H_{n}} X_{C_{m} H_{n}, \infty}\right)\right)}{M_{\infty} x\left(X_{C_{X} H_{y}, F G}\right)\left(X_{C O_{2}, p l u m e}-X_{C O_{2}, \infty}+F\right)} \times 100$ \\
\hline
\end{tabular}

The systematic error on combustion efficiency calculated using the carbonbalance method can now be evaluated with Eq. (A.5) using the sensitivity index expressions from Table A2 and appropriate component systematic error values (such as those specified in Table A1):

$$
B_{\eta}=\left(\sum_{i=1}^{15}\left[\theta_{\eta, i} B_{x_{i}}\right]^{2}\right)^{1 / 2}
$$

This systematic error ((A.5)) can then be combined in quadrature with the experimental precision error (Eq. (A.2)) to determine the total uncertainty on a set of measurements in accordance with Eq. (A.3). 


\section{A2 Sensitivity Indices for Plume Flow Rate Determined using the Carbon-Balance Method}

The plume flow rate, $\dot{n}_{\text {plume,gas }}$, calculated using the carbon-balance method including black carbon measurement is defined per Eq. (3.17) in the manuscript. By incorporating the substitution from Eq. (3.18), $\dot{n}_{\text {plume,gas }}$ may be written as:

$$
\dot{n}_{\text {plume,gas }}=\frac{x\left(X_{C_{x} H_{y, F G}}\right) \frac{\dot{m}_{F G}}{M_{F G}}+X_{C O_{2}, F G} \frac{\dot{m}_{F G}}{M_{F G}}-\left(X_{C O_{2}, \infty}+X_{C O, \infty}+X_{C H_{4}, \infty}+\sum_{i} \#_{C, C_{m} H_{n}} X_{C_{m} H_{n}, \infty}\right) \frac{\dot{m}_{F G}}{M_{\infty}}}{X_{C O_{2}, \text { plume }}-X_{C O_{2}, \infty}+\frac{\rho_{C_{(s)}} f_{v, \text { measured }} R_{u} T_{\text {sample }}}{M_{C_{(s)}} P_{\text {plume }}}+A}
$$

where $\mathrm{A}=\left(X_{C O, p l u m e}-X_{C O, \infty}+X_{C H_{4}, p l u m e}-X_{C H_{4}, \infty}+\sum_{m, n} \#_{C, C_{m} H_{n}}\left(X_{C_{m} H_{n}, p l u m e}-X_{C_{m} H_{n}, \infty}\right)\right)$, and

$$
D=\left(X_{\text {Co,plume }}+X_{C H_{4}, \text { plume }}+\sum_{i} \#_{C, C_{m} H_{n}} X_{C_{m} H_{n}, p l u m e}\right)
$$

The sensitivity indices for evaluating the systematic error on $\dot{n}_{\text {plume,gas }}$ calculated with the carbon-balance method are shown in Table A3 below. Similar to the calculation of systematic error for combustion efficiency, if black carbon is not measured

the term $f_{v, \text { measured }}$ and indices $\theta_{\dot{n}_{\text {plume,gas }}, 12}$ through $\theta_{\dot{n}_{\text {plume,gas }}, 14}$ should be set equal to zero. 
Table A3: Sensitivity indices for plume flow rate, $\dot{\boldsymbol{n}}_{\text {plume,gas }}$

\begin{tabular}{|c|c|}
\hline$\theta_{\dot{n}_{\text {plume,gas }}, 1}$ & 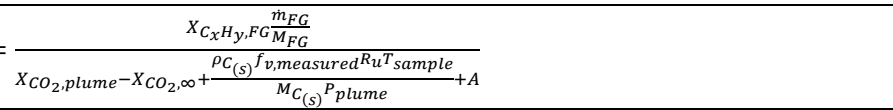 \\
\hline$\theta_{\dot{n}_{\text {plume }, \text { gas }},}$ & 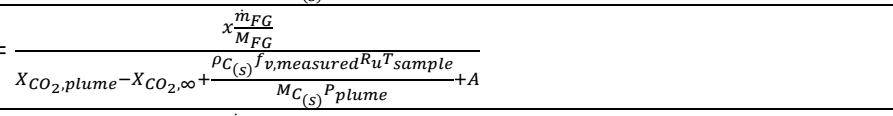 \\
\hline$\theta_{\dot{n}_{\text {plume,gas }}}$ & 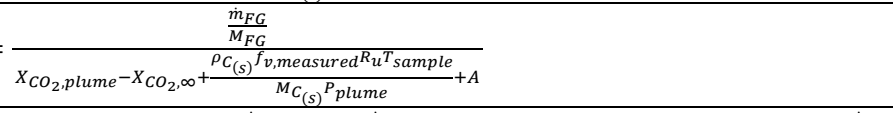 \\
\hline \multicolumn{2}{|c|}{ 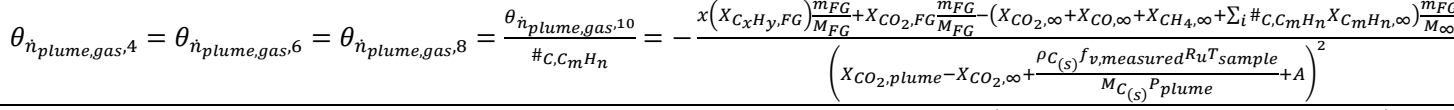 } \\
\hline$\theta_{\dot{n}_{\text {plume }, \text { gas }, 5}}=\theta_{\dot{n}_{\text {plume }, \text { gas }, 7}}=\theta_{\dot{n}_{\text {plume }, \text { gas }, 9}}=\frac{\theta}{\theta}$ & 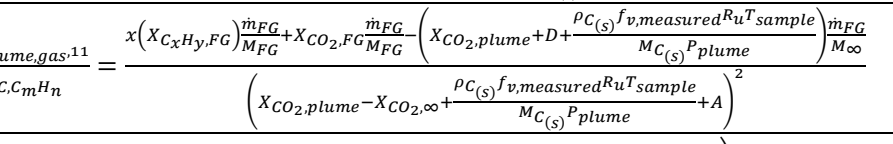 \\
\hline$\theta_{\dot{n}_{\text {plume }, \text { gas }, 12}}=-\frac{\rho_{C_{(s)} R_{u} T_{\text {sample }}}}{M_{C_{(s)}} P_{\text {plume }}}$ & 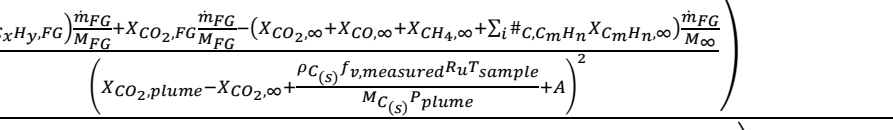 \\
\hline$\theta_{\dot{n}_{\text {plume,gas }, 13}}=-\frac{\rho_{C_{(s)}} f_{v, \text { measured }} R_{u}}{M_{C_{(s)}} P_{\text {plume }}}$ & 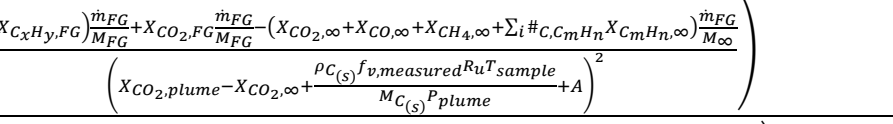 \\
\hline$\theta_{\dot{n}_{\text {plume,gas }}, 14}=\frac{\rho_{C_{(s)} f_{v, \text { measured }} R_{u} T_{\text {sample }}}}{M_{C_{(s)}}\left(P_{\text {plume }}\right)^{2}}$ & 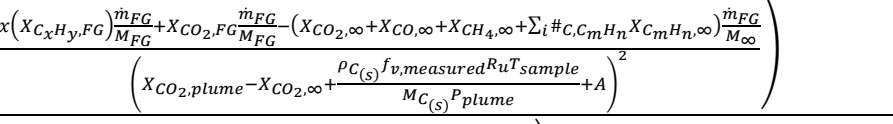 \\
\hline$\theta_{\dot{n}_{\text {plume,gas }, 15}}=-$ & 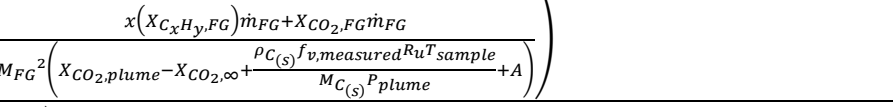 \\
\hline$\theta_{\dot{n}_{\text {plume }, \text { gas }, 16}}=\frac{\frac{x\left(X_{C_{x}}\right.}{M}}{}$ & 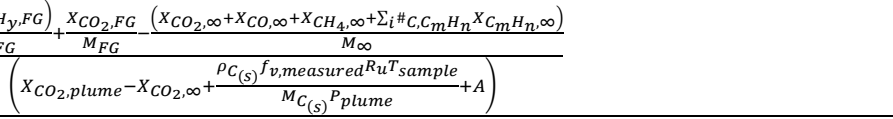 \\
\hline
\end{tabular}

The systematic error on $\dot{n}_{\text {plume,gas }}$ calculated using the carbon-balance method can now be evaluated with Eq. (A.7) using the sensitivity indices provided in Table A3 in combination with appropriate component bias error values (such as those specified in Table A1):

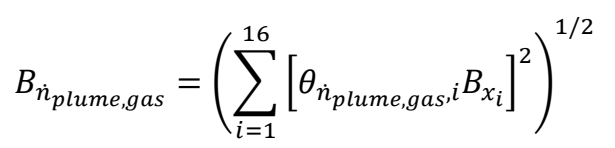


This systematic error (Eq. (A.7)) can then be combined in quadrature with the experimental precision error (Eq. (A.2)) to determine the total uncertainty on a set of measurements in accordance with Eq. (A.3).

\section{A3 Sensitivity Indices for Plume Flow Rate using Tracer Gas Measurement}

For a measurement of $\dot{n}_{\text {plume,gas }}$ using the tracer-injection method, Eq. (3.22) from the manuscript is used:

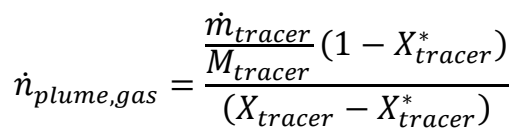

Calculation of $\dot{n}_{\text {plume,gas }}$ via the tracer-injection method utilizes a different set of variables than those used in the carbon-balance method. These appear as variables 17 through 19 in Table A1 alongside typical values of their systematic errors. The corresponding sensitivity indices for calculating the systematic error on $\dot{n}_{\text {plume,gas }}$ deterimed via the tracer-injection method are given in Table A4.

Table A4: Sensitivity indices for plume flow rate measurement using tracer gas, $\dot{n}_{\text {plume,gas }}$

\begin{tabular}{|c|c|}
\hline & 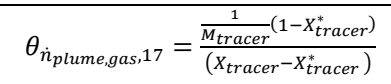 \\
\hline & $\theta_{\dot{n}_{\text {plume,gas }}, 18}=-\frac{\frac{\dot{m}_{\text {tracer }}}{M_{\text {tracer }}\left(1-X_{\text {tracer }}^{*}\right)}}{\left(X_{\text {tracer }}-X_{\text {tracer }}^{*}\right)^{2}}$ \\
\hline & $\theta_{\dot{n}_{\text {plume,gas }, 19}}=\frac{\frac{\dot{m}_{\text {tracer }}\left(1-X_{\text {tracer }}\right)}{\bar{M}_{\text {tracer }}}}{\left(X_{\text {tracer }}-X_{\text {tracer }}^{*}\right)^{2}}$ \\
\hline
\end{tabular}

The systematic error on $\dot{n}_{\text {plume,gas }}$ calculated using the tracer-injection method can now be determined with Eq. (A.8) using the sensitivity indices from Table A4 and appropriate component systematic error values (such as those specified in Table A1). 


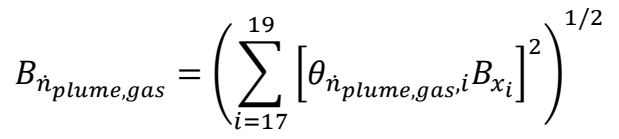

This systematic error (Eq. (A.8)) can then be combined in quadrature with the experimental precision error (Eq. (A.2)) to determine the total uncertainty on a set of measurements in accordance with Eq. (A.3).

\section{A4 Sensitivity Indices for Species Emission Rates and Destruction Removal Efficiency}

All species emission rates and DREs are functions of the general intermediate variable, $\dot{n}_{\text {plume,gas }}$, which can be calculated using either the carbon-balance, Eq. (3.11) or Eq. (3.17), or the tracer-injection method, Eq. (3.22). General expressions derived in the manuscript for the mass production rate of a gas species $i$, Eq. (3.13), and black carbon as soot, Eq. (3.21), are reprinted below. A generalized expression for DRE is defined by Eq. (A.9). The specific sensitivity indices used to calculate systematic error on a species emission rate or DRE are not identical between the carbon-balance and tracer-injection methods in all instances. When calculating the emission rate of a carbon-based species (either gas-phase carbon-based species or black carbon) or DRE of a carbon-based species present in the flare gas using the carbon-balance method, the uncertainty analysis is complicated by a lack of independence between the species of interest and the calculated plume flow rate. This is addressed in Section A4.2. Section A4.1 details the procedure for calculating uncertainties in any species emission rate or DRE determined via the tracer-injection method, and for non-carbon-based species emission rates DRE determined via the carbon-balance method.

$$
\dot{m}_{i, \text { produced }}=M_{i}\left(\left(X_{i, p l u m e}-X_{i, \infty}\right) \dot{n}_{\text {plume }, \text { gas }}-\left\{X_{i, F G} \frac{\dot{m}_{F G}}{M_{F G}}\right\}_{\text {inert }}+X_{i, \infty} \frac{\dot{m}_{F G}}{M_{\infty}}\right)
$$




$$
\begin{gathered}
\dot{m}_{C_{(s)} \text { produced }}=\frac{\rho_{C_{(s)}} f_{v, \text { measured }} R_{u} T_{\text {sample }}}{P_{\text {plume }}} \dot{n}_{\text {plume }, \text { gas }} \\
D R E_{i}[\%]=\left(1-\frac{\left(X_{i, \text { plume }}-X_{i, \infty}\right) \dot{n}_{\text {plume,gas }}+X_{i, \infty} \frac{\dot{m}_{F G}}{M_{\infty}}}{X_{i, F G} \frac{\dot{m}_{F G}}{M_{F G}}}\right) \times 100
\end{gathered}
$$

\section{A4.1 Sensitivity Indices for Species Emission Rates and DREs Determined using the Tracer-Injection Method and for Non-Carbon-Based Gas-Phase Species Emission Rates and DREs Determined using the Carbon-Balance Method}

The equations in this section are used to calculate the systematic error in any species emission rate or DRE determined via the tracer-injection method, and the systematic error in any non-carbon-based species emission rate (e.g. $\mathrm{NO}_{\mathrm{X}}$ ) or DRE (e.g. $\mathrm{H}_{2} \mathrm{~S}$ ) determined via the carbon-balance method. The sensitivity indices for these cases are given in Table A5 (gas-phase emission rate), Table A6 (black carbon emission rate) and Table A7 (DRE). The indices include the sensitivity to the flare gas molar mass, $\theta_{f, 15}$,

and mass flow rate, $\theta_{f, 16}$, as well as several unique indices. $\theta_{f, 20}$ refers to the plume flow rate systematic error as calculated using Eq. (A.7) or Eq. (A.8), and $\theta_{f, 21}$ through $\theta_{f, 23}$ refer to the specific gas species for which the emission rate or DRE is being quantified. 
Table A5: Sensitivity indices for gas species emission rate, $\dot{\boldsymbol{m}}_{\boldsymbol{i} \text {,produced }}$ (used for calculation of systematic error in any species emission rate determined via the tracer-injection method and for calculation of systematic error in any non-carbonbased species emission rate determined via the carbon-balance method)

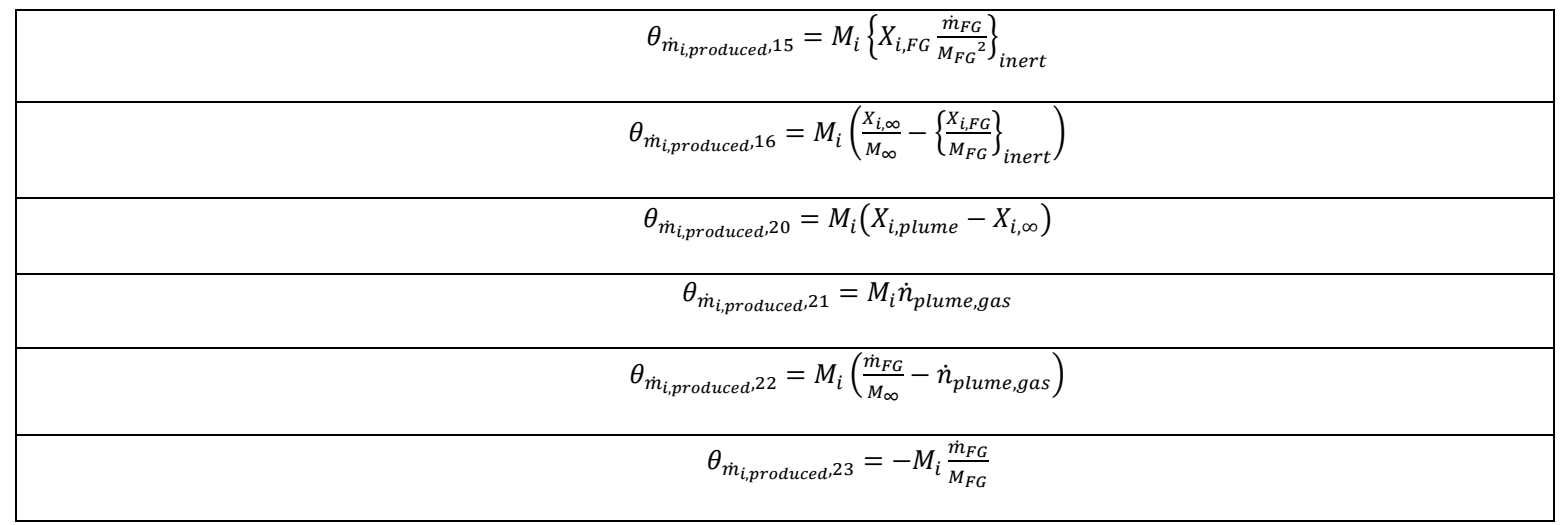

Table A6: Sensitivity indices for soot emission rate, $\dot{\boldsymbol{m}}_{C_{(s)}, \text { produced }}$ (used for calculation of systematic error in black carbon emission rates determined via the tracer-injection method)

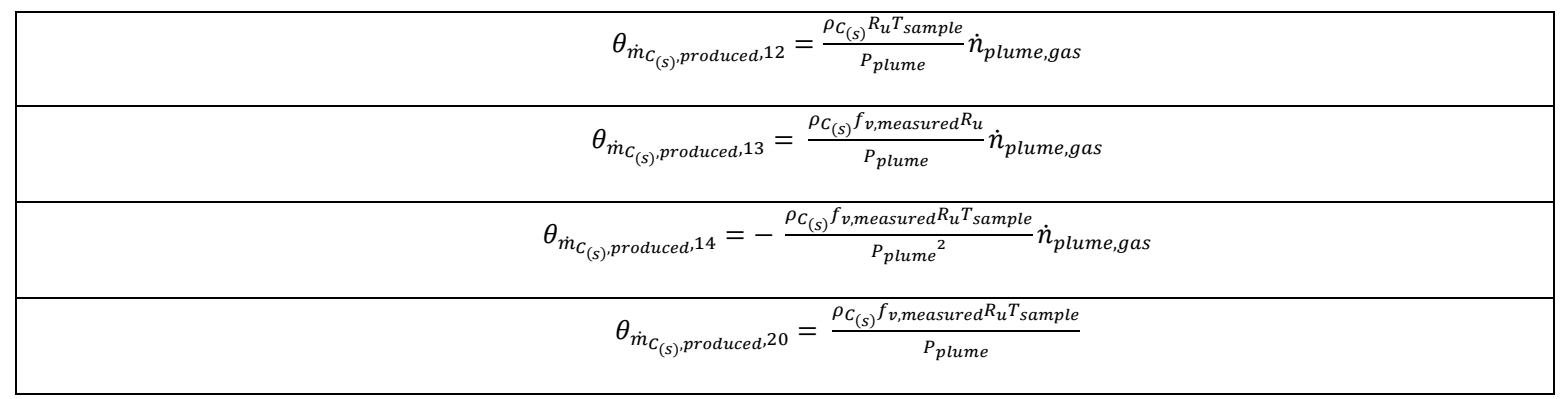


Table A7: Sensitivity indices for destruction removal efficiency, $D R E_{i}$ (used for calculation of systematic error in any species DRE determined via the tracerinjection method and for calculation of systematic error in any non-carbon-based species DRE determined via the carbon-balance method)

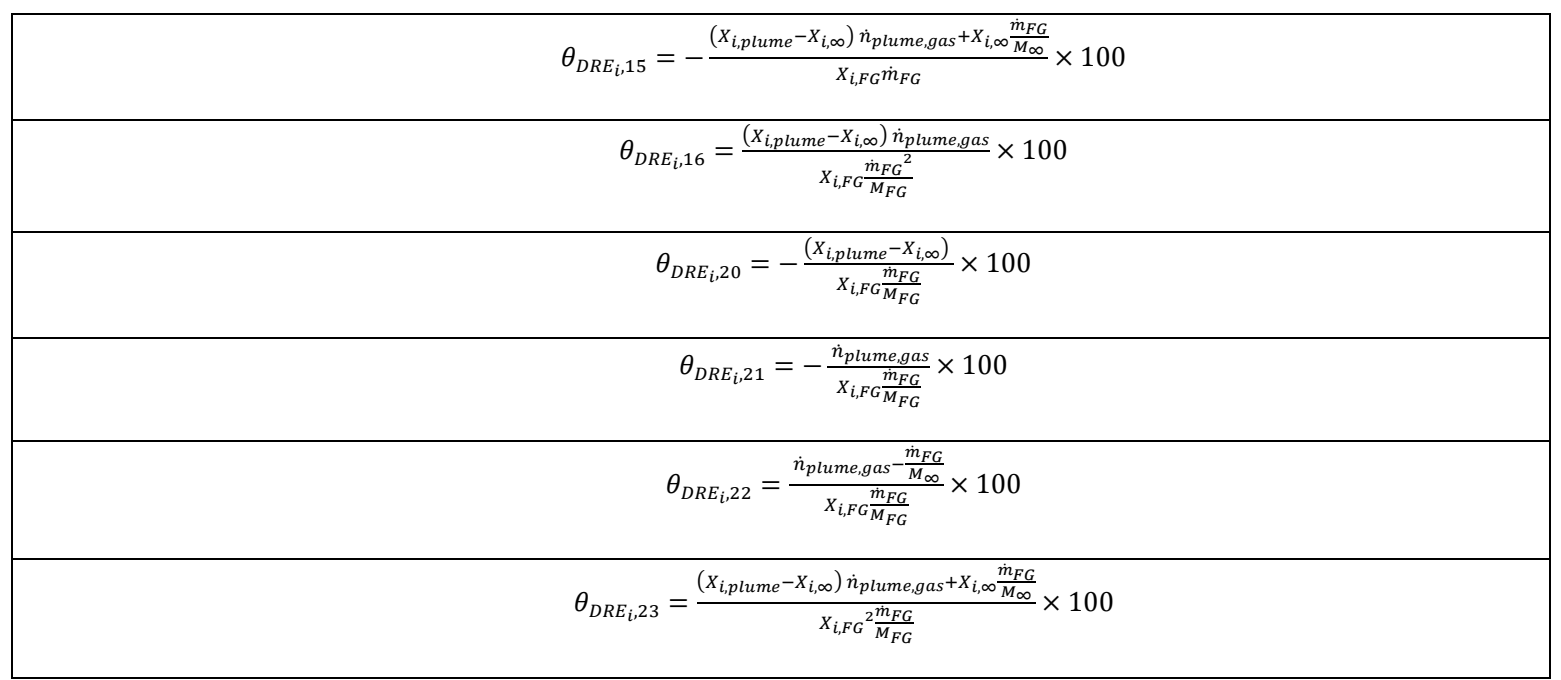

The systematic error on a gaseous species emission rate defined by Eq. (3.13) in the manuscript can now be evaluated with Eq. (A.10) using the sensitivity index expressions from Table A5 and appropriate component systematic error values (such as those specified in Table A1):

$$
B_{\dot{m}_{i, p r o d u c e d}}=\left(\left[\theta_{\dot{m}_{i, \text { produced }}, 16} B_{x_{16}}\right]^{2}+\sum_{i=20}^{23}\left[\theta_{\dot{m}_{i, \text { produced } i} i} B_{x_{i}}\right]^{2}\right)^{1 / 2}
$$

Similarly, the systematic error on the black carbon emission rate defined by Eq. (3.21) in the manuscript can be evaluated with Eq. (A.11) using the sensitivity index expressions from Table A6 and appropriate component systematic error values (such as those specified in Table A1):

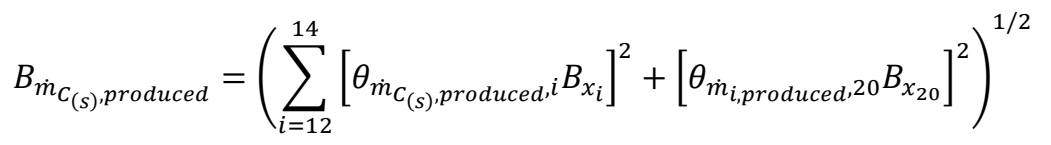


Finally, the systematic error on the destruction removal efficiency defined by Eq. (A.9) can be evaluated with Eq. (A.12) using the sensitivity index expressions from Table A7 and appropriate component systematic error values (such as those specified in Table A1):

$$
B_{D R E_{i}}=\left(\sum_{i=15}^{16}\left[\theta_{D R E_{i} i} B_{x_{i}}\right]^{2}+\sum_{i=20}^{23}\left[\theta_{\dot{m}_{i, p r o d u c e d} i} B_{x_{i}}\right]^{2}\right)^{1 / 2}
$$

The systematic error can then be combined in quadrature with the experimental precision error (Eq. (A.2)) to determine the total uncertainty on a set of measurements in accordance with Eq. (A.3).

\section{A4.2 Sensitivity Indices for Soot and Carbon-Based Gas-Phase Emission Rates using Carbon-Balance to Calculate $\dot{\boldsymbol{n}}_{\text {plume,gas }}$}

As mentioned in Section A4, for calculation of carbon-based species emission rates or carbon-based species DRE using the carbon-balance method there is a lack of independence between the calculated plume flow rate and the equations used to evaluate the species emission rate or DRE. For emission rates of gas-phase carbon-based species calculated with Eq. (3.13) of the manuscript, the applicable sensitivity indices are given in Table A8. For black carbon emission rates calculated with Eq. (3.21) of the manuscript, the relevant sensitivity indices are given in Table A9. For carbon-based species DRE calculated with Eq. (A.9), the relevant sensitivity indices are given in Table A10. 
Table A8: Sensitivity indices for carbon-based gas emission rates calculated with the carbon-balance method

\begin{tabular}{|c|}
\hline$\theta_{\dot{m}_{i, p r o d u c e d}, 1}=M_{i}\left(X_{i, p l u m e}-X_{i, \infty}\right) \theta_{\dot{n}_{\text {plume,gas }, 1}}$ \\
\hline$\theta_{\dot{m}_{i, p r o d u c e d}, 2}=M_{i}\left(X_{i, p l u m e}-X_{i, \infty}\right) \theta_{\dot{n}_{\text {plume,gas },},}$ \\
\hline$\theta_{\dot{m}_{i \text { produced }} 3}=M_{i}\left(X_{i, p l u m e}-X_{i, \infty}\right) \theta_{\dot{n}_{\text {plume,gas }, 3}}$ \\
\hline$\theta_{\dot{m}_{i, p r o d u c e d}, 4}=\theta_{\dot{m}_{i, p r o d u c e d}, 6}=\theta_{\dot{m}_{i, p r o d u c e d}, 8}=\frac{\theta_{\dot{m}_{i, p r o d u c e d} 10}}{\#_{c, c_{m} H_{n}}}=M_{i}\left(X_{i, \text { plume }}-X_{i, \infty}\right) \theta_{\dot{n}_{\text {plume }, \text { gas }, i}}$ \\
\hline 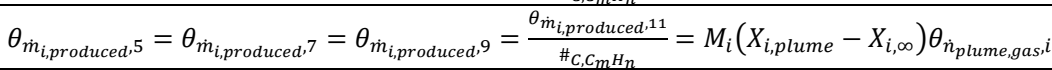 \\
\hline$\theta_{\dot{m}_{i, p r o d u c e d}, 12}=M_{i}\left(X_{i, p l u m e}-X_{i, \infty}\right) \theta_{\dot{n}_{\text {plume,gas }, 12}}$ \\
\hline$\theta_{\dot{m}_{i \text { produced }, 13}}=M_{i}\left(X_{i, p l u m e}-X_{i, \infty}\right) \theta_{\dot{n}_{\text {plume,gas }, 13}}$ \\
\hline 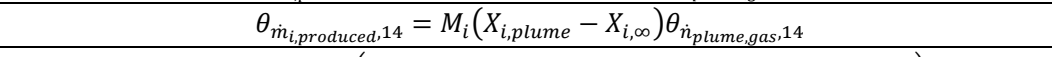 \\
\hline$\theta_{\dot{m}_{i, p r o d u c e d}, 15}=M_{i}\left(\left(X_{i, \text { plume }}-X_{i, \infty}\right) \theta_{\dot{n}_{\text {plume,gas }, 15}}+\left\{X_{i, F G} \frac{\dot{m}_{F G}}{M_{F G}{ }^{2}}\right\}_{\text {inert }}\right)$ \\
\hline 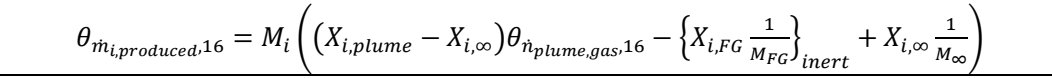 \\
\hline$\theta_{\dot{m}_{i \text { produced }, 21}}=M_{i}\left(\dot{n}_{\text {plume,gas }}+\left(X_{i, \text { plume }}-X_{i, \infty}\right) \theta_{\dot{n}_{\text {plume,gas },} i}\right)$ \\
\hline$\theta_{\dot{m}_{i, p r o d u c e d}, 22}=M_{i}\left(-\dot{n}_{\text {plume,gas }}+\left(X_{i, \text { plume }}-X_{i, \infty}\right) \theta_{\dot{n}_{\text {plume,gas } i} i}+\frac{\dot{m}_{F G}}{M_{\infty}}\right)$ \\
\hline$\theta_{\dot{m}_{i, p r o d u c e d}, 23}=M_{i}\left(\left(X_{i, p l u m e}-X_{i, \infty}\right) \theta_{\dot{n}_{\text {plume }, g a s, 3},}-\frac{\dot{m}_{F G}}{M_{F G}}\right)$ \\
\hline
\end{tabular}

Table A9: Sensitivity indices for black carbon emission rates calculated with the carbon-balance method

\begin{tabular}{|c|}
\hline$\theta_{\dot{m}_{C_{(s)}, \text { produced }, 1}}=\rho_{C_{(s)}} f_{v, \text { measured }} \frac{R_{u} T_{\text {sample }}}{P_{\text {plume }}} \theta_{\dot{n}_{\text {plume,gas }, 1}}$ \\
\hline$\theta_{\dot{m}_{C_{(s)}, \text { produced }, 2}}=\rho_{C_{(s)}} f_{v, \text { measured }} \frac{R_{u} T_{\text {sample }}}{P_{\text {plume }}} \theta_{\dot{n}_{\text {plume }, \text { gas }, 2}}$ \\
\hline$\theta_{\dot{m}_{C_{(s)}, \text { produced }, 3}}=\rho_{C_{(s)}} f_{v, \text { measured }} \frac{R_{u} T_{\text {sample }}}{P_{\text {plume }}} \theta_{\dot{n}_{\text {plume }, \text { gas },}, 3}$ \\
\hline 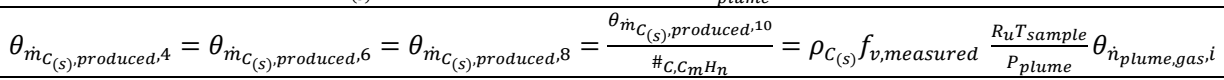 \\
\hline$\theta_{\dot{m}_{(s)}, \text { produced }, 5}=\theta_{\dot{m}_{C_{(s)}, \text { produced }, 7}}=\theta_{\dot{m}_{C_{(s)}, \text { produced }, 9}}=\frac{\theta_{\dot{m}_{C_{(s)}, \text { produced }, 11}}}{{ }_{C, C_{m} H_{n}}}=\rho_{C_{(s)}} f_{v, \text { measured }} \frac{R_{u} T_{\text {sample }}}{P_{\text {plume }}} \theta_{\dot{n}_{\text {plume,gas }, i}}$ \\
\hline$\theta_{\dot{m}_{C_{(s)}, \text { produced }, 12}}=\frac{\rho_{C_{(s)} R_{u} T_{\text {sample }}}}{P_{\text {plume }}}\left(\dot{n}_{\text {plume,gas }}+f_{v, \text { measured }} \theta_{\dot{n}_{\text {plume,gas }, 12}}\right)$ \\
\hline$\theta_{\dot{m}_{C_{(s)}, \text { produced }, 13}}=\frac{\rho_{C_{(s)} f_{v, m e a s u r e d} R_{u}}}{P_{\text {plume }}}\left(\dot{n}_{\text {plume,gas }}+T_{\text {sample }} \theta_{\dot{n}_{\text {plume,gas }, 13}}\right)$ \\
\hline$\theta_{\dot{m}_{C_{(s)}, \text { produced }, 14}}=\frac{\rho_{C_{(S)}} f_{v, \text { measured }} R_{u} T_{\text {sample }}}{P_{\text {plume }}}\left(\theta_{\dot{n}_{\text {plume,gas }, 14}}-\frac{\dot{n}_{\text {plume,gas }}}{P_{\text {plume }}}\right)$ \\
\hline$\theta_{\dot{m}_{C_{(s)}, \text { produced }, 15}}=\rho_{C_{(s)}} f_{v, \text { measured }} \frac{R_{u} T_{\text {sample }}}{P_{\text {plume }}} \theta_{\dot{n}_{\text {plume }, \text { gas }, 15}}$ \\
\hline$\theta_{\dot{m}_{C_{(s)}, \text { produced }, 16}}=\rho_{C_{(s)}} f_{v, \text { measured }} \frac{R_{u} T_{\text {sample }}}{P_{\text {plume }}} \theta_{\dot{n}_{\text {plume }, \text { gas }, 16}}$ \\
\hline
\end{tabular}


Table A10: Sensitivity indices for DRE of a carbon-based species calculated with the carbon-balance method

\begin{tabular}{|c|}
\hline$\theta_{D R E_{i}, 1}=-\frac{\left(x_{i, p l u m e}-X_{i, \infty}\right)}{X_{i, F G} \frac{\dot{m}_{F G}}{M_{F G}}} \theta_{\dot{n}_{\text {plume }, \text { gas },}} \times 100$ \\
\hline$\theta_{D R E_{i}, 2}=-\frac{\left(X_{i, p l u m e}-X_{i, \infty}\right)}{X_{i, F G} \frac{\dot{m}_{F G}}{M_{F G}}} \theta_{\dot{n}_{\text {plume }, g a s}, 2} \times 100$ \\
\hline$\theta_{D R E_{i}, 3}=-\frac{\left(X_{i, p l u m e}-X_{i, \infty}\right)}{X_{i, F G} \frac{\dot{m}_{F G}}{M_{F G}}} \theta_{\dot{n}_{\text {plume }, g a s, 3}} \times 100$ \\
\hline$\theta_{D R E_{i}, 4}=\theta_{D R E_{i}, 6}=\theta_{D R E_{i}, 8}=\frac{\theta_{D R E_{i}, 10}}{\#_{C, C_{m} H_{n}}}=-\frac{\left(X_{i, p l u m e}-X_{i, \infty}\right)}{X_{i, F G} \bar{m}_{F G}} \theta_{\dot{n}_{\text {plume }, \text { gas }, i}} \times 100$ \\
\hline$\theta_{D R E_{i}, 5}=\theta_{D R E_{i}, 7}=\theta_{D R E_{i}, 9}=\frac{\theta_{D R E_{i}, 11}}{\#_{C, C_{m} H_{n}}}=-\frac{\left(x_{i, p l u m e}-X_{i, \infty}\right)}{X_{i, F G} \bar{m}_{F G}} \theta_{\dot{n}_{p l u m e, g a s}, i} \times 100$ \\
\hline$\theta_{D R E_{i}, 12}=-\frac{\left(x_{i, p l u m e}-X_{i, \infty}\right)}{X_{i, F G} \frac{\bar{m}_{F G}}{M_{F G}}} \theta_{\dot{n}_{\text {plume }, \text { gas }}, 12} \times 100$ \\
\hline$\theta_{D R E_{i}, 13}=-\frac{\left(X_{i, p l u m e}-X_{i, \infty}\right)}{X_{i, F G} \frac{\dot{m}_{F G}}{M_{F G}}} \theta_{\dot{n}_{\text {plume }, \text { gas }, 13}} \times 100$ \\
\hline$\theta_{D R E_{i}, 14}=-\frac{\left(x_{i, p l u m e}-X_{i, \infty}\right)}{X_{i, F G} \frac{m_{F G}}{M_{F G}}} \theta_{\dot{n}_{\text {plume }, \text { gas }, 14}} \times 100$ \\
\hline$\theta_{D R E_{i}, 15}=-\left(\frac{\left(X_{i, p l u m e}-X_{i, \infty}\right)\left(\dot{n}_{\text {plume,gas }}+M_{F G} \theta_{\dot{n}_{\text {plume,gas }}, 15}\right)+X_{i, \infty} \frac{\dot{m}_{F G}}{M_{\infty}}}{X_{i, F G} \dot{m}_{F G}}\right) \times 100$ \\
\hline$\theta_{D R E_{i}, 16}=0$ \\
\hline$\theta_{D R E_{i}, 21}=-\frac{\dot{n}_{\text {plume,gas }}+\left(X_{i, p l u m e}-X_{i, \infty}\right) \theta_{\dot{n}_{\text {plume }, \text { gas }}, i}}{X_{i, F G} \dot{m}_{F G}} \times 100$ \\
\hline$\theta_{D R E_{i}, 22}=\frac{\dot{n}_{\text {plume }, \text { gas }}-\frac{\dot{m}_{F G}}{M_{\infty}}-\left(X_{i, p l u m e}-X_{i, \infty}\right) \theta_{\dot{n}_{\text {plume }, g a s, ~}, i}}{X_{i, F G} \frac{\dot{m}_{F G}}{M_{F G}}} \times 100$ \\
\hline$\theta_{D R E_{i}, 23}=\frac{\left(X_{i, p l u m e}-X_{i, \infty}\right) \dot{n}_{\text {plume }, \text { gas }}+X_{i, \infty} \dot{m}_{M_{\infty}}}{X_{i, F G} \frac{\dot{m}_{F G}}{M_{F G}}} \times 100$ \\
\hline
\end{tabular}

The sensitivity indices Table A8, Table A9 and Table A10 are written in terms of $\theta_{\dot{n}_{\text {plume,gas }}, i}$ for consistency and simplicity of presentation. The dependence of $\dot{n}_{\text {plume,gas }}$ and the overall emission rate or DRE on the measured concentrations of the species being evaluated are accounted for with the sensitivity indices $\theta_{f, 21}$ and $\theta_{f, 22}$. For example, to determine the systematic error of a carbon-based gaseous species emission rate measured using the carbon-balance method (e.g. $\mathrm{CH}_{4}$ ), Eq. (A.13) would be used with the sensitivity indices from Table A8:

$$
B_{\dot{m}_{C H_{4}, p r o d u c e d}}=\left(\sum_{i=1}^{7}\left[\theta_{\dot{m}_{C_{4}, p r o d u c e d i} i} B_{x_{i}}\right]^{2}+\sum_{i=10}^{16}\left[\theta_{\dot{m}_{C H_{4}, p r o d u c e d}, i} B_{x_{i}}\right]^{2}+\sum_{i=21}^{22}\left[\theta_{\dot{m}_{C H_{4}, \text { produced } i}} B_{x_{i}}\right]^{2}\right)^{1 / 2}
$$

Here the indices $\theta_{f, 21}$ and $\theta_{f, 22}$ are used in place of the specific indices for $\mathrm{CH}_{4}$ $\left(\theta_{f, 8}\right.$ and $\left.\theta_{f, 9}\right)$ when evaluating the systematic error in the $\mathrm{CH}_{4}$ emission rate. Similarly, 
if the species of interest were $\operatorname{CO}, \theta_{f, 21}$ and $\theta_{f, 22}$ would be used in place of $\theta_{f, 6}$ and $\theta_{f, 7}$ (specific indices for CO). Finally, if the species of interest were $\mathrm{CO}_{2}, \theta_{f, 21}$ and $\theta_{f, 22}$ would be used in place of $\theta_{f, 4}$ and $\theta_{f, 5}$ (specific indices for $\mathrm{CO}_{2}$ ) and, if $\mathrm{CO}_{2}$ were present as a diluent in the fuel stream, $\theta_{f, 23}$ would be used in place of $\theta_{f, 3}$.

The calculation of a black carbon emission rate using the carbon-balance method to calculate the plume flow rate is more straightforward. In this case the sensitivity indices given in Table A9 should be evaluated as follows:

$$
B_{\dot{m}_{(s)}, p r o d u c e d}=\left(\sum_{i=1}^{16}\left[\theta_{\dot{m}_{C_{(s)}, p r o d u c e d}, i} B_{x_{i}}\right]^{2}\right)^{1 / 2}
$$

Similar to the procedure used to evaluate Eq. (A.13), calculation of a DRE using the carbon-balance method to calculate the plume flow rate utilizes indices $\theta_{f, 21}$ through $\theta_{f, 23}$. In this case the sensitivity indices given in Table A10 should be evaluated as follows (e.g. $\left.\mathrm{CH}_{4}\right)$ :

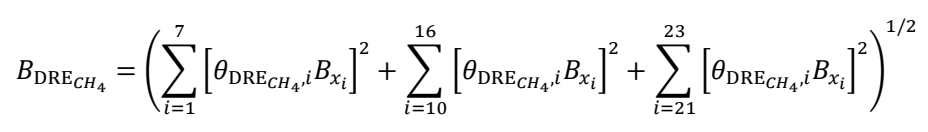

This systematic error for either the gas-phase (Eq. (A.13)) or black carbon (Eq. (A.14)) emission rate or the DRE (Eq. (A.15)) can then be combined in quadrature with the experimental precision error (Eq. (A.2)) to determine the total uncertainty on a set of measurements in accordance with Eq. (A.3).

\section{A5 Synthetic Data and Experimental Measurement Systematic Error Comparison}

A comparison with the systematic error of experimental measurements can be used to validate the expected systematic errors calculated for the synthetic data. The systematic 
error on the measured combustion efficiency (expressed as an absolute error, i.e. $2 \%$ error on $95 \%$ efficiency is equivalent to error range of $93-97 \%$ ) calculated with the carbonbalance method falls at the low end of the range expected as shown in Figure A1. The systematic error on the measured combustion efficiency calculated with the tracerinjection method falls just above the range expected for the synthetic data. This results from a higher component error on the tracer gas species for the current experimental measurements than that used for the synthetic data, where it was assumed that a specifically tailored instrument for measuring the tracer (e.g. a cavity ringdown gas analyzer) could be used to improve accuracy.

Figure A2 shows the systematic errors of species yield of both carbon monoxide and nitrogen oxides measured using the carbon-balance method. Here the errors are plotted relative to the measured value (i.e. as a percentage of the measured value). The respective systematic errors of the species yields were nearly identical using the carbonbalance and tracer-injection methods, where only the former are plotted in Figure A2 for clarity. Carbon monoxide and nitrogen oxides have slightly different detection limits when measured with the current gas analysis instrument which is reflected in the differences in the resulting systematic errors. The relative systematic error of a given species yield fits well with expected values from the synthetic data. 


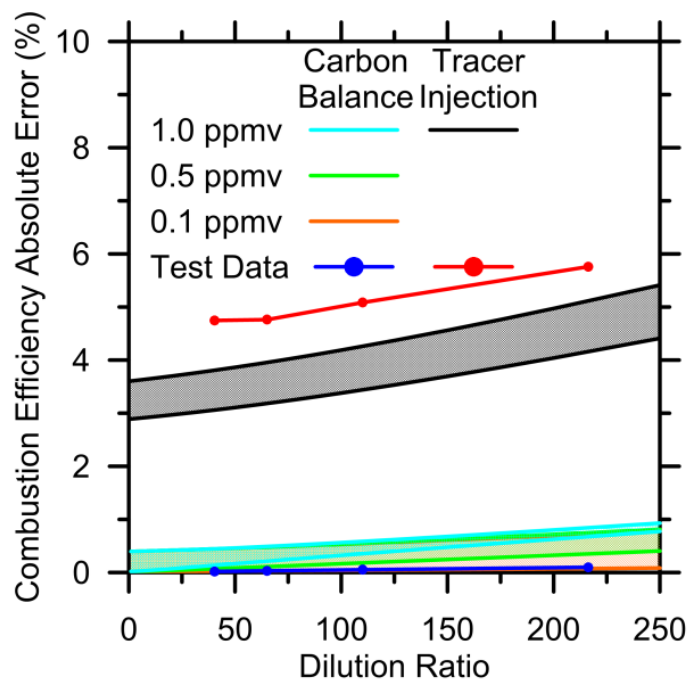

Figure A1: Comparison of absolute uncertainty of combustion efficiency for synthetic data and experimental measurements.

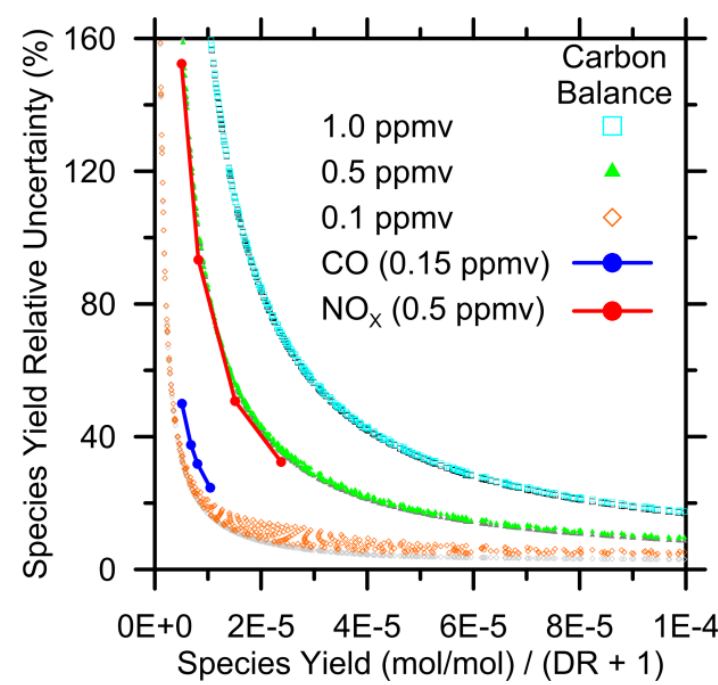

FigureA2: Comparison of relative uncertainty of species yields for synthetic data and experimental measurements. 


\section{Appendix B CO and Hydrocarbon Results, Analysis and Discussion}

Carbon monoxide $(\mathrm{CO})$ and hydrocarbon emissions from combustion processes are an important consideration as the primary gas-phase carbon-based emissions. CO yield, as shown in Figure B1, tends to decrease to as mass flow rate increases before levelling off at yield values unique to the different flare gases. For the HVY 4-Mix flare gas, which was tested on multiple burner sizes, there does not appear to be any discernable change among the different diameters tested. However, more apparent than any trend with flow rate or diameter are the differences in emission rates for the different flare gas compositions. As with the soot yield discussed previously, $\mathrm{CO}$ yields increased from the methane-based flare gases, which yielded the least $\mathrm{CO}$, to ethylene which yielded the highest $\mathrm{CO}$. The $\mathrm{CO}$ yields for propane and ethylene were approximately 2 and 3 times greater than the CO yield for the HVY 4-Mix respectively. 


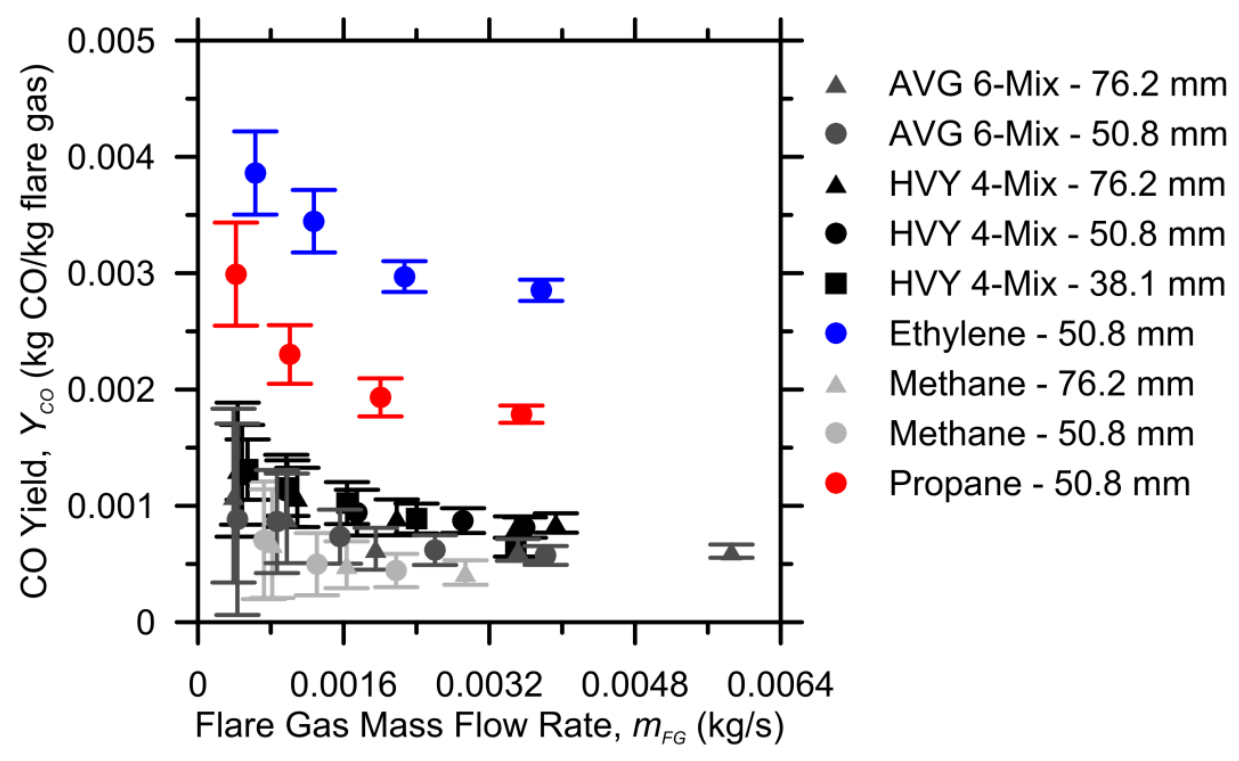

\section{Figure B1: CO yield calculated using the carbon balance method for the 38.1, 50.8 and 76.2 mm burners with AVG 6-Mix, HVY 4-Mix, ethylene, methane, and propane flare gas mixtures.}

Methane yields for the flames tested are shown in Figure B2a. For both the propane and ethylene flare gases, the methane emissions are essentially zero. For the methane-based flare gases there are minimal methane emissions at the lower flow rates on all burners, however the uncertainties are high and include the possibility of zero emissions. At higher flow rates the emissions approach zero and the uncertainties decrease. Ethane yields for the flames tested are shown in Figure B2b and are essentially zero for all cases. Propane yields for the flames tested are shown in Figure B2c. For the methane-based flare gases on all burners the propane yield is zero or near zero with the uncertainties including the possibility of zero yield. For the test flow rates using ethylene flare gas, negligible propane emissions were detected. Propane yields from the propane burning flames were in the range of $0.5 \mathrm{~g} / \mathrm{kg}$-flare-gas. Ethylene yields for the flames tested are shown in Figure B2d. The yields of ethylene from propane burning flames 
were negligible, whereas for two of the four ethylene cases, the yield of ethylene is in the range of $1 \mathrm{~g} / \mathrm{kg}$-flare-gas.

The results presented suggest that hydrocarbon emissions from turbulent nonpremixed diffusion flames are near zero for flames burning in quiescent conditions with high-heating values. A tentative further conclusion is that the form of the hydrocarbons emitted from a flare are likely to be unburned hydrocarbons of the same chemical structure as the flare gas and not reformed hydrocarbons. 


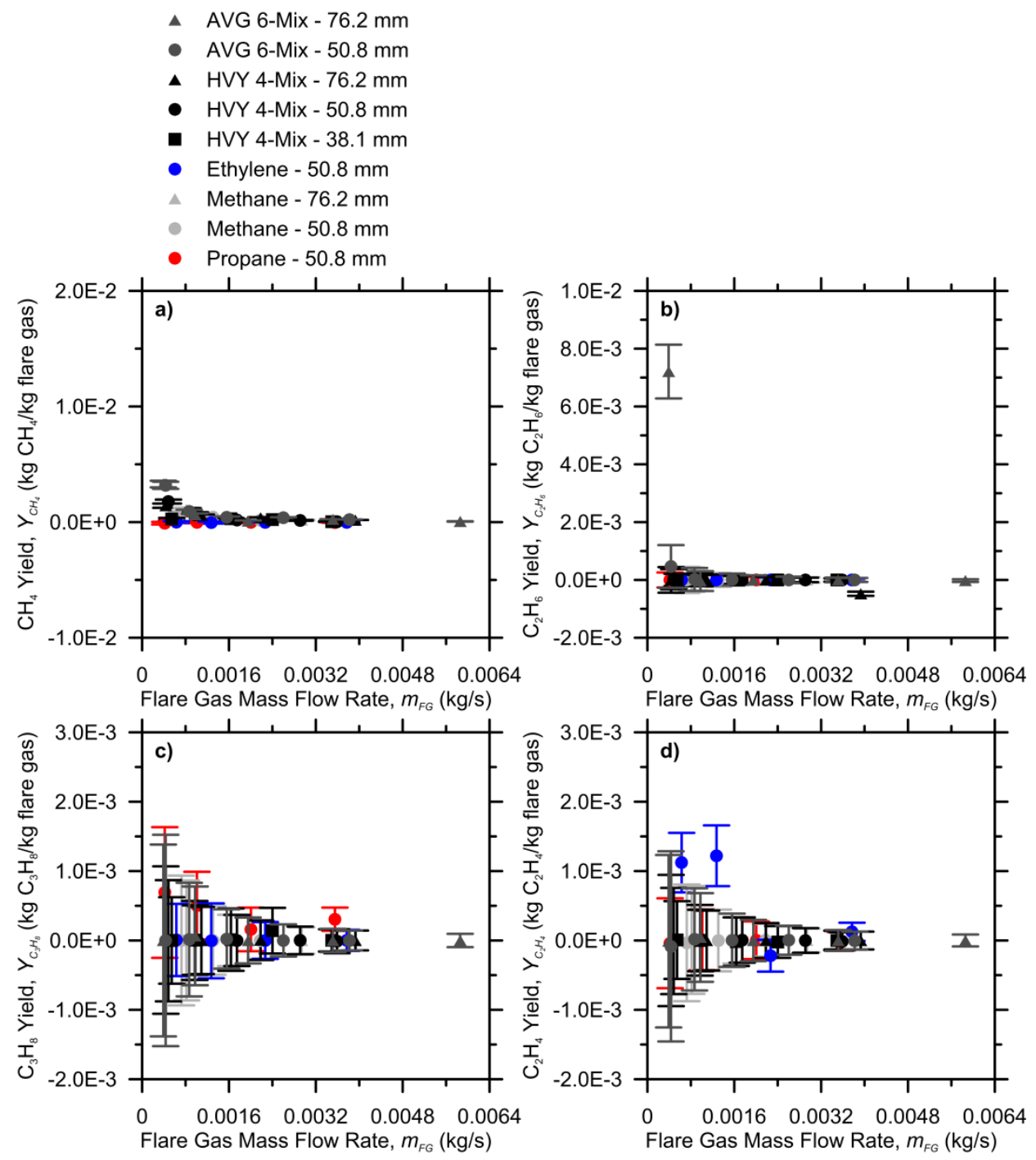

Figure B2: a) $\mathrm{CH}_{4}$, b) $\mathrm{C}_{2} \mathrm{H}_{6}$, c) $\mathrm{C}_{3} \mathrm{H}_{8}$, d) $\mathrm{C}_{2} \mathrm{H}_{4}$ yields calculated using the carbon balance method for the 38.1, 50.8 and $76.2 \mathrm{~mm}$ burners with AVG 6-Mix, HVY 4Mix, ethylene, methane and propane flare gas mixtures. 


\section{Appendix C Flame Length Results, Analysis and Discussion}

Flame length was measured using the equipment and methodology outlined in Section 2.6. As shown in Figure $\mathrm{C}$ 1, the measured flame lengths for all flare gases and all burner sizes tested increased with minimal scatter as the mass flow rate was increased. In Figure $\mathrm{C} 2$, the measured flame lengths are compared to flame lengths calculated using the correlation defined by Delichatsios (1993) (Eq. (C.1) below) for flames with Fire Froude numbers (See Eq. (1.3)) less than 5. The available data for all tests fits very well with the flame length correlation.

$$
L_{f}=13.5 d_{e} \frac{F r_{f}^{0.4}}{f_{s}\left(1+0.07 F r_{f}^{2}\right)^{0.2}}\left(\frac{\rho_{e}}{\rho_{\infty}}\right)^{0.5}
$$




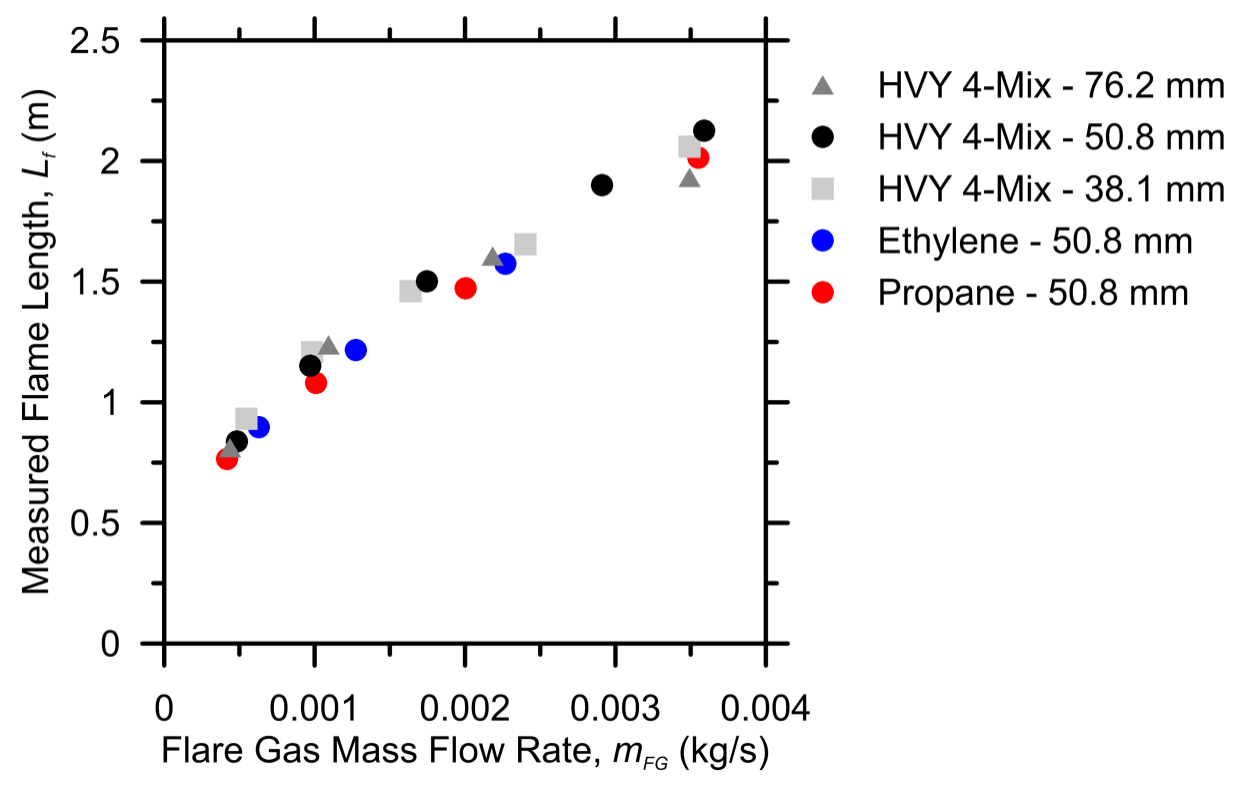

Figure C1: Measured flame length for 38.1, 50.8 and 76.2 mm burners with HVY 4Mix, ethylene and propane flare gas mixtures.

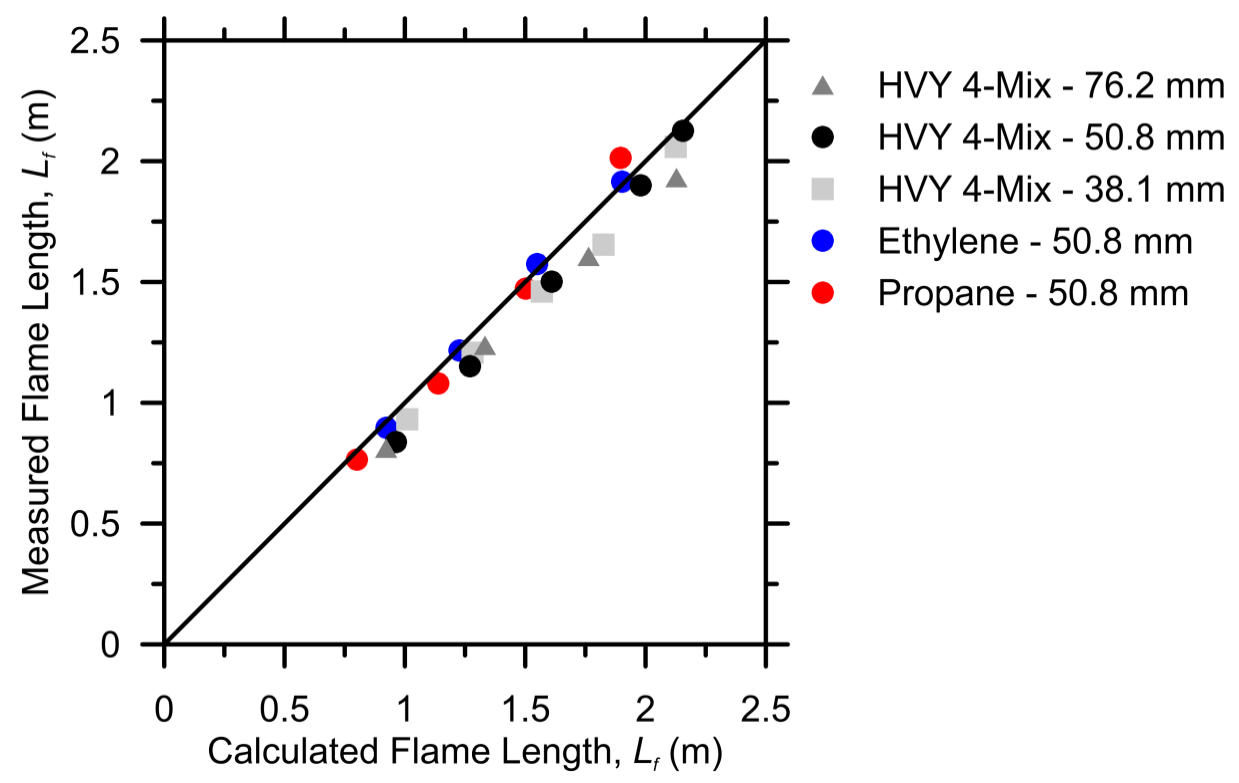

Figure C2: Comparison of measured flame length and flame length calculated using Delichatsios (1993) correlation for 38.1, 50.8 and 76.2 mm burners with HVY 4-Mix, ethylene and propane flare gas mixtures. 


\section{Appendix D Soot Yield Tabulated Results}

\begin{tabular}{|c|c|c|c|c|c|c|c|}
\hline $\begin{array}{c}\text { Flare Gas } \\
\text { Mixture }\end{array}$ & $\begin{array}{c}\text { Diameter } \\
(\mathrm{mm})\end{array}$ & $\begin{array}{l}\text { Set Flow } \\
\text { (SLPM) }\end{array}$ & $\begin{array}{c}\text { Total Flow } \\
(\mathrm{kg} / \mathrm{s})\end{array}$ & $\begin{array}{c}\text { Reynolds } \\
\text { number }\end{array}$ & $\begin{array}{c}\text { Global Froude } \\
\text { number }\end{array}$ & $\begin{array}{c}\text { Soot Yield } \\
(\mathrm{kg} / \mathrm{kg})\end{array}$ & $\begin{array}{c}\text { Soot Yield } \\
\text { Uncertainty }(\mathrm{kg} / \mathrm{kg})\end{array}$ \\
\hline \multirow{15}{*}{ HVY 4-Mix } & \multirow{5}{*}{38.1} & 34.20 & $5.46 \mathrm{E}-04$ & 1925 & $1.03 \mathrm{E}-02$ & $1.34 \mathrm{E}-03$ & $2.80 \mathrm{E}-04$ \\
\hline & & 61.56 & $9.82 \mathrm{E}-04$ & 3466 & $1.85 \mathrm{E}-02$ & 1.29E-03 & 2.69E-04 \\
\hline & & 102.61 & $1.64 \mathrm{E}-03$ & 5777 & $3.06 \mathrm{E}-02$ & $1.23 \mathrm{E}-03$ & $2.56 \mathrm{E}-04$ \\
\hline & & 150.49 & $2.40 \mathrm{E}-03$ & 8474 & $4.48 \mathrm{E}-02$ & 8.78E-04 & $1.83 \mathrm{E}-04$ \\
\hline & & 218.90 & 3.49E-03 & 12325 & $6.43 \mathrm{E}-02$ & 3.84E-04 & 7.97E-05 \\
\hline & \multirow{5}{*}{50.8} & 30.40 & $4.85 \mathrm{E}-04$ & 1283 & 4.41E-03 & $1.25 \mathrm{E}-03$ & 2.61E-04 \\
\hline & & 60.80 & 9.70E-04 & 2567 & 8.80E-03 & 1.29E-03 & 2.68E-04 \\
\hline & & 109.45 & 1.75E-03 & 4623 & $1.58 \mathrm{E}-02$ & 1.14E-03 & 2.37E-04 \\
\hline & & 182.41 & 2.91E-03 & 7705 & 2.64E-02 & $1.05 \mathrm{E}-03$ & 2.17E-04 \\
\hline & & 224.98 & 3.59E-03 & 9501 & $3.24 \mathrm{E}-02$ & $1.02 \mathrm{E}-03$ & 2.11E-04 \\
\hline & \multirow{5}{*}{76.2} & 27.36 & 4.37E-04 & 770 & 1.49E-03 & 1.09E-03 & $2.28 \mathrm{E}-04$ \\
\hline & & 68.41 & 1.09E-03 & 1926 & $3.68 \mathrm{E}-03$ & $1.02 \mathrm{E}-03$ & 2.11E-04 \\
\hline & & 136.81 & $2.18 \mathrm{E}-03$ & 3852 & 7.38E-03 & 1.07E-03 & 2.23E-04 \\
\hline & & 218.90 & 3.49E-03 & 6163 & 1.17E-02 & 1.10E-03 & 2.29E-04 \\
\hline & & 246.26 & 3.93E-03 & 6935 & $1.34 \mathrm{E}-02$ & 8.90E-04 & $1.85 \mathrm{E}-04$ \\
\hline \multirow{4}{*}{ Ethylene } & \multirow{4}{*}{50.8} & 30.40 & 6.30E-04 & 1668 & $6.53 \mathrm{E}-03$ & 1.59E-02 & $3.42 \mathrm{E}-03$ \\
\hline & & 60.80 & $1.27 \mathrm{E}-03$ & 3370 & $1.32 \mathrm{E}-02$ & $1.24 \mathrm{E}-02$ & 2.57E-03 \\
\hline & & 109.45 & 2.27E-03 & 6004 & $2.36 \mathrm{E}-02$ & 1.07E-02 & $2.20 \mathrm{E}-03$ \\
\hline & & 182.41 & 3.77E-03 & 9976 & 3.91E-02 & 8.97E-03 & $1.84 \mathrm{E}-03$ \\
\hline \multirow{4}{*}{ Propane } & \multirow{4}{*}{50.8} & 182.41 & 4.17E-04 & 1398 & $2.25 \mathrm{E}-03$ & 7.74E-03 & $1.76 \mathrm{E}-03$ \\
\hline & & 30.40 & 1.01E-03 & 3366 & 5.38E-03 & $6.20 \mathrm{E}-03$ & 1.30E-03 \\
\hline & & 60.80 & 2.00E-03 & 6686 & 1.07E-02 & $5.25 \mathrm{E}-03$ & $1.08 \mathrm{E}-03$ \\
\hline & & 109.45 & 3.55E-03 & 11896 & $1.88 \mathrm{E}-02$ & 4.70E-03 & 9.64E-04 \\
\hline
\end{tabular}




\begin{tabular}{|c|c|c|c|c|c|c|c|}
\hline $\begin{array}{c}\text { Flare Gas } \\
\text { Mixture }\end{array}$ & $\begin{array}{c}\text { Diameter } \\
(\mathrm{mm})\end{array}$ & $\begin{array}{l}\text { Set Flow } \\
\text { (SLPM) }\end{array}$ & $\begin{array}{c}\text { Total Flow } \\
(\mathrm{kg} / \mathrm{s})\end{array}$ & $\begin{array}{c}\text { Reynolds } \\
\text { number }\end{array}$ & $\begin{array}{c}\text { Global Froude } \\
\text { number }\end{array}$ & $\begin{array}{c}\text { Soot Yield } \\
(\mathrm{kg} / \mathrm{kg})\end{array}$ & $\begin{array}{c}\text { Soot Yield } \\
\text { Uncertainty }(\mathrm{kg} / \mathrm{kg})\end{array}$ \\
\hline \multirow{6}{*}{ Methane } & \multirow{3}{*}{50.8} & 60.80 & $7.25 \mathrm{E}-04$ & 1770 & $1.18 \mathrm{E}-02$ & 8.54E-05 & $1.81 \mathrm{E}-05$ \\
\hline & & 109.45 & 1.31E-03 & 3187 & 2.12E-02 & 8.11E-05 & 1.71E-05 \\
\hline & & 182.41 & $2.18 \mathrm{E}-03$ & 5311 & 3.53E-02 & 7.35E-05 & $1.55 \mathrm{E}-05$ \\
\hline & \multirow{3}{*}{76.2} & 68.41 & 8.16E-04 & 1328 & 4.93E-03 & $6.84 \mathrm{E}-05$ & $1.45 \mathrm{E}-05$ \\
\hline & & 136.81 & $1.63 \mathrm{E}-03$ & 2656 & 9.89E-03 & 5.95E-05 & $1.25 \mathrm{E}-05$ \\
\hline & & 246.26 & 2.94E-03 & 4780 & $1.80 \mathrm{E}-02$ & 7.26E-05 & $1.53 \mathrm{E}-05$ \\
\hline \multirow{10}{*}{ AVG 6-Mix } & \multirow{5}{*}{50.8} & 30.40 & 4.34E-04 & 1080 & 5.48E-03 & 5.35E-04 & 8.05E-05 \\
\hline & & 60.80 & 8.68E-04 & 2160 & 1.09E-02 & 4.90E-04 & $1.03 \mathrm{E}-04$ \\
\hline & & 109.45 & $1.56 \mathrm{E}-03$ & 3882 & $1.95 \mathrm{E}-02$ & 5.69E-04 & 1.19E-04 \\
\hline & & 182.41 & 2.60E-03 & 6480 & $3.26 \mathrm{E}-02$ & 4.13E-04 & 8.62E-05 \\
\hline & & 267.54 & $3.82 \mathrm{E}-03$ & 9505 & 4.73E-02 & $3.56 \mathrm{E}-04$ & 7.42E-05 \\
\hline & \multirow{5}{*}{76.2} & 27.36 & 3.91E-04 & 648 & $1.80 \mathrm{E}-03$ & 3.93E-04 & 8.30E-05 \\
\hline & & 68.41 & $9.76 \mathrm{E}-04$ & 1620 & 4.50E-03 & 4.32E-04 & 9.05E-05 \\
\hline & & 136.81 & $1.95 \mathrm{E}-03$ & 3240 & 9.04E-03 & $4.52 \mathrm{E}-04$ & $9.43 \mathrm{E}-05$ \\
\hline & & 246.26 & 3.51E-03 & 5833 & $1.65 \mathrm{E}-02$ & 4.27E-04 & 8.89E-05 \\
\hline & & 410.43 & $5.86 \mathrm{E}-03$ & 9722 & 2.73E-02 & $3.70 \mathrm{E}-04$ & 7.78E-05 \\
\hline
\end{tabular}




\section{Appendix E $\quad$ NO $_{\mathrm{X}}$ Yield Tabulated Results}

\begin{tabular}{|c|c|c|c|c|c|c|c|}
\hline $\begin{array}{c}\text { Flare Gas } \\
\text { Mixture }\end{array}$ & $\begin{array}{l}\text { Diameter } \\
(\mathrm{mm})\end{array}$ & $\begin{array}{l}\text { Set Flow } \\
\text { (SLPM) }\end{array}$ & $\begin{array}{c}\text { Total Flow } \\
(\mathrm{kg} / \mathrm{s})\end{array}$ & $\begin{array}{l}\text { NO }_{x} \text { Yield } \\
(\mathrm{kg} / \mathrm{kg})\end{array}$ & $\begin{array}{c}\mathrm{NO}_{\mathrm{X}} \text { Yield } \\
\text { Uncertainty }(\mathrm{kg} / \mathrm{kg})\end{array}$ & $\begin{array}{c}\text { NOX Yield } \\
(\mathrm{kg} / \mathrm{GJ})\end{array}$ & $\begin{array}{c}\mathrm{NO}_{\mathrm{X}} \text { Yield } \\
\text { Uncertainty }(\mathrm{kg} / \mathrm{GJ})\end{array}$ \\
\hline \multirow{15}{*}{ HVY 4-Mix } & \multirow{5}{*}{38.1} & 34.20 & $5.46 \mathrm{E}-04$ & $1.98 \mathrm{E}-03$ & 1.19E-03 & 0.037 & 0.022 \\
\hline & & 61.56 & $9.82 \mathrm{E}-04$ & 2.08E-03 & 9.77E-04 & 0.039 & 0.018 \\
\hline & & 102.61 & $1.64 \mathrm{E}-03$ & $2.09 \mathrm{E}-03$ & $7.69 \mathrm{E}-04$ & 0.039 & 0.014 \\
\hline & & 150.49 & $2.40 \mathrm{E}-03$ & $2.13 \mathrm{E}-03$ & 4.93E-04 & 0.040 & 0.009 \\
\hline & & 218.90 & $3.49 E-03$ & 2.13E-03 & $3.15 \mathrm{E}-04$ & 0.040 & 0.006 \\
\hline & \multirow{5}{*}{50.8} & 30.40 & $4.85 \mathrm{E}-04$ & $1.94 \mathrm{E}-03$ & $1.94 \mathrm{E}-03$ & 0.036 & 0.036 \\
\hline & & 60.80 & 9.70E-04 & $1.95 \mathrm{E}-03$ & $1.23 \mathrm{E}-03$ & 0.036 & 0.023 \\
\hline & & 109.45 & $1.75 \mathrm{E}-03$ & 1.97E-03 & 7.98E-04 & 0.037 & 0.015 \\
\hline & & 182.41 & $2.91 \mathrm{E}-03$ & $2.01 \mathrm{E}-03$ & 4.37E-04 & 0.038 & 0.008 \\
\hline & & 224.98 & 3.59E-03 & 2.00E-03 & 3.00E-04 & 0.037 & 0.006 \\
\hline & \multirow{5}{*}{76.2} & 27.36 & 4.37E-04 & $1.81 \mathrm{E}-03$ & $2.45 \mathrm{E}-03$ & 0.034 & 0.046 \\
\hline & & 68.41 & 1.09E-03 & 1.91E-03 & $1.05 \mathrm{E}-03$ & 0.036 & 0.020 \\
\hline & & 136.81 & 2.18E-03 & 2.02E-03 & $6.22 \mathrm{E}-04$ & 0.038 & 0.012 \\
\hline & & 218.90 & $3.49 E-03$ & 2.03E-03 & 3.16E-04 & 0.038 & 0.006 \\
\hline & & 246.26 & 3.93E-03 & $2.03 E-03$ & $3.89 \mathrm{E}-04$ & 0.038 & 0.007 \\
\hline \multirow{4}{*}{ Ethylene } & \multirow{4}{*}{50.8} & 30.40 & $6.30 \mathrm{E}-04$ & $2.31 \mathrm{E}-03$ & $1.00 \mathrm{E}-03$ & 0.046 & 0.020 \\
\hline & & 60.80 & 1.27E-03 & 2.09E-03 & 1.03E-03 & 0.042 & 0.020 \\
\hline & & 109.45 & 2.27E-03 & 2.03E-03 & $5.26 \mathrm{E}-04$ & 0.040 & 0.010 \\
\hline & & 182.41 & 3.77E-03 & $2.06 \mathrm{E}-03$ & $2.88 \mathrm{E}-04$ & 0.041 & 0.006 \\
\hline \multirow{4}{*}{ Propane } & \multirow{4}{*}{50.8} & 182.41 & 4.17E-04 & $1.78 \mathrm{E}-03$ & $1.42 \mathrm{E}-03$ & 0.035 & 0.028 \\
\hline & & 30.40 & $1.01 E-03$ & 1.69E-03 & $9.29 \mathrm{E}-04$ & 0.034 & 0.018 \\
\hline & & 60.80 & $2.00 \mathrm{E}-03$ & $1.78 \mathrm{E}-03$ & 5.99E-04 & 0.035 & 0.012 \\
\hline & & 109.45 & $3.55 \mathrm{E}-03$ & $1.79 \mathrm{E}-03$ & 3.01E-04 & 0.035 & 0.006 \\
\hline
\end{tabular}




\begin{tabular}{|c|c|c|c|c|c|c|c|}
\hline $\begin{array}{c}\text { Flare Gas } \\
\text { Mixture }\end{array}$ & $\begin{array}{c}\text { Diameter } \\
(\mathrm{mm})\end{array}$ & $\begin{array}{c}\begin{array}{c}\text { Set Flow } \\
\text { (SLPM) }\end{array} \\
\end{array}$ & $\begin{array}{c}\begin{array}{c}\text { Total Flow } \\
(\mathrm{kg} / \mathrm{s})\end{array} \\
\end{array}$ & $\begin{array}{c}\text { NO }{ }_{x} \text { Yield } \\
(\mathrm{kg} / \mathrm{kg})\end{array}$ & $\begin{array}{c}\mathrm{NO} \mathrm{X}_{\mathrm{X}} \text { Yield } \\
\text { Uncertainty }(\mathrm{kg} / \mathrm{kg})\end{array}$ & $\begin{array}{c}\text { NOX Yield } \\
\text { (kg/GJ) }\end{array}$ & $\begin{array}{c}\mathrm{NO}_{\mathrm{X}} \text { Yield } \\
\text { Uncertainty }(\mathrm{kg} / \mathrm{GJ})\end{array}$ \\
\hline \multirow{6}{*}{ Methane } & \multirow{3}{*}{50.8} & 60.80 & $7.25 \mathrm{E}-04$ & $2.34 \mathrm{E}-03$ & $2.50 \mathrm{E}-03$ & 0.042 & 0.045 \\
\hline & & 109.45 & $1.31 \mathrm{E}-03$ & $2.33 \mathrm{E}-03$ & $1.33 \mathrm{E}-03$ & 0.042 & 0.024 \\
\hline & & 182.41 & $2.18 \mathrm{E}-03$ & $2.10 \mathrm{E}-03$ & $7.08 \mathrm{E}-04$ & 0.038 & 0.013 \\
\hline & \multirow{3}{*}{76.2} & 68.41 & 8.16E-04 & $2.16 \mathrm{E}-03$ & 2.31E-03 & 0.039 & 0.042 \\
\hline & & 136.81 & $1.63 \mathrm{E}-03$ & $2.23 \mathrm{E}-03$ & $9.95 \mathrm{E}-04$ & 0.040 & 0.018 \\
\hline & & 246.26 & 2.94E-03 & $2.22 \mathrm{E}-03$ & $5.22 \mathrm{E}-04$ & 0.040 & 0.009 \\
\hline \multirow{10}{*}{ AVG 6-Mix } & \multirow{5}{*}{50.8} & 30.40 & $4.34 \mathrm{E}-04$ & 1.36E-03 & $2.90 \mathrm{E}-03$ & 0.027 & 0.057 \\
\hline & & 60.80 & $8.68 \mathrm{E}-04$ & $1.88 \mathrm{E}-03$ & $2.19 \mathrm{E}-03$ & 0.037 & 0.043 \\
\hline & & 109.45 & $1.56 \mathrm{E}-03$ & $1.78 \mathrm{E}-03$ & 1.14E-03 & 0.035 & 0.022 \\
\hline & & 182.41 & $2.60 \mathrm{E}-03$ & $1.86 \mathrm{E}-03$ & $6.25 \mathrm{E}-04$ & 0.037 & 0.012 \\
\hline & & 267.54 & 3.82E-03 & $2.02 \mathrm{E}-03$ & 3.93E-04 & 0.040 & 0.008 \\
\hline & \multirow{5}{*}{76.2} & 27.36 & 3.91E-04 & 1.57E-03 & 3.69E-03 & 0.031 & 0.072 \\
\hline & & 68.41 & $9.76 \mathrm{E}-04$ & $1.62 \mathrm{E}-03$ & 1.90E-03 & 0.032 & 0.037 \\
\hline & & 136.81 & $1.95 \mathrm{E}-03$ & 1.96E-03 & 8.86E-04 & 0.038 & 0.017 \\
\hline & & 246.26 & 3.51E-03 & $2.01 \mathrm{E}-03$ & 4.55E-04 & 0.039 & 0.009 \\
\hline & & 410.43 & $5.86 \mathrm{E}-03$ & $2.03 \mathrm{E}-03$ & $2.68 \mathrm{E}-04$ & 0.040 & 0.005 \\
\hline
\end{tabular}




\section{Appendix F Combustion Efficiency Tabulated Results}

\begin{tabular}{|c|c|c|c|c|c|c|c|}
\hline $\begin{array}{c}\text { Flare Gas } \\
\text { Mixture }\end{array}$ & $\begin{array}{c}\text { Diameter } \\
(\mathrm{mm})\end{array}$ & $\begin{array}{c}\text { Set Flow } \\
\text { (SLPM) }\end{array}$ & $\begin{array}{c}\text { Total Flow } \\
(\mathrm{kg} / \mathrm{s})\end{array}$ & $\begin{array}{l}\text { Mixed-Phase } \\
\text { Efficiency (\%) }\end{array}$ & $\begin{array}{c}\text { Mixed-Phase } \\
\text { Uncertainty (\%) }\end{array}$ & $\begin{array}{c}\text { Gas-Phase } \\
\text { Efficiency (\%) }\end{array}$ & $\begin{array}{c}\text { Gas-Phase } \\
\text { Uncertainty (\%) }\end{array}$ \\
\hline \multirow{15}{*}{ HVY 4-Mix } & \multirow{5}{*}{38.1} & 34.20 & $5.46 \mathrm{E}-04$ & 99.73 & 0.10 & 99.90 & 0.09 \\
\hline & & 61.56 & $9.82 \mathrm{E}-04$ & 99.70 & 0.08 & 99.86 & 0.08 \\
\hline & & 102.61 & $1.64 \mathrm{E}-03$ & 99.76 & 0.07 & 99.92 & 0.06 \\
\hline & & 150.49 & $2.40 \mathrm{E}-03$ & 99.80 & 0.05 & 99.92 & 0.04 \\
\hline & & 218.90 & $3.49 E-03$ & 99.91 & 0.03 & 99.96 & 0.02 \\
\hline & \multirow{5}{*}{50.8} & 30.40 & $4.85 E-04$ & 99.60 & 0.14 & 99.76 & 0.13 \\
\hline & & 60.80 & 9.70E-04 & 99.71 & 0.09 & 99.88 & 0.09 \\
\hline & & 109.45 & 1.75E-03 & 99.78 & 0.06 & 99.93 & 0.06 \\
\hline & & 182.41 & 2.91E-03 & 99.80 & 0.04 & 99.94 & 0.03 \\
\hline & & 224.98 & $3.59 E-03$ & 99.82 & 0.04 & 99.95 & 0.02 \\
\hline & \multirow{5}{*}{76.2} & 27.36 & 4.37E-04 & 99.65 & 0.17 & 99.79 & 0.16 \\
\hline & & 68.41 & $1.09 \mathrm{E}-03$ & 99.75 & 0.08 & 99.88 & 0.07 \\
\hline & & 136.81 & $2.18 \mathrm{E}-03$ & 99.78 & 0.05 & 99.91 & 0.04 \\
\hline & & 218.90 & $3.49 E-03$ & 99.81 & 0.04 & 99.95 & 0.02 \\
\hline & & 246.26 & 3.93E-03 & 99.87 & 0.03 & 99.99 & 0.02 \\
\hline \multirow{4}{*}{ Ethylene } & \multirow{4}{*}{50.8} & 30.40 & $6.30 \mathrm{E}-04$ & 97.84 & 0.38 & 99.69 & 0.07 \\
\hline & & 60.80 & $1.27 \mathrm{E}-03$ & 98.27 & 0.30 & 99.71 & 0.07 \\
\hline & & 109.45 & 2.27E-03 & 98.63 & 0.26 & 99.87 & 0.04 \\
\hline & & 182.41 & 3.77E-03 & 98.80 & 0.21 & 99.84 & 0.02 \\
\hline \multirow{4}{*}{ Propane } & \multirow{4}{*}{50.8} & 182.41 & 4.17E-04 & 98.84 & 0.23 & 99.78 & 0.12 \\
\hline & & 30.40 & $1.01 \mathrm{E}-03$ & 99.07 & 0.17 & 99.83 & 0.07 \\
\hline & & 60.80 & $2.00 \mathrm{E}-03$ & 99.24 & 0.14 & 99.88 & 0.04 \\
\hline & & 109.45 & $3.55 \mathrm{E}-03$ & 99.30 & 0.12 & 99.88 & 0.02 \\
\hline
\end{tabular}




\begin{tabular}{|c|c|c|c|c|c|c|c|}
\hline $\begin{array}{c}\text { Flare Gas } \\
\text { Mixture }\end{array}$ & $\begin{array}{c}\text { Diameter } \\
(\mathrm{mm})\end{array}$ & $\begin{array}{l}\text { Set Flow } \\
\text { (SLPM) }\end{array}$ & $\begin{array}{c}\text { Total Flow } \\
(\mathrm{kg} / \mathrm{s})\end{array}$ & $\begin{array}{l}\text { Mixed-Phase } \\
\text { Efficiency (\%) }\end{array}$ & $\begin{array}{c}\text { Mixed-Phase } \\
\text { Uncertainty (\%) }\end{array}$ & $\begin{array}{c}\text { Gas-Phase } \\
\text { Efficiency (\%) }\end{array}$ & $\begin{array}{c}\text { Gas-Phase } \\
\text { Uncertainty (\%) }\end{array}$ \\
\hline \multirow{6}{*}{ Methane } & \multirow{3}{*}{50.8} & 60.80 & $7.25 E-04$ & 99.88 & 0.15 & 99.89 & 0.15 \\
\hline & & 109.45 & $1.31 \mathrm{E}-03$ & 99.92 & 0.08 & 99.93 & 0.08 \\
\hline & & 182.41 & $2.18 \mathrm{E}-03$ & 99.95 & 0.04 & 99.96 & 0.04 \\
\hline & \multirow{3}{*}{76.2} & 68.41 & $8.16 \mathrm{E}-04$ & 99.84 & 0.14 & 99.85 & 0.14 \\
\hline & & 136.81 & $1.63 \mathrm{E}-03$ & 99.93 & 0.06 & 99.94 & 0.06 \\
\hline & & 246.26 & $2.94 \mathrm{E}-03$ & 99.95 & 0.03 & 99.96 & 0.03 \\
\hline \multirow{10}{*}{ AVG 6-Mix } & \multirow{5}{*}{50.8} & 30.40 & 4.34E-04 & 99.50 & 0.26 & 99.57 & 0.26 \\
\hline & & 60.80 & $8.68 \mathrm{E}-04$ & 99.78 & 0.14 & 99.85 & 0.14 \\
\hline & & 109.45 & $1.56 \mathrm{E}-03$ & 99.83 & 0.07 & 99.91 & 0.07 \\
\hline & & 182.41 & 2.60E-03 & 99.86 & 0.04 & 99.92 & 0.04 \\
\hline & & 267.54 & $3.82 \mathrm{E}-03$ & 99.89 & 0.03 & 99.94 & 0.02 \\
\hline & \multirow{5}{*}{76.2} & 27.36 & $3.91 E-04$ & 98.73 & 0.24 & 98.79 & 0.24 \\
\hline & & 68.41 & $9.76 \mathrm{E}-04$ & 99.81 & 0.12 & 99.87 & 0.12 \\
\hline & & 136.81 & $1.95 \mathrm{E}-03$ & 99.89 & 0.06 & 99.95 & 0.06 \\
\hline & & 246.26 & $3.51 E-03$ & 99.88 & 0.03 & 99.94 & 0.03 \\
\hline & & 410.43 & $5.86 \mathrm{E}-03$ & 99.91 & 0.02 & 99.96 & 0.02 \\
\hline
\end{tabular}

